\title{
Empirischer Teil: Vorstellungen von Lernenden über Globalisierung aus dekolonialer Perspektive
}

\subsection{Das Kategoriensystem}

Im Zuge der Auswertung haben sich - nach zahlreichen Umwegen - drei Hauptkategorien ergeben: Eurozentrismus, Selfing/Othering und Agency/Subalternität. Diese stellen den Versuch dar, die auch induktiv entwickelten Subkategorien zu ordnen und den sich aus der theoretischen Diskussion ergebenden Fragestellungen gerecht zu werden. Die titelgebenden Begriffe der drei Hauptkategorien stellen grundlegende Elemente dekolonialer Theoriebildung dar. Dementsprechend ergibt sich eine Trennschärfe der Kategorien keineswegs selbsterklärend. Diese Elemente spielen explizit oder implizit in unzähligen Diskussionen um Dekolonialität eine Rolle, es kursieren zahlreiche voneinander abweichende Definitionen und sie sind auf verschiedene Weisen miteinander verwoben. Dabei konnte im Zuge des Auswertungsprozesses eine angemessene Trennschärfe der Kategorien erreicht werden. Eine Auseinandersetzung mit den jeweiligen Kategorien und die ihnen eigenen Logiken finden sich am Anfang des jeweiligen Abschnitts. Dort versuche ich, die jeweils spezifische Perspektive herauszuarbeiten.

Um eine bessere Orientierung beim Lesen zu ermöglichen, skizziere ich an dieser Stelle bereits überblicksartig den jeweiligen Fokus der Abschnitte. In der Kategorie Eurozentrismus setze ich mich mit Vorstellungen auseinander, die auf Bilder und Erklärungsmodelle globaler Konstellationen in der Gegenwart und ihrer Konstruktion in der Geschichte zielen. Im Rahmen der Kategorie Selfing/Othering setze ich mich mit Prozessen der Selbst- und Fremdkonstruktionen in postkolonialen Konstellationen auseinander. Dabei beschränke ich mich per definitionem auf migrationsgesellschaftliche Kontexte - andernfalls wären die Überschneidungen zu den anderen beiden Kategorien zu groß bzw. die Trennschärfe ungenügend. Im Rahmen der Kategorie Agency/Subalternität setze ich 
mich mit Vorstellungen der Schüler_innen über Akteure und Nicht-Akteure auseinander. Anhand der drei als subaltern vorgefundenen Gruppen ,Arbeiter_innen im Globalen Süden', ,Kolonisierte" und ,Geflüchtete" schaue ich mir auch an, wer in der mehrheitlichen Perspektive der Schüler_innen an ihrer statt als Akteur erscheint.

\subsection{Eurozentrismus}

\subsubsection{Das Feld strukturieren:Was ist Eurozentrismus?}

Es gibt keine einheitliche Definition von Eurozentrismus. Ausgangspunkt des von mir verwendeten Begriffs stellen zwei bekannte Definitionen von Eurozentrismus dar:

„Eurozentrismus ist der Begriff dafür, den Westen für das naturgemäße Zentrum des Universums zu halten.“ (Thiong'o 1993: 17)

„Eurocentrism is a culturalist phenomenon in the sense that it assumes the existence of irreducibly distinct cultural invariants that shape the historical paths of different people. Eurocentrism is therefore anti-universalist, since it is not interested in seeking possible general laws of human evolution. But it does present itself as universalist, for it claims that imitation of the Western model by all peoples is the only solution to the challenges of our time." (Amin 1988: vii)

Das „naturgemäß“ ist in der Definition von Ngugi wa Thiong'o sehr ernst zu nehmen. Es meint nicht, dass es tatsächlich natürlich so sei, dass der Westen das Zentrum des Universums war oder ist. ,Naturgemäß‘ verweist - ähnlich wie der ideologiekritische Begriff der zweiten Natur - vielmehr darauf, dass diese Annahme nicht etwa behauptet werden muss, sondern als implizite Denkvoraussetzung, eben als natürlich, erscheint. Samir Amin stellt heraus, dass sich der Universalismus als universalistisch darstellt, also als Maßstab für alle Menschen, Entwicklungen und Kontexte, während er doch in Wirklichkeit keine allgemeine Theorie der menschlichen Entwicklung ist und vielmehr irreduzibel unterschiedliche kulturelle Konstanten verschiedener Völker behauptet. Unabhängig davon, wie die allgemeinen Gesetze menschlicher Entwicklung aussehen könnten und ob die Suche danach erfolgversprechend ist, stellt er damit den partikularistischen Ausgangspunkt des Eurozentrismus heraus. Dabei gibt es nicht nur ein Entweder-Oder zwischen Eurozentrismus oder Universalismus, sondern vielmehr ein komplexes, widersprüchliches und verwobenes Verhältnis. Häufig finden sich eurozentrische 
Aspekte in universalistischen Vorstellungen, beispielsweise in Forderungen nach Gerechtigkeit. Diese Verwobenheit von eurozentrischen und universalistischen Formen stellt eine besondere Herausforderung für die Analyse dar. Aus der Einsicht in die Verwobenheit von Universalismus und Eurozentrismus entwickelte sich das Projekt, Europa zu provinzialisieren (Chakrabarty 1992). Paul Rabinow formuliert dieses Projekt programmatisch folgendermaßen:

„We need to anthropologize the West: show how exotic its constitution of reality has been; emphasize those domains most taken for granted as universal (this includes epistemology and economics); make them seem as historically peculiar as possible; show how their claims to truth are linked to social practices and have hence become effective forces in the social world." (Rabinow 1986: 241)

In den genannten Definitionen bleiben aber viele Fragen ungeklärt oder zumindest offen für widersprüchliche Interpretationen. Ich sehe hier zahlreiche Probleme, die ich im Folgenden anhand von drei Punkten darstelle:

(1) In der Regel wird unter Eurozentrismus verstanden, dass eine Form, wie sie in Europa entstanden sei, anderen Teilen der Welt übergestülpt oder aufgezwungen wird. Dies kann beispielsweise administrative Vorgänge, ökonomische Strukturen oder diskursive Ordnungen meinen. Das heißt, es geht sowohl um real stattfindende gesellschaftspolitische Prozesse, die im nicht-europäischen Raum umgesetzt werden, als auch um rein diskursive Blicke auf Aspekte innerhalb dieses Raums. Aber: Dasjenige, was hier als ,europäisch` imaginiert wird, basiert nicht auf einer realen Entwicklung von oder in Europa, sondern vielmehr auf einer Imago Europas. Das bedeutet, dass nicht Etwas, was in Europa Wirklichkeit war oder ist, auf andere Teile der Welt projiziert wird, sondern vielmehr Etwas, das in der kolonialen Vorstellungswelt als europäisch konstruiert wird. Die Ideologie des Eurozentrismus bringt also sein eigenes Subjekt, ,Europa', erst hervor. Eurozentrismus war also nie ein Gegeneinander von tatsächlichen Nationen, vorgestellt als homogene Entitäten, sondern eine Ideologie. Dies wird umso deutlicher, als eurozentrisch-koloniale Diskurse und Politiken auch auf die Arbeiter_innenklasse in Europa angewandt wurden (Conrad 2010: 74 ff).

(2) Die ideologische Form mit dem Namen ,Europa' bezieht sich auf ein Territorium, auf einen Raum. Aber welcher Raum ist damit denn eigentlich gemeint? Es ist nicht Osteuropa, welches einen untergeordneten Sonderplatz im Denken von Europa innehält, da es geographisch zu Europa und gleichzeitig ideologisch zu Europas Anderem gehört. Wenn im eurozentrischen Diskurs von ,Europa ' die Rede ist, dann ist damit geographisch West- und Mitteleuropa gemeint. Allerdings ist ,Europa' in diesem Kontext nicht in erster Linie ein geographischer Signifikant. 
Vielmehr ist es die implizite Norm und das implizite Zentrum der asymmetrischen Welt und insofern stellt Westeuropa nur einen Teil dieser dar. Um Westeuropa und die USA in dieser Ideologie zu fassen, müsste der Begriff Eurozentrismus möglicherweise durch den etwas unhandlichen Begriff des Okzidentalozentrismus abgelöst werden. Doch auch hier stellt sich letztlich das gleiche Problem. Amin zufolge müssten neben den USA mindestens auch Japan und Australien dazugezählt werden (1988: xii). Diese liegen jedoch geographisch gesehen - zumindest in der hegemonialen geographischen Sicht auf die Welt - nicht im Westen, während Lateinamerika zwar schon im Westen liegt, aber nicht als implizite und naturalisierte Norm konstruiert wird. Nebenbei: Im Westen wovon eigentlich? Auch hier wird die implizite und naturalisierte Norm Europas als ,naturgemäßes Zentrum des Universums“ (Thiong'o 1993: 17) offenbar. Es gibt also keine geographische Lösung des begrifflichen Problems. Entscheidend ist vielmehr die ideologische Form der impliziten und naturalisierten Form ,Europas' im eurozentrischen Diskurs. ,Europa' kann dabei mehrere Namen und unterschiedliche geographische Bezüge haben.

(3) Dementsprechend ist - wiederum Amin folgend - Eurozentrismus nicht als banaler Ethnozentrismus zu verstehen:

„Eurocentrism is not the sum of Westerners' preconceptions, mistakes, and blunders with respect to other peoples. After all, these errors are no more serious that corresponding presumptions that non-European peoples hold with respect to Westerners. Eurocentrism is thus not a banal ethnocentrism testifying simply to the limited horizons beyond which no people on this planet has yet truly been able to go. Eurocentrism $[\ldots]$ constitutes one dimension of the culture and ideology of the modern capitalist world.“ (Amin 1989: vii)

Eurozentrismus ist also nicht als scheiternder interkultureller Dialog zu verstehen, sondern fußt auf den massiven Ungleichheiten und Hierarchien zwischen Globalem Norden und Globalem Süden in einer kapitalistisch organisierten Welt. Ein banaler Ethnozentrismus, verstanden als beschränkter Horizont, könnte in jeder Weltregion anzutreffen sein. Eurozentrismus zeichnet sich dadurch aus, dass er als Ideologie - Arbeitsdefinition mit Althusser, verstanden als das imaginäre Verhältnis zu den realen Existenzbedingungen (Althusser 1969: 139) - nicht einfach eine Weltanschauung war, sondern derart an Hegemonie gewinnen konnte, dass der Westen als das „naturgemäße“ (Thiong'o 1993: 17) Zentrum des Universums erscheint.

Diese skizzenhafte Definition von Eurozentrismus stellt im Folgenden den theoretischen Rahmen für die Analyse der Aussagen der Schüler_innen dar. Dabei 
soll es nicht darum gehen, möglichst viele Aspekte aufzuzeigen, wo sie eurozentrische Motive verwenden, sondern vielmehr möchte ich Widersprüche, Ambivalenzen und Spannungsfelder herausarbeiten, die letztendlich entscheidender für das Gelingen von Bildung sind. Wie sich in der Analyse zeigen wird, werden von den Schüler_innen im Sprechen über globale Ungleichheit ganz verschiedene Aspekte, Bilder und Erklärungsmodelle vorgebracht. In der Analyse wird nun der Blick darauf gelegt, inwiefern diese eurozentrisch sind oder eurozentrische Perspektiven unterlaufen. Die Vorstellungen der Schüler_innen von globaler Ungleichheit sind geprägt davon, dass sie einen universalistischen Standpunkt einnehmen, der Ungleichheit und Ungerechtigkeit als normativ falsch ansieht. Gleichzeitig sind aber eurozentrische und herrschaftslegitimierende Aspekte stark verbreitet. Anders formuliert: Der humanistische Universalismus wird durch die eurozentrischen Partikularismen geprägt und verliert dadurch seinen universalistischen Gehalt. Und andersherum: Die eurozentrischen Vorstellungen werden durch die humanistische Norm der Schüler_innen ständig unterminiert. Dies ist ein Spannungsfeld, das das ganze Kapitel durchziehen wird.

Dieser Hauptkategorie liegen alle Aussagen zugrunde, in denen die Schüler_innen Vorstellungen der Differenz von Globalem Norden und Globalem Süden bzw. dem Westen und dem Rest (Hall 1992) als auch vermutete Ursachen für diese diskutieren. Diese so ausgewählten Aussagen wurden unter Einbeziehung dekolonialer Perspektiven in einem induktiv-deduktiven Verfahren weiter in sechs Subkategorien codiert. Jeweils zwei dieser Subkategorien bilden eine Gruppe, da sie sich mit verwandten Aspekten beschäftigen, die sich gegenseitig ergänzen. Der Gruppe ,Stagnation vs. Fortschritt' liegen alle Aussagen der Schüler_innen zugrunde, die die Aspekte von Stagnation und Fortschritt in den Mittelpunkt ihres Denkens über globale Ungleichheit stellen. Die beiden hier vertretenen Subkategorien ,Teleologische Geschichtsnarrative' und ,Afrika, Armut und die „Stämme“" bilden die hier aus dekolonialer Theorieperspektive im Material aufscheinenden entscheidenden Spannungsfelder ab. In der Gruppe ,Mentalität der Freiheit' liegen alle Aussagen zugrunde, die Attribute wie Freiheit, Aufklärung und Demokratie bzw. Despotie, Traditionalismus und Unfreiheit als zentrale Differenzmerkmale zwischen Globalem Norden und Globalem Süden bzw. dem Westen und dem Rest ansehen. Dies diskutiere ich in den beiden Subkategorien ,Freiheit als europäisch-westliche Idee“ und „Zur Ambiguität der Menschenrechte". Der dritten Subkategoriengruppe liegen alle Aussagen zugrunde, die die Frage von ,Ordnung und Staatlichkeit" ins Zentrum ihrer Diskussion um globale Ungleichheit stellen. Hier habe ich die Denkweisen über ,Korruption' und ,Ordnung als Voraussetzung von Entwicklung' als zentrale Topoi ausgemacht. 


\subsubsection{Stagnation vs. Fortschritt I:Teleologische Geschichtsnarrative}

In diesem Abschnitt geht es um die Frage, inwiefern teleologische Geschichtsnarrative von den Lernenden reproduziert werden. Dabei ist zu überprüfen, inwiefern in diesen Narrativen das eurozentrische Moment auftaucht, nach dem Europa bzw. der Westen an der Spitze der geschichtlichen Entwicklung verortet werden. Narrativ ist ein großes Wort. Die meisten Lernenden verwenden vielmehr diskursive Versatzstücke solcher Narrative. Um dies zu veranschaulichen, wird hier exemplarisch ein zusammenhängender Auszug vom Interview mit David (Gym14) vorgestellt, der ein solches Narrativ beinhaltet.

Im Anschluss an eine Interviewpassage zu Lebensweisen in Afrika stelle ich die Nachfrage, ob die Mehrheit der Menschen in Afrika auf die von ihm beschriebene Weise, als auf das „Wesentliche beschränkt“, lebe, woraufhin er das Feld erweitert, auf die vorher diskutierte Frage von Entwicklung im Sinne von Fortschritt zurückkommt und diese an die räumliche Nähe zu Europa koppelt.

I: Und wie, ähm .../ Lebt die Mehrheit der Menschen in Afrika so?

S: Nein, die Minderheit.

I: Die Minderheit?

S: Die Mehrheit ist ja oberhalb der Sahara in den Staaten am Mittelmeer. Die sind ja schon durch die Nähe zu Europa ziemlich weit. Südafrika ist auch relativ weit. Und selbst in den Republiken wie Kongo haben die Leute ja auch inzwischen richtige Waffen leider. Also die sind schon fortschrittlich. (David, Gym14)

Hier wird also als zentrale Differenz in den vorgestellten Entwicklungsstufen Afrika unterhalb der Sahara und oberhalb der Sahara, also den „Staaten am Mittelmeer“ eingeführt. Im Anschluss stelle ich die zurückspiegelnde Nachfrage, um dem Zusammenhang von der territorialen Nähe zu Europa mit der Möglichkeit von Fortschritt nachzugehen.

I: Mhm. Und, ähm, die Nähe zu Europa hat den Fortschritt in den arabischen Ländern ermöglicht?

S: Begünstigt!

I: Begünstigt?

S: Also natürlich wenn man .../ Schon früher ja der Handel am Mittelmeer, Rom war da ja auch früher mit einer fortschrittlichen Kultur in Ägypten. Ägypten hat ja schon immer eine fortschrittliche Kultur gehabt früher. Also die fortschrittliche Kultur 
Europas wird das ein bisschen begünstigt haben. Letztendlich haben sich die Leute auch selber entwickelt. Dadurch dass die auch am Mittelmeer die Nähe zu Spanien hatten - da ist ja die Straße von Gibraltar, glaube ich - da ist ja reger Handel und so was. Und Konversation. Und da vermischen sich die Kulturen ja auch. Und das sieht man halt, dass in Afrika schon Teile der fortschrittlichen Kultur mit drin sind.

I: Mhm.

S: Natürlich auch Nachteile vielleicht der europäischen Kultur. Das gehört immer dazu. Aber halt der Fortschritt wird dadurch, DENKE ich mal, auch ein bisschen angekurbelt. (David, Gym14)

David vermerkt, dass Ägypten ,,schon immer eine fortschrittliche Kultur“ gehabt habe. Gleichzeitig stellt er die Fortschrittlichkeit des antiken Ägyptens in den Zusammenhang mit dem Einfluss des römischen Reichs. Neben der Andeutung, dass es sich dabei um einen begünstigenden Einfluss gehandelt habe, bleibt weitgehend unklar, wie das Verhältnis von eigener Entwicklung und Entwicklung durch Europa zu verstehen ist. Das zweite Argument ist die durch „Konversation“ und insbesondere den ,,regen Handel“ im mediterranen Raum hergestellte Einflussnahme. Dadurch würden sich die Kulturen ,vermischen“. Das Resultat des Prozesses sei darin auszumachen, dass ,,in Afrika schon Teile der fortschrittlichen Kultur mit drin“seien. An mehreren Stellen benennt David auch die Nachteile, die durch die Verbreitung der ,europäischen Kultur“ entstanden sind; dazu weiter unten mehr. Diese erscheinen ihm jedoch akzeptabel, da der Fortschritt ,,auch ein bisschen angekurbelt" werde. An dieser Stelle benutzt er relativierende Ausdrücke (,auch ein bisschen“), die an der Gesamtstruktur seiner Argumente nichts ändern, die wir jedoch für die Interpretation im Hinterkopf behalten sollten. Der Ursprung der Entwicklung selbst scheint nach David jedenfalls die Einflussnahme Europas zu sein. Auf die erzählgenerierende Frage dazu, wie es überhaupt zum Fortschritt in Europa kam, wusste David zwar keine Antwort. Nichtsdestotrotz wiederholt er hier die Denkweise einer Verknüpfung von territorialer Nähe zu Europa und Fortschritt.

I: Und, ähm, wie kam es überhaupt zum Fortschritt? Also Europa .../

$\mathrm{S}$ : Na ja, Europa war ja .../ Na ja, eigentlich das alte Rom war ja - mit Griechenland zusammen - die erste große antike Kultur. Warum die genau da entstanden ist weiß man nicht.

I: Ja.

S: Aber es ist halt so gewesen. Und seitdem hat sich ja, dadurch dass Rom und Griechenland auch so großen Einfluss genommen haben, die ganze Kultur danach entwickelt. Die arabische Kultur war auch relativ weit, aber die sind ja weit weg. Die waren nur 
durch Russland mit Europa verbunden. Und die Türkei, da war ja das Osmanenreich und die waren ja auch relativ weit. Aber es ist halt so gekommen, dass in Afrika nicht so viel war. Bis dann die Kolonialherren halt nach Afrika gegangen sind. Und dadurch kam das dann denke ich auch, diese fortschrittliche Kultur teils. (David, Gym14)

Das „alte Rom“ und „Griechenland“ sieht David als „erste große antike Kultur[en]“". Den Grund dafür vermag er an dieser Stelle nicht auszumachen. Den Grund wisse „,man nicht“, aber es sei „,halt so gewesen“. Die Prämisse des Narrativs - die Differenz von fortschreitenden und stagnierenden Kulturen - wird hier explizit gesetzt. Diese stellen für ihn den Startpunkt von der Entwicklung von Kultur selbst dar, denn der „große Einfluss“ Roms und Griechenlands habe zur Entwicklung der ,ganze[n] Kultur danach“ geführt. Das Verhältnis zu ,Afrika“ - gemeint ist hier ,Afrika' südlich der Sahara - lässt sich bei David klar beschreiben, während das Verhältnis zur ,arabische[n] Kultur“ und zum „Osmanenreich“ auf mehrere Weisen zu interpretieren ist. So sei in Afrika „nicht so viel“ gewesen. Dies habe sich erst dadurch geändert, dass die „Kolonialherren nach Afrika gegangen sind“. Dadurch sei dann „,diese fortschrittliche Kultur“ dahingekommen. Dieses Argument werde ich im Folgenden Abschnitt genauer analysieren.

Das Verhältnis der ,arabische[n] Kultur“ und des „Osmanenreich[s]“ beschreibt David wiederum in Begriffen von Entwicklungsniveaus und räumlichen Beziehungen. Die „arabische Kultur“" sei ,auch relativ weit“ gewesen. Allerdings hätten sich diese auch „weit weg“ von Europa befunden - also in diesem Fall des vermeintlichen Ursprungs Europas, also Rom und Griechenland - und nur „,durch Russland mit Europa“ verbunden. Ähnliches gelte für das „Osmanenreich“. Unabhängig von der historischen und geographischen Stimmigkeit dieses Arguments lässt sich hier folgende Interpretation vornehmen: Es gab mehrere Kulturen mit unterschiedlichen Entwicklungsniveaus. In der europäischen Antike hat sich dann Europa an die Spitze dieser Entwicklung gesetzt und im Folgenden den Fortschritt anderer Kulturen befördert, wie beispielsweise die „arabische Kultur“ und das „Osmanenreich“; oder den Fortschritt anderer Kulturen erst hervorgebracht, wie am Beispiel der erst durch den Kolonialismus durchbrochenen Fortschrittslosigkeit Afrikas. Die ,arabische Kultur“ und das „Osmanenreich“ werden von David in universalen Entwicklungsstufen auf einer Stufe zwischen „Afrika“ auf der einen und „Europa“ bzw. „Rom“ und „Griechenland" auf der anderen Seite der Stufenfolge angeordnet. Einem Raum wird eine Zeit und einer Zeit ein Raum zugeschrieben. Der Ort des „Osmanenreiches“ oder des heutigen ,Afrikas ' erscheint in dieser Logik also als früher und ,Europa“ ist jetzt und dabei der Zukunft zugewandt. Diese koloniale Raum-Zeit-Matrix 
(4.2.2.2) stellt ein wesentliches Moment kolonialer Ideologie dar. Ab dem Zeitpunkt der Existenz des antiken Griechenlands und des ,,alten Roms“ steht Europa an der Spitze einer teleologischen Geschichte; nach dem antiken Griechenland und dem alten Rom entwickelte sich die ,ganze Kultur danach“. Dabei changiert das Argument zwischen einer, realen' Entwicklung, die die vermeintliche Fortschrittlichkeit durch Kolonialismus, andere Einflussnahmen oder Handel von Europa in andere Teile der Welt trägt, einer Vorannahme der Differenz der Kulturen und der Beschreibung der Weltgeschichte über Entwicklungsstufen anhand eurozentrischer Maßstäbe.

Von diesem Bild vom Europa des antiken Griechenlands und Roms zieht David eine Linie zum heutigen Europa, dessen Fortschrittlichkeit immer noch ausstrahlen kann. In Bezug auf den arabischen Frühling ist er zwar der Ansicht, dass die Demokratie da ,noch nicht weit genug“ sei. Um dies zu ändern, sieht er aber kein militärisches Eingreifen, sondern Unterstützung der Aufständischen, humanitäre Hilfe, Verständigung und vor allem Schulbildung als adäquate Mittel an. Im Hintergrund dessen steht dabei der Gedanke, dass Libyen und Syrien auf einer anderen Entwicklungsstufe stehen würden und diese Bildung bräuchten, um den Fortschritt und damit die Überwindung der andauernden Konflikte zu ermöglichen.

S: Man hat jetzt ja auch gesehen, in Libyen und Syrien ist ja immer noch der arabische Frühling. So hieß das glaube ich? Ich bin mir nicht ganz sicher.

I: Mhm [bejahend].

S: Also es ist schon in der Umsetzung, aber die politische Lage ist einfach noch zu risikoreich da. Oder die Demokratie ist da noch nicht weit genug.

I: Und wie könnte das dazu kommen?

S: Also dass die Demokratie weit genug ist?

I: Ja.

S: Also militärisches Eingreifen halte ich nicht für sinnvoll von der EU oder NATO. Also die Leute müssen sich im Grunde selber irgendwann dazu aufraffen. Man kann die dabei unterstützen. Also kann man, wie es ja zum Beispiel gemacht wird in Syrien, die Aufständischen mit Lebensmitteln und so versorgen, damit die das schaffen. Und man muss halt möglichst das fördern. Immer die politische Verständigung fördern. Und, ja, eben auch mehr humanitäre Hilfe hinsenden. Nicht nur jetzt vielleicht Leute die da kochen und da, weiß ich nicht, Wasser verteilen. Sondern auch Leute .../ Schulbildung muss ganz dolle gefördert werden. Und die das psychologisch auch alles managen da mit den Diplomaten. (David, Gym14) 
Anders als in der kolonialen Vergangenheit hält er also eine direkte Intervention Europas in Libyen und Syrien nicht für sinnvoll. Er scheint hier aus der Sicht der EU zu argumentieren und plädiert dafür, Bildung dorthin zu senden, um die Demokratie dort voranzubringen. In Verbindung mit seinen Vorstellungen $\mathrm{zu}$ den Entwicklungsstufen und dem Zentrum des Fortschritts in Europa erscheint auch dieser Gedanke als problematisch, da dort fehlende Bildung durch hier vorhandenes Wissen aufgefüllt werden könne.

Auf die Nachfrage, wie er sich das Leben in einem "Stamm“ in Afrika vorstellt, malt David ein Bild des Alltags in einem ,afrikanischen Stamm“.

I: Mhm. Ja. Nochmal kurz zurück zu Afrika: Wie kann man sich das denn vorstellen, so Leute die noch in so einem Stamm leben? Wie sieht so ein Alltag aus?

S: Mhm. Also die stehen auf und dann sorgen die für alles was sie zum Überleben halt brauchen. Essen. Wasser. Eventuell, wenn irgendjemand krank ist, bestimmte Heilkräuter. Ich weiß nicht auf was da noch vertraut wird. Tiermedizin ja teils. Ja, Häuser, wenn die ein Dorf haben vielleicht mal irgendwas reparieren oder so. Rohstoffe, Vorräte für den Winter anlegen. Obwohl in Afrika, im Regenwald, gibt es eigentlich keinen richtigen Winter. Da bleibt das Klima eigentlich konstant. Also die leben halt noch auf das Wesentliche beschränkt. Alles, was sie zum Leben brauchen, holen sie sich. Und der Rest wird zelebriert vom Leben.

I: Mhm.

S: Genossen [lacht]. (David, Gym14)

Dieses Bild des Alltags illustriert Davids Konzept von der Fortschrittslosigkeit der ,afrikanischen Stämme“. Sie vertrauten nicht einfach nur auf anachronistische Techniken, wie „Heilkräuter“ oder „Tiermedizin“. Vielmehr wird hier implizit auf das koloniale Bild der ,Naturvölker“ angespielt. Nach David lebten sie „halt noch auf das Wesentliche beschränkt". Das Leben wird aber nicht nur als ,einfach" vorgestellt. Im Gegensatz zu europäischen Bäuerinnen und Bauern, deren Leben ja auch oft als ,einfach ' dargestellt wird, scheinen in Davids Bild die Bewohner_innen der „Stämme“ weder zu arbeiten, noch die Natur zu formen: „Alles, was sie zum Leben brauchen, holen sie sich. Und der Rest wird zelebriert vom Leben." Die Ausdrücke des zelebrierenden Lebens und des Genießens verweisen implizit auf die fehlende Anstrengung, die diese im Gegensatz zu ,modernen“ Subjekten aufbringen müssen; Davids Haltung dazu erscheint als Abwertung und Neid zugleich. Im kommenden Abschnitt werde ich mich ausführlicher mit der Rolle der „afrikanischen Stämme“ auseinandersetzen. 
Im Anschluss an seine Ausführungen zur Verbindung vom „Osmanenreich“ bringt David Anhaltspunkte für einen von ihm ausgemachten Grund für die Differenz von fortschreitenden, weniger fortschreitenden und stagnierenden Kulturen vor. Vorher hatte er ja behauptet, er wisse den Grund für das Entstehen der fortschrittlichen Kulturen in Griechenland und Rom nicht. Ich frage, ob der Fortschritt überhaupt erst durch den Kolonialismus nach Afrika kam.

\section{I: Dadurch kam überhaupt der Fortschritt erst dahin?}

S: Eben. Diese Lebensart. Natürlich auch der Rassismus da unten. Das ist etwas anderes, das war nicht so gut. Aber so dieser Lebensgedanke dahinter, nicht nur von der Hand in den Mund zu leben, sondern halt sich Häuser zu bauen und all so was und nicht umherzuziehen. Das kam, denke ich, daher ein bisschen. (David, Gym14)

Nach David sei also der Fortschritt als solcher erst durch den Kolonialismus nach Afrika gekommen. Als Grund für die Differenz macht er hier implizit „diese Lebensart" aus. Eine ,europäische" Lebensart zeichne sich für ihn dadurch aus, „nicht nur von der Hand in den Mund zu leben, sondern halt Häuser zu bauen und all so was und nicht umherzuziehen". Die nicht-europäische bzw. afrikanische Lebensart zeichne sich dementsprechend genau durch das Gegenteil aus. Dies scheint für ihn einen Grund für die Überlegenheit und die Fortschrittlichkeit der ,europäischen' Kultur darzustellen.

Gleichzeitig problematisiert er „den Rassismus da unten“ und die oben genannten „Nachteile“ der europäischen Kultur, die durch den europäischen Einfluss, respektive Kolonialismus, dort vorhanden sind. Der Kolonialismus hat nach David den Rassismus nach Afrika gebracht. Dies führt er an einer anderen Stelle des Interviews an einem Beispiel aus. Im Abschnitt zur Entwicklung Afrikas führt er als Grund für die vermeintliche ,Unterentwicklung ' Afrikas aus, dass „die Kolonialherren da mal [im Kongo] die Stämme gegeneinander aufgewiegelt haben, um sie besser besiegen zu können“. Seitdem sei „da Blutrache“. Wiederum sieht er hier die Notwendigkeit dort Bildung voranzubringen: „Also man müsste da die politische Verständigung vielleicht erstmal voranbringen.“ Er sieht also durchaus auch die ,schlechten' Seiten des europäischen Expansionismus. Nichtsdestotrotz erscheinen diese als notwendige Begleiterscheinungen, um ,Afrika' überhaupt auf den Weg des Fortschritts zu bringen. Insgesamt verfügt er - im Vergleich zur großen Mehrheit der anderen Lernenden - über viel Wissen über die Geschichte des Kolonialismus:

I: Mhm. Und, ähm, hatte denn Deutschland auch Kolonien?

S: Ein paar in Afrika. Ich weiß nicht mehr genau welche. 


\section{I: Mhm.}

S: Aber die Mehrheit hatten Frankreich, Portugal und Spanien. Und England auch noch ein bisschen. Aber Deutschland hatte schon ein paar. Deutschland hatte auch ursprünglich mal welche in Amerika. Aber die sind dann ja alle zu Amerika geworden. Halt United States. Und das ist ja nicht mehr .../ Die haben sehr früh da ihre Anteile gestrichen. (David, Gym14)

Dieses Wissen führt aber nicht zu einer generell kritischen Haltung dem Kolonialismus gegenüber.

Die koloniale Raum-Zeit-Matrix und das damit verknüpfte teleologische Geschichtsnarrativ, in dem Europa als Zentrum der Weltgeschichte fungiert, kommt bei den anderen Lernenden weniger explizit vor. Jedoch finden sich in einer Mehrheit der Interviews Momente dieser.

\subsubsection{Stagnation vs. Fortschritt II: Afrika, Armut und die "Stämme"}

In diesem Abschnitt wird dem Bild von Afrika nachgegangen. Annähernd alle Interviewten äußerten sich zu Afrika. Einige Lernende bringen Afrika mit ,Stämmen' in Verbindung. Zwei Beispiele dafür werde ich am Beginn dieses Abschnitts ausführlicher analysieren - Finn und Jan. Ich räume ihnen viel Platz in diesem Abschnitt ein, da sie für eine dekoloniale Perspektive wichtige Einblicke in das Bild von Afrika geben. Oft kommt Afrika als Kontinent vor, der als Exempel für Armut fungiert. Zum Ende werde ich zwei Interviewpassagen analysieren, in denen die europäische Kolonialisierung Afrikas in Bezug auf gegenwärtige globale Ungleichheit thematisiert wird.

Finn (HS04) eröffnet das Interview mit einer Aussage zu Afrika:

I: Okay. Vielleicht kannst du einfach nochmal anfangen und sagen, was dir zu Globalisierung einfällt?

S: Zu Globalisierung fällt mir ein, dass eben die Länder der Welt, sag' ich mal, aufgebaut werden. Alle gleichberechtigt sind, sag' ich jetzt mal. Zum Beispiel Afrika ist, sag ich jetzt mal, nachteilhaft. Weil das eben noch nicht so modernisiert wurde, wie eben unser Deutschland, sag' ich jetzt mal, zum Beispiel. Und ich denke mal das hat damit zu tun, dass eben alles aufgebaut wird. Die ganze Welt gleich ist. Modern. Ja, so verstehe ich das darunter.

I: Mhm. Was heißt modern für dich? 
S: Na ja, das, sag' ich jetzt mal, eben auch jedes Land der Welt Straßen hat. Autos und alles. Die Technik. Alles so was.

I: Mhm. Und findest du das gut oder schlecht?

S: Ähm, auf eine Art finde ich das ganz gut, weil dann eben nicht mehr .../Zum Beispiel für Afrika muss jetzt ja immer gespendet werden. Und das muss man dann nicht mehr, weil die dann auch sich selbst versorgen können. Wenn die eben aufgebaut werden. Ja, also daher finde ich das eigentlich ganz gut, wenn das so ist. (Finn, HS04)

Unter Globalisierung versteht Finn, dass alle Länder gleichberechtigt sein werden, indem sie modernisiert werden. Afrika sieht er als ,nachteilhaft“ an, weil es noch nicht ,so modernisiert wurde, wie eben unser Deutschland“. Er sieht hier also eine Differenz im Grad der Modernisierung zwischen Afrika und Deutschland. Bei seinem Verständnis von Modernisierung scheint ein Fokus auf der Frage von Technik und Infrastruktur zu liegen. Mit Afrika verbindet er außerdem die Notwendigkeit zu spenden.

Auf die folgende Frage nach dem Grund für die benannte Benachteiligung Afrikas, bringt er zwei miteinander in Verbindung stehende Argumente.

I: Mhm. Und woran liegt das, dass Afrika jetzt so, ähm ... wie hast du das genannt ... benachteiligt ist?

S: Ich denke mal das liegt daran .../ Die wurden ja früher versklavt. Und, ich sag' jetzt mal, veräppelt. Also, die haben wertlose Gegenstände bekommen und haben dafür ihr ganzes Gold und so was dahin gegeben. Und die Entwicklung ist noch nicht so weit da vorangekommen. Beim Menschen jetzt selbst. Dass ihr Gehirn vielleicht das eben nicht so weiß und nicht so viel Ahnung davon hat. Weil sie es eben nicht beigebracht bekommen haben.

I: Mhm. Und dann ist das Gehirn nicht so weit entwickelt meinst du?

S: Denke ich jetzt mal, dass das so ist. Dass das Gehirn nicht so fortgeschritten ist, wie unseres. (Finn, HS04)

Den Grund für die Benachteiligung sieht Finn zunächst in der Geschichte der Sklaverei. Damit ist er einer der Wenigen, die auf diesen Zusammenhang aufmerksam machen. Außerdem deutet er den Prozess kolonialer Ausbeutung an. Solche dependenztheoretischen Momente finden sich bei neun Schüler_innen. Den historischen Ablauf der kolonialen Begegnung stellt Finn sich allerdings in einem stereotypen kolonialen Bild vor. „Die“ seien „,veräppelt“ worden und hätten „ihr ganzes Gold“ gegen „wertlose Gegenstände“ getauscht. Dann bringt er sein zweites Argument, das scheinbar unabhängig vom ersten aufgeführt wird, jedoch 
eng mit ihm verzahnt ist. Die „Entwicklung“ sei „da“ „,noch nicht so weit“ vorangekommen. Das Argument der verspäteten Entwicklung zieht sich durch die große Mehrheit der Interviews. Ein Spezifikum von Finn ist allerdings, dass er es im Folgenden auf den ,Menschen jetzt selbst“ bezieht. Er behauptet, dass ,ihr Gehirn vielleicht das eben nicht so weiß“. Als Grund dafür fügt er hinzu, ,weil sie es eben nicht beigebracht bekommen haben“. Verwirrt von diesem Argument, dessen Interpretation zwischen einem biologistisch-rassistischen - die „Gehirne“ seien noch nicht so weit - und einem dieser Interpretation widersprechenden konstatierten Bildungsdefizit - hier wäre „Gehirn“ möglicherweise als technizistische Metapher für Lernen zu verstehen -, stellte ich eine Klärungsfrage, in der ich die biologistische Interpretation nahelegte, woraufhin Finn dies bestätigte: „Denke ich jetzt mal, dass das so ist. Dass das Gehirn nicht so fortgeschritten ist, wie unseres." Trotz der Affirmation der Nachfrage kann hier nicht als geklärt angesehen werden, welcher der beiden Momente nun der für ihn ausschlaggebende ist. In der diskursiven Konstellation dieses Textabschnittes scheinen aber beide Momente - das biologistische und kulturalistische - eine Rolle zu spielen. Von hier aus rückblickend auf das erste Argument der Sklaverei und der kolonialen Ausbeutung erscheint dieses in einem anderen Licht, da sie sich haben ,veräppeln“ lassen, weil sie weniger intelligent gewesen sein müssen; und vice versa die Europäer_innen klüger. Im Anschluss versuchte ich durch eine Nachfrage, ihn das Thema von einer anderen Seite nochmals angehen zu lassen.

I: Mhm. Und wie könnte man das .../ Du sagst ja, Globalisierung ist, das alles sozusagen gleicher wird oder gleichberechtigter wird. Und wie könnte dann zum Beispiel so eine Entwicklung dann aussehen?

S: Ja, zum Beispiel, wenn es dann aufgebaut wurde, dann sind da ja auch Schulen dort und das alles. Und dann lernen ja die Kinder dann das auch kennen. Die ganzen neuen Techniken. Computer. Eben alles, was wir kennen. Und dass das dann im Laufe der Jahre auch automatisch bei denen reinkommt in den Kopf, sag' ich jetzt mal. (Finn, HS04)

Den Weg für eine solche Entwicklung der Modernisierung Afrikas sieht er insbesondere in Bildung. Seinem Bildungskonzept liegt dabei eine Hierarchie zugrunde. Die Kinder in Afrika sollen ,lernen“. Was sie lernen sollen, weiß er genau, nämlich ,eben alles, was wir kennen“. Dadurch würde das, was wir schon wissen, ,im Laufe der Jahre auch automatisch bei denen [...] in den Kopf“ reinkommen. Dieses Bildungskonzept ist eng mit dem Modernisierungsparadigma verbunden. Im Anschluss an den vorherigen Abschnitt wird hier wieder die koloniale Raum-Zeit-Matrix vorausgesetzt und direkt auf die Subjekte übertragen. 
,Wir' hätten das Wissen, das ,denen` fehle, da ,wir` auf der Modernisierungsstufe über ,denen'stünden. Auch bei Finn nimmt Afrika eine Sonderstellung ein. Während seine Einschätzung zu Afrika wohl für alle Menschen dort zu gelten scheint, schränkt er dies bei anderen Weltregionen ein.

I: Mhm. Mhm. Und, ähm, ist das nur Afrika?

S: Es gibt viele Länder. Zum Beispiel, sag' ich jetzt mal, Indien. Obwohl da gibt es auch schon welche die modernisiert sind. Aber, da gibt es auch noch so einzelne Dörfer, wo es eben nicht so fortgeschritten ist. Also es gibt so manche Orte, wo das noch nicht so ist. (Finn, HS04)

In Bezug auf Indien unterscheidet er in Menschen dort, die ,schon [...] modernisiert" seien und welche, die es nicht seien. Vermutlich liegt sein Fokus bei der Modernisierung auf der Frage der Technik. Es wird aber deutlich, dass dies zwar im Fokus liegt, aber gleichzeitig transportiert der Marker ,modernisiert/nichtmodernisiert" noch etwas anderes als die Verbreitung von Technik. Am deutlichsten wird dieses Andere bei Finns Auseinandersetzung mit „afrikanischen Stämmen“ zu einem späteren Zeitpunkt des Interviews.

I: Mhm. Und, ähm, wir haben schon kurz über Kultur gesprochen, ne? Fällt dir noch mehr zu Kultur ein? Was Kultur und Globalisierung miteinander zu tun hat?

S: Kultur und Globalisierung? Ich sag' ich jetzt wieder .../ Afrikanische Stämme, sag' ich jetzt mal, die haben ihre Bräuche noch. Ihre Traditionen, sag' ich mal, die sie machen. So leben die eben. Und die wollen glaube ich auch mal gar kein anderes Leben. So, wie die das da führen, da sind die so dran gewöhnt, denke ich mal. Und vielleicht wollen die das eben auch gar nicht dann. Also, so leben wie wir. (Finn, HS04)

Bei den Begriffen Kultur und Globalisierung assoziiert Finn direkt ,afrikanische Stämme“. Wie im Abschnitt „Die Anderen als ,Kultur““ (3.3.6) weiter ausgeführt, ist zunächst interessant, dass Kultur bei Finn als etwas Statisches bzw. Altes gilt, das der Modernisierung entgegengesetzt erscheint. Dementsprechend beschreibt er auch das, was die ,afrikanischen Stämme“ ausmache. Diese hätten „,ihre Bräuche noch“ und ,ihre Traditionen, [...] die sie machen. So leben die eben." Tradition wird hier von Finn als Praxis definiert. Der imaginäre Gegensatz dazu, das imaginäre ,Wir', wäre eben eine traditionslose Moderne bzw. eine Moderne, die ihre Traditionen nicht ,macht" oder , lebt', sondern - wenn überhaupt - vielmehr artifiziell behandelt. Die Moderne scheint keine Tradition zu kennen. Die ihr zuzurechnenden Menschen scheinen sich selbst bewusst und selbstbestimmt in der Gegenwart zu leben. Die ,afrikanischen Stämme“ leben 
laut Finn „eben“ so und wollten auch ,gar kein anderes Leben“ und nicht „,so leben wie wir". Die ,afrikanischen Stämme" scheinen nach Finn auch insofern das Gegenbild der Moderne zu sein, als sie nicht zum Fortschritt bzw. zur Modernisierung streben, sondern in einer Art ,Naturzustand“ verharren. Diesen kolonialen Begriff führe ich hier in die Analyse von Finns Interview ein, da Finn den Begriff zwar nicht benutzt, seine Konzepte aber stark an diesen erinnern.

Im Folgenden stelle ich die Frage, ob dies für ganz Afrika gelte.

I: Mhm.

S: Vielleicht. Ich kann das nicht genau sagen, aber ich denke das mal so.

I: Mhm. In ganz Afrika?

S: Nee, nicht in ganz Afrika. Wenn ich mir zum Beispiel Ägypten oder so angucke, das ist ja auch schon etwas moderner als Südafrika. Da gibt es eben sehr viele Stämme noch, die noch sehr weit in der Vergangenheit zurückleben, sag' ich mal. Und ihre Stammesbräuche und alles Mögliche .../ Ihr Leben so führen, wie sie eben das haben. Und sich nicht so weiterentwickeln, wie andere Menschen das tun. (Finn, HS04)

Ähnlich wie schon bei David im vorherigen Abschnitt wird hier eine Differenz zwischen dem ,eigentlichen" Afrika südlich der Sahara und Nordafrika - hier vertreten durch Ägypten - eingeführt. An dieser Stelle expliziert Finn auch das vorher nur angedeutete Wesensmerkmal dieser „Stämme“, deren Bewohner_innen „sich nicht so weiterentwickeln, wie andere Menschen das" täten. Dies verweist wiederum auf die Sonderstellung Afrikas, die schon im ersten Abschnitt dargestellt wurde. Wie schon bei Hegel steht Afrika nicht einfach nur weiter unten bzw. früher in der kolonialen Raum-Zeit-Matrix, wie etwa Indien, sondern außerhalb. Dies gilt in der kolonialen Ideologie im Übrigen häufig auch für die Repräsentation der Indígenas der Amerikas, den Aborigines in Australien sowie für die Bewohner_innen des Pazifiks. Diese kommen in den Interviews jedoch - mit zwei Ausnahmen - nicht vor; dieser Platz wird von Afrika besetzt. Finn konstatiert, dass es in Afrika „eben sehr viele Stämme“ gäbe, „die noch sehr weit in der Vergangenheit zurückleben“. Hier scheint die koloniale Raum-Zeit-Matrix erneut auf: Menschen, die in „afrikanischen Stämmen“ wohnen würden, wohnen nicht einfach an einem anderen Ort als ,wir', sondern gleichzeitig zu einer anderen Zeit. Die Gegenwart hat also auch einen Ort, nämlich Europa bzw. den Westen.

Alle diese mit kolonialen Momenten verwobenen Argumente von Finn widersprechen nicht seinem Ausgangsverständnis von Globalisierung. Er hatte Globalisierung mit der Aufgabe verbunden, dass ,die Länder der Welt [...] aufgebaut 
werden“, damit ,,alle gleichberechtigt sind“. Dieses Ziel der Gleichberechtigung aller Länder und der darin wohnenden Menschen möchte Finn durch Modernisierung erreichen. Das Modernisierungs- bzw. Entwicklungsparadigma bestimmt dabei sein Ziel der Gleichberechtigung so sehr, dass beides nicht voneinander $\mathrm{zu}$ trennen ist. Dies wird auch deutlich an seiner Bewertung des historischen Kolonialismus.

I: Ja. Und, na ja, die leben noch so weit in der Vergangenheit und dann kamen die aber irgendwann auch in Kontakt mit Europäern. Glaubst du, das ist gut oder das ist schlecht?

S: Also ich fand' den Kontakt zwischen den beiden .../ Also eigentlich finde ich das gut, dass die sich getroffen haben. Aber das schlechte war dann ja wieder, dass die Europäer die ausgenutzt haben und veräppelt mit dem ganzen Gold und dem alles. Und dann Sklaven gekauft haben. Das fand ich dann irgendwie eben auch schon wieder blöd.

I: Aber gab es auch einen Vorteil?

S: (... $)^{1} \mathrm{Ja}$, es gab natürlich einen Vorteil. Dass eben die europäischen Länder, die dann gehandelt haben, eben reicher geworden sind. Durch das Gold zum Beispiel. Und durch die Sklaven, denke ich mal, dass viel Arbeit von den Ländern abgenommen wurde. Weil eben .../ Zum Beispiel Bauern, das waren ja die meisten, sag' ich mal, zu der Zeit. Und andere Leute konnten sich dann auf andere Sachen konzentrieren. Zur Entwicklung dann eben. (Finn, HS04)

Finn kritisiert, dass „,die Europäer“ die Menschen in Afrika ausgenutzt, betrogen und als „Sklaven“" verkauft hätten. Positiv fand er, dass die ,europäischen Länder“ reicher geworden seien und durch den Reichtum und die Sklaverei der Raum für „Entwicklung“ geschaffen worden sei. Zum Beispiel hätten die ,Sklaven [...] viel Arbeit von den Ländern abgenommen“, sodass ,zum Beispiel Bauern [...] und andere Leute" die Möglichkeit gehabt hätten, die Entwicklung in Europa so voranzubringen. Diese von Finn vorgebrachte Verknüpfung zwischen der Entstehung der europäischen Moderne mit der Sklaverei und dem historischen Kolonialismus - dass also Sklaverei und Kolonialismus als Voraussetzung für die Entwicklung europäischer Ökonomien und Gesellschaften anzusehen ist - ist bis heute in Europa jenseits dekolonialer Geschichtsschreibung eine umkämpfte These.

Das zweite Beispiel für die Rolle , afrikanischer Stämmen“ in den Vorstellungen von Globalisierung ist Jan (Gym20). Im Kontext vom Sprechen über

\footnotetext{
${ }^{1}$ Mit diesen Klammern werden die Pausen hier und in allen folgenden Interviewpassagen mittranskribiert, wobei jeder Punkt eine Sekunde der Pause markiert.
} 
verschiedene Kulturen in Deutschland bringt Jan ,Kulturen“ in Afrika ins Spiel, wo ,wir halt auch nicht alles mitbekommen“.

Es gibt ja auch in Afrika, gibt es ja auch so Bevölkerungen die halt so richtig abgeschottet sind. Also die, ähm .../ Also ich will jetzt nicht sagen, dass die so leben wie früher. Aber es gibt noch so, ich weiß nicht ob man das Dörfer nennt, oder halt .../ Stämme will ich jetzt auch nicht sagen, das hört sich ein bisschen komisch an. Aber halt, ähm, so verschiedene Stämme, die dann halt ohne Internet und ohne neue Technik halt überleben können. Die sind dann halt in irgendwelchen Wäldern. Aber das ist jetzt nicht genauso wie früher, das ist halt nur im Gegensatz zu heute, wie wir leben, etwas ganz anderes. (Jan, Gym20)

Jan spricht hier von „Bevölkerungen“. Das Wort „Stamm“ hört sich für ihn ,komisch" an. In der Folge benutzt er es aber doch. Das Wort löst bei ihm ein unbestimmtes Unbehagen aus, möglicherweise hat er irgendwo mitbekommen, dass es in vielen Kontexten heute nicht als politisch korrekt gilt, es zu benutzen, aber es scheint ihm nicht ganz klar zu sein, warum. Er möchte auch nicht sagen, dass die so ,leben wie früher“, wobei das im diskursiven Kontext offensichtlich eine Rolle zu spielen scheint. Jan ringt hier mit Kontexten, Sprechweisen und sich selbst. Er scheint einen Ausweg darüber zu finden, dass es ,im Gegensatz zu heute, wie wir leben, etwas ganz anderes ist“. Es ist also nicht ,wie früher", sondern ,etwas ganz anderes“. Das ,heute“ bringt natürlich genau die Zeit-RaumDimension wieder in sein Argument, die er zunächst auszuschließen versuchte. Möglicherweise beruht sein Unwohlsein auf eigenen Erfahrungen des Otherings, denn in der Folge bezieht er dieses Anderssein auf seinen familiären Hintergrund.

I: Mhm. Und wie stellst du dir so ein Leben da in so einem Stamm in Afrika vor?

S: Mhm. Das ist eine schwierige Frage, weil ich ja hier so aufgewachsen bin, in so einer Großstadt, Hannover halt. Ich kenn' das Leben jetzt gar nicht so, wie die da .../ Ich kann mir das jetzt auch schlecht vorstellen, weil meine Eltern kommen halt aus Jugoslawien. Also mein Vater ist in Mazedonien auch geboren. Und da bin ich halt auch oft. Also in den Ferien, falls das geht.

I: Mhm.

S: Und, ähm, ja da ist das Leben jetzt .../ Ich würde nicht sagen, dass es genauso ist, wie in Afrika oder in Stämmen oder so. Aber da ist das Leben halt auch irgendwie anders als hier. Und ich nehme an, dass das in Afrika dann noch anderer wäre. Sie wissen was ich meine? (Jan, Gym20)

„Anders“, „,das Leben“ ist ,,anders als hier“, sind die Parallelen, die Jan zwischen Afrika und Mazedonien sieht. Im Anschluss spricht er darüber, dass ein Leben 
ohne Technik für ihn unvorstellbar wäre. Daran anknüpfend stelle ich die Frage, warum , die' denn ganz ohne Technik leben würden.

I: Und warum ist das so, dass die da ganz ohne Technik leben?

S: Ähm, da gab’ es mal, glaube ich, so eine Reportage. Aber genau weiß ich das auch nicht. Ähm, das ist halt .../ Ich glaube das sind so Ureinwohner oder so. Also es gibt ja auch in Australien diese Aborigines. Aber es gibt ja gar nicht mehr so viele davon. Habe ich gehört, aber ich weiß es aber auch nicht so.

I: Mhm.

S: Ähm, und, ja die leben dann halt .../ Die meisten sind bestimmt auch jetzt so, wie .../ Ich will jetzt nicht sagen, dass die jetzt andere Menschenarten sind oder so. Nur halt, dass die so leben wie deren Vorfahren. Dass das vielleicht so weitergegeben wurde, wie sie leben wollen und sollen. Und deswegen tun sie das auch. Dann haben sie vielleicht in ihrem Gedächtnis, dass es so sein soll. Und das wollen die dann auch wiedergeben. Und dann .../

I: Die leben so ganz ihre Tradition, sozusagen?

S: Ja. Würde ich sagen. (Jan, Gym20)

Er bezieht sich auf eine Reportage, die er mal über die Aborigines gesehen hat. Anders als Finn geht er aber weder bei „Stämmen“ in Afrika noch bei den Aborigines davon aus, dass es sehr viele wären und die einzigen Bewohner_innen bestimmter Großregionen. Nichtsdestotrotz scheinen sie eine große Bedeutung für seine Vorstellungen zu haben. Er spricht erneut die Lebensweise an und charakterisiert sie als grundlegend anders. Dann kommt er wieder in die Auseinandersetzung mit sich selbst über das, was er sagen möchte, sollte und will: „Ich will jetzt nicht sagen, dass die jetzt andere Menschenarten sind oder so." Wie so oft, wenn Menschen sagen, dass sie etwas ,zwar nicht sagen wollen", sagt er aber damit schon, dass sie das quasi oder möglicherweise seien bzw. dass diese so angesehen werden könnten. Vorher hatte er versucht, zu umgehen zu sagen, dass , sie" in der Vergangenheit lebten. Hier bringt er dann eine andere Differenz in Bezug auf Zeitlichkeit ein: Die Art und Weise mit Tradition und Fortschritt umzugehen. Wie auch schon Finn geht er davon aus, dass sie ihrer Tradition verhaftet sind; sie lebten ,wie deren Vorfahren“, so wie es ,,weitergegeben“"werde. Es gibt hier also nach Jan keinen Fortschritt, keine Autonomie der Subjekte, sondern stattdessen ein Leben im Gleichfluss der Traditionen der Vorfahren.

Im Anschluss stellte ich, im Sinne der Fragetechnik der Konfrontation, die Nachfrage danach, was das für mich bzw. ,uns‘ bedeuten würde. 
I: Und .../ Aber lebe ich nicht in meiner Tradition? Leb' ich quasi als moderner Mensch, sozusagen, ohne Tradition?

S: Ja, ohne Tradition .../ Wir leben ja auch eigentlich so, wie das unsere Eltern gemacht haben. Also wenn unsere Eltern .../ Es gibt ja auch Arbeiterfamilien und dann würde ich sagen, dass halt die Kinder von den Arbeitern, also von den Eltern, die aus einer Arbeiterfamilie stammen, dann auch Arbeiter werden. Oder halt .../ Ähm, es gibt halt auch wenige, die aus einer schlechten Familie dann hochsteigen und dann plötzlich .../ Oder halt die ganze Zeit ackern und dann, ähm, sagen wir mal Millionär, werden oder so. Das ist halt .../ Man macht eigentlich das, was die Eltern machen. Also man bleibt da so in den Reihen von den Eltern. Das ist jetzt keine richtige Tradition oder so. Aber das ist halt so, wie man das beigebracht bekommen hat. Ja. Genau. (Jan, Gym20)

Diese Nachfrage bringt Jan dazu, die Antinomie von traditionsdeterminierten und traditionslosen Kulturen nachzudenken. Zunächst stimmt er der konfrontativen Aussage zu, dass , wir' keine Tradition hätten. Doch im Anschluss stellt er fest, dass es auch in unseren Gesellschaften ein Verhaftetsein gäbe, da auch hier oft die Kinder so leben würden, wie es die Eltern getan haben und meist in der gleichen sozialen Klasse verblieben. Anders als Finn sieht er es nicht so, dass das Leben in Afrika typischerweise im ,Stamm' stattfände.

I: Mhm. Stimmt. (...) Ach, zu den Stämmen habe ich noch eine Frage: Ist es denn in den meisten Teilen von Afrika so, dass die Leute so in Stämmen leben.

S: Ähm, ich will jetzt auch nichts Falsches sagen. Weil, ähm, das kommt dann halt komisch, wenn man dann so sagt, dass halt alle Afrikaner dann so auf einem anderen Level sind als wir. Weil das stimmt ja auch gar nicht. Es gibt ja auch Reiche in Afrika. Ich will jetzt nicht sagen, dass Armen, ähm, jetzt zurückgeblieben sind. Aber halt auf einem anderen Level sind als wir. Aber, ähm, ich glaube, da ist halt auch viel Armut und so. Und, ähm, man hört ja auch immer von RTL oder so, dass die da so Spenden machen. Und man soll ja auch spenden dafür und so. Aber, ähm, mit den Stämmen .../ Ich würde sagen, dass es da .../ Das sind ja auch so Gruppen von, weiß ich nicht, zwanzig, dreißig Leuten. Das sind ja auch keine richtigen, ähm, dann Städte oder so da. Die haben, glaube ich, bei Galileo gesagt, das ist jetzt keine richtige Bevölkerung oder so. Das sind ja auch mehrere Stämme eigentlich dann immer. Und, ähm, ich würde sagen, dass es nicht so viele davon gibt. Weil Afrika hat ja auch eigentlich ... ist ja auch eigentlich ein relativ großes Monopol halt auch für verschiedene Sachen. Also da gibt es ja aber auch Kinderarbeit und so in Afrika, oder? (Jan, Gym20)

Auffällig ist wiederum, dass Jan hier offenbar von der Frage geplagt wird, dass er „nichts Falsches sagen“ will und dass ,das dann halt komisch“ kommt, „wenn man das so sagt“. Er hat also Bedenken auszusprechen, dass ,halt alle Afrikaner dann so auf einem anderen Level sind als wir“. Eine solche Aussage scheint er als gesellschaftlich unerwünscht anzusehen, gleichzeitig ist dieser Gedanke sehr 
präsent. Sein Argument, warum das nicht stimme, ist zunächst, dass es ,,ja auch Reiche in Afrika" gäbe. Daraus folgt aber sein nächstes Sagbarkeitsproblem, nämlich, dass er „nicht sagen“ will, dass die Armen „zurückgeblieben“ seien. Sie seien vielmehr auf einem ,anderen Level als wir“. Der Unterschied zwischen „zurückgeblieben“ und ,auf einem anderen Level“ ist schwer zu entschlüsseln. Möglicherweise lässt sich durch den Kontext schlussfolgern, dass ,zurückgeblieben“ auf den Zustand der Menschen als solche und ,auf einem anderen Level“ auf die soziale Situation von Menschen in Armut zielt. Diese Nuance scheint Jan sehr wichtig zu sein und damit trifft er womöglich einen entscheidenden Punkt im Sprechen über Afrika und Armut im Globalen Süden. In entwicklungstheoretischen Argumentationen in den Interviews ist häufig ein Changieren zwischen der Ebene der Benennung von Armut bzw. mangelhafter Infrastruktur auf der einen und Aussagen über den ,Entwicklungsstand" der Menschen oder ihrer ,Kultur" als solcher auf der anderen Seite festzustellen. Oft lässt sich hier nicht zuordnen, worauf Jans Aussage abzielen.

In diesem Kontext ist auch sein Verweis auf RTL und die Spendenaufrufe für Afrika interessant. Die Rezeption des gesellschaftlichen Diskurses über Spenden und Hilfe für Afrika ist Teil dieses Changierens der Repräsentation Afrikas zwischen „Zurückgeblieben“ und ,auf einem anderen Level“, das Jan hier ins Feld führt. Offensichtlich wird hier auch, dass Jan nicht davon ausgeht, dass Menschen in Afrika alle in „Stämmen“ leben. Er stellt heraus, dass dies nur eine kleine Minderheit sei und setzt dem entgegen, dass Afrika auf dem Weltmarkt auch eine wichtige Rolle spiele. Zur diskursiven Rolle der von ihm angesprochenen Kinderarbeit werde ich mich im Abschnitt 3.4.3 beschäftigen. Während in Finns Vorstellungswelt also Afrika - bis auf Ägypten - von „Stämmen“ bewohnt scheint, stellt Jan heraus, dass dies eine Minderheit sei. Nichtsdestotrotz bestimmt sein Konzept des ,afrikanischen Stammes“ sein Denken über Afrika. Dieses Widerspruchs scheint er sich teilweise auch bewusst zu sein, was aber zunächst wenig an der Wirkmächtigkeit des Konzeptes in seinen Denkweisen zu ändern scheint.

In einigen Interviews taucht auch eine ähnliche Figur ,zurückgebliebener Gesellschaften auf, ohne dass diese geographisch verortet werden. Im Gespräch über ,ärmere Länder“ stellt beispielsweise Lukas (HS13) seine Vorstellungen dar.

I: Mhm.

S: Das sieht man ja, da sind keine Läden und so. Bei uns, wenn man Klamotten kauft, geht man in Läden rein und bezahlt an der Kasse und so. Und hier ist das nicht so.

I: Mhm. 
S: Da ist das bestimmt noch so, dass die Tauschen. Ware gegen Ware und so was.

I: Und noch gar kein Geld haben?

S: Mhm [bejahend].

I: Wo könnte das zum Beispiel sein?

S: Mhm. Ja, in ärmeren Ländern ist das ja so .../ Man kann ja nicht bezahlen wenn man kein Geld hat. Zum Beispiel, der eine hat Mais und der andere hat Milch und die brauchen das halt so. Und dann tauschen die das, weil die halt nicht anders bezahlen können.

I: Mhm. (.....) Und du sagst ja, dass ist da NOCH so. Also glaubst du, das wird sich da irgendwann auch verändern?

S: Ja, ich denke mal schon. Irgendwann wird sich das auch verändern.

I: Wäre das gut oder schlecht?

S: Das wäre gut. (Lukas, HS13)

Der Grund für die Armut scheint für Lukas in der Abwesenheit von Geld als gesellschaftlicher Form überhaupt zu liegen. Die Geldform als solche hat sich nach Lukas „noch“ nicht entwickelt; es gäbe immer noch Tauschhandel. Sein „noch“ macht deutlich, dass er dies als ein Entwicklungsdefizit ansieht.

Insgesamt wird Afrika sehr häufig mit Armut in Verbindung gebracht. Wenn es um ärmere Regionen der Welt geht, ist Afrika das mit Abstand häufigste Beispiel in den Interviews. Bei Beispielen für schlechte Arbeitsbedingungen ist es übrigens Bangladesch und China. Das folgende Beispiel von Şahin (HS21) illustriert eine solche Nennung Afrikas, in der Afrika als das Beispiel par excellence für Armut erscheint:

I: Und diese Marken, woher kommen die?

S: Die werden hergestellt. Dann werden die verbreitet und irgendwann werden die dann immer teurer. Bis es dann soweit ist und die sagen: „Oh. Die ist teuer.“ Und dann sagen die: „Oh. Der hat ja so was an. Der das dies an.“

I: Und gibt es die dann überall auf der Welt? Oder ist das nur so ein Ort, wo es dann so eine Marke gibt.

S: Meistens auf der Welt. Oder zum Beispiel in Europa bestimmt. Es kommt darauf an, in Deutschland so, wie es denen finanziell geht. Keine Ahnung. Zum Beispiel in Afrika bestimmt nicht.

I: Mhm.

S: Die haben ja nicht so was. Vielleicht schon in eins, zwei Ländern. Aber nicht mehr. 
I: Wieso nicht? Wieso haben die das in den meisten Ländern nicht?

S: Ja, weil die ärmer sind.

I: Wie sieht denn das aus da? Jetzt in den ärmeren Ländern?

S: Ja, die sind .../ Die Menschen sind halt richtig arm, haben fast nichts zu Essen und zu Trinken. Kommen nur mit Ach und Krach durchs Leben.

I: Mhm. Was denkst du, wenn du so was hörst?

S: Man wird halt schon traurig. Aber ich mach' mir nie drüber so einen Kopf. Ich bin froh, dass ich schon hier lebe. Wenn ich helfen könnte, dann würde ich das, damit es denen anders geht. Aber ich kann jetzt selber nicht helfen. Ich arbeite ja nicht. Mehr kann ich ja nicht machen.

I: Und wenn du arbeiten würdest, wie würdest du dann helfen?

S: Dann würde ich jetzt nicht direkt so viel spenden, dass ich nichts mehr für mich habe. Aber so spenden, dass ich auch noch normal weiterleben kann. Denn ich arbeite ja nicht umsonst. (Şahin, HS21)

Eine solche assoziative Verknüpfung von Afrika mit Armut kommt bei der Mehrheit der Schüler_innen vor. Şahin verweist an keiner Stelle des Interviews auf die koloniale Raum-Zeit-Matrix. Ebenfalls auffällig - bei Şahin, aber bei zahlreichen weiteren Lernenden - ist die Nennung des Kontinents ,Afrikas' im Kontrast zu einzelnen Ländern, wie zum Beispiel Deutschland oder Indien. Afrika erscheint oft als homogene Entität, so als ob alle Menschen in Afrika Armut und Hunger leiden würden. Zwar unterscheidet Şahin darin, dass es solche teuren „Marken“ schon in ein oder zwei Ländern gäbe, jedoch verbleibt das Bild einer relativ differenzlosen, homogenen Bevölkerung Afrikas, die Armut und Hunger leide. Şahin benennt in diesem Kontext auch die an seine geopolitische Lage geknüpfte Privilegierung; er sei „froh“, dass er „hier lebe“. Grundsätzlich ist er aber mit dieser Ungleichheit nicht einverstanden. Wenn er „helfen könnte“, dann würde er das tun, ,damit es denen anders geht“.

Antonia (Gym03) verknüpft ebenfalls Afrika und Armut miteinander. Im ersten Interviewabschnitt hatte sie zunächst über Globalisierung im Verständnis von Klimawandel gesprochen. Auf die Frage, was sie noch unter Globalisierung verstehen würde, spricht sie über wirtschaftliche Ungleichheit. Anders als Şahin spricht sie aber nicht über eine homogene, Armut erleidende Bevölkerung, sondern setzt den Schwerpunkt ihrer Betrachtung auf die „Spalte zwischen Arm und Reich“.

I: Und, ähm, hast du eine Idee, was man sonst noch unter Globalisierung verstehen könnte? Außer die Erderwärmung? 
S: Ähm, Globalisierung ist das nicht auch so was, wie die Wirtschaft in allen Ländern zu steigern?

I: Mhm [bejahend].

S: Also dass es überall gleichberechtigt ist und nicht wie in Afrika, wo dann alle noch, ähm, zwar arbeiten aber für einen Hungerlohn. Und, dass es überall halt eigentlich gleich sein sollte? Ich bin mir nicht sicher, ich denke das nur so.

I: Mhm. Nee, das ist super. Und kannst du das nochmal erklären? Also den Unterschied zwischen Afrika und hier?

S: Ähm, in Afrika gibt .../ Also das hat auch damit zu tun, dass .../ Also früher wurden die Afrikaner ja versklavt. Und, ähm, dass sie dadurch glaube ich auch so wirtschaftlich zurückgeblieben sind. Weil halt viele aus dem Land rausgeholt wurden. Und, dass es halt auch schwierig ist, weil es da viele Vorkommen an Diamanten und allen Rohstoffen eigentlich gibt. Und, dass sie halt deshalb sozusagen die Leute, die halt viel Geld haben, bei viel Geld bleiben und die, die arm sind, eigentlich arm bleiben. So. Also es gibt natürlich Ausnahmen, aber .../

I: Klar. Das sind sozusagen .../ Das ist dann .../ Irgendein afrikanisches Land hat man da. Und da ist es dann einfach so, dass es ein ganz paar Reiche und ganz viele Arme gibt?

S: Ja. Also ich denke, weil .../ Also ein bisschen beschäftige ich mich gerade damit, weil ich ja in den Sommerferien nach Kapstadt fliegen möchte. Also in den Kruger Nationalpark. Und da sollte man ja auch schon wissen, wie es da ist. Weil wenn man da einfach so hinfliegt und nicht weiß was da eigentlich so läuft, das ist ja ein bisschen blöd. Man soll sich ja schon vorher erkundigen. Und ich habe halt gelesen, dass es viele .../ Also dass die Spalte zwischen Arm und Reich sehr groß ist.

I: Mhm. Und hast du eine Idee, woran das liegen könnte?

S: Ja, ich denke mal durch die Versklavung von früher. Dass sich da halt manche dann, die dann dageblieben sind, halt durchgesetzt haben. Und die anderen, die dann halt ein bisschen weiter unten waren, sind halt nicht hochgekommen. (Antonia, Gym03)

Unter Globalisierung versteht sie, die „Wirtschaft in allen Ländern zu steigern“. Ziel sei es, dass ,es überall gleichberechtigt“ sei und nicht wie ,in Afrika, wo dann alle noch [...] zwar arbeiten, aber für einen Hungerlohn“. Antonia scheint die keynesianistische Vorstellung zu vertreten, dass das gesamtgesellschaftliche Wirtschaftswachstum zu mehr Wohlstand für alle führen würde. Ihr Globalisierungsbegriff ist normativ darin bestimmt, dass die Globalisierung darauf abzielt, Gleichberechtigung aller Menschen herzustellen. Ihr ,noch“ in Bezug auf die Unterbezahlung der Arbeit in Afrika kann sowohl als eine noch zu leistende Realisierung dieser normativ erwünschten Gleichheit als auch als ein 
Bezug zum Ort bzw. Zeit Afrikas in der kolonialen Raum-Zeit-Matrix interpretiert werden. Letzteres wird auch durch ihre Vorstellung davon nahegelegt, dass Afrika ,wirtschaftlich zurückgeblieben“" sei. Statt sich für eine Interpretation zu entscheiden, erscheint es mir für angemessener, genau dieses Changieren der beiden Bedeutungskontexte als eigenes Merkmal hervorzuheben, das sich in vielen Interviews wiederfinden lässt. Im Gegensatz $\mathrm{zu}$ vielen anderen führt Antonia diese, wirtschaftliche Zurückgebliebenheit" aber nicht auf klimatische, staatsdefizitäre, biopolitische oder ähnliche, entwicklungstheoretische Gründe zurück (Fischer et al 2015: 69), sondern argumentiert sozialgeschichtlich, indem sie auf die Versklavung und die Rohstoffvorkommen verweist. Viele seien ,,aus dem Land rausgeholt“ worden. Dadurch hätten sich ,manche dann, die dann dageblieben sind, halt durchgesetzt", während die ,anderen [...] nicht hochgekommen" seien. So erklärt sie sich die große „Spalte zwischen Arm und Reich“. Welche Rolle hier die Vorkommen an „Diamanten und allen Rohstoffen“ spielt, erklärt sie leider nicht.

Im Gespräch darüber, wie sich denn diese Situation verändern könnte, benutzt Antonia ihr Bild von der ,Spalte zwischen Arm und Reich“ nicht nur für die die Situation sozialer Ungleichheiten innerhalb einzelner Nationalstaaten, sondern auch, um die Beziehung verschiedener Länder zwischen einander zu charakterisieren.

\section{I: Okay. Und wer sollte das Geld geben?}

S: Ich, ähm, ich denke mal, da sollten sich alle Länder zusammentun. Dass man überlegt, wie man den Nicht-Industriestaaten [zögernd] weiterhelfen kann, dass sie halt auch zu Industriestaaten werden und nicht weiter unten bleiben und immer nur ... darf ich ,zurückgeblieben sind“ sagen? Ja, dass die zurückbleiben und nicht irgendwie mit hochkommen. Weil sonst würde das ja auch zwischen den Ländern immer diese Spalte größer werden zwischen Arm und Reich. Und das ist ja auch nicht gut.

I: Mhm. Also du würdest dir wünschen, dass es nicht so eine Spalte gibt zwischen Arm und Reich?

S: Ja, dass das auch so ein bisschen verteilt ist und auch die Armen die Chance haben, ähm, in die Mittelschicht oder so zu kommen. (Antonia, Gym03)

Die Differenz zwischen reichen und armen Ländern beschreibt sie mit den Begriffen von „Industriestaaten“ und „Nicht-Industriestaaten“. Die Industriestaaten sollten den Nicht-Industriestaaten ,,weiterhelfen“, damit diese ,auch zu Industriestaaten“" werden könnten. Die Nicht-Industriestaaten beschreibt sie als „,zurückgeblieben“; gleichzeitig thematisiert sie ihre eigene Sprechweise, indem 
sie nachfragt, ob sie das sagen dürfe. Sie möchte, dass sie nicht „,weiter unten bleiben“, da sie eine Vergrößerung diese „Spalte zwischen Reich und Arm [...] nicht gut findet“. Auch die „Armen“ müssten ihrer Meinung nach „die Chance haben [...], in die Mittelschicht oder so zu kommen“. Mit der Beschreibung der sozialen Hierarchisierung der Länder der Welt durch den Begriff „Industriestaaten“ scheint Antonia den Grad der Industrialisierung zum Unterscheidungsmerkmal zu machen. In großen Teilen des Interviews beschreibt sie aber die Auslagerung der Produktion in Länder des Globalen Südens, da hier die Arbeitskraft billiger sei. Insgesamt scheint der Grad der Industrialisierung kein zentrales Argument für sie zu sein. Nicht-Industriestaaten scheint vielmehr ihr Synonym für sonst häufig verwendete Begriffe wie ,Dritte-Welt-Land“ oder ,Entwicklungsland` zu sein. Diesen scheint sie ein unbehagliches Gefühl entgegen zu bringen; ein ähnliches Gefühl, das sie zu der Nachfrage motiviert, ob sie den Ausdruck ,zurückgeblieben“ verwenden dürfe. Möglicherweise basiert ihr Unbehagen auf der Hierarchisierung, die diese Ausdrücke transportieren. Letztlich übernimmt dann aber „Industriestaaten" die gleiche hierarchisierende Funktion. Dieses Spannungsfeld kann sie nicht durch den reinen Austausch von Begriffen verlassen. Es treibt sie während des ganzen Interviews um.

Auch bei Alexander (Gym05) findet sich die Assoziierung von Afrika mit Armut. Er sieht die Gründe für die Armut Afrikas aber nicht nur in der Vergangenheit der Sklaverei, sondern auch in wirtschaftlichen Ungleichheiten der Gegenwart.

I: Auf jeden Fall. Du kannst auch gerne .../ Also wir haben keinen Zeitdruck. Du kannst einfach .../Wenn du zwischendurch noch einen Keks essen willst, machen wir einfach eine Pause. Ähm, von mir aus können wir gerne einfach so anfangen, dass du nochmal erzählst, was dir einfällt, wenn du Globalisierung hörst. Was du darunter verstehst.

S: Ja. Also Welthandel. Der Handel in der ganzen Welt. Ob mit Waren, Import, Export. Und, ja, ist halt meiner Meinung nach .../ Also ich finde es nicht so super, weil ich denke, dass ärmere Länder darunter ziemlich leiden. Weil die reicheren halt die ganzen Waren importieren können, exportieren können. Und ich denke, dass für die armen Länder, also so afrikanische Länder und so was, die ganze Globalisierung relativ schwierig ist.

I: Inwiefern ist das schwierig?

S: Ja, ich denke einfach, dass die, ähm, Großmächte - also Russland, USA, China und so - einfach ziemlich viel Handel treiben und die eventuell dabei auch ausnutzen. In Form von .../ Wie kann man das sagen? Ja, so teilweise von denen was nehmen, aber denen sozusagen nicht wirklich was zurückgeben. Also nicht viel. Und ich denke, das ist eigentlich ziemlich schwierig für die ärmeren Länder.

I: Mhm. Und warum wird das so gemacht? Oder warum machen die Großmächte das? 
$\mathrm{S}$ : Ja, ich denke, das ist einfach weil man Gewinn haben will. Weil man ja eben eine Weltmacht sein will. Und bleiben will. Und, ähm, ich denke, hauptsächlich wegen Gewinn, Weltmacht und so was. Das ist schon für die relativ wichtig. (Alexander, Gym05)

Die ,afrikanischen Länder“" stellen hier wieder das Beispiel par excellence für Armut dar. Alexander thematisiert auch endogene Faktoren nach dem Ende der Sklaverei, die er vor allem in ungleichen Handelsbedingungen zwischen den „Weltmächten“ und den ,,ärmere[n] Ländern“ sieht. Die „Weltmächte“ könnten sich ,von denen was nehmen, aber denen sozusagen nicht wirklich was zurückgeben“. Die „Weltmächte“ verfolgten dabei laut Alexander die Ziele, ihre Weltmachtstellung zu halten und Gewinn zu erzielen. Ihre Macht scheint ihnen dabei die Möglichkeit zu geben, diese ungleichen Handelsbedingungen zu diktieren. Im weiteren Verlauf des Interviews stellt er seine sozialgeschichtlichen Vorstellungen für die Gründe dieser Ungleichheit dar.

I: Mhm. Du hast jetzt so ein paar Beispiele für ärmere Länder genannt. Also Vietnam oder afrikanische Länder. Und warum ist das überhaupt so, dass es ein paar Länder gibt, die arm sind und dann halt ein paar Supermächte?

$\mathrm{S}$ : Ja, ich denke das hat teilweise noch mit früherer Zeit zu tun. Mit den Weltkriegen und so. Dass immer wieder Länder es nicht geschafft haben, sich zu befreien. Also Frankreich hat Kolonien in Afrika aufgebaut und so etwas. Und ich denke, diese Kolonien sind halt dann nicht ziemlich stark. Also die sind sehr schwach halt. Weil sie, sozusagen, Frankreich unterworfen waren und Frankreich damals schon ihre Sachen abgeben mussten. Arbeiten mussten. Die Sachen wieder abgeben mussten. Und so weiter. Und das halt ein ewiger Kreislauf war. Und ich denke, dadurch passiert, dass diese ärmeren Länder überhaupt entstehen. Und ich denke, dadurch werden auch so Großmächte wie China oder so gemacht, die auch früher immer wieder gearbeitet haben lassen. Und da Kolonien eröffnet, äh, erobert haben. Und ich denke, daher kommen diese ärmeren Länder. Und die reicheren Länder halt auch.

I: Und welche Rolle spielt Deutschland dabei?

S: Dabei würde ich sagen, dass auch Deutschland Kolonien in Afrika hat. Und auch Deutschland, ähm, da schon eine Rolle spielt. Weil sie schon auch damals, ähm, Länder ihnen unterworfen haben. Und, ja, ich denke, dass Deutschland das einfach .../ Wie kann man das sagen? Ähm, ja, dass Deutschland die ärmeren Länder eben so arm gemacht hat. Auch teilweise mit Frankreich und so. Wie es jetzt so ist. Also Afrika oder so, da weiß ich, dass Deutschland da auch Kolonien hatte. Und, ähm, ich denke dadurch sind auch diese ärmeren Länder überhaupt entstanden. Und auch Deutschland hatte da, denke ich mal, eine ordentliche Rolle. (Alexander, Gym05) 
Den Grund dafür, dass es überhaupt arme Länder und „ein paar Supermächte“ gibt, sieht Alexander vor allem in der Geschichte des Kolonialismus. Frankreich habe beispielsweise „Kolonien in Afrika aufgebaut“. Diese Kolonien sieht Alexander dann heute als ,sehr schwach“ an, da sie Frankreich „unterworfen“ gewesen seien und sie „damals schon ihre Sachen abgeben mussten“. Er präzisiert, dass es einen „ewigen Kreislauf" gegeben habe, in welchem die Menschen in den Kolonien ,arbeiten mussten“ und die „Sachen wieder abgeben“ mussten. Dies also die koloniale Ausbeutung - sieht er als Grund sowohl für die Entstehung von den ärmeren als auch den reicheren Ländern an, die auch die gegenwärtige Situation globaler Ungleichheit und Hierarchien entscheidend geprägt habe. Die Verbindung von der Geschichte kolonialer Ausbeutung und gegenwärtiger globaler Ungleichheit benennen insgesamt fünf Lernende. Auf Nachfrage, welche Rolle Deutschland gespielt habe, stellt Alexander dar, dass Deutschland „Kolonien in Afrika“ hatte und da „schon eine Rolle“ gespielt hätten. Er spitzt sein Argument der Kausalität zwischen dem historischen Kolonialismus und der gegenwärtigen Armut im Globalen Süden noch einmal zu, indem er sagt, dass „Deutschland die ärmeren Länder [...] arm gemacht" habe. Der deutsche Kolonialismus wird insgesamt von vier Lernenden angesprochen. Dabei werden im Übrigen ausschließlich die deutschen Kolonien in Afrika angesprochen.

$\mathrm{Zu}$ dieser Gruppe gehört auch Pascal (Gym12). Im Gespräch über die Frage, ob alle Menschen das gleiche Recht auf Bewegungsfreiheit hätten, unterscheidet er zunächst mögliche Immigrant_innen nach ihrer Herkunftsregion. Er wählt Afrika als Beispiel für arme Länder und Geflüchtete.

I: Mhm. Und ist das für alle Menschen weltweit gleich einfach oder schwierig zu reisen? Oder ist das unterschiedlich?

S: Nee, also wenn wir jetzt mal Afrika nehmen, die Leute die da in die EU flüchten, einfach aus dem Grund, dass sie in ihrem Land eine viel schlechtere Lebenshaltung haben. Angefangen von der politischen Situation, die da nicht so gut ist, über die arbeitstechnische Situation, weil die ja einfach keine Arbeit haben. Für die ist es deutlich schwerer, in die EU reinzukommen, als für hochqualifizierte Doktoranden die in Harvard in den USA studiert haben und nach Europa wollen. Die werden natürlich mit offenen Armen empfangen. Und die Afrikaner die dann kommen, die werden oft abgestoßen, weil sie ja als Flüchtlinge gelten. Und dann meistens wieder in ihr Heimatland zurück müssen, wenn sie über achtzehn sind.

I: Mhm. Und was denkst du dazu, wenn du so was hörst?

S: Ja, also ich denk' dazu, dass .../ Mir tut es auf jeden Fall für die Leute leid, die gerne nach Europa wollen und einfach nicht reinkommen, weil sie halt .../ Ja, die können ja selber nichts dazu, dass sie geflüchtet sind. Sie können ja in den meisten Teilen .../ Das ist ja in Afrika sehr extrem. Die können ja einfach nichts dafür, dass die nicht 
so gut gebildet sind, weil das Bildungssystem einfach da nicht so gut ist, wie hier. Und die können ja auch nichts für die politische Situation im Land. Obwohl politische Flüchtlinge ja, ähm, aufgenommen werden meistens. Aber generell finde ich es ... kann ich auch die EU verstehen, dass man die Leute abschiebt oder wieder in ihr Land zurückschickt, weil es ist vielleicht irgendwann einfach auch nicht mehr der Platz da. Oder auch so von der wirtschaftlichen Lage. Weil gerade, wenn die jetzt immer mehr nach Deutschland einwandern würden und alle die deutsche Staatsangehörigkeit bekommen würden und die alle keinen Job finden würden und die alle Hartz IV kriegen würden. Das würde ja auch der Wirtschaft zur Last fallen und im Endeffekt dann auch wieder uns selber. Also das ist vielleicht etwas egoistisch, aber ich kann es in einer Weise auch verstehen. (Pascal, Gym12)

Pascal sieht zwei Typen von Herkunftsregionen und dementsprechend auch Migrant_innen. Die Menschen aus Afrika würden von da „einfach aus dem Grund“ in die EU flüchten, dass sie ,,in ihrem Land eine viel schlechtere Lebenshaltung haben". Die Hauptgründe für die Migration aus Afrika sieht er in der „nicht so guten“ politischen Situation in ihren Ländern sowie in der Arbeitslosigkeit. Dem gegenüber steht die Herkunftsregion, deren Platzhalter das Bild des ,hochqualifizierte[n] Doktoranden“ aus Harvard (USA) darstellt. Diese würden „natürlich“ mit „offenen Armen“ empfangen. Die aus Afrika Migrierenden würden hingegen „oft abgestoßen“ und müssten „,dann meistens wieder in ihr Heimatland“ zurück. Pascal diskutiert hier das Spannungsfeld zwischen der wirtschaftlichen Nützlichkeit für den nationalen Wirtschaftsstandort und der ethischen Verantwortung gegenüber den Geflüchteten. Wobei bei ihm im Folgenden stark die Seite der Nützlichkeit überwiegt, wie schon sein Ausdruck ,natürlich“ nahelegt, mit dem er die Priorisierung des wirtschaftlich nützlichen Doktoranden beschreibt. Hier konzentriere ich mich auf das Bild Afrikas in den Vorstellungen von Pascal. Pascal begründet an einer Stelle den Grund für die Abweisung der afrikanischen Migrant_innen damit, dass diese ,ja als Flüchtlinge gelten“würden. Er schreibt hier nicht, dass sie es sind; der Ausdruck ,gelten“ legt vielmehr nahe, dass sie abgewiesen werden, weil sie als Geflüchtete gesehen würden. Es scheint also eine wirkungsmächtige Zuschreibungspraxis zu sein. In den anderen Argumentationen scheint es hingegen so zu sein, dass für ihn migrierende Menschen aus Afrika tatsächlich Geflüchtete sind. Hier findet eine Art von Viktimisierung statt. Im von Pascal gemalten Bild von ,Afrikaner_innen' erscheinen diese als Opfer von der politischen Situation und von Armut, die diese in die Flucht treibe. Er äußert auch Mitgefühl mit den Geflüchteten. „Die“ könnten „,nichts dafür, dass die nicht so gut gebildet sind“, da das Bildungssystem dort „nicht so gut“ sei „wie hier“. Nach Worten ringend - ,sie können ja in den meisten teilen .../“ - kommt er zu der Aussage, dass Afrika ,ja [...] sehr extrem“ sei. Das Bild 
Afrikas erscheint hier wiederum als etwas tendenziell homogenes, das geprägt ist von Armut und fehlender Bildung. Die empathische Haltung gegenüber afrikanischen Migrant_innen produziert gleichzeitig ein Bild von weniger intelligenten, hilfsbedürftigen, zwar unschuldigen, aber eben unnützen Opfern. Hier dockt er an einen Diskurs an, in der die Figur ,des afrikanischen Migrant_innen' zu einer migrations- und bevölkerungspolitischen Masse wird. Afrika sowie die von dort kommenden Migrant_innen erscheinen so als ethisch zwar wichtiges Feld, doch gleichzeitig als Bedrohung. Folgerichtig kommt er zu dem Schluss, dass er auch „die EU verstehen“ könne, ,dass man die Leute abschiebt oder wieder in ihr Land zurückschickt".

Interessant ist, dass er diese ethischen Fragen auch in Beziehung mit dem historischen Kolonialismus diskutiert.

I: Mhm. Und hast du eine Idee, woran das liegt, dass die Situation in zum Beispiel afrikanischen Ländern so ist?

S: Ja, also damit hat auf jeden Fall auch Europa und gerade .../ Also die europäischen Länder, England und USA, glaube ich, eine ganz große Schuld daran. Und auch Deutschland. Weil Amerika .../ Amerika sag' ich schon. Weil Afrika war ja mal kolonialbesetzt, da gab es ja ganz viele Kolonien. Und die wurden ja von den Europäern, gerade von den Engländern, extrem ausgeraubt. Und ich glaube, die wirtschaftliche Lage und auch die Lage von der afrikanischen Bevölkerung wäre um einiges besser, wären die Bodenschätze noch erhalten. Weil wenn man jetzt hört, wie viel Gold, Öl und diese ganzen fossilen Brennstoffe Wert sind - oder allgemein die endlichen Stoffe - dann würde die Wirtschaft da ja boomen. Und auch der Bevölkerung würde es in dem Punkt besser gehen. Deswegen wäre es von der EU auch nur gerecht, oder von Europa auch nur gerecht, diese Leute aufzunehmen. Aber an der jetzigen Situation kann unsere Generation ja zum Beispiel nichts. Ich kann ja nichts dafür, dass damals meine, ähm, Vorfahren die afrikanischen Kolonien ausgeraubt haben. (Gym12, Pascal)

Als Ursache für die soziale Situation in Afrika sieht er die koloniale Praxis „,europäischer Länder“ und der USA. Er berichtet, dass „Afrika [...] mal kolonialbesetzt“ gewesen sei, dass es dort ,ganz viele Kolonien“ gegeben habe. Er benennt Deutschland, sieht aber insbesondere England, als einflussreiche Kolonialmacht. Unklar bleibt, welche Rolle nach ihm die USA in diesem Prozess gespielt haben sollen. Als koloniale Praxis beschreibt er insbesondere den ,extrem[en]“ Raub an „Bodenschätzen“. Wenn diese heute noch erhalten wären, würde in Afrika die „Wirtschaft [...] boomen“ und der ,Bevölkerung würde [...] es besser gehen“. An die europäische Täterschaft für die koloniale Ausplünderung Afrikas knüpft er die Frage von Schuld und Gerechtigkeit. Einerseits sähe er es vor diesem Hintergrund als „gerecht“ an, wenn die EU ,diese Leute“ aufnehmen würde. Andererseits 
könne er und seine Generation nichts dafür, ,dass damals meine [...] Vorfahren die afrikanischen Kolonien ausgeraubt" hätten. Der Diskurs, der durch den Kolonialismus aufgeladenen Schuld, spielt nur in zwei anderen Interviews eine Rolle. Der Bezug zu der Verantwortung für die eigenen ,,Vorfahren“ wird nur von Pascal hergestellt. Diese spezifische Form die - ethische - Annahme oder Nicht-Annahme eines Erbes zu diskutieren, erinnert im deutschen Kontext an die Diskussion um die Verantwortung heutiger Generationen für die Verbrechen des Nationalsozialismus. Es wirkt, als wären Pascals Überlegungen davon inspiriert.

\subsubsection{Mentalität der Freiheit I: Freiheit als europäisch-westliche Idee}

In diesem Block von zwei Abschnitten geht es darum, inwiefern die Lernenden universalistische Konzepte, wie etwa Freiheit, Demokratie und Menschenrechte, an einen Ort binden, ihnen einen Ursprung geben, ihnen ein bevorzugtes Subjekt zuschreiben und es kontextuell oder essenziell denken. Es geht darum, herauszuarbeiten, inwiefern die Lernenden diese universalistischen Konzepte eurozentrisch denken oder es aus dem eurozentrischen Kontext herauslösen. Dafür werde ich im ersten Abschnitt drei Beispiele ausführlicher vorstellen, an denen ich verschiedene Aspekte oder verschiedene Nuancen des gleichen Aspekts veranschaulichen werde.

In dem im Folgenden ausführlich analysierten Abschnitt von Melina (Gym08) kommen eine Vielzahl von relevanten Aspekten für die Frage der (nicht-) eurozentrischen Konzeptionalisierung universalistischer Ideen vor. Sie antwortet am Beginn des Interviews zunächst auf die Frage ihrer Vorstellungen über Globalisierung.

I: Okay, super. Ähm, ja, vielleicht fangen wir einfach so an, dass du nochmal erzählst was du dir unter Globalisierung vorstellst? Woran du dabei denkst?

S: Ähm, ja also in erster Linie eigentlich so an Wirtschaft. So vor allem die Ausdehnung. Also ich glaube auch so .../ Total allgemein kann man auch sagen, irgendwie so die Ausdehnung der westlichen Kultur. Also habe ich irgendwo mal gelesen. Ähm, weil es ist ja so, dass nicht halt zum Beispiel alles jetzt nur so, was in Deutschland geschieht auch in Deutschland bleibt. Sondern, dass es auch über die Grenzen hinausgeht. Und halt auch, äh, so weltweit auch gemacht wird. Das kann so Import oder Export sein. Oder es kann also vielleicht auch so eine Firma oder so sein, glaube ich. Halt so was, was halt zuerst in einem Land war und nicht nur in dem Land bleibt, sondern halt auch weltweit. Genau, international. (Melina, Gym08) 
Auf die Frage ihrer Vorstellung über Globalisierung antwortet sie zweigleisig. Unter Globalisierung versteht sie „Ausdehnung“, einerseits wirtschaftlich gesehen und andererseits die „Ausdehnung westlicher Kultur“. Da in vielen Interviews die ökonomischen Aspekte von den Lernenden an den Anfang gestellt wurden, entschied ich mich hier dafür, den Aspekt der „,westlichen Kultur“ weiterzuverfolgen.

I: Und was heißt das? „Ausbreitung der westlichen Kultur“?

S: Ähm, ja. Also ich glaube zum einen halt, Wirtschaft. Fortschritte, die gemacht wurden. Ähm, ich weiß nicht, in Sachen vielleicht. Wenn man halt neue Maschinen oder so hergestellt hat [lacht]. Oder neue Entwicklungsmethoden oder so. Aber vielleicht auch, äh, Kultur kann ja auch Musik heißen. Oder solche Sachen. So eher kulturell halt [lacht].

I: Mhm. Und das heißt, dass aus dem Westen dann Sachen verbreitet werden?

S: Ja. Zum Beispiel. Also ,westlich“, damit ist ja auch oft gemeint, so diese modernen Länder, wo es halt irgendwie offener ist. In Deutschland ist es ja auch so, dass man Meinungsfreiheit hat und Religionsfreiheit. Also dass das halt alles so offener und freier auch ist. Und dass da ja auch neue Sachen entwickelt werden. Oder halt neue Sachen vielleicht so erfunden werden. Und dass das halt auch so vielleicht ein bisschen übertritt und viele so in anderen Regionen, in, weiß nicht, Asien oder Afrika, dass da so dieses „Westliche“ schon so ein Begriff eigentlich ist. Das ist „westlich“, das kommt aus dem Westen. Oder dieses Land ist „westlich orientiert“. Gibt's ja auch. (Melina, Gym08)

In ihrer zweiten Antwort erklärt sie ihren Begriff von „westlich“. Damit seien „diese modernen Länder gemeint, wo es halt irgendwie offener ist“. ,Moderner" und ,offener" sind zunächst zwei nebeneinander stehende Attribute, die aber wie ich im Folgenden zeigen werde - eng miteinander verschachtelt sind. Sie scheinen für Melina zentrale Wesens- und Unterscheidungsmerkmale der, westlichen Kultur ${ }^{\star}$ zu sein. Diese diskursive Figur, die universalistische Ideen, wie Offenheit, Modernität und Freiheit an die ,westliche Kultur' koppelt, findet sich in etwa einem Drittel der Interviews. Melina bringt das Beispiel von Deutschland, wo „man Meinungsfreiheit [...] und Religionsfreiheit“ habe. Hier sei es „halt alles so offener und freier auch“. Diese Wesensmerkmale scheinen nach Melinas Verständnis eine Voraussetzung für Erfindungsreichtum, Innovationskraft und Entwicklung darzustellen. Das heißt, dass die ,westlichen“ Länder „Sachen“ entwickeln würden, während das in anderen Teilen der Welt nicht möglich sei, da hier die kulturellen Voraussetzungen dafür fehlen würden. Diese im ,Westen' entwickelten Sachen träten dann in andere Regionen über. Melina bringt hier die Beispiele Asien und Afrika, die sie offenbar dann assoziiert, wenn es 
darum geht, wo die Eigenschaften der, westlichen Kultur' nicht vorkommen. Sie stellen also für sie das Andere des, Westens “ dar. An dieser Stelle probiert sie Verwendungsweisen und Kontextualisierungen des Ausdrucks ,Westen“ aus. Dieses „Westliche“ sei in Asien und Afrika ,schon so ein Begriff“, etwas könne ,westlich“ sein, etwas könne aus dem ,Westen“ kommen oder ein Land könne ,westlich orientiert" sein. Hier scheint die Außenperspektive zu überwiegen, nach der also Menschen aus ,nicht-westlichen ' Regionen diese Kategorie verwenden, um damit etwas Bestimmtes auszudrücken. Es erscheint nicht abwegig davon auszugehen, dass sie sich vorstellt, dass im ,Nicht-Westen“ das ,Westliche" mit Offenheit, Modernität und Freiheit assoziiert wird. Melina spricht in ihrer ganzen Antwort eher über das Sprechen über den Begriff, Westen“ und scheint ontische Aussagen, also Aussagen über das Sein des ,Westens', vermeiden zu wollen. Gleichzeitig schreibt sie ihm aber doch Wesensattribute zu. Vielleicht angeregt durch ihr Changieren zwischen ihrem Sprechen über den ,Westen“ und ihrem Sprechen über das Sprechen über den ,Westen', frage ich nach ihrem geographischem Verständnis des, Westens'.

I: Mhm. Und welche Länder würdest du jetzt zum Westen dazuzählen?

S: Ähm, ja [lacht].

I: Du musst jetzt nicht alle Länder nennen. Aber halt so ein paar Beispiele oder so.

S: Also jetzt Deutschland würde ich schon sagen. Dann auf jeden Fall so Amerika, so USA.

I: Mhm.

S: Ähm, was noch? Halt auf jeden Fall die, die so .../ Vielleicht Italien, Frankreich so. Auf jeden Fall so die, die auch bekannter sind. Und wo auch viel rüberkommt.

I: „Viel rüberkommt“"? Also was .../

S: Also mit „,viel rüberkommt“ meine ich jetzt so zum Beispiel so mit Ausdehnung. Also Frankreich ist ja bekannt für Mode oder so. Und, ähm, Amerika ja für ganz viele Sachen. Also eigentlich mehr als die Hälfte der Musik die man hört, kommt ja eigentlich aus Amerika. Ähm, und es gibt aber auch ganz andere Sachen zum Beispiel. Keine Ahnung, es gibt ja auch viele entwickelte Sachen, so Kopfhörer oder was weiß ich, ähm, die nicht mehr in Deutschland hergestellt werden. (Melina, Gym08)

An Ländern, die zum, Westen` zählen, fallen ihr Deutschland, die USA, Italien und Frankreich ein. Interessanter als die Länder, ist aber ihr Kriterium dafür, zum ,Westen` zu gehören. Hier kommt sie auf ihre Eingangsformulierung zurück. Das Kriterium für sie ist, dass die Länder ,bekannter“ sind und dass ,auch viel rüberkommt“. Mit ,viel rüberkommt“ meint sie wiederum „Ausdehnung“. 
Darunter würde ich an dieser Stelle zunächst verstehen, dass beispielsweise die Mode aus Frankreich weltweit bekannt sei und von Frankreich in andere Weltregionen gelangt und dort angesehen sei. ,Ausdehnung' bedeutet also, dass eine Idee, eine Sache oder ein Produkt weltweit Bekanntheit und Ansehen hat sowie in andere Regionen transferiert wird. Im Anschluss stelle ich die Nachfrage nach Werten, um von den ökonomischen Aspekten im Gespräch zunächst wieder wegzukommen.

I: Mhm. Und du hast auch gesagt, dass so bestimmte Werte, also so was wie Meinungsfreiheit und so, auch Teil vom Westen sind? Oder von der westlichen Kultur?

S: Ja, oder vielleicht so der Umgang damit. Das könnte ich mir auch vorstellen. Also, dass ist jetzt das, was ich so da rein interpretiere eigentlich.

I: Ja. Und wie ist der Umgang? Oder wie ist der in Asien zum Beispiel nicht?

S: Ja, zum Beispiel Asien ist ja ziemlich fest. Also zum Beispiel, ähm, Islam, Buddhismus und so weiter. Ähm, und in vielen Ländern .../ Also jetzt ein ganz krasses Beispiel ist ja zum Beispiel Nordkorea. Da wird man ja auch echt verfolgt, wenn man halt was anderes glaubt. Und wird auch echt eingesperrt. Und in Deutschland, ähm, oder Amerika ist das natürlich auch viel freier, dass man da einfach seine Religion auch ausleben kann. Und, ähm, um auf Nordkorea zurückzukommen, da ist es ja auch echt total streng. Also auch mit Musik, ähm, und Fernsehen und Radio und Internet und so weiter.

I: Mhm. Also fändest du das auch gut, wenn sich der Westen, die westliche Kultur noch mehr ausbreiten würde?

S: Ähm, ja. Also in vielen Sachen, in vielen Aspekten auf jeden Fall. (Melina, Gym08)

Werte, wie etwa Meinungsfreiheit, sieht sie nicht als solche als Teil der,westlichen Kultur“ an, sondern vielmehr den „Umgang“ damit. Auf meine Nachfrage, wie der Umgang sei bzw. wie er in Asien, als beispielhafter Platzhalter für das Andere des ,Westens', eben nicht sei, versucht Melina die Differenz zwischen der ,westlichen Kultur' und Asien zu definieren. Asien schreibt sie das Attribut „fest“ zu. Dies versucht sie über die Verbreitung der Religionen Islam und Buddhismus zu fassen, setzt aber dann neu an und bringt das Beispiel Nordkoreas. Dort gäbe es Medienzensur und man würde ,echt verfolgt, wenn man halt was anderes glaubt“. Es ist hier unklar, ob es ihr hier um Meinungsfreiheit oder Religionsfreiheit geht. Als Gegensatz dazu führt sie Deutschland oder „Amerika“2 an, wo es ,natürlich auch viel freier“ sei und man ,einfach seine Religion auch

${ }^{2}$ „Amerika“ wird von vielen Schüler_innen synonym für die USA verwendet. Diese Verwendungsweise wurde vielfach von dekolonialen Theoretiker_innen kritisiert. Hier würden Mittel- und Südamerika unsichtbar gemacht sowie die geopolitische Machtstellung der USA 
ausleben" könne. Um die Differenz von der , westlichen Kultur" mit seinen Attributen der Freiheit und Offenheit im Gegensatz zu Asien zu verdeutlichen, wählt Melina das „krasse Beispiel“ Nordkorea. Dieses Beispiel dient ihr scheinbar als Ausprägung einer allgemeinen asiatischen Kultur. Es fungiert als Negativ für die Bestätigung ihrer Annahme, dass die ,westliche Kultur' mit diesen Attributen zu charakterisieren sei.

In Melinas Antwort auf die Nachfrage, welche Ursachen sie für die von ihr aufgestellte Differenz zwischen ,westlicher Kultur' und ,nicht-westlicher Kultur ausmacht, wechselt sie das Beispiel.

I: Mhm. Und woran liegt das, dass jetzt der .../ Oder du hast ja gesagt, der Westen ist auch quasi das Moderne. Woran liegt das, dass jetzt in den nicht westlichen Ländern, dass es eben nicht so ist? Also wie kommt dieser Unterschied zustande?

S: Ähm, also ich denke zum Beispiel Afrika oder so, also jetzt als Kontinent, da sind ja auch viele Regionen .../ Also klar, man definiert mit Afrika halt fast nur die ärmeren Sachen. Also, das ist natürlich nicht immer so. Aber dass die dort gar nicht die Möglichkeiten haben, zu forschen und zu entwickeln. Und dass die Wissenschaft oder halt allgemein auch das ganze System, also, ob es das Bildungssystem ist oder halt auch die Regierung, halt gar nicht so weit ist, wie jetzt Deutschland oder Amerika. Und, dass die einfach gar keine Möglichkeiten haben, sowas zu entwickeln. (Melina, Gym08)

Mit Afrika würden Melina zufolge „fast nur die ärmeren Sachen“ assoziiert. Sie schränkt dieses Argument ein, indem sie nachsetzt, dass dies ,natürlich nicht immer so“ sei. Die Armut sieht sie dennoch als Grund dafür an, dass in Afrika nicht geforscht und entwickelt werden könne. In Afrika sei ,die Wissenschaft oder halt allgemein auch das ganze System, also, ob es das Bildungssystem ist oder halt auch die Regierung, halt gar nicht so weit ist wie jetzt Deutschland oder Amerika“. Das sei der Grund, warum sie gar nicht ,sowas [...] entwickeln“ könnten. Ihr Entwicklungsbegriff schillert hier zwischen einem allgemeinen, den Entwicklungsstand der ganzen Gesellschaft als solche betreffend und der - eher technisch verstandenen - Entwicklung wissenschaftlicher Innovationen. Beide Ebenen scheinen dabei miteinander verknüpft zu sein. Das ,ganze System“ dort sei im Gegensatz zu Deutschland oder „Amerika“ „,nicht so weit“, was wiederum die Möglichkeitsbedingung wäre, ,sowas zu entwickeln“. Auf die Nachfrage, auf welchem Stand ,die“ denn seien, bringt sie drei Argumente, die die Differenz zur ,westlichen Kultur' herstellen.

innerhalb der Amerikas diskursiv reproduziert. In dekolonialen Diskursen wird deswegen in der Regel von ,den Amerikas ‘ oder, Abya Yala“ gesprochen (Garbe / Cárdenas / Sempértegui 2018: 137). 
I: Mhm. Auf welchem Stand sind die denn? Was würdest du sagen?

S: Also ich meine jetzt nicht, dass die irgendwie so total niedrig sind oder so. Aber, ähm, bei der Regierung ist ja nicht überall so die Demokratie durchgesetzt worden. Sondern oft ist es so, dass es noch Monarchen oder einen Diktator ja sogar gibt. Ähm, was sich jetzt ja auch langsam ändert. Aber, ähm, dass es halt auch so ist, dass da noch viel bestochen wird. Also klar, ich denke nicht, dass bei uns nicht bestochen wird. Aber es ist halt dort viel auffälliger. Und dass dort deshalb auch andere Gesetze sind. Und vielleicht halt andere Verbote, die es manchmal gar nicht zulassen, so was zu entwickeln halt. Also weiterzukommen. (Melina, Gym08)

Zunächst wehrt sie sich gegen den von mir eingeführten Begriff des „Stands“. Zwar hatte sie mehrfach von ,nicht so weit" und fehlender Entwicklung gesprochen, von einer Benennung von Entwicklungsstufen scheint sie sich aber zumindest partiell distanzieren zu wollen. Sie meine nicht, dass „die irgendwie so total niedrig“ seien. Darauf folgt ein Satz mit „aber“. Die Deutung dieses „Abers“ ist nicht ganz einfach. Sind die folgenden drei Argumente zur Charakterisierung der Differenz zur, westlichen Kultur ' Teil einer Vorstellung eines linearen Entwicklungsmodells oder stellen die Merkmale vielmehr unabhängig von der Entwicklungslogik Differenzkriterien dar? Diese Frage wird sich zumindest teilweise in der folgenden interpretierenden Darstellung der drei Argumente klären. Das erste Argument ist, dass die Regierungen dort nicht demokratisch seien. Es sei oft so, dass es ,noch Monarchen oder einen Diktator ja sogar gibt“. Das ,noch“ lässt möglicherweise auf einen Bezug zur Entwicklungslogik schlieBen. Es könnte aber auch auf die normative Hoffnung zielen, dass sich in der Zukunft demokratische Regierungsformen durchsetzen werden, was allerdings nicht im Gegensatz zur Entwicklungslogik steht. Auch die ideengeschichtliche Kontextualisierung lässt nicht mehr Klarheit aufkommen. Die Figur des ,orientalischen Despotismus ' lässt sich ausgehend von kolonialen Reiseberichten bei zentralen Wissenschaftler_innen von Montesquieu über Hegel und Weber bis zu Vertretern der Frankfurter Schule wie Wittfogel finden (Kleinschmidt 2013). Nach diesem Konzept sei die Regierungsform des Alleinherrschers wesentlicher Bestandteil ,orientalischer Kulturen'. Das zweite Argument und Differenzmerkmal von Melina ist die in Afrika vermeintlich herrschende Korruption. Damit setze ich mich in Abschnitt 3.2.6 ausführlicher auseinander. Das dritte Argument sind die dort von Melina angenommenen ,andere[n] Gesetze“ und ,andere[n] Verbote“, die Entwicklung verhindern würden, ,also weiterzukommen“.

Auf die Rückfrage, woran es liegt, dass sich Afrika und der ,Westen' so anders entwickelt hätten, beginnt sie einen anderen Argumentationsstrang. 
I: Mhm. Und woran liegt das, dass es in Afrika sich so entwickelt hat? Und im Westen anders?

$\mathrm{S}$ : Na, ich denke es ist auch so ein bisschen, ähm, eine Möglichkeit .../ Einerseits, Afrika ist ja auch so ein ganz anderes, ähm, also so geografisch und so auch ein ganz anderes Land. Also, dass man dort vielleicht gar keine so Sachen entwickeln kann, wie in Deutschland. Ich weiß nicht, ähm, also keine Ahnung. Mir fällt jetzt kein Beispiel ein. Aber auch, ähm, dass es halt ärmer ist zum Teil. Und, dass dann keine neuen Geräte oder so gekauft werden können. Ähm, ja.

I: Und wie kommt das, dass es da mehr Armut gibt?

S: Ähm, das ist ja auch zum Teil so, weil es gibt ja auch sehr viel Wüste. Zum Beispiel. Und sehr viel auch unfruchtbares, also nicht unfruchtbar, aber manche Gegenden wo der Boden ja auch sehr arm ist. So Bodenarmut. Und wo man halt gar nicht so viel, ähm, anbauen kann. Und gar nicht so viel herstellen kann. Und, ähm, wo auch zum Teil der Import und Export, dieses System, noch gar nicht so richtig funktioniert. Sodass die gar nicht richtig reich werden können.

I: Mhm.

S: Also in manchen Gebieten so. (Melina, Gym08)

Afrika sei Melina zufolge ein ,geographisch und so auch ein ganz anderes Land“, wo eine solche Entwicklung vielleicht nicht möglich sei. Den Grund dafür sowie für die Armut vermutet sie im anderen Klima. Auch dieser klimatheoretische Begründungszusammenhang für ungleiche Entwicklung ist sowohl unter den Lernenden als auch in kolonialen Diskursen seit der Aufklärung weit verbreitet. Er spielt aber für die Frage der (nicht-)eurozentrischen Konzeptionalisierung universalistischer Ideen nur eine untergeordnete Rolle, da das Klimatheorem für Melina zwar die Begründung für das vermeintliche ,Entwicklungsdefizit' Afrikas liefert, das aus ihrer Sicht verantwortlich für den unterschiedlichen Umgang mit den universalistischen Konzepten ist, das jedoch nicht die Differenz im Umgang mit diesen selbst thematisiert.

Ein weiteres universalistisches Konzept, das Melina der ,westlichen Kultur zuordnet, benennt sie im weiteren Verlauf des Interviews.

I: Mhm. Und glaubst du das passiert, dass Hilfe von anderen Ländern kommt?

S: Ähm, also ich denke, vielleicht kommt das immer mehr schleichend. Also so, weil jetzt gibt es ja ganz viele Hilfsorganisationen, die halt Schulen bauen oder so. Ähm, aber ich denke nicht, dass das jetzt irgendwie in ein paar Jahren schon total ausgereift ist, weil dazu halt oft einfach die Mittel fehlen.

I: Mhm. Und sollten die Länder versuchen, möglichst viel von der westlichen Kultur zu übernehmen? 
S: Ähm, also ich denke .../ Also man muss das halt schon irgendwie .../ Also zum Teil. Also ich denke halt, wenn man das total übernehmen würde, dann würde ja auch diese eigene Kultur ja auch gar nicht mehr da sein. Also ich finde die Länder sollten schon ihre eigene Kultur behalten. Aber was halt gerade das Bildungssystem oder, ähm, Versorgungssystem oder so anbelangt .../ Oder vor allem, was ich auch bei der westlichen Kultur ziemlich schätze und auch sehr wichtig finde, ist auch Gleichberechtigung zwischen Männern und Frauen. Was auch sogar in den westlichen Kulturen ja noch nicht mal richtig ausgereift ist. (Melina, Gym08)

Sie plädiert dafür, dass die ,nicht-westlichen ' Länder die , westliche Kultur ‘ nicht „total übernehmen“ sollten, sondern auch ,ihre eigene Kultur behalten“ sollten. Einige Aspekte - und hier meint sie vermutlich die Melina zufolge der ,westlichen Kultur' eigenen, universalistischen Konzepte - sollten aber aus dem ,Westen“ exportiert werden. Hier bringt sie den Aspekt der „Gleichberechtigung zwischen Männern und Frauen“. Diese würde sie an der ,westlichen Kultur ziemlich schätze[n]“ und sie sei ihr ,sehr wichtig“. Dies sei „,sogar in den westlichen Kulturen ja noch nicht mal richtig ausgereift“. Die von Melina konstruierte Differenz erscheint hier nicht absolut, da sie darauf hinweist, dass die "Gleichberechtigung zwischen Männern und Frauen“" auch im Westen nicht komplett realisiert sei. Gleichzeitig erscheint die „Gleichberechtigung zwischen Männern und Frauen“ als kategoriales Differenzmerkmal. Sie rechnet diese eindeutig der ,westlichen Kultur' zu. In ,nicht-westlichen Kulturen' scheint es nach Melina so etwas nicht zu geben; wenn sie das in ,nicht-westlichen Kulturen "wahrnehmen würde, erschiene es ihr möglicherweise als eine bereits erfolgte Ausdehnung eines, westlichen' Konzepts. Gleiches gilt auch für die Frage der anderen von ihr genannten Wesensmerkmale der, westlichen Kultur', wie etwa der demokratischen Regierungsform im Gegensatz zur Alleinherrschaft, des Rechtsstaats im Gegensatz zu Korruption, der Offenheit oder der Freiheit. Wenn diese - wie im Fall von Melina - als der ,westlichen Kultur' angehörend definiert werden, erscheinen diesen zuzuordnenden Phänomene oder Prozesse in ,nicht-westlichen ‘ Ländern als erfolgter Transfer, westlicher' Konzepte universalistischer Ideen in ,nicht-westliche Kulturen'.

Im Folgenden zweiten Beispiel werden universalistische Konzepte weniger explizit der ,westlichen Kultur ' zugeordnet. Vielmehr - und das passiert auch in zahlreichen Interviews - werden durch die Darstellung des ,Anderen', des ,Nicht-Westens', des ,Nicht-Modernen', implizit Wesensunterschiede in Bezug auf universalistische Ideen konstruiert. Merle (Gym21) hatte über globale soziale Ungleichheit in Bezug auf Asien, die dortigen Produktionsbedingungen und die von Armut geprägten Lebensbedingungen berichtet. Anknüpfend an ihre Ausführungen, frage ich sie nach ihren Vorstellungen für die Ursachen dieser. 
I: Mhm. Ja. Mhm, woran liegt das denn überhaupt, dass es ein paar Länder gibt, die so arm sind. Oder, beziehungsweise, warum gibt es diesen Unterschied? Dass es hier relativ reich ist im Vergleich zu anderen Ländern?

S: Mhm. Das weiß ich gar nicht. Das habe ich mich auch schon ganz oft gefragt, ähm, wieso das so ist, dass wir hier so einen hohen Lebensstandard haben und die nicht. Aber, ähm, so genau kann ich das gar nicht sagen. Vielleicht liegt es an der Politik, die da geführt wird. Aber ich habe eigentlich gar keine Ahnung. Das habe ich mich auch schon richtig oft gefragt.

I: Ja. Ähm, ein bisschen Ahnung hast du ja. Also, was meinst du denn mit „der Politik, die da gemacht wird“? Woran denkst du da?

S: Mhm. Also ich habe jetzt, als ich gerade überlegt hab', habe ich darüber nachgedacht .../ Es ist ja so, zum Beispiel in Afrika, ist es ja ganz oft so, dass es so einen Alleinherrscher gibt, der dann halt über das Land da .../ Und das sind ja meistens so Leute, die dann halt noch mehr Macht wollen, als sie sowieso schon haben. Und dann auch nicht wirklich interessiert, wie es ihren Bürgern geht, sondern einfach nur darum, dass sie dann halt noch größere Besitztümer kriegen. Und dann, ähm, deswegen interessiert die weniger das Volk halt, als sich selber. Und, ähm, ich weiß aber nicht genau, wie es halt in den Ländern ist wo die Klamotten hergestellt werden. So in Indien und so. Da weiß ich nicht so viel drüber. Aber so Afrika hat man ja jetzt auch oft gehört, dass da irgendwelche Bürgerkriege waren und so. (Merle, Gym21)

Zunächst bemerkt Merle ihr Interesse an der Frage, die sich auch ,schon ganz oft" gestellt hätte. Sie benennt dazu aber ihre eigene Unwissenheit. Sie vermutet die Ursache zunächst in ,,der Politik, die da geführt wird“. Auf Nachfrage konkretisiert sie diese sehr globale Aussage durch ein Beispiel. In Afrika sei es ,ja ganz oft so, dass es so einen Alleinherrscher" gäbe. Hier taucht das Bild des , afrikanischen Despoten“ wieder auf. Dieser würde sich laut Merle nicht wirklich dafür interessieren, wie es den „Bürgern“ gehe, sondern nur dafür, ,,dass sie dann halt noch größere Besitztümer kriegen“. Er sei egoistisch, da er sich ,,weniger [für] das Volk halt als [für] sich selber" interessiere. Dies wisse sie aber nur über Afrika; ob es auch für andere Regionen gelte, wisse sie nicht. Auf Nachfrage kann sie auch begründen, wie es dazu kommt, dass es in Afrika, aber nicht im ,Westen “ - auch wenn sie diesen Begriff nicht verwendet - Alleinherrscher gäbe.

I: Mhm. Und wieso ist das ausgerechnet zum Beispiel in Afrika so, dass da oft so Alleinherrscher sind? Hast du da eine Ahnung?

S: Mhm. Na ja, also ich kann mir halt nur denken, dass es halt in Deutschland nicht so ist wegen Hitler halt. Weil das natürlich niemand nochmal möchte. Und deswegen darf hier auf keinen Fall nochmal ein Alleinherrscher sein. Und, ähm, das haben die anderen Länder um uns herum wahrscheinlich auch so sich als Vorbild genommen, sozusagen. Dass das halt nicht, ähm, gut ist, sag' ich jetzt mal. Und, ähm, in Afrika haben die, 
glaube ich, nicht so .../ Also natürlich haben die auch was davon mitbekommen, aber, ähm, ich glaube nicht, dass die das so wirklich getroffen hat halt. Und deswegen, ähm .../ Keine Ahnung. Vielleicht finden die das auch gut, wenn da ein Herrscher ist, den sie sich angucken können und sagen: "Hey. Das ist unser Herrscher." Weiß ich jetzt nicht so genau.

I: Mhm. Aber dadurch, dass es hier dann die Erfahrung - oder in den westlichen Ländern - die Erfahrung von Nationalsozialismus gab, ist sozusagen allen klar, dass das schlecht ist? Dass so eine Alleinherrschaft schlecht ist?

S: Mhm [bejahend].

I: Und darüber konnte sich überhaupt so was wie eine Demokratie entwickeln, würdest du sagen?

S: Ja, genau. (Merle, Gym21)

Den Grund für die Differenz im politischen System zwischen dem Globalen Norden und Afrika sieht sie in der Erfahrung des Nationalsozialismus. In Deutschland gäbe es das nicht „,wegen Hitler“, da das ,natürlich niemand nochmal möchte“. Die ,,anderen Länder um uns herum“ hätten sich das ,wahrscheinlich auch so [...] als Vorbild genommen“. Im Gegensatz dazu hätten „die“ das nicht „mitbekommen“ bzw. es hätte „sie“ nicht so getroffen. Sie vermutet also, dass die Erfahrung des Nationalsozialismus die Entwicklung der Demokratie ermöglicht bzw. fundiert hat, während die Regionen die diese Erfahrung nicht so gemacht hätten weiter Alleinherrscher als Regierungsform haben. Die Erfahrung des Nationalsozialismus wird so zum Ausgangspunkt eines Überlegenheitsnarrativs. Das Bild davon, dass die „Länder um uns herum“ sich Deutschland zum „Vorbild genommen" hätten, stellt den deutschen Nationalsozialismus ins Zentrum der globalen Geschichte bzw. zumindest der globalen Geschichte der Regierungsformen. Merle ergänzt ihre Überlegungen zu der Frage der Ursache der Alleinherrschaft als in Afrika verbreitete Regierungsform. „Vielleicht“, fährt sie fort, „fänden die das auch gut, wenn da ein Herrscher ist, den sie sich angucken können und sagen: ,Hey. Das ist unser Herrscher." Es ist unklar, ob dies ein ergänzendes oder alternatives Argument ist. Als ergänzendes würde es davon ausgehen, dass Afrikaner_innen die Regierungsform der Alleinherrschaft einfach gut fänden und nicht das Bedürfnis nach einer anderen Regierungsform hätten, da sie nicht die Erfahrung des Nationalsozialismus gemacht hätten bzw. nicht davon getroffen worden seien. Als ergänzendes Argument würde es ohne den historischen Begründungszusammenhang Afrikaner_innen als solchen, im Gegensatz zu Bewohner_innen des Globalen Nordens, eine Vorliebe für die Alleinherrschaft unterstellen. Es ist wahrscheinlich, dass Merle einer solchen Formulierung nicht zustimmen würde, 
doch ihr Argument funktioniert meiner Interpretation nach so. Für eine Interpretation, die die Vorliebe für eine bestimmte Regierungsform an die Herkunft bindet, spricht auch ihre Formulierung, dass ,,die das auch gut fänden, wenn da ein Herrscher ist, den sie sich angucken können und sagen: ,Hey. Das ist unser Herrscher. " Dies ruft ein Bild ,der' Afrikaner_innen hervor, in dem , sie' nicht nur homogenisiert, sondern auch als Einzelne als naiv und simpel dargestellt werden.

Timo (Gym19) versteht unter Globalisierung die verbesserte globale Verständigung durch Kommunikationstechnologien. Im Sprechen darüber stelle ich die Nachfrage, ob alle Menschen gleichermaßen daran teilhaben.

I: Und, ähm, gilt das für alle Menschen gleichermaßen? Also haben alle Menschen die Chance?

S: Das würde ich jetzt nicht unbedingt sagen. Da einerseits diese Technik halt auch was kostet. Und weil viele Länder halt verschieden weit entwickelt sind. Von daher .../

I: Und welche Länder sind zum Beispiel weiter entwickelt als andere?

S: Ich würde sagen, dass beispielsweise Länder wie Japan oder jetzt auch Deutschland - also genau die westlichen Staaten - weiter entwickelt sind als beispielsweise jetzt die afrikanischen, ärmeren Staaten. Und teilweise auch Orte in Asien, also Gebiete. (Timo, Gym19)

Nach Timo können nicht alle Menschen gleichermaßen an den Kommunikationstechnologien teilhaben, da sich nicht alle die Technik leisten könnten und weil „viele Länder halt verschieden weit entwickelt“ seien. Er erklärt an dieser Stelle nicht, worauf sich der Entwicklungsgrad bezieht; die Nennung von Entwicklungsunterschieden scheint als solches eine Erklärung hervorbringen zu können. Auf die Nachfrage, welche Länder weiter entwickelt sind als andere, führt er die Kategorie der „,westlichen Staaten“ ein, die den ,afrikanischen, ärmeren Staaten“ und teilweise auch „Gebieten“ in Asien entgegengesetzt werden. Als Beispiele für „,westliche Staaten“ bringt Timo Japan und Deutschland. Dadurch, dass Timo das Beispiel Japan wählt, sehe ich eine Chance der diskursiven Konstruktion des Westens nachzuspüren.

I: Mhm. Japan liegt ja jetzt eigentlich total ganz weit im Osten von hier jetzt, ne?

S: Ja [lacht].

I: Wie kommt das, dass man das auch zum westlichen Staat .../ Oder was heißt ,westliche Staaten“? 
S: Also ich würde einfach sagen, generell demokratische, gut entwickelte Staaten, die sich halt human für ihre Mitbürger, ähm, Bürger einsetzen und so was einfach. (Timo, Gym19)

Wenig verunsichert durch meine leicht provokative Nachfrage formuliert er eine Definition für , westliche Staaten'. Westliche Staaten' würden sich nach Timo dadurch auszeichnen, dass sie ,demokratische, gut entwickelte Staaten“ seien, die sich „,halt human für ihre [...] Bürger einsetzen“ würden. Das heißt, er löst hier die Kategorie des ,Westens “ aus der geographischen Logik heraus. Die geographische Lage eines Landes stellt kein Kriterium dafür dar, ob es als ,westlich“ gilt. Dies stellt eine Lösung für das Problem dar, dass - entgegen jeder geographischen Logik im hegemonialen geographischen Bezugsrahmen - Japan in vielen diskursiven Kontexten als ,westlich“ angesehen wird, während lateinamerikanische Staaten hingegen meist nicht zu dieser Gruppe gezählt werden. Er koppelt die Zugehörigkeit auch nicht an die Frage der Industrialisierung oder des Reichtums. Noch bemerkenswerter ist, dass sich in seinen Ausführungen kein Bezug zu so etwas wie der, westlichen Kultur' findet. Das bedeutet möglicherweise, dass es in seiner Argumentation keinen Bezug zu einem kulturalistischen Verständnis des ,Westlichen“ gibt, nach dem es eine versteckte kulturelle Essenz gibt, die in vielen orientalistischen Diskursen den Grund für die kulturell-zivilisatorische Überlegenheit darstellt. Für ihn ist per definitionem ein Staat dann als ,westlich“ anzusehen, wenn er ,demokratisch“ und ,gut entwickelt“ ist und sich ,human“ für seine „Bürger“ einsetzt. Der Zusammenhang zwischen dem Entwicklungsstadium und der demokratischen Verfasstheit bzw. der Humanität gegenüber den Bürgern wird leider nicht deutlich. Eine widerspruchsfreie Interpretation wird für mich auch durch die folgenden Aussagen nicht leichter.

I: Und wie kommt das .../ Also, du sagst in den westlichen Staaten, in denen wird das so gemacht. Aber, ähm, wie kommt das dazu? Du sagst, in den westlichen Staaten gibt es so was wie Demokratien, die setzen sich irgendwie ein und es ist humaner. Und in anderen ist es nicht so.

S: Das ist wahrscheinlich .../ Das hat mit der Regierung zu tun. Und mit dem Volk auch an sich. Ich meine, es gibt zurzeit jetzt viele Revolutionen, wo so was halt jetzt gestürzt wird.

I: Mhm.

S: Aber ich denke einfach, dass jetzt beispielsweise in Deutschland die Demokratie nicht zu vergleichen ist mit einer dann zum Beispiel im Iran oder so was.

I: Mhm. Was unterscheidet das hauptsächlich? 
S: Dass hier ein Mensch auch richtige Rechte hat. Also, dort ist das ja alles ziemlich eingeschränkt, zum Beispiel. (Timo, Gym19)

Auf die Frage nach den Ursachen dafür, dass es verschieden verfasste Regierungsformen gibt, antwortet er nicht mit einem Bezug zur allgemeinen Entwicklung, der Armut oder der Vorliebe bestimmter Nationen für Alleinherrschaft; vielmehr argumentiert er über das Verhältnis der „Regierung“ zum „Volk“ und vor allem vom „Volk“ zur „Regierung“. Dies wäre tautologisch, würde er nicht noch die Kategorie der Revolutionen einführen, in denen das „Volk“ undemokratische Regierungsformen stürzen könnte. ,Nicht-westliche Staaten ' zeichneten sich also dadurch aus, dass dort bislang keine zu einer demokratischen Regierungsform führende Revolution stattgefunden hätte. Über sein Beispiel des Kontrasts zwischen dem demokratischen Deutschland und dem undemokratischen Iran führt er aber - zumindest auf der assoziativen Ebene - die geographische Deutung der Definition des ,Westens' wieder ein; oft ist die Form des Beispiels weniger unschuldig als sie zu sein vorgibt. Im Kontrast der beiden formuliert er den für ihn zentralen Punkt einer Demokratie bzw. einer, westlichen' Regierungsform. In der Demokratie - Deutschland - habe „ein Mensch auch richtige Rechte“, während in nicht-demokratischen bzw. , westlichen “ Ländern - ,dort“ im Iran - ,alles ziemlich eingeschränkt" sei. Dies bestätigt er auch im folgenden Auszug.

I: Mhm. Und was könnte man machen, um das zu verändern?

S: Es werden jetzt teilweise auch schon ziemlich viele Revolutionen .../ Zum Beispiel in den arabischen Ländern waren jetzt ziemlich viele. In der Türkei wird jetzt ja auch wieder protestiert.

I: Mhm.

S: Man muss sich einfach einsetzen dafür. Unter anderem auch auf Hilfe von anderen Staaten hoffen.

I: Mhm. Und, ähm, wie findest du das? Oder, worauf hoffst du dabei? Dass die sich quasi auch so entwickeln können wie hier?

S: Ich hoffe, ja. Das wäre eine positive Entwicklung.

I: Und ist das Ziel, dass die genauso werden wie hier?

S: Genauso nicht. Aber ich denke einfach das Ziel ist, dass ein Mensch mit seinen Rechten leben kann, die ihm zustehen. Und .../ Ja, das ist eigentlich das Hauptziel. (Timo, Gym19) 
Wiederum entsprechen hier die Beispiele wieder der geographischen Logik und es werden die typischerweise als Kontrast zum ,Westen' fungierenden Weltregionen bzw. Länder herangezogen. Timo macht hier noch einmal klar, dass er die Regierungsform nicht an einen allgemeinen Entwicklungsbegriff koppelt. Es müsse nicht „,genauso“ wie ,hier werden“. Für ihn sei „eigentlich das Hauptziel“, dass „ein Mensch mit seinen Rechten leben kann, die ihm zustehen“.

Timos Vorstellung von der Existenz verschiedener Regierungsformen und der Zugehörigkeit zu den ,westlichen Staaten' formuliert er in ,politischen' - im engen Sinne des Begriffs - Kategorien, die ohne Bezug zur kolonialen Entwicklungsmatrix oder essenzialiserende Zuschreibungen funktionieren, sondern stattdessen das Verhältnis vom „Volk“, der „Regierung“ und der „Revolution“ denken. Gleichzeitig ist eine zentrale Kategorie die der „westlichen Staaten“, die er von der geographischen Lage löst und mit der Existenz von demokratischen Verhältnissen gleichsetzt - sein weiteres Kriterium, dass ein Staat „gut entwickelt" sein müsse, lasse ich hier kurz außen vor. Außerdem spricht die Auswahl seiner Beispiele dafür, dass seine Vorstellung der Welt auf eurozentrische, okzidentalistisch-orientalistische Einteilungen und Hierarchisierungen der Welt referiert. Dazu kommt, dass er wenig in Grauzonen zu denken scheint, sondern vielmehr ein Staat entweder, westlich' ist oder nicht bzw. kurz vor einer Revolution steht. An keiner Stelle im Interview gibt es aber eine dahingehende Andeutung, dass möglicherweise in ,westlichen Staaten' die proklamierte Demokratie nicht, oder nicht in diesem Maße, realisiert sein könnte; er befragt diese nicht auf ihre Substanz und möglicherweise auch vorhandene soziale und politische ,Schieflagen“. Einen essenzialisierenden Begriff des ,Westens', der sich auf irgendeine ,kulturelle“ Tradition, Essenz oder eine Geographie bezieht, scheint Timo vermeiden zu wollen. Gleichzeitig produziert der Diskurs die okzidentalistisch-orientalistische Differenz. Wie ist vor dem Hintergrund dieser Überlegungen nun seine Verwendung des Begriffs von ,westlichen Staaten ${ }^{\text { zu }}$ deuten? Meine Überlegungen, wie ich mit diesem Feld der Widersprüche und Ambivalenzen umgehe, führen mich zu folgenden Überlegungen. Dabei geht es - wie im Übrigen in der ganzen Untersuchung - nicht darum, zu entschlüsseln, was denn Timo, eigentlich' gemeint hat, sondern wie ich seine Vorstellungen vor dem Hintergrund meiner eigenen Perspektive und kontextuellen Verortung kokonstruiere. Zum einen scheint mir hier die Frage der diskursiven Bedeutung davon relevant, was gesagt wurde und von dem, was zwar nicht ausgesprochen und dennoch gesagt wurde. Wenn Timo hier von den ,westlichen Staaten spricht, wissen trotz seines nicht-essenzialistischen Konzepts die Rezipient_innen im hegemonialen diskursiven Kontext, wer gemeint ist und wer nicht. Es werden trotzdem die Bilder okzidentalistisch-orientalistischer Vorstellungswelten wach 
gerufen. Diese zwei Ebenen - die ,politische" und die essenzialisierende - changieren im Diskurs. Es muss nicht mehr ausgesprochen werden, was sowieso allen klar erscheint, nämlich dass der ,Westen' bestimmte Weltteile umfasst, die den anderen, nicht-zugehörigen, überlegen sind.

\subsubsection{Mentalität der Freiheit II: Zur Ambiguität der Menschenrechte}

In diesem Abschnitt werde ich mich mit Vorstellungen zu Menschenrechten beschäftigen. Dabei gehe ich der Frage nach, wie Menschenrechte im Spannungsfeld von Dekolonialität und Kolonialität stehen. Zur Herausarbeitung dieses Spannungsfeldes werde ich mich ausführlich mit einem Interviewauszug von Lara (Gym18) beschäftigen.

Lara stellt die Menschenrechte an den Anfang ihrer Erzählung über ihr Verständnis von Globalisierung.

I: Vielleicht fangen wir einfach mal so an, dass du mal erzählst, was dir zu Globalisierung einfällt.

S: Mhm, also, unter Globalisierung versteh ich halt, wegen „global“, dass es auf der ganzen Welt passiert.

$\mathrm{I}: \mathrm{Mhm}$.../

S: Und dann dachte ich, also ich kenn' das Wort ja so irgendwie: es gibt halt eine Veränderung und die ist global. Also, ein paar Staaten, oder, keine Ahnung, Wissenschaftler oder so entscheiden sich halt für irgendetwas Besonderes. Keine Ahnung, zum Beispiel die Menschenrechte oder so. Das ist ja auch so was Globales gewesen, und dann entscheiden sich halt alle dafür. Oder so gut wie alle. Und das passiert dann halt auf der ganzen Welt und jeder wird betroffen, ob er es will. Vielleicht .../ Ich weiß ja jetzt nicht, kommt auf die Veränderung an, aber .../

Unter Globalisierung versteht Lara eine „Veränderung“, die ,auf der ganzen Welt passiert“. Ihr Bild von diesen globalen Veränderungsprozessen ist dabei eins der Ausbreitung von einem Entstehungsort auf große Teile des Restes der Welt. Sie stellt sich vor, dass ein „paar Staaten“ oder „Wissenschaftler“ sich für eine Sache entschieden, und dann würden sich ,halt alle dafür“ entscheiden. Ich fragte daraufhin nach, woher denn zum Beispiel die Menschenrechte kämen. 
I: Mhm, und zum Beispiel die Menschenrechte. Woher kommen die?

S: Ja, also ich glaub', das war ein Franzose oder so. Das war irgendwo in Amerika, La Fayette oder so? Ja, da waren halt Artikel und alles. Und dann mussten mehrere Städte das unterschreiben. (Lara, Gym18)

Zu Beginn sprach Lara nicht davon, dass die „paar Staaten“ oder „Wissenschaftler" Urheber der Idee der Menschenrechte waren, vielmehr hätten diese entschieden, die Menschenrechte zu verbreiten. Auf die Nachfrage scheint es aber so, als würde Lara hier den Ursprung der Menschenrechte benennen. Mit der Nennung von La Fayette spielt sie auf die nach der Französischen Revolution verkündete Erklärung der Menschen- und Bürgerrechte an, an deren Formulierung La Fayette beteiligt war. Sie scheint offenbar auch zu wissen, dass La Fayette im US-amerikanischen Unabhängigkeitskrieg aktiv war und eine Art Brückenfunktion zwischen den US-amerikanischen und den französischen Liberalen eingenommen hat. Durch die Gleichsetzung der Menschenrechte als Idee mit der historisch spezifischen Erklärung der Menschen- und Bürgerrechte in Frankreich 1789 ergibt sich ein diskursiver Effekt, der die Menschenrechte als solche mit einem Ursprung versieht. Dadurch erscheinen menschenrechtliche Praxen Kämpfe um Gleichheit mit Bezug auf allgemeine menschliche Grundrechte - an anderen Orten als die Übernahme eines französisch-amerikanisch-europäischwestlichen Konzepts betrachtet. Dieser Effekt kann als eurozentrisch angesehen werden. Alternative, postkoloniale Geschichtsschreibungen der Menschenrechte sehen menschenrechtliche Ideen in vielen verschiedenen Gesellschaften, Zeitpunkten und Kontexten am Werk. Auch ein Blick auf die Durchsetzung der Erklärung der Menschenrechte zeigt ein Bild, in dem insbesondere einige europäische Staaten die allgemeine Anerkennung in den Staatengemeinschaften lange verhinderte, um eigene diskriminierende Politiken weiterführen zu können (Kalny 2008).

Die Menschenrechte sind dabei nicht einfach ein Beispiel unter anderen. Die diskursive Europäisierung des Konzepts der Menschenrechte bezeugte und bezeugt in vielen kolonialen und neokolonialen Kontexten die vermeintliche ,zivilisatorische' Überlegenheit des ,Westens'. In über einem Viertel der Interviews taucht die Idee auf, dass die Menschenrechte europäischen Ursprungs seien bzw. dass die ,nicht-westlichen ' Gesellschaften diese ,noch nicht" implementiert hätten. In diesem Sprechen über Menschenrechte wird das Narrativ reproduziert, in welchem ,Europa ' bzw. der ,Westen' als die Wiege des Humanismus erscheint, der dann in den Rest der Welt hinausgetragen wurde. In einer markanten Form findet sich dies beispielsweise in der mission civilisatrice des französischen Kolonialismus. Diese diskursiven Verwendungsweisen der eurozentrischen Sichtweise 
auf Menschenrechte hat Lara hier, meiner Einschätzung nach, nicht im Kopf, dennoch erscheint ihre Sicht zunächst offen für eine solche Lesart zu sein. In den folgenden Fragen versuche ich ihrer Vorstellung von der Ausbreitung der Menschenrechte nachzugehen.

I: Mhm, und das wurde dann verbreitet über der ganzen Welt?

S: Also, ich weiß nicht. Ich glaube, nicht alle haben unterschrieben oder so. Aber ja, viele.

I: Mhm. Und weißt du, wann das war oder wie das kam, dass das verbreitet wurde?

S: Also, das war im 18. Jahrhundert oder so 17. Jahrhundert irgendwas. Also, ich weiß jetzt nicht genau, wie er darauf kam, aber es hat sich verbreitet und ich weiß nicht, ob man darüber geredet hat oder so, aber es mussten halt irgendwann alle, Könige und so, zustimmen, oder so. Und es war wahrscheinlich auch irgendwas Politisches und so, dass man sich geeinigt hat, dann mehr so im Frieden zu leben, damit es weniger Kriege gibt und so.

I: Mhm.

S: Und dann haben die das alles so eingeleitet.

I: Mhm. Und waren denn da alle Länder gleichermaßen dann gleich beteiligt. Oder wie stellst du dir das vor? Also jetzt, ob im 18. Jahrhundert oder später ja vielleicht auch ...l

S: Also, unter Globalisierung - habe ich auch aufgeschrieben - verstehe ich auch, dass man ein bisschen so unter Gruppenzwang ist oder so.

I: Mhm.

S: Also, jedenfalls sehr viel, also vielleicht die ersten fünf oder so entscheiden sich möglicherweise für die Veränderung und die anderen sind so: „Ja okay. Das machen jetzt richtig viele und wir wollen jetzt nicht irgendwie einen Konflikt oder so machen.“ Und ja, dann entscheiden sie sich halt zwangsweise dazu, um in Frieden zu stehen oder so. (Lara, Gym18)

Sie benennt hier wiederum die Autorenschaft der Menschenrechte, indem sie sagt, dass sie nicht genau wisse, wie ,er“ darauf kam. Ihr Bild des über die Globalisierung als Gruppenzwang verbreiteten Konzepts der Menschenrechte, die von La Fayette entwickelt, in Frankreich oder den USA implementiert und dann von dort exportiert wurden, kann als eine Form des Diffusionsmodells gedeutet werden. Das Diffusionsmodell beschreibt in postkolonialen Ansätzen eine von der Wissenschaft bis zum Alltag verbreitete Denkweise, nach der der Ursprung von Ideen oder gesellschaftlichen Entwicklungen im ,Westen' verortet wird, bevor diese dann über den Rest der Welt verbreitet werden. Dieser Rest der Welt wird 
dabei dann - fast notwendigerweise - immer als ,zu spät' in der Entwicklung und möglicherweise fehlerhaft in der Anwendung dieses ,westlichen' Konzepts imaginiert. Die Autorenschaft für menschliche Universalien liegt nach diesem Modell fest in der Hand von ,weißen ', , westlichen', bürgerlichen, meist männlichen Autoren. Dabei problematisiert Lara an einer späteren Stelle des Interviews durchaus dieses kolonial strukturierte Wissensarchiv. Im Kontext ihrer Erzählung über die Schwierigkeiten, mit ihrem Wunsch als Schwarze Frau Autorin werden zu wollen akzeptiert zu werden, stellt sie fest, dass die Autoren ,,in den Büchern [...] halt auch alle Europäer" seien: „Aber irgendwann habe ich halt gemerkt, dass in den Büchern die Autoren halt auch alle Europäer sind. Oder Weiße oder Engländer mehr so." Das Thema von Macht und Kolonialität der Wissensarchive scheint ihr also durchaus präsent zu sein.

Eine andere Lesart ihrer Vorstellungen über Menschenrechte - legen wir kurz die Brille des Diffusionsmodells ab - ist die Perspektive auf die Menschenrechte als etwas Kontingentes. Die Art der Verbreitung beschreibt sie in der Motivation der Könige, „Frieden“ und „,weniger Kriege“ zu haben. Sie charakterisiert diesen Prozess der Verbreitung und damit die „Globalisierung“ selbst als „Gruppenzwang“. Ihre Sichtweise erscheint hier als Top-Down-Prozess, in dem ausschließlich Könige als Akteure vorkommen, die sich aufgrund des Gruppenzwangs auch dieser Idee anschließen. Mit ihrer Darstellung der Durchsetzung der Menschenrechte als Gruppenzwang beschreibt Lara die Verbreitung der Menschenrechte als etwas Kontingentes. Anders als Darstellungen der Menschenrechte, die die vorherrschende Form ihrer Formulierung als etwas Universelles - wie beispielsweise die Naturrechtsansätze - ansehen, historisiert sie das Konzept der Menschenrechte und schreibt ihnen einen Entstehungskontext zu. Ihre Verbreitung beschreibt sie nicht als einen Prozess des ,Fortschritts“, sondern als eine Frage von Hegemonie, wie in ihren Ausführungen zum Gruppenzwang deutlich wird. Die dekoloniale Sicht auf die Menschenrechte als etwas Partikulares eröffnet die Möglichkeit, ihre hegemoniale Artikulation als etwas Universelles bzw. als Recht mit universellem Anspruch zu problematisieren. Kritisiert werden in postkolonialen Diskursen beispielsweise die den Menschenrechten inhärenten spezifischen, eurozentrischen Vorstellungen, etwa zu Individualität, sozialen Beziehungen und insbesondere zum Bild des Menschen der Menschenrechte. Der Mensch der Menschenrechte war zunächst weiß, männlich, europäisch, gesund etc. Olympe de Gouges und Toussaint L'Ouverture wurden für den Kampf für die Ausweitung der Menschenrechte auf andere Gruppen von den Autoren der Erklärung der Menschen- und Bürgerrechte und ihren Nachfolgern ermordet. In liberalen Diskursen um Menschenrechte wird dabei davon ausgegangen, dass die Rechte als Mensch sich aus der Natur des Menschen ergäben (Fitzpatrick 2013: 
103). Fitzpatrick stellt fest, dass der Mensch der Menschenrechte einem impliziten Bild entsprechen muss: ,The human of human rights must not be too backward, too traditional, behave inhumanly, and so on." (ebd.) Er arbeitet einige Kriterien für das implizit wirksame Bild des Menschen der Menschenrechte heraus: ,criteria to do with abnormality, race and gender, various corporeal and genetic endowments, monstrosity and the sub-human, culture and language, rationality and dominium, among others." (ebd.) Auf einer anderen Ebene werden die Verwendungsweisen von Menschenrechten zur Durchsetzung neoliberaler, neokolonialer und entwicklungspolitischer Prozesse in den Blick genommen (ebd.). Fitzpatrick schlägt aus einer dekolonialen Perspektive - statt einer universalistischen Sicht auf die Menschenrechte - ein Konzept vor, das auf Pluralität und die widerständige Anwendung und Kontextualisierung von Menschenrechten baut (ebd.: 104). All diese Überlegungen sind erst vor dem Hintergrund von Laras Bruch mit der liberalen Naturalisierung der Menschenrechte möglich und denkbar.

Mit der Brille des Diffusionsmodells erscheint es als problematisch, dass die keinesfalls ausschließlich europäische Idee von Würde, Gleichheit und Freiheit als europäisch definiert wird. Dies ist Teil der Konstruktion ,westlicher' Überlegenheit und kann der Instrumentalisierung der Menschenrechte für neokoloniale Ziele Vorschub leisten. Mit der Brille der Menschenrechte als etwas Kontingentem erscheint an Laras Vorstellungen sehr interessant, dass sie nicht etwa davon ausgeht, dass die Erklärung der Menschen- und Bürgerrechte von 1789 etwas universelles seien, sondern kontextualisiert sie und bindet sie an die Frage von Hegemonie.

In der Folge thematisiert sie die Differenz zwischen der Ratifizierung und der Realisierung von Menschenrechten.

I: Mhm. Und, ähm, ja galten denn .../ Also, was denkst du denn von den Menschenrechten zum Beispiel? Ich mein', die sind in Frankreich entstanden im 18. Jahrhundert, aber damals gab es ja auch Länder, wo die dann noch nicht galten. Kannst du da noch mehr zu erzählen?

S: So inhaltlich?

I: Zum Beispiel, ja.

S: Ja, also, ich find' das eine gute Idee. Also ich hab das ja auch in Geschichte und Politik und so gehabt und es sind gute Dinge dabei. Und ich fand das eigentlich .../ Also, es war eine gute Idee, also es wurde halt nicht von allen eingehalten, aber an sich ist das schön halt, alles aufzuschreiben. (Lara, Gym18)

Lara lässt sich zum Glück nicht davon irritieren, dass ich offenbar unaufmerksam zuhöre, da ich in der Zusammenfassung ihrer Ausführungen Frankreich und nicht „Amerika“ als Entstehungsort der Menschenrechte nenne. Sie stellt hier fest, dass 
die Menschenrechte nicht „,von allen eingehalten“ wurden. Prinzipiell findet sie das „schön halt alles aufzuschreiben“. Damit problematisiert sie die Frage der Substanz eines positiven Rechts, wie auch im Folgenden deutlich wird.

I: Mhm, und wer würde dir zuerst einfallen, wer das nicht eingehalten hat?

S: Also heutzutage, oder?

I: Was du willst.

S: Also damals, zum Beispiel Amerika oder so, da war halt .../ Oder generell so Europa. Da gab es ja immer noch den Absolutismus teilweise. Oder generell irgendeine Form von Diktatur oder so. Und vor allem gab es halt Sklavenhandel, so im 18. Jahrhundert. Und, ähm, also in den 50er Jahren, also 1950er Jahren, war ja halt Rassentrennung. Und das war jetzt auch gegen die Menschenrechte. Und heutzutage ist es ja halt immer so, zum Beispiel mit der Ehe zwischen Mann und Mann oder Frau und Frau. Und das ist halt, zum Beispiel in Deutschland, immer noch nicht ganz fair, soweit ich weiß. Obwohl in den Menschenrechten ja steht, dass man alles machen darf, ähm, solange man dem anderen nicht schadet. Und deswegen, finde ich, sollte es eigentlich erlaubt sein. Und das steht ja in den Menschenrechten und demnach ist es halt hier zum Beispiel auch nicht richtig gut. Oder .../ Ja. Und in den, ähm, östlichen Ländern zum Beispiel gibt es halt Kinderarbeit oder .../ Ja.

I: Mhm. Und jetzt sagst du ja aber, dass in Frankreich und Amerika .../ Diese Idee von den Menschenrechten kam daher. Und zur gleichen Zeit gab es da Sklavenhandel und noch Rassentrennung?

S: Ach so, ähm, Rassentrennung kam ja später. Und Sklavenhandel hat, glaube ich, irgendwann im 19. Jahrhundert geendet.

I: Mhm.

S: Und, ja, zur gleichen Zeit gab es, soweit ich weiß, noch Sklavenhandel.

I: Mhm. Und wie passt das zusammen? Menschenrechte und .../

S: Also eigentlich passt das gar nicht zusammen. Und es war ja auch so, dass gesetzlich nicht so geschrieben war, dass man das machen darf. Und in den 50er Jahren zum Beispiel bei der Rassentrennung, hieß es ja, dass alle dieselben Rechte haben. Und dass die ehemaligen Sklaven halt frei waren und, genau, Bürger waren. Aber trotzdem haben halt die Aufsichtspersonen und so, die Polizisten und alle, das irgendwie ignoriert. Und .../ Ja. Also, es stand schriftlich, aber sie haben es ignoriert. (Lara, Gym18)

Vor dem Hintergrund der Erfahrung mit den anderen Interviews, in der die NichtEinhaltung von Menschenrechten fast ausschließlich in der ,nicht-westlichen“ Hemisphäre verortet wurden, sind die Auswahl der Beispiele von Lara als etwas Besonderes anzusehen. Als Beispiele für die Nicht-Einhaltung der Menschenrechte führt sie absolutistische oder diktatorische Staatsformen in Europa, den 
europäischen Sklavenhandel, das bis in die zweite Hälfte des 20. Jahrhunderts herrschende System der Rassentrennung in den USA und die Ungleichbehandlung gleichgeschlechtlicher Ehen in Deutschland an. Nur das Beispiel der Kinderarbeit in „östlichen Ländern“ verortet die Nicht-Einhaltung außerhalb des ,Westens“. Trotz ihrer Vorstellung des Ursprungs der Menschenrechte im ,Westen ' und der Momente des Diffusionsmodells reproduziert sie hier nicht mal ansatzweise das binäre Bild des die Menschenrechte einhaltenden ,Westens' und des die Menschenrechte nicht-einhaltenden Rests. Durch die Auswahl ihrer Beispiele wird das Bild des ,Westens“ als Wiege der Humanität, die oft in den Erzählungen über die Menschenrechte auftaucht, infrage gestellt. In Bezug auf die Rassentrennung formuliert sie den Unterschied zwischen formalen und substanziellen Rechten. Während es ,hieß“, dass ,alle dieselben Rechte“ hätten und die „,ehemaligen Sklaven halt frei [...] und genau Bürger" gewesen wären - formale Rechte -, hätten das die „Aufsichtspersonen und so, die Polizisten und alle, das irgendwie ignoriert" - fehlende substanzielle Rechte. Sie fasst den Unterschied formaler und substanzieller Rechte so: „Also es stand schriftlich, aber sie haben es ignoriert.“

Später im Interview hake ich beim Thema der Menschenrechte wieder ein und frage nach den Möglichkeiten der Veränderung in Bezug auf die Nicht-Einhaltung der Menschenrechte.

I: Mhm. Und, ähm, du hast ja auch gesagt, dass immer noch nicht alle Länder zu den Menschenrechten stehen. Was sollte man da machen?

S: Ja, also ich denke mal, protestieren hilft da. Also ich meine, das hat zum Beispiel in Frankreich jetzt geholfen. Also in den westlichen Ländern wird das auf jeden Fall, dadurch dass man die Möglichkeit hat, auch was zu sagen, leichter sein. Man muss einfach irgendwie zeigen, dass es richtig ist und dass man es will. Und irgendwie die Regierung ein bisschen unter Druck setzen dadurch. Weil, es ist ja so, dass durch die Proteste und so, die Regierung vielleicht ein bisschen Angst hat und so. Und nicht irgendwie so eine Art Bürgerkrieg oder irgendwas in der Richtung halt haben möchte. Und dadurch muss sie ja irgendwie was machen. Und die Bürger müssen halt die Regierung mögen. Und deswegen muss die Regierung dann was machen, was die Bürger wollen. So Proteste sind gut.

Lara bricht hier mit dem von ihr vorher gezeichneten Bild der Verbreitung oder Durchsetzung der Menschenrechte als einem Top-Down-Prozess im Sinne des Gruppenzwangs der Globalisierung. Durch die möglichen Implikationen meiner Frage wäre, vor dem Hintergrund der Erfahrungen der anderen Interviews, eine Antwort wahrscheinlich gewesen, die entwicklungspolitisch argumentiert und auf die Implementierung der Menschenrechte durch, westliche' Staaten im Globalen Süden zielt. Doch Lara setzt ganz andere Akzente. Sie führt aus, dass Proteste 
nötig seien, um Menschenrechte durchzusetzen. Dadurch könnte gezeigt werden, „dass es richtig ist und dass man es will“. Sie verbindet hier den Gedanken der Aufklärung mit dem Gedanken der Hegemonie. Nicht Aufklärung oder Hegemonie als getrennte Frames können, Laras Meinung nach, zur Realisierung der Menschenrechte beitragen, sondern beide Frames erscheinen als miteinander verknüpft. Die Regierung erscheint in ihrer Vorstellung nicht als ein Motor des Fortschritts zur Durchsetzung der Menschenrechte, sondern vielmehr müsse diese „unter Druck“ gesetzt werden. Wenn die Regierung ,ein bisschen Angst“ vor sozialen Unruhen habe, müsse sie aktiv werden. Sie sei auf die Gunst der „Bürger" angewiesen, deswegen müsse sie dann letztlich machen, ,was die Bürger wollen“. Vor diesem Hintergrund kommt sie zu dem Fazit: „So Proteste sind gut.“ Dabei erwähnt sie Frankreich. Auf Nachfrage bringt sie andere Aspekte ein, wo sie die Nicht-Einhaltung der Menschenrechte in ,westlichen' Ländern sieht.

I: Mhm. Ja. Und du hast jetzt das Beispiel der Gleichstellung von homosexuellen Paaren in Frankreich und auch in Deutschland gebracht. Fallen dir noch andere Sachen ein, wo in westlichen Ländern Menschenrechte nicht eingehalten werden?

S: Mhm. Also, in Menschenrechten .../ Also im Sinne von .../ Ich glaube irgendwie, es ist zwischen Mann und Frau irgendwie nicht ganz gerecht, weil ein Mann und eine Frau auf selber Position verdienen irgendwie nicht gleich viel Geld. Und, ja, ich weiß gar nicht woher das kommt. Und ich verstehe das irgendwie nicht. Also, ich habe es oft gehört und das finde ich irgendwie total unverständlich. Vor allem so heute ist das komisch. Und ich habe irgendwie auch das Argument gehört, dass Frauen in Mutterschaftsurlaub gehen können. Und ich finde, das ist aber kein Grund dafür, irgendwie das irgendwie so zu machen. Und das ist irgendwie nicht gerecht. Und oft hört man halt auch, dass Frauen irgendwie nicht so wichtig oder nicht direkt wichtig, aber eher schwächer sind oder so. Oder die Tatsache, dass sie Mütter sein können, ist irgendwie was Schlechtes. Aber das ist eigentlich was ganz Wichtiges. Und ich finde, das müsste von der Regierung so eher verstanden werden. (Lara, Gym18)

Lara führt als weiteres Beispiel die Ungleichbehandlung der Geschlechter in der Arbeitswelt an. Während in den meisten anderen Interviews die Ungleichberechtigung der Geschlechter im Zusammenhang mit den Unterschieden zwischen ,westlichen' und ,nicht-westlichen' Gesellschaften behandelt wird, spricht Lara hier von der Ungleichbehandlung innerhalb, westlicher' Länder. Um dieses von der Mehrheit der anderen Interviews abweichende Bild bestätigt zu bekommen, fragte ich genau an dieser Stelle noch mal nach.

I: Mhm. Und manche sagen ja immer: „Das ist ja in manchen Ländern ganz schlimm, aber in Deutschland ist schon alles gut in Bezug auf die Gleichstellung von Mann und Frau." Da würdest du sagen, dass das nicht so ist? 
S: Ja. Also ich glaube, es ist nirgendwo wirklich gerecht in dem Sinne.

Ihre Antwort, dass es ,nirgendwo wirklich gerecht in diesem Sinne“ sei, unterstützt das von der Mehrheit der Interviews abweichende Bild, in dem die Geschlechterungerechtigkeit nicht an die Frage von ,Westen' oder ,Nicht-Westen “ gekoppelt ist. Auf die Frage, ob ihr noch ein anderes Beispiel für die NichtEinhaltung der Menschenrechte einfalle, bringt sie einen weiteren interessanten Punkt.

I: Ja. Und fällt dir noch etwas anderes ein, wo Menschenrechte nicht eingehalten werden?

S: Mhm. Also, es gibt dann halt immer so Einzelfälle. Es gibt auch so was mit Geld wiederum. Also dass man halt, wenn man wenig Geld hat, meistens so mehr Probleme kriegt oder so. Es ist halt, wenn man im Wohlstand lebt, hat man es generell - in westlichen Ländern vor allem - denke ich viel, viel leichter als manche Menschen, die halt weniger Geld haben. (Lara, Gym18)

Lara verknüpft in ihrem Argument die Frage der Nicht-Einhaltung der Menschenrechte mit der Frage von Reichtumsverteilung und Armut, insbesondere in der globalen Dimension. Möglicherweise meint sie hier, dass Menschen in , westlichen Ländern“ durch ein Leben mit mehr „Wohlstand“ einen besseren Schutz durch Menschenrechte genießen. Plausibler erscheint mir aber die Interpretation, dass sie hier die Menschenrechte mit der Ungerechtigkeit von der Reichtumsverteilung selbst in Verbindung setzt. Dieser Interpretation zufolge verstößt also die globale Ungleichheit als solche gegen die Menschenrechte, da die einen ,meistens so mehr Probleme kriegen“, während die anderen es ,viel, viel leichter“ hätten. Indem sie soziale Ungleichheit als den Menschenrechten widersprechendes Moment definiert, bricht sie mit einem liberalen Verständnis der Menschenrechte, das den Rahmen kapitalistischer Produktion und Klassenungleichheiten unangetastet bzw. ungenannt lässt, wohingegen danach Symptome dieser dann durch die Menschenrechte abgefedert werden sollen. Die ökonomische Struktur wird aber in einer liberalen Lesart nicht durch die Menschenrechte berührt oder gar infrage gestellt. Laras Argument hingegen macht genau das.

\subsubsection{Ordnung und Staatlichkeit I: Korruption}

In den folgenden zwei Abschnitten ,Ordnung und Staatlichkeit" werde ich der Frage nachgehen, auf welche Weisen die Unterscheidung zwischen Globalem 
Norden und Globalem Süden durch die Differenzmarker Korruption und Ordnung bzw. fehlender Staatlichkeit konstruiert wird und dabei als Erklärungsweisen globaler sozialer Ungleichheit fungiert. Zugrunde liegen hier also alle Aussagen, die sich mit der Erklärung globaler sozialer Ungleichheit und Gründen für die Differenz zwischen Globalem Norden und Globalem Süden beschäftigen. Ein zentrales Argumentationsfeld stellt dabei die Auseinandersetzung mit Staatlichkeit und Korruption dar, das die Grundlage für diesen Analysebereich legt. Dabei sind die Argumente rund um Korruption und Ordnung in längere Argumentationen verwoben, die hier teilweise auch dargestellt werden, um den Eindruck zu vermeiden, dass die Lernenden eindimensional und widerspruchsfrei argumentieren würden.

Pascal (Gym12) hatte mehrfach im Interview von den ,westlichen Ländern“ gesprochen, sowohl im Kontext von globaler Ungleichheit als auch im Kontext von Entwicklungshilfe und Demokratie. Zu einem späten Zeitpunkt des Interviews frage ich dann nach, wie er denn das Gegenstück zu den ,westlichen Ländern“ nennen würde.

I: Ja. Und du hast vorhin von den westlichen Ländern gesprochen. Ähm, also es gibt einmal die westlichen Länder. Und wie würdest du die anderen nennen?

S: Ja, also die westlichen Länder sind für mich Europa und Nordamerika, halt USA. Die Länder, denen es sehr gut geht. Wo es auch der Bevölkerung im Durchschnitt sehr gut geht. Und die anderen .../ Ja, man kann die jetzt ja nicht die östlichen Länder nennen. Aber das sind halt die teilweise noch Dritte-Welt-Länder einfach. Wo das halt noch nicht so angekommen ist, dass es der Bevölkerung so gut geht wie hier. Also wir können das schon schätzen, so wie es hier bei uns ist.

I: Mhm. Und, ähm .../

S: Oder Entwicklungsländer viel besser. (Pascal, Gym12)

Als Unterscheidungsmerkmal von ,westlichen' und ,nicht-westlichen' Ländern führt er den Lebensstandard an. Man könne die ,nicht-westlichen' Länder allerdings nicht die „östlichen Länder“ nennen. Auf der Suche nach einem passenderen Begriff kommt er auf den scheinbar passenden Begriff. Es seien ,teilweise noch Dritte-Welt-Länder einfach“. Hier scheint der Ausdruck auch gleich die Erklärung mitzuliefern: Dort sei ,das halt noch nicht so angekommen, dass es der Bevölkerung so gut gehe wie hier". Durch die reine Nennung des Begriffs „Dritte-Welt-Länder“ scheint sich ihm die plausible Erklärung einer verspäteten Entwicklung zu erschließen, indem er offenbar implizit auf eine koloniale Entwicklungsteleologie Bezug nimmt. Nach einem kurzen Stottern meinerseits 
korrigiert er sich und erklärt, dass er den Begriff „Entwicklungsländer“ für besser halte. Dieser scheint das gleiche für ihn zu transportieren. Erscheint er ihm weniger pejorativ und abwertend, einfach zeitgemäßer und modischer oder weniger starr auf die Stufenfolge des Entwicklungsparadigmas bezogen? Warum er den Begriff bevorzugt, führt er leider nicht aus. In der Folge charakterisiert er verschiedene Unterschiede zwischen „Entwicklungsländern“ und ,entwickelten“ Ländern.

I: Mhm. Und was heißt .../ Also, wie könnten die sich jetzt entwickeln?

S: Ja, ähm, ich glaube einen ganz großen Teil muss die Regierung einfach dazu beitragen. Dass die anfangen einen Teil des Reichtums des Staates auch auf die Bevölkerung zu übertragen. Dass die, keine Ahnung, dass die Städte sauber gehalten werden. Dass der Lebensstandard einfach von dem Umfeld her, von der Bevölkerung durch den Staat erhöht wird. Dass sie auf Wünsche der Bevölkerung bestimmte Sachen einkaufen oder importieren, die sie dann ihrem Volk zur Verfügung stellen können, damit die einfach auf dieselbe Palette von Produkten zugreifen können, die wir hier auch haben. Weil das ist, glaube ich, ein ganz großer Unterschied. Und was halt natürlich ganz, ganz wichtig ist, um den Lebensstandard zu erhöhen ist, dass einfach bessere Löhne gezahlt werden. Dass die dahin kommen, dass Dienstleistungen hier in Deutschland genauso viel Wert ist, wie dieselbe Dienstleistung in China.

I: Mhm. Ja.

S: Und in manchen Ländern ganz wichtig das Bildungssystem. Weil wenn man kein Bildungssystem hat, dann ist es auch ein großer Nachteil für die Wirtschaft, glaube ich einfach. Weil, die können keine guten Wissenschaftler ausbilden. Und Wissenschaftler sind ja auch immer ganz gut für das Land an sich. Oder können ja auch immer viel dazu helfen, dass die Wirtschaft halt boomt. (Pascal, Gym12)

In der Verantwortung sieht Pascal hauptsächlich die jeweilige Regierung, die den „Reichtum des Staates“ auch auf die Bevölkerung übertragen sollte. Damit meint er aber offenbar keine nicht-marktwirtschaftliche Ökonomie im Sinne von einer Reichtumsumverteilung, sondern, dass der „Lebensstandard“ durch die Veränderung des „Umfeldes“ erhöht wird, wie beispielsweise durch das Sauberhalten von Städten. Er wünscht sich also, dass der Staat in den ,Entwicklungsländern“ seinen infrastrukturellen Aufgaben zur gesamtgesellschaftlichen Organisation nachkommt und trifft damit die Aussage, dass er es bisher, im Gegensatz zu ,entwickelten Ländern', nicht tue. Wichtig findet er außerdem, dass die Regierung durch Einkauf oder Import dafür sorgt, dass das „,Volk“ auf dieselbe „Palette von Produkten zugreifen“ könne, ,die wir hier auch“ hätten. Dies sei ein ,ganz großer Unterschied“. Für ihn scheint also das Problem an dieser Stelle darin zu bestehen, dass die Produktauswahl nicht ausreichend bzw. nicht wie bei ,uns ' sei. ,Unsere“ 
Produktauswahl scheint also derjenigen in den ,nicht-westlichen' Ländern überlegen zu sein bzw. Grund oder Ausdruck von einer für Pascal anstrebenswerten ,Entwicklung'. Der kausale Zusammenhang wird hier zwar nicht klar, aber der Zusammenhang ist trotzdem bemerkenswert und wird von einigen Schüler_innen in den Interviews vorgebracht. Das auf dem Markt verfügbare Angebot an Produkten wird also einerseits an das Handeln des Staates geknüpft und andererseits als Ausdruck oder gar Grund mangelnder ,Entwicklung' gesehen.

Daran anschließend spricht er die unterschiedlichen Lohnniveaus an. Er hält es für "ganz, ganz wichtig“" zur Erhöhung des Lebensstandards in ,nicht-westlichen“ Ländern, dass ,einfach bessere Löhne gezahlt“ werden. Pascal meint, „die“ müssten „dahin kommen, dass Dienstleistungen hier in Deutschland genauso viel Wert ist, wie dieselbe Dienstleistung in China“. Er stellt damit fest, dass dieselbe Dienstleistung aufgrund ihrer geopolitischen Verortung unterschiedlich viel „Wert“ sein kann. Er wünscht sich offenbar, zur Verminderung der globalen sozialen Ungleichheit, eine Angleichung des „Wertes“ dieser Dienstleistungen. Es bleibt aber unklar, warum die Dienstleistung in ,nicht-westlichen " und ,westlichen ' Ländern für Pascal unterschiedlich viel Wert ist. Pascal bezieht sich an anderen Stellen auf marktwirtschaftliche Prinzipien. Nach diesen erscheint die Ungleichwertigkeit des gleichen Produkts zunächst paradox. Eine mögliche Erklärung für diese Ambivalenz könnte darin bestehen, dass Pascal Marktwirtschaften eher als nationale denn als globale Räume fasst. Eine andere Erklärung wäre, dass er hier auf ein Erklärungsmuster referiert, das eigentlich nicht die Ungleichwertigkeit einer Dienstleistung, sondern vielmehr der Ware Arbeitskraft meint. Dies ist an dieser Stelle nicht weiter aufklärbar. Klar wird jedoch, dass Pascal eine solche Entwicklung nicht global, sondern vielmehr als endogenen Prozess in den jeweiligen Ländern sieht. Schließlich müssten laut Pascal „,die dahin kommen“, dass der Wert sich , unserem' angleiche. Damit klammert er all die Themen aus, die mit seiner Beobachtung der Ungleichwertigkeit von Dienstleistungen potenziell verbunden werden könnten, wie beispielsweise die Hierarchien innerhalb globaler Wertschöpfungsketten. Dem Wunsch nach mehr Gleichheit, dass ,die dahin kommen“ sollten, liegt offenbar auch die Idee zugrunde, dass "die“ (1) noch nicht so weit sind und (2) so werden sollten wie, wir". Dies sind zentrale Charakteristika des Entwicklungsparadigmas.

Im Anschluss führt Pascal aus, wie er sich eine solche Entwicklung vorstellt. Er hält das Bildungssystem für ,ganz wichtig“. Ohne Bildung gäbe es keine Wissenschaftler_innen. Wissenschaftler_innen könnten, Pascal zufolge, ,ja auch immer viel dazu helfen, dass die Wirtschaft halt boomt“. Entwicklungspolitisch stellt sein Argument eine klare Kausalkette dar, die durch die Förderung von 
Bildung und den damit entstehenden Wissenschaftler_innen einen wirtschaftlichen Aufschwung zur Folge hätte. Aus einer dekolonialen Perspektive kann dies aber gleichzeitig auch als eine Beschreibung der, eigenen“ Überlegenheit gedeutet werden; der ,eigene " soziale ,Vorsprung' ist darauf begründet, dass es ,hier" ein gutes Bildungssystem, Wissenschaftler und dadurch einen Wirtschaftsboom gäbe. Eine solche Interpretation erscheint vielleicht als eine Unterstellung einer nicht vorhandenen Absicht, aber es geht hier eben nicht darum, Pascals Intentionen zu erforschen, sondern seine Vorstellungen. Dieser Komplex der Konstruktion der ,eigenen“ Überlegenheit und der impliziten Rechtfertigung globaler sozialer Ungleichheiten steht dabei bei Pascal - und bei fast allen Schüler_innen - in einem Gegensatz zu ihren formulierten normativen Vorstellungen einer globalen sozialen Gleichberechtigung.

Anschließend hake ich nach, um den von Pascal vermuteten Gründen für diese Ungleichheit nachzuspüren.

I: Mhm. Ja. Und warum machen die das bisher nicht? Also du sagst ja, die Regierungen SOLLTEN das machen. Aber bisher machen die das ja noch nicht. Und gibt es einen Grund dafür oder sind die einfach noch nicht so weit in der Entwicklung?

S: Ich glaube, die sind sich dessen bewusst, dass das auf jeden Fall eine gute Sache für die Bevölkerung wäre. Aber ich glaube, in den Entwicklungsländern will die Regierung sich selber reich machen. Und die Bevölkerung ist ihnen quasi egal. Das ist denen relativ schnuppe, was mit der Bevölkerung passiert, solange die selber reich sind und selber genug Geld haben, um sich alles Mögliche leisten zu können.

I: Mhm.

S: Weil es gibt bestimmt viele Produkte auch in Entwicklungsländern, die wir hier in Deutschland auch haben. Aber wahrscheinlich nur zu einem so hohen Preis, dass der normale Bürger sich das halt einfach nicht leisten kann. Was halt auch an dem geringen Einkommen liegt. Und, ja, einfach weil die Bevölkerung .../ Ähm, nicht die Bevölkerung. Weil einfach die Regierung von dem Geld nichts abgibt und sich selber eigentlich nur reich machen will. Und ein bisschen egoistisch denkt und nicht daran denkt mal, ein bisschen in die Bevölkerung zu investieren. (Pascal, Gym12)

Pascal glaubt - und hier kommen wir zum zentralen Punkt für diesen Abschnitt -, dass es den Regierungen der ,Entwicklungsländer ' bewusst ist, dass die angesprochenen Punkte für die Bevölkerung eine ,gute Sache“ wären. Er vermutet jedoch, dass die Regierung in ,Entwicklungsländern“ ,sich selber reich“ machen wolle und ihnen die „Bevölkerung [...] quasi egal“" sei. Die Regierung wolle von dem Geld nichts abgeben. Sie denke ,egoistisch“ und denke nicht daran, „mal ein bisschen in die Bevölkerung zu investieren“. Aus einer dekolonialen Perspektive 
lassen sich diese Ideen auf mehrere Weisen interpretieren. Zum einen ist festzuhalten, dass Pascal generell den ,Entwicklungsländern' eine korrupte Regierung zuschreibt und Korruption als ein Charakteristikum dieser ansieht. Korruption stellt somit einen - und aus meiner Sicht in Pascals Argumentationsmuster den zentralen - Differenzmarker zwischen, entwickelten' Ländern und ,Entwicklungsländern` dar. Unklar bleibt, welche Ursachen er hierfür sieht. Gerade die starke Bezugnahme darauf, dass die Regierungen der ,Entwicklungsländer' nichts für die Bevölkerung tun wollten, erinnert an die Theorie der Rentiersökonomie.

Das Konzept der Rentiersökonomie stammt aus der internationalistischen Bewegung und der marxistisch Theoriebildung. Kurz zusammengefasst besagt das Konzept, dass die Eliten vieler Länder des Globalen Südens aus strukturellen Gründen innerhalb einer neokolonialen Arbeitsteilung kein Interesse an einer qualitativen Verbesserung der Lebensumstände und der Perspektiven der Bevölkerung sowie des Binnenmarktes haben. Als Grund wird angeführt, dass die Macht dieser Eliten in erster Linie auf den Renten basiere, also auf der Abschöpfung von Mehrwert durch Land- und Ressourcenbesitz oder Entwicklungshilfegelder und nicht durch einen Binnenmarkt oder Produktion, die in neokolonialen Wertschöpfungsketten oft in anderen Regionen des Globalen Südens oder im Globalen Norden stattfindet (Schmid 2011). Pascal bringt Aspekte vor, die an diese Theorie erinnern. Möglicherweise hätten weitere Nachfragen ergeben, dass seine Vorstellungen für das Konzept anschlussfähig sind und dem Weiterdenken seiner Ideen ein kritisches Werkzeug an die Hand geben könnte. Allerdings scheint gegenwärtig ein anderes Konzept mindestens ebenso präsent. Die Art und Weise seiner Formulierungen der Beobachtungen von der Korruption als Charakteristikum von ,Entwicklungsländern' lässt vielmehr vermuten, dass er den ,Entwicklungsländern' bzw. ihren Eliten eine Mentalität der Korruption zuschreibt. Eine Erklärung dazu gibt er leider nicht. Seine Beobachtungen basieren zu großen Teilen auf der Prämisse dieser Mentalität der Korruption, woraus sich seine anderen Argumente ergeben bzw. begründen.

Vorstellungen, die auf der Annahme einer Mentalität der Korruption in ,Entwicklungsländern' basieren, finden sich in zahlreichen Interviews. Mal steht dieser Aspekt im Zentrum, mal wird er nur am Rande erwähnt; mal erinnert er mehr an die Konzepte der Rentiersökonomie, mal eher an essenzialisierende Zuschreibungen einer Mentalität der Korruption. ,Korruption“ als Differenzmarker zwischen ,entwickelten ' Ländern und ,Entwicklungsländern' spielt jedoch in jedem Fall eine wichtige Rolle in den Denkweisen der Schüler_innen.

Im Anschluss fragte ich Pascal, ob er noch andere Aspekte sehe, die, westliche' Länder ausmache. 
I: Mhm. Ja. Und du hast ja jetzt gesagt, die westlichen Länder, die zeichnen sich vor allem dadurch aus, dass da der Lebensstandard höher ist. Gibt es noch andere Sachen, die die westlichen Länder ausmachen?

S: Ja, also in den westlichen Ländern gibt es ja auch ein geordnetes politisches System. Das kommt, glaube ich, noch erschwerend dazu. Es gibt in jedem westlichen Land, meines Wissens nach, eigentlich eine relativ solide Bildungspolitik. Und die westlichen Länder arbeiten auch viel mit der Bevölkerung, also weil es halt ein demokratisches Land ist. Wenn man jetzt guckt, in China ist immer noch Diktatur. Und in Nordkorea, da hat die Bevölkerung auch nicht wirklich viel zu bestimmen. Und das ist hier halt anders, weil die Bevölkerung halt ihre Wünsche ausdrücken kann. Und dann auch noch von der Regierung angehört wird. Also einfach auch, weil die Menschenrechte da in Kraft treten. Oder die Redefreiheit. Oder, weil auch die Presse da viel mehr aufdecken kann, weil da objektive Nachrichten möglich sind. Und die Leute über das Geschehen im Land und außerhalb des Landes viel genauer informiert sind. Weil, ich könnte mir auch vorstellen .../ Oder ich weiß, dass in Nordkorea die Leute nicht wissen, wie wir hier leben.

I: Mhm.

S: Die haben keine Ahnung, dass es uns so gut geht. Die denken, denen geht es gut. Aber denen geht es ja eigentlich nicht gut. So was wir wissen.

I: Mhm.

S: Und ich glaube das ist auch ein ganz großer Punkt. Dass wir einfach wissen, wie es in den anderen Ländern abgeht, sag' ich jetzt mal. (Pascal, Gym12)

Die von ihm genannten Aspekte als Differenzmarker von , westlichen " und ,nichtwestlichen ' Ländern - ,geordnetes politisches System“, ,,solide Bildungspolitik“, „,demokratisches Land“, „Menschenrechte“ - diskutiere ich in anderen Abschnitte der Inhaltsanalyse ausführlich. An dieser Stelle möchte ich nur kurz auf zwei interessante Aspekte von Pascals Aussagen verweisen, die beide in zahlreichen Interviews auftauchen. Als Beispiele, um seine Annahme der demokratischen Verfasstheit als Differenzmarker zu veranschaulichen, wählt Pascal China und Nordkorea. Hier zeigt sich einmal mehr, dass Beispiele keineswegs nur als Veranschaulichung einer Idee fungieren, sondern wie sie vielmehr Ideen überdeterminieren können. Auch aus diesen Beispielen heraus entwickelt Pascal eine Art epistemische Differenz, wie ich es aus einer dekolonialen Perspektive interpretativ zu fassen versuche. Aus der fehlenden Pressearbeit leitet er ab, dass im ,Westen“ „objektive Nachrichten“ möglich seien. In ,westlichen“ Ländern seien „die Leute über das Geschehen im Land und außerhalb des Landes viel genauer informiert“. Er schließt ein ,weil“" an und kommt dann über Umwege zu der Aussage, dass er wisse, ,dass in Nordkorea die Leute nicht wissen, wie wir hier leben“. „Die“ hätten ,keine Ahnung, dass es uns so gut geht“. „Die“ - und hier 
bleibt unklar, ob er gerade über Nordkoreaner_innen oder allgemein die Menschen in ,nicht-westlichen“ Ländern spricht - würden ,denken, denen geht es gut“. Das was die Menschen über ihre Situation zu wissen meinen, stimme aber nach Pascal nicht, schließlich ginge es ihnen ,,ja eigentlich nicht gut“. Daran schließt er an: „So was wir wissen“. Das sei einfach ein „ganz großer Punkt“, dass ,wir einfach" wüssten, ,wie es in den anderen Ländern abgeht“. Mit einer dekolonialen Perspektive erscheinen diese Vorstellungen von Pascal als eine Konstruktion einer epistemischen Hierarchie. Die Differenz von Westen und Nicht-Westen wird hier zur Differenz der Wissenden und Unwissenden. Das ist ein traditionsreiches koloniales Theorem, dass , wir' wissen und ,die" nicht - sogar in Bezug auf das ,richtige“ Verständnis der Lebensverhältnisse in den Ländern der kolonialen Anderen. Dabei ist dieses Theorem bei Pascal in seinen Wunsch nach Gleichheit oder Gleichberechtigung des Wissens eingebunden. Er empfindet es offensichtlich als ungerecht, dass die einen - , wir ' - über Informationen verfügen, die anderen - , denen “ - nicht zugänglich sind. Er wünscht den Nordkoreaner_innen - stellvertretend für die ,nicht-westlichen' Länder -, dass sie ihre eigene Situation so gut sehen könnten, wie er, damit sie ihre Lebensverhältnisse verbessern. Die im gleichen Zuge mit diesem Wunsch nach Gleichberechtigung konstruierten kolonialen epistemischen Hierarchie erscheint aus einer dekolonialen Perspektive problematisch. Aus einer didaktischen Perspektive kann genau diese Widersprüchlichkeit aber ein Anknüpfungspunkt sein, um bestehende Denkmuster zu reflektieren.

\subsubsection{Ordnung und Staatlichkeit II: Ordnung als Voraussetzung für Entwicklung}

Im Nachdenken über globale Ungleichheit ist einer der zentralsten Differenzmarker die Frage der Ordnung. Ordnung wird hier im Sinne eines Systems geregelter gesellschaftlicher Abläufe und von Staatlichkeit selbst gefasst. Das Gegenstück dazu stellt dementsprechend Unordnung bzw. das Fehlen von Ordnung dar, wozu dann eben Chaos, verbreitete Willkür in gesellschaftlichen Abläufen, mangelhafte Infrastruktur und das Fehlen von Staatlichkeit, beispielsweise im Sinne von failed states, gehört. In diesem Abschnitt liegen also alle Aussagen zugrunde, die (1) sich mit Beobachtungen von und Gründen für die Differenz zwischen dem Globalen Norden und dem Globalen Süden beschäftigen und (2) die Dimension der Ordnung im oben genannten Sinne ansprechen. Das (Un-)Ordnungstopos ist als Erklärungsmuster für globale Ungleichheit das am weitesten verbreitete. Teilweise wird es einfach genannt, teilweise stellt das Topos den Zusammenhang von detailreichen Ausführungen zu den Lebensverhältnissen im Globalen 
Süden im Gegensatz zum Globalen Norden dar, meist ist es jedoch in verschiedenen anderen Argumentationen und Bildern eingebettet und mit anderen Vorstellungen verwoben. Im Folgenden werde ich zwei Beispiele von Jannik (Gym01) und Mark (Gym09) vorstellen, die alle wesentlichen Charakteristika der weit verbreiteten Vorstellungen zu (Un-)Ordnung beinhalten, diese jedoch auf spezifische Weise entwickeln und mit anderen Argumentationsmustern verknüpfen. Die zwei Schüler kontextualisieren das (Un-)Ordnungsargument auf jeweils sehr unterschiedliche Weise. Das Spezifische in Bezug auf das Ordnungstopos bei Jannik besteht darin, dass er es mit zahlreichen anderen sehr verbreiteten Mustern verwebt und alles in einer Mentalität der Ordnung bzw. Unordnung auflöst. Das Spezifische bei Mark ist seine Verknüpfung des Ordnungstopos mit dem Kolonialismus und zur Weltgeschichte. Bei der Auswahl dieses Beispiels hat auch mein dekoloniales Forschungsinteresse eine Rolle gespielt. Als Ordnungsargument ist er eher als Spezialfall anzusehen, der aber als solcher aus meiner Sicht in Bezug auf mein Erkenntnisinteresse sehr interessant erscheint. Beide ausgewählten Beispiele zeichnen sich dadurch aus, dass sie das Ordnungstopos in eine breite Argumentation einbauen, während andere es häufig nur in kurzen Abschnitten verwenden, aus deren Analyse wenig über das Verständnis der Ordnungsdimension selbst hervorgeht als vielmehr darüber, dass sie bei der Mehrzahl der Schüler_innen und in anderen Argumentationen eine Rolle spielt. Beide Beispiele sind insofern nicht als Idealtypen zu verstehen, sondern in ihrer Spezifizität zu begreifen - wobei die verbreiteten Charakteristika des Ordnungstopos an ihrem Beispiel herausgearbeitet werden. Um den Facettenreichtum der (Un-)Ordnungsargumentation aufzuzeigen, werde ich beide Beispiele ausführlich vorstellen.

\section{Jannik: Der,Stock im Arsch'}

Jannik (Gym01) beschreibt lange die unterschiedlichen sozioökonomischen Situationen im Globalen Norden am Beispiel von Deutschland und dem Globalen Süden am Beispiel Südafrikas. Im Zuge dessen - und nach meiner Nachfrage nach den Ursachen der Unterschiede - kommt er dann zur Frage der Staatlichkeit.

I: Ähm, woran liegt das? Also warum gibt es ein paar Länder, wo das so und ein paar Länder wo es, sozusagen, wo dann die Wassermelone acht Cent kostet statt einen Euro, und ich weiß nicht mehr wie viel?

S: Mhm. (...) Ich denke mal, hier liegt das daran, in Deutschland, am Import/Export, dass die Preise so geworden sind. Weil, man kann jetzt nicht sich zum Beispiel Wassermelonen aus ... ich weiß nicht wo die herkommen ... mit dem Transportschiff hier rüber schiffen, was ja auch einige, ich weiß nicht wie viel, zehn- oder hunderttausend 
Euro kostet, um so ein Schiff dann mit so einer Ladung nach Deutschland zu bringen. Dementsprechend muss das dann .../ Also durch diesen ganzen Transport wird das halt teurer.

I: Mhm.

S: Ähm, hier muss man aber auch sagen, wir haben hier genug Wasser. Wir haben hier genug. Wir haben genug Materialien um Strom zu erzeugen. (...) Und die gibt es in den Ländern nicht. Die haben dann zum Beispiel große Wasserprobleme und so weiter und so fort. Und müssen sich vielleicht auch erstmal darauf konzentrieren und beschränken. Der Staat gibt auch viel, denke ich mal, aus, um sichere Bedingungen zu schaffen für die Länder. Und nicht, inwiefern man jetzt den Staat komplett ausbauen könnte, dass er so aussieht wie hier in Deutschland. Weil wir ja wenig Probleme mit Lebenswichtigem oder Lebensgrundlagen haben. (...) Es könnte damit zusammenhängen. Anderseits sind die Regierungen immer ein ganz großes Thema. Auch zum Thema Korruption und so weiter und so fort. Weil, ich denke mal hier ist ... okay, gibt es ein paar Steuerhinterzieher, die auch eine ganze Menge machen. Aber der Staat hat trotzdem noch genug Geld, um sich so was leisten zu können, wie Deutschland halt jetzt eben gerade ist. Andere Staaten haben halt nicht so die große Möglichkeit, weil die .../ Deutschland ist auch Exportweltmeister vor kurzem geworden, oder? 2008 oder so?

I: Ja. Wird es immer .../ Heißt es immer, dass die .../

S: Ja, das heißt, sie müssten ja auch ordentlich am Export verdient haben. Und andere Länder haben die Möglichkeiten halt nicht. Und da ist es dann so, dass die nicht so viel verdienen am Export und vielleicht auch mehr am Import ausgeben müssen. Und, $\mathrm{mhm}$, das ist auch eine schwierige Frage. Aber das mit den Wassermelonen acht Cent, das ist aber, weil das halt da direkt produziert wird. [...]

S: Aber wie das jetzt mit den .../ Warum die so arm sind [überlegt leise] .../ Mhm. Das könnte ich so jetzt nicht beantworten eigentlich. Also nicht sicher, sagen wir es so. (Jannik, Gym01)

In der Auseinandersetzung um die ungleichen Preise für die gleichen Produkte am Beispiel der Wassermelone und die damit verbundenen ungleichen sozioökonomischen Bedingungen formuliert Jannik in diesem Auszug vier Argumente über die Ursachen dieser Ungleichheit. (1) Während ,wir“ ,hier“ ,genug Wasser“ und „Materialien um Strom zu erzeugen“ hätten, gäbe es die ,,in den Ländern“ nicht. ,Dort" gäbe es dann ,,zum Beispiel große Wasserprobleme und so weiter und so fort“. Auf diese Probleme müsse sich der Staat „,konzentrieren und beschränken“. Diese ressourcenbezogene Argumentation von Jannik sieht als Ursache der ungleichen Preise und der ungleichen Staatlichkeit die unterschiedlichen Voraussetzungen der natürlichen Ressourcen in den jeweiligen Ländern. (2) Ein weiteres genanntes Argument 
ist das sicherheitspolitische. So müsse der Staat viel ausgeben, ,um sichere Bedingungen zu schaffen für die Länder". Da alle Mittel für die Sicherheit ausgegeben werden müssten, bleiben nicht genügend, um ,jetzt den Staat komplett“" auszubauen, „dass er so aussieht wie hier in Deutschland“. Die Prämisse ist hier, dass in den Ländern des Globalen Südens mehr Unsicherheit als im Globalen Norden herrsche, die dann vom Staat eingedämmt werden müsse. Welche Art von Unsicherheit Jannik meint, bleibt an dieser Stelle unklar. Wie weiter unten beschrieben, beschäftigt ihn das Thema der Sicherheit in Bezug auf Kriminalität; möglicherweise meint er also diese Art von Unsicherheit, also ein großes Ausmaß von Kriminalität im Globalen Süden. Mit Bezug auf beide Argumentationen - also das klimatheoretische und das sicherheitspolitische - kommt er zu der Aussage, dass die Preise und Lebensbedingungen im Globalen Süden so viel schlechter seien, ,weil wir ja wenig Probleme mit Lebenswichtigem oder Lebensgrundlagen haben“. Das Ziel stellt für Jannik dar, dass die Länder des Globalen Südens einen Staat entwickeln würden, der ,so aussieht wie hier in Deutschland“. Das implizite Ziel ist für Jannik dabei, dass die Preise nicht mehr so unterschiedlich sind und es den Menschen im Globalen Süden besser geht.

Er nennt im zitierten Abschnitt zwei weitere Argumente zur Begründung der globalen Ungleichheit. (3) So seien ,,andererseits [...] die Regierungen immer ein ganz großes Thema“. Jannik zielt hier nicht mehr auf die ungleichen Ausgangsbedingungen für die Entwicklung eines Staates, sondern auf den Charakter der Regierungen. Er sieht hier die Korruption als zentrales Problem an. Anders als zahlreiche andere Schüler_innen sieht er aber keine Dichotomie zwischen den korrupten Staaten des Globalen Südens und den nicht-korrupten des Globalen Nordens. Er fängt mit einem dichotomisierenden Argument an und schränkt es sofort wieder ein: „Weil ich denke mal, hier ist ... okay, gibt es ein paar Steuerhinterzieher, die auch eine ganze Menge machen." Die Frage der Korruptheit der Staaten ist also für Jannik keine dichotomische Frage, sondern eher ein Kontinuum. Die Korruption habe jedoch, so Janniks Argument weiter, weniger negative Auswirkungen auf Deutschland als auf Länder des Globalen Südens, da Deutschland ökonomisch erfolgreicher sei. (4) Schließlich habe der Staat in Deutschland, im Gegensatz zu anderen Staaten, ,trotzdem noch genug Geld, um sich so was leisten zu können, wie Deutschland halt jetzt eben gerade ist“. Den Grund dafür sieht er darin, dass Deutschland ,ordentlich am Export verdient“ habe und „Exportweltmeister“"sei. Die über den Export erzielten Gewinne würden es Deutschland ermöglichen, einen starken Staat aufzubauen. Andere Staaten könnten ,nicht so viel verdienen am Export“ und müssten ,,auch mehr am Import“" ausgeben. Jannik beschreibt hier ein negatives Handelsdefizit, welches er als weiteren Grund für die fehlende Infrastruktur und ökonomische Entwicklung der Länder des Globalen Südens ausmacht. 
Bemerkenswert erscheint mir seine tastende Haltung, die beispielsweise im letzten Abschnitt offenbar wurde. Er nimmt sich die Zeit nachzudenken und reformuliert die Frage für sich. Er benennt oft im Verlauf des Interviews, dass er Dinge nicht genau wisse. Oft bekundet er sein Interesse an der Fragestellung bezüglich der globalen Ungleichheit. Diese Haltung schlägt sich auch in der Art und Weise seiner Argumentation wieder, die eher als Suchbewegung und weniger als die Verkündung fest stehender Überzeugung zu verstehen ist. Sein ernsthaftes Interesse an der Beantwortung der Gründe für die globale Ungleichheit scheint dabei auch von einem Gerechtigkeitsgefühl und der Empathie mit Armen im Globalen Süden getrieben zu sein. Für Jannik scheint sein Aufenthalt in Südafrika - den er im übernächsten Zitat benennt - prägend gewesen zu sein und ein Schlüsselmoment, der die Relevanz dieses Themas für ihn stark erhöht hat.

Im Anschluss frage ich nach, wie es dazu komme, dass es in einigen Ländern Sicherheit gäbe und in anderen nicht.

I: Mhm. Und, ähm, wie hängt das .../ Also wie kommt das dazu, dass es einige Länder gibt, wo es sozusagen Sicherheit gibt und andere Länder, wo es keine Sicherheit gibt?

S: (...) Hier haben wir sehr viel das Glück, dass das eigentlich perfekte .../ Also, man sieht das ja eigentlich auch an den klimatischen Zonen zum Teil schon, welche Länder ziemlich wohlhabend sind und welche nicht. Europa liegt halt sehr groß an den, ja, halt zwischen .../Gemäßigtes Klima. Das heißt, wir haben hier sehr wenig Lebensprobleme, was zum Beispiel Wasser, Nahrung oder .../ Die Lebensstandards sind bei uns da. Die ganzen armen Regionen sind eigentlich auch ziemlich, wenn man sich das anguckt: Äquatornähe und, ähm, bei den Wendekreisen eigentlich auch. Ich weiß nicht, ob .../ Also damit, denke ich mal, dass das auch zusammenhängen könnte. Ähm, ja. Weil die sich halt eher auf andere Dinge beschränken müssen als wir hier in Deutschland. Oder in Europa. (Jannik, Gym01)

Jannik bringt hier ein fünftes Argument für die Ursachen der globalen Ungleichheit vor. (5) Sein klimatheoretisches Argument knüpft dabei an das ressourcenbezogene Argument an. Aufgrund des ,hier“ herrschenden ,gemäßigte[n] Klima[s]“ hätten ,wir“ in Europa ,sehr wenig Lebensprobleme, was zum Beispiel Wasser, Nahrung“. Dies führe dazu, dass , die sich halt eher auf andere Dinge beschränken müssen als wir hier in Deutschland. Oder in Europa." Dieses kausale Argument fußt dabei auf einer Beobachtung. Er beobachtet, dass man ,ja eigentlich auch an den klimatischen Zonen zum Teil schon [sehe], welche Länder ziemlich wohlhabend sind und welche nicht“. Die „ganzen armen Regionen“ seien „,in Äquatornähe“ und „,bei den Wendekreisen“. ,Wir“ hätten hingegen „sehr viel Glück“, da hier das „eigentlich perfekte [Klima]" sei. 
Im Anschluss fragte ich danach, auf was für Dinge sich die Länder des Globalen Südens denn beschränken müssten.

I: Auf was für Dinge? (...) Sorry, wenn ich so nachbohre.

S: Ja, ja, das ist ja .../ (........) [lacht].

I: Also wirklich total schwierige Fragen. Wenn du da was nicht weißt, ist das, ähm, gar kein Problem.

S: Aber es ist halt trotzdem cool, darüber nachzudenken. Eigentlich. Weil man sonst nicht so darüber nachdenkt, wenn man jetzt so lebt. Also, als ich in Südafrika war, habe ich auch öfter mal gedacht: „Uns geht es hier ziemlich gut.“ Aber, ähm, ja .../ (...) Könnte das vielleicht aber auch zusammenhängen an einer großen Arbeitslosigkeit in den Ländern? Eventuell? Oder halt, ähm, Schwarzarbeit, die in den Ländern dann gemacht wird? Dass da Leute beschäftigt werden von Leuten, die dann halt auch nichts an den Staat dann abgeben. Dass dieser auch kein Geld hat. Weil hier in Deutschland haben wir ja eine relativ geringe Arbeitslosenquote im Vergleich zu ganz anderen Ländern. Ich weiß nicht, wie es so komplett um Europa steht. Aber zu den .../ Aber wenn ich mir in Südafrika die Slums angucke, ich denke nicht, dass da jeder einen Job hat, der dann wirklich legal ist. Ähm, dass das da vielleicht eine große Rolle auch spielt. Dass dann die Lebensstandards da auch ganz andere sind.

I: Mhm.

S: Weil Schwarzarbeit generell halt günstiger ist. Sowohl für den, der bezahlt, als auch der, der kriegt. Aber dann haben sie immerhin einen Job. Und müssen dann nicht komplett auf dem .../Ja, haben dann halt ein wenig Geld immerhin. Das wäre vielleicht ein Grund, der mir plausibel klingt. Aber weiß ich halt auch nicht. Bin ich mir auch nicht sicher. (Jannik, Gym01)

Hier werden wieder seine tastende Haltung und sein Interesse an der Frage der Gründe für die globale Ungleichheit deutlich. Er findet es trotz der Komplexität „,cool, darüber nachzudenken“. Sonst im Alltag, ,wenn man jetzt so lebt“, denke „man sonst nicht so darüber" nach. Sein Aufenthalt in Südafrika habe ihn zum Nachdenken darüber gebracht, dass es ,uns [...] hier ziemlich gut" gehe. Dies verstehe ich als eine Benennung eigener Privilegien innerhalb der Strukturen globaler Ungleichheit.

Im Anschluss tastet er sich zu einem weiteren Argument vor, das er wiederum fragend und suchend rahmt. (6) Er vermutet, dass die „Schwarzarbeit“ ein Grund für die globale Ungleichheit und die Differenz von „Lebensstandards“ sein könnte. Jannik verwendet den Ausdruck „Schwarzarbeit“. In der postkolonialen Diskussion wird diskutiert, inwiefern dieser Begriff rassistische Vorstellungen impliziert. 
In der Verwendung von Jannik kann ich keine Hinweise auf die latenten Sinnbildungen finden, die dieser Begriff möglicherweise transportiert. Ich verstehe ihn im Rahmen der Analyse deswegen einfach als undokumentierte Arbeit. Jannik zufolge führe die hohe Arbeitslosigkeit dazu, dass die Menschen undokumentierte Arbeitsverhältnisse eingingen. In diesen Arbeitsverhältnissen würde „,nichts an den Staat“ abgegeben werden, sodass dieser „,kein Geld“ habe. Im Vergleich zu „ganz anderen Ländern“ habe Deutschland eine „relativ geringe Arbeitslosenquote“. Mit „ganz anderen Ländern" meint er offensichtlich tendenziell nicht-europäische Länder und konkretisiert dies am Beispiel von Südafrika. Wenn Jannik sich ,in Südafrika die Slums “ angucke, dann denke er nicht, dass da ,jeder einen Job hat, der dann wirklich legal“"sei. „Schwarzarbeit" sei sowohl für Arbeitgeber_in als auch Arbeitnehmer_in „günstiger". Er versucht dabei, sich in die Position eines arbeitenden Menschen in südafrikanischen Slums hineinzuversetzen, die dadurch „ein wenig Geld immerhin“ hätten. Doch auch bei diesem Argument wird seine tastende, fragende Art offenbar, denn ihm klingt der Grund vielleicht ,plausibel“, aber er wisse auch nicht und ist sich nicht sicher. Die ganzen genannten Facetten sind dabei weitere Suchbewegungen auf die Frage, was der Grund für die Ungleichheit der Lebensbedingungen ist. In diesem sechsten Argument der ,Schwarzarbeit“" geht es also darum, dass die nach ihm im Globalen Süden verbreitete Form der undokumentierten Arbeitsverhältnisse am Staat vorbei gingen und so der Staat keine Einnahmen hätte, die dieser wiederum für die Entwicklung einer Ordnungsstruktur bzw. von Staatlichkeit selbst verwenden könnte, die für ihn die Voraussetzung der wirtschaftlichen und sozioökonomischen Verhältnisse darstellen.

Unklar bleibt bei diesem Argument, was wiederum der Grund für das unterschiedliche Ausmaß der Arbeitslosigkeit ist. Dies ist die nächste Frage, die ich im Interview gestellt habe.

I: Ich könnte jetzt nachhaken und .../ Warum ist die Arbeitslosigkeit höher? Jetzt zum Beispiel in .../ Oder, warum ist sozusagen der Anteil von legaler Arbeit hier höher als in südafrikanischen Slums?

S: (....) Mhm.

I: Das sind wirklich richtig komplizierte Fragen. Also falls du da irgendeine Idee hast: raus, raus - es gibt kein richtig oder falsch.

S: Ja, ich überlege. Ähm (.....), also warum das da so ist? Hier in Deutschland sagt man ja immer, dass die ziemlich .../ Die Aufnahme wird ja nicht weitergegeben, nee?

I: Nee, nee, nee .../

S: ... einen Stock im Arsch haben [lacht]. Sagt man so. (...) Weil man halt kontrolliert, was kontrolliert wurde und weil halt alles fest geregelt ist hier, wirklich. Hier gibt 
es ja kaum richtig krasse Grauzonen in den Gesetzen. Und hier ist wirklich alles super, extrem geregelt. Teilweise hat das Nachteile, aber im Großen und Ganzen hat das ziemliche Vorteile. Wie zum Beispiel, dass halt regelt ist, ähm .../ Wir haben ja auch eine sehr gute Exekutive mit der Polizei. Die ist ja jetzt nicht so korrupt und steht komplett hinterm Staat. Wir haben ja eine Gewaltenteilung. Das ist auch nicht in jedem Land eine Voraussetzung. Ähm, dass das da dann halt komplett anders ist. Und wir haben hier auch Arbeitsplatzschaffung. Ich meine, ähm, hier gibt es Putzfrauen. Die gibt es zum Beispiel in vielen anderen Ländern nicht. Nicht in dem Ausmaß, wie es das hier zum Beispiel gibt. Oder Straßenreinigung. Oder so was. Wenn ich mir jetzt .../In Südafrika, eine Straßenreinigung habe ich da nie gesehen, als ich da war. Ähm, und auch in anderen Ländern sind das halt ganz andere Verhältnisse. Wir schaffen hier Arbeitsplätze, die es teilweise in anderen Ländern gar nicht gibt. Die dann aber trotzdem bezahlt werden. Ich denke mal, die haben teilweise auch gar nicht das Geld dafür, das zu bezahlen. Ähm, ja. Wenn wir so die Arbeitsplätze nehmen würden, wie es halt in anderen Ländern geregelt ist, würde es hier wahrscheinlich auch eine viel höhere Arbeitslosenquote geben.

I: Mhm.

S: Ja, das ist halt, weil es vielleicht in anderen Ländern nicht ganz so gut geregelt ist, wie hier in Deutschland. Oder in Europa generell. (Jannik, Gym01)

Zunächst muss ich an dieser Stelle einen forschungsethischen Aspekt einschieben, schließlich sollte es doch Irritation bei der/dem Lesenden verursacht haben, dass er hier nachfragt, ob die Aufnahme nicht weitergegeben wurde. Ich habe ihn - und alle anderen - vor dem Interview gefragt, ob es für ihn in Ordnung wäre, wenn ich das Gespräch aufzeichne. Dazu habe ich gesagt, dass ich die Tonaufnahme nicht weitergeben werde und nur Zitate aus seinem Interview mit verändertem Namen in Texten zur Reflexion von Bildung verwenden würde. Insofern verstehe ich seine Nachfrage als eine Versicherung über diese Vereinbarung. Es ist aber auch für die Analyse interessant, dass er an dieser Stelle die Nachfrage nach der Anonymität stellt. Das Argument von (Un-)Ordnung und (fehlender) Staatlichkeit war implizit schon in den vorangegangenen Argumentationen präsent. Hier findet er im Sinne seiner denkenden Suchbewegung eine Lösung, die für ihn verschiedene Aspekte erklärbar zu machen scheint. Die Differenz der Staatlichkeit im Globalen Süden und Globalen Norden erscheint hier auf einer unterschiedlichen Mentalität zu basieren. Ich gehe dies aber nun Schritt für Schritt am Material durch.

Das, vor dessen Aussprache er Hemmungen hatte - was auch von seinem Lachen und seinem von ihm wegweisenden Ausdruck ,sagt man so" verstärkt wird -, ist, dass man in Deutschland einen „Stock im Arsch“ habe. Er illustriert dies dadurch, dass „man halt kontrolliert, was kontrolliert wurde“, dass „halt alles fest geregelt“ bzw. ,wirklich alles super, extrem geregelt“" sei sowie, dass es ,kaum richtig krasse 
Grauzonen in den Gesetzen“ gäbe. Dies habe teilweise „Nachteile“, aber ,im Großen und Ganzen“ habe das ,ziemliche Vorteile“. So gäbe es eine „sehr gute Exekutive mit der Polizei“, die „,nicht so korrupt“ sei und „komplett hinterm Staat“ stehe. Im Gegensatz zu anderen Ländern gäbe es hier eine „Gewaltenteilung“. Hier wird über eine vorgestellte kulturelle Mentalität der Deutschen - „Stock im Arsch“ die im Gegensatz zum Globalen Süden in Deutschland vermeintlich vorhandene Ordnung und Staatlichkeit erklärt. Unklar bleibt hier, ob Deutschland als Platzhalter für alle Länder des Globalen Nordens dient. Dafür würde sprechen, dass er sich ja gerade Gedanken darüber macht, warum im Globalen Süden mehr Armut, schlechtere sozioökonomische Bedingungen und beispielsweise höhere Arbeitslosigkeit herrschten. Allerdings diskutiert er dies nicht in den Begriffen vom Globalen Norden und Globalen Süden, sondern immer am Beispiel von Deutschland und Südafrika. An einigen Stellen, wie am Ende des obigen Zitats, setzt er Deutschland und „Europa generell“ in den Gegensatz zu ,,anderen Ländern, wo das nicht ganz so gut geregelt ist". Diese Unklarheit ist an dieser Stelle nicht aufzulösen.

Im Anschluss scheint er in seiner Argumentation von der Begründung des ,Stockim-Arsch"-Arguments abzuweichen und spricht wieder über Arbeitslosigkeit. ,Wir" hätten hier „Arbeitsplatzbeschaffung“. Während es hier „Putzfrauen“ gäbe, gäbe es die , in vielen anderen Ländern“ nicht. Straßenreinigung habe er bei seinem Aufenthalt in Südafrika nie gesehen. In der Verallgemeinerung dieser Beispiele zu einem Argument sagt er, dass ,wir“ „hier Arbeitsplätze“ schaffen würden, „,die es teilweise in anderen Ländern gar nicht gibt“. Er schlussfolgert, dass ,wenn wir so die Arbeitsplätze nehmen würden, wie es halt in anderen Ländern geregelt ist, würde es hier wahrscheinlich auch eine viel höhere Arbeitslosenquote geben“. Es klingt bei Jannik an, dass er die Vorstellung hat, dass es der Staat ist, der die Arbeitsplätze festlegt und möglicherweise sogar finanziert; also, dass der Staat entscheidet, dass es für bestimmte Arbeiten - Putzfrau, Straßenreinigung - Geld gibt und für andere nicht. Der Grund für die geringere Arbeitslosenquote in Deutschland liegt demzufolge darin, dass der Staat eine Ordnung festgelegt hat, nach der für mehr Arbeiten Geld bezahlt wird.

Bevor ich weiter auf die beiden Argumente - das der Ordnungsmentalität und der Arbeitsplatzbeschaffung - eingehe, möchte ich zur Interpretation noch den folgenden Interviewabschnitt miteinbeziehen. Ich habe nachgefragt, wie denn das Gegenstück im Globalen Süden zur hiesigen Haltung des ,Stock im Arsch` aussieht.

I: Und du hast ja gesagt, hier die Leute haben eher so ein - wie gesagt, wird nicht weitergegeben - Stock im Arsch. Und wie ist es dann .../ Und wie würdest du es dann beschreiben, wie dann eher so die Haltung in anderen Ländern ist? 
S: Die Mentalität in den anderen Ländern ist halt komplett .../ Die ist viel lockerer. Gerade was dann auch von, ähm .../ Straftaten werden teilweise härter bestraft. Aber ich habe jetzt zum Beispiel gestern in der Zeitung einen Bericht gelesen über Südafrika, dass da jährlich fünfzehntausend Morde, fünfzehntausend Mordversuche stattfinden, siebzigtausend Vergewaltigungen im Jahr. Und davon irgendwie nur 10 Prozent aufgeklärt werden oder so.

I: Mhm.

S: Das heißt, irgendwas stimmt da ja nicht so ganz an der Arbeit von den Regierungen komplett. Ähm, das hat glaube ich einen ganz großen Anteil daran, ob die jetzt .../ Ja, an der Mentalität auf jeden Fall. Die ist halt komplett anders in diesen Ländern. Und dementsprechend ist das halt alles nicht so geregelt. Es gibt nicht so viele Arbeitsplätze und auch, ähm, kommen die halt nicht so zu diesen ganzen Arbeitsplätzen. Die Infrastruktur spielt glaube ich auch eine ganz große Rolle. Wenn die da in den Slums außerhalb von Johannesburg sind. Sind wirklich teilweise zehn Kilometer um die ganze Stadt rum so, wo die dann leben. Da leben ich weiß nicht wie viele Leute. Die aber nicht in die Stadt kommen, weil es keine Busverbindungen oder so was in der Art gibt. Das ist halt auch einer der Gründe. Das wirklich arme Volk kann da wirklich auch relativ wenig auch gegen tun, dass die arbeitslos dann auch sind. (Jannik, Gym01)

Jannik führt hier selber die Kategorie der Mentalität ein, die ich schon im vorherigen Absatz zur Beschreibung seiner Vorstellungen verwendet habe. „Die Mentalität in den anderen Ländern ist halt komplett ..."; wie geht dieser Satz zu Ende? Aus meiner Analyseperspektive assoziiere ich hier ein ,komplett anders', was die implizite Binarität der Mentalitäten explizit machen würde. Er kommt dann dazu zu sagen, dass die Mentalität ,in den anderen Ländern [...] viel lockerer“ sei. Das anschlieBende Beispiel der härteren Bestrafung von Straftaten scheint auf den ersten Blick nicht richtig zu seiner Aussage zu passen. Doch Jannik stellt danach heraus, dass es sehr viel Kriminalität dort gäbe und die Aufklärungsquote sehr gering sei. Aus diesem Verhältnis folgert er, dass da ,irgendwas [...] nicht so ganz an der Arbeit von den Regierungen komplett“ stimmen könne. Dies führt er auf die „Mentalität“ zurück, die ,in diesen Ländern [...] halt komplett anders“ sei. Nach seiner langen Tastbewegung scheint er mit der Entdeckung der Mentalität endlich an einem für ihn verhältnismäßig sicheren Hafen angekommen zu sein. Aufgrund dieser ,ganz anderen " Mentalität sei ,dort" „dementsprechend [...] halt alles nicht so geregelt“". Jannik stellt die Mentalität hier als den Grund für die fehlende Ordnung und Staatlichkeit dar. Diese Mentalität sei auch verantwortlich dafür, dass es ,nicht so viele Arbeitsplätze“ gäbe. Damit führt er die beiden Argumentationen zum ,Stock im Arsch - also den ordnenden Staat und die Arbeitsplatzbeschaffung explizit zusammen, indem er beide als Ausdruck einer weniger Ordnung bringenden Mentalität im Globalen Süden deutet. Hier bringt er noch ein ergänzendes Argument. Jannik 
glaubt, dass fehlende Infrastruktur am Beispiel von fehlenden Busverbindungen dafür sorgen würde, dass die Menschen, das ,wirklich arme Volk“, aus den Slums in die Stadt und damit zu einem Arbeitsplatz kommen könnten. In diesem Kontext erscheint die fehlende Infrastruktur aber auch als Resultat dieser nicht auf Ordnung zielenden Mentalität.

Aus einer dekolonialen Perspektive erscheint die Binarität der Mentalitäten des Globalen Nordens und des Globalen Südens als erklärungsmächtige Vorstellungen sehr plausibel. Was in dem Ausdruck „Stock im Arsch“ noch anklingt ist ein Bezug zu der im Rahmen dieser Binarität stattfindenden Kritik an der ordnungsliebenden Mentalität des Globalen Nordens und einer , positiven ‘ Zuschreibung zur Mentalität des Globalen Südens. Dazu findet sich bei Jannik über den Ausdruck selbst hinaus nur eine Anspielung, wenn er davon spricht, dass die ordnungsbringende Mentalität des Globalen Nordens auch Nachteile mit sich bringe. In rassismuskritischen Diskursen wird dies auch als ,positiver Rassismus ‘ bezeichnet. Das bedeutet, dass im kolonialen Diskurs die , positive ' Zuschreibung zur Mentalität des Globalen Südens in Lebensfreude, ausschweifender Sexualität, Lockerheit etc. besteht, während sich die Mentalität des Globalen Nordens eben durch das Ausbleiben dieser Eigenschaften zugunsten von Disziplin, Ordnung, Rationalität etc. auszeichne. Dies ist aber bei Jannik so explizit nicht vorfindbar, dennoch finden sich einige Andeutungen, die diese Deutung nahegelegen.

Insgesamt ist aus meiner Perspektive bei diesem Fallbeispiel hervorzuheben, dass Janniks Suchbewegungen nach den Ursachen für globale Ungleichheit von einem Gefühl der Ungerechtigkeit über diese getrieben sind. Auf der Suche nach Antworten für dieses für ihn hoch relevante Problem bringt er zahlreiche mögliche Gründe vor, die größtenteils aber aus einer dekolonialen Perspektive als problematisch erscheinen. All seine sechs Argumente können als entwicklungstheoretische Argumente kategorisiert werden und nehmen keine Abhängigkeits- oder Ausbeutungsstrukturen in den Blick. Im Laufe der tastenden Entwicklung seiner sechs Argumente spielt die Idee der Binarität des (Un-)Ordnungstopos regelmäßig eine Rolle. Aufgelöst wird seine Suchbewegung scheinbar in dem Argument der Binarität der Mentalitäten, deren zentrales Unterscheidungsmerkmal ihr Bezug zu Ordnung darstellt und damit als übergeordneter Begründungszusammenhang für eine Vielzahl der von ihm vorher genannten Aspekte fungiert. Die koloniale Binarität der Mentalitäten in Bezug auf (Un-)Ordnungen scheint eine mächtige Erklärungskraft für Jannik zu besitzen. Der letztgenannte Aspekt trifft in verschiedener Ausprägung auf eine Vielzahl der zu dieser Analysekategorie, Ordnung als Voraussetzung für Entwicklung ' gehörenden Aussagen vieler Schüler_innen zu. 


\section{Mark: Ordnung und Kolonialismus}

Mark (Gym09) versteht unter Globalisierung Kolonialismus, zu welchem er über sehr viel und detailreiches Wissen verfügt. Im Abschnitt ,Subalterne Positionen II: Die Kolonisierten' setze ich mich ausführlich mit seinem Verständnis des Kolonialismus auseinander. An dieser Stelle interessiere ich mich für die mit seiner Vorstellung von Kolonialismus verbundenen Idee von Ordnung als Voraussetzung von Entwicklung. Im Interviewverlauf geht es nach einer langen thematischen Phase zum Kolonialismus dann um die Frage von globaler Ungleichheit heute. In diesem Zusammenhang stelle ich die Frage nach d er Ursache dafür.

I: Ja. Und wieso ist das so, dass jetzt einige Länder ärmer sind? Oder in einigen Ländern so viele Kriege sind und in anderen nicht?

S: Ähm, die großen Mächte Deutschland, England, Spanien und so weiter hatten ja schon von Anfang an eine funktionierende Regierung, einen funktionierenden Staat. Sie hatten alles organisiert und versorgten auch jeden Einzelnen im Volk. Und die, ähm, im zweiten, also im dritten Reich oder so hatten auch zwar Probleme gehabt, aber konnten durch eine gute Regierung zumindest wieder einen Aufschwung bekommen. Aber so ärmere Länder, wie zum Beispiel in Afrika oder in Asien, hatten noch nie so eine richtige Regierung. Die Völker dort lebten dort wie in den alten Traditionen, wo es noch gar keine Regierung gab oder wo sie überhaupt nie eine Regierung hatten. Weil sie dort einfach so lebten, wie sie früher gelebt haben. Wie vor tausend Jahren oder so. Und da sich das ja bis jetzt noch nicht geändert hat, zumindest .../In den meisten Ländern hat sich das zwar geändert, aber die meisten konnten noch nicht sich richtig an eine Regierung binden.

I: Mhm.

S: Diese Länder haben dann nicht so eine Entwicklung gemacht wie jetzt zum Beispiel .../ Welches Land kann man nehmen? Brasilien oder so. Mittlerweile kann man ja sehen, dass die es ja auch geschafft haben, die WM da auszutragen und die Olympischen Spiele. Und früher war es ja auch eine Kolonie von Spanien gewesen. Oder von Portugal?

I: Von Portugal. Auf jeden.

S: Ja, von Portugal. Ähm, ja Portugal selbst hatte Macht und Brasilien, eher so eine Kolonie, hatte nicht so die Macht. Aber, ähm, durch die Umstände, dass es überhaupt eine Kolonie war, hatten sie auch eine eigene Regierung, zumindest überseeisch durch die portugiesische. Und Länder wie jetzt in Afrika, Kenia und so was, hatten erst eine Regierung als die, ähm, als die anderen Länder schon eine hatten.

I: Mhm. Und bevor jetzt die kolonisiert wurden, haben die noch gelebt, wie schon vor hunderten Jahren zuvor?

S: Mhm [bejahend]

I: Und hätten die das auch aus eigner Kraft geschafft? 
S: Ich glaube nicht, weil sie sich immer an ihr eigenes Leben schon so gewöhnt haben und keine Änderungen haben möchten. Und wenn sie auf einmal eine Regierung da haben und ihnen gefällt das nicht, dann möchten sie es natürlich wieder ändern. Aber so entwickelt sich auch das Land nicht weiter. Wenn man keine Regierung hat und keine Ordnung, dann bleibt es immer so wie es ist. (Mark, Gym09)

Auf die Frage nach den Ursachen dafür, dass reichere und ärmere Länder gäbe, antwortet Mark direkt mit dem Ordnungstopos. So hätten „die großen Mächte Deutschland, England, Spanien und so weiter" - im Kontext des Interviewverlaufs können diese Staaten aufgrund ihrer gemeinsamen Eigenschaften auch Kolonialmächte genannt werden - ,schon von Anfang an eine funktionierende Regierung, einen funktionierenden Staat“. Sie hätten ,alles organisiert und versorgten auch jeden Einzelnen im Volk“. Mark stellt die Frage der Staatlichkeit ins Zentrum seiner Vorstellungen über die Gründe für globale Ungleichheit. Er benennt hier das Funktionieren von Staat und Regierung und bringt dafür die Beispiele, nach denen alles organisiert sei-womit er wohl gesellschaftliche Abläufe meint. Als Bedingung für funktionierende Staatlichkeit scheint er auch anzusehen, dass jeder Einzelne im Volk versorgt sei; funktionierende Staatlichkeit deutet für ihn also auf ein spezifisches Verhältnis von Staat zur Bevölkerung hin, in der die Existenz jedes Einzelnen direkt in staatliche Funktionen eingebettet ist. Mark ergänzt, dass es zwar auch bei den ,großen Mächten“ während und nach dem Zweiten Weltkrieg einige „Probleme" gegeben habe. Diese hätten jedoch durch „eine gute Regierung" überwunden werden können, deren Handeln zu einem Aufschwung geführt hätte.

Hervorzuheben ist der Ausdruck ,von Anfang an“. Denn im Gegensatz zu den Kolonialmächten, die „,von Anfang an [...] einen funktionierenden Staat“ gehabt hätten, hätten ,,so ärmere Länder, wie zum Beispiel in Afrika oder in Asien, [...] noch nie so eine richtige Regierung" gehabt. Die starken kontrastierenden Ausdrücke ,von Anfang an“ und ,noch nie“ in Bezug auf Staatlichkeit erscheinen hier als zentrale Kategorien und deuten in ihrer Absolutheit auf ein essenzialistisches Verständnis der von Mark angenommenen Differenz und ihrer Ursache zwischen kolonisierenden und kolonisierten Ländern hin. Dieser Eindruck verstärkt sich durch seine weiteren Ausführungen. So lebten die „Völker“ in den „ärmeren Ländern“ nach ,den alten Traditionen, wo es noch gar keine Regierung gab oder wo sie überhaupt nie eine Regierung hatten“. „Dort“ würden „einfach so“ leben, ,,wie sie früher gelebt" hätten, ,wie vor tausend Jahren oder so“. Dies kann aus einer dekolonialen Perspektive als ein Bezug zur kolonialen Raum-Zeit-Matrix interpretiert werden, die ich in den Abschnitten zu ,Stagnation und Fortschritt' (3.2.2, 3.2.3) diskutiert habe. Hier wird die Frage der fortschreitenden Zivilisationen und der stagnierenden, 
traditionellen, quasi im Naturzustand verharrenden Länder oder Kulturen anhand der Frage von Staatlichkeit und Ordnung ausgebreitet.

Dieser verharrende, regierungslose Zustand der ,ärmeren Länder“ habe sich ,,bis jetzt noch nicht geändert". Diese Aussage schränkt er dann wieder ein und stellt fest, dass die meisten Länder sich noch nicht ,richtig an eine Regierung binden“ konnten. Es gäbe Beispiele für die „Entwicklung“ von Regierungen in ,ärmeren Ländern“, wie er am Beispiel der Austragung der WM und der Olympischen Spiele in Brasilien festmacht. Er sieht aber scheinbar einen Unterschied zwischen tatsächlich gut funktionierenden Regierungen und Regierungen der ,ärmeren Länder“. Ein Grund dafür könnte darin begründet sein, dass die Entwicklung von Staatlichkeit und Regierungen nach Mark nicht aus einer endogenen Entwicklung hervorgegangen sei. So habe Brasilien nur durch den Umstand, dass es ,überhaupt eine Kolonie“ war, ,auch eine eigene Regierung“ bekommen, auch wenn diese ,überseeisch“ gewesen sei. Andere Länder, „wie jetzt in Afrika, Kenia und so was“, hätten erst verspätet eine Regierung bekommen, als die ,,anderen Länder schon eine“ gehabt hätten. Aufgrund des Kontextes kann gemutmaßt werden, dass der Grund dafür in der späteren Kolonisierung dieser Länder liegt, die Mark bewusst ist (s. Abschnitt 3.4.3 zu ,Subalterne Positionen II: Die Kolonisierten '). Staatlichkeit als solche scheint den ärmeren Ländern also nicht eigen, sondern eher aufgepfropft zu sein, was auch die vermeintlich eingeschränkte Realisierung begründe.

Auch die Rückfragen bestätigen Marks dichotomisches Bild und den Bezug zur kolonialen Raum-Zeit-Matrix. Mark glaubt nicht, dass ,sie' es aus eigener Kraft geschafft hätten, eine Regierung zu entwickeln, ,weil sie sich immer an ihr eigenes Leben schon so gewöhnt haben und keine Änderungen haben möchten“. Wenn ,sie“ ,auf einmal eine Regierung da“ hätten, dann würden ,sie es natürlich wieder ändern“ wollen. Durch den Ausdruck ,,auf einmal“" wird nochmals deutlich, dass das Konzept von Staatlichkeit selbst den ,ärmeren Ländern“ fremd und von außen aufgestülpt sei, während es den kolonisierenden Ländern eigen sei. Ob Mark diese Differenz als eines wesensmäßige oder eine historisch gewachsene versteht, ist nicht eindeutig zu klären, doch scheint für ihn diese Differenz tendenziell sehr tief und nicht oder kaum veränderbar zu sein. Staatlichkeit bzw. Ordnung stellen dabei für ihn die zentrale Bedingung von ,Entwicklung' dar. So führt er aus, dass sich das Land so, also ohne oder mit eingeschränkter Staatlichkeit, nicht weiterentwickeln könne. Dies bringt er auf folgende Formel: „Wenn man keine Regierung hat und keine Ordnung, dann bleibt es immer so wie es ist." Dies scheint bei ihm die zentrale These zu sein, nach der er seine Argumente strukturiert, die Darstellung der Weltgeschichte ordnet und die Akteure - kolonisierte und kolonisierende Länder - konstruiert. Diese Argumentation werde ich an zwei weiteren Auszügen aus dem Interview mit Mark illustrieren, in denen noch weitere Facetten und Spielarten 
dieses Arguments deutlich werden. Die in verschiedenen Kontexten wiederauftauchenden Argumentationsfiguren bei Mark legen nahe, dass er - ganz anders als beim tastenden Vorgehen von Jannik - eine sehr gefestigte und feststehende Vorstellung von diesen Zusammenhängen hat.

Zu einem späteren Zeitpunkt im Interview antwortet Mark auf die Frage danach, wer aus seiner Sicht die Gewinner und die Verlierer der Globalisierung sind.

I: Mhm. Was würdest du sagen, wer sind die Gewinner und wer sind die Verlierer der Globalisierung?

S: Ich glaube, nicht so wirklich hat einer gewonnen. Weil, die großen Mächte sind zwar jetzt immer noch auf dem hohen Rang, aber sehr viel hat sich nicht geändert. Abgesehen davon, dass sie jetzt mehr Geld besitzen. Das Land an sich haben sie eigentlich nicht vergrößern können. England muss sich immer noch auf das eigenes Mutterland beschränken. Und die Kolonien haben sich mittlerweile aufgelöst, bis auf die paar Ausnahmen.

I: Mhm.

S: Und die USA hat sich eigentlich am besten entwickeln können. Eigentlich für mich einer der großen Gewinner. Durch England erst mal kolonisiert werden. Dann die Kriege mit den anderen Kolonien aus Frankreich und Spanien. Und dann konnten sie sich die Unabhängigkeit erkämpfen und sich innerhalb von ein paar hundert Jahren zu einer der größten Mächte der Welt entwickeln. Das ist schon einmalig. Und, ähm, da muss man schon von Anfang an eine große Macht sein, um überhaupt am Ende noch eine Macht zu sein.

I: Mhm.

S: Und für die Verlierer, ja, eigentlich hat sich für sie auch nichts geändert. Weil, früher waren sie ja arm, sie hatten keine Regierung, keine Ordnung. Jetzt haben die meisten zwar eine kleine Ordnung mit Regierung, aber sehr viel hat sich nicht geändert. (Mark, Gym09)

Die Kolonialmächte hätten zwar durch den Kolonialismus Profite erwirtschaftet. Abgesehen davon hätten sie aber weder ihr Territorium vergrößern noch - bis auf wenige Ausnahmen - die Kolonien halten können. Als besonderen Gewinner sieht Mark die USA an, die es geschafft hätten, sich von einer Kolonie zur Weltmacht zu entwickeln. Wie dies zu seiner Idee des Zusammenhangs von Ordnung und Entwicklung passt, wird leider nicht ganz deutlich. Als Verlierer sieht er die kolonisierten, ärmeren Länder an. Für diese habe sich ,eigentlich [...] auch nichts geändert“. So seien sie „früher [...] ja arm gewesen“ und hätten „keine Regierung, keine Ordnung“ gehabt. Heutzutage hätten „die meisten zwar eine kleine Ordnung mit Regierung“, aber sehr viel habe ,sich nicht geändert“. Hier stellt er noch einmal heraus, dass 
das Grundproblem - also die ,Nicht-Entwicklung ' der ärmeren Länder - in den ,ärmeren Ländern' liege. Der Kolonialismus stellt für Mark einen Moment dar, der die ,ärmeren Länder“ teilweise aus ihrem stagnierenden Status herausgelöst hätte. Er sieht den Kolonialismus also als Teil der Lösung, keinesfalls jedoch als Teil des Problems an. Aus einer bildungswissenschaftlichen Perspektive ruft es - zumindest für mich - Irritationen hervor, dass sein fundiertes Wissen über den historischen Kolonialismus (siehe dazu Abschnitt 3.3.5 ,Subalterne Positionen: Die Kolonisierten') nicht zu dekolonialen Reflexionsansätzen führt. Hier wird deutlich, dass es bildungswissenschaftlich naiv zu sein scheint, von einem Automatismus auszugehen, der von einer großen Menge an Wissen zu einer kritischen Reflexion führen würde.

Im letzten von mir ausgewählten Abschnitt aus dem Interview mit Mark geht es um die Verknüpfung seiner Ordnungs- und Entwicklungstheorie mit gegenwärtigen Arbeitsbedingungen und einer darüber funktionierenden Geschichtsschreibung. Im Interview spricht er mehrfach über globalen Handel. Ich frage nach, ob er etwas über die Arbeitsbedingungen weiß.

I: Mhm. Dann mal was ganz anderes: Weißt du was du was über die Arbeitsbedingungen von .../ Zum Beispiel du hast gesagt, Diamanten werden in Afrika abgebaut. Oder Baumwolle auch in Afrika oder, ähm, in den USA. Weißt du was über die Arbeitsbedingungen von den Leuten da?

S: Ja. Also, meistens sind die Bedingungen sehr schlecht. Weil die meisten, ähm, nur auf ihre primitive Arbeit fixiert sind und nicht irgendwie verlangen, dass sie so viel Geld wollen. Oder, dass sie überhaupt irgendwas wollen. Weil sie halt, ähm, davon nichts wissen. Weil vielleicht kriegen sie einen Euro am Tag oder in der Woche, wissen aber nicht, dass die Diamanten an sich irgendwie tausend Euro wert sind. Und müssen sie dann bearbeiten für wenig Geld, obwohl es eigentlich viel mehr wert dort zu arbeiten. Und da das ja so eine große Masse ist, kann man natürlich nicht sehen, wer wie viel Geld kriegt. Natürlich sind die Waren immer irgendwie mehr wert, weil man ja Gewinn machen will. Und wenn die Arbeiter dann wenig Geld kriegen für eine Leistung, die viel mehr geschätzt werden müsste, dann sieht man auch, dass die ärmeren Länder auch immer so bleiben werden, wie sie sind. Schon vor und nach der Kolonisierung und auch jetzt, dass die meisten ärmeren Länder sich nur auf ihre, ähm, primitiven Einstellungen fixieren können und nicht irgendwie höher hinaus wie die reicheren Länder.

I: Mhm. Was sind denn zum Beispiel diese „primitiveren Einstellungen“?

S: So wie bei den Höhlenmenschen, dass die Männer jagen und die Frauen kochen oder halt den Haushalt pflegen. Das hat man dann bis zu den Römern durchgezogen. Und dann hat sich so eine Regierung gebildet mit dem Senat und so was. Ja, dann hat man so eine Ordnung gehabt. Jeder war reich, jeder konnte alles bezahlen. Irgendwann kamen diese Barbaren und haben dann die Römer aufgespalten in zwei Reiche. Immerhin 
haben die beiden Reiche unabhängig voneinander noch ihre Ordnung gehalten. Aber danach wurde es auch ein bisschen brenzlig, weil noch mehr Barbaren kommen und die Ordnung zerstören und dann wieder auf einen Stand kommen, den man vor den Römern hatte. (Mark, Gym09)

Als Grund für die „schlecht[en]“ Arbeitsbedingungen führt er an, dass die „,meisten [...] nur auf ihre primitive Arbeit fixiert" seien. Sie würden weder verlangen, dass sie „so viel Geld wollen“ oder ,überhaupt irgendwas wollen“, da sie nicht wüssten, dass die Produkte eigentlich viel mehr Wert seien. Den Grund für das von ihm benannte Lohngefälle innerhalb der internationalen Arbeitsteilung sieht Mark im fehlenden Bewusstsein der Arbeiter_innen. Wenn „die Arbeiter“, so Mark weiter, dann „wenig Geld“ kriegten für ,eine Leistung, die viel mehr geschätzt werden müsste“, dann sehe man, ,dass die ärmeren Länder auch immer so bleiben werden, wie sie sind“. Den Grund dafür sieht Mark, dass die „,meisten ärmeren Länder sich nur auf ihre [...] primitiven Einstellungen fixieren“ könnten. Dies führe zu einer Art Stagnation, einem Status des ,Nicht-Entwickelns '; um es mit Marks Worten zu sagen, kämen die ,ärmeren Länder“ aufgrund ihrer Fixierung auf die „primitiven Einstellungen“ irgendwie nicht „höher hinaus“, wie es den „reicheren Ländern“ gelänge. Hervorheben möchte ich noch eine Nuance, die sich aus dem Changieren zwischen den Ausdrücken ,primitive Arbeit“ und ,primitive Einstellungen“ ergibt.

Am Ende des Interviews konfrontierte ich Mark damit, dass es mir als problematisch erscheint, den ärmeren Ländern ,primitive Einstellungen“ zu attestieren. Daraufhin führte er die ,primitiven Einstellungen“ explizit nicht auf eine Wesensanlage zurück, sondern auf ihre Lebensbedingungen. Konkret sagte er, dass er nicht gemeint habe, dass , die ",jetzt irgendwie dumm denken oder so was“, sondern, dass ,die“ „halt gerade an nichts anders denken [könnten] als an ihr eigenes Überleben“. Die Nuance besteht also darin, dass die Zuschreibung der ,primitiven Einstellungen" einerseits als Wesensanlage und andererseits als Folge von sozioökonomischen Lebenslagen verstanden wird. Beides erscheint aus einer dekolonialen Perspektive höchst problematisch, dennoch erscheint mir für eine Analyse dieser Unterschied relevant. Auch wenn er am Ende des Interviews die sozioökonomische Deutung favorisiert, bleibt doch der Eindruck, dass hier die Logik der Wesensanlage ebenso am Werke ist. Insbesondere die von ihm formulierte Idee, dass sich die „meisten ärmeren Länder" nur auf ,,ihre [...] primitiven Einstellungen“ “ fixieren könnten und das dies „schon vor und nach der Kolonisierung“ der Fall gewesen sei, legt die Deutung nahe, dass er hier von einer Wesensanlage der kolonisierten Länder und ihrer Menschen ausgeht, nach der diese nicht fähig zu Ordnung und Staatlichkeit und deswegen auch nicht zu Entwicklung seien. Durch die Formulierung, insbesondere im Kontext dieses Interviewauszugs, erscheint außerdem der Kolonialismus 
als ein Intervall, in welchem sie das erste und letzte Mal einer solchen Ordnung und Staatlichkeit näher gekommen seien und zwischenzeitlich aus ,ihrem‘ Status der ,Nicht-Entwicklung' herausgerissen worden wären.

Auf die Nachfrage, was denn zum Beispiel ,primitivere Einstellungen“ seien, erzählt er eine Art Weltgeschichte, deren strukturierenden Parameter wiederum Ordnung und Staatlichkeit darstellen. Mark fängt in dieser Darstellung bei den „Höhlenmenschen“ an. Dort sei es so gewesen, dass „,die Männer jagen und die Frauen kochen oder halt den Haushalt pflegen“. Dies sei der Zustand bis zur Entstehung des Römischen Reichs gewesen, wo sich ,eine Regierung gebildet“ und damit eine „Ordnung“ etabliert habe. Dort sei jeder ,reich“ und in der Lage gewesen, ,,alles“ zu bezahlen. „Irgendwann“ seien die „Barbaren“ gekommen und hätten letztlich dafür gesorgt, dass „die Ordnung“ zerstört worden sei und wieder ein „Stand“ eintrat, den „,man vor den Römern“ gehabt habe. Mark konstruiert hier die Weltgeschichte anhand der strukturierenden Kategorie der Ordnung. Der Startpunkt dieser Ordnung sei das Römische Reich gewesen. Später sind es, nach Mark, die Kolonialmächte gewesen, die dann das Erbe Roms angetreten und Ordnungen etabliert hätten, was zu ihrer Überlegenheit und dem Kolonialismus geführt habe.

\subsection{Selfing/Othering}

\subsubsection{Das Feld strukturieren: Was meint Selfing/Othering?}

Die Kategorie Selfing/Othering beschreibt den Prozess der Konstruktion des Eigenen und des Anderen. Diese Dimension spielte auch in der vorherigen Kategorie Eurozentrismus immer wieder eine entscheidende Rolle, hier wird sie aber ins Zentrum der Analyse gerückt. Ging es beim Eurozentrismus um den Kontext globaler Ungleichheit, fokussiert diese Kategorie auf das Zugehörigkeitsregime in der Migrationsgesellschaft. Der Kategorie Selfing/Othering liegen also alle Aussagen der Schüler_innen zugrunde, in denen die Fragen von Zugehörigkeit in migrationsgesellschaftlichen Kontexten, die Frage des Selbst und des Anderen, diskutiert werden. Die Kategorie könnte, wie gerade deutlich geworden ist, auch Zugehörigkeitsregime oder Produktion von Differenz in der Migrationsgesellschaft heißen. Ich habe mich aber für die Begriffe Selfing und Othering entschieden, da sie aus meiner Sicht stärker als der Begriff des Zugehörigkeitsregimes den Konstruktionscharakter, die Verwobenheit beider Prozesse und die subjektive Dimension herausstellen. Nichtsdestotrotz bleibt der Begriff des Zugehörigkeitsregimes für mich wichtig. Er hat den Vorzug, dass mit ihm stärker die Wechselwirkung von 
staatlichen (Zugehörigkeits-)Politiken und der Verteilung symbolischer Macht in den Blick gerät, die in meiner Analyse ebenfalls eine wichtige Rolle einnehmen.

Die Perspektive von Othering und Selfing, verstanden als die wechselseitige Konstruktion des Eigenen und des Anderen, hat lange und vielfältige ideengeschichtliche Wurzeln. Ich widerstehe hier dem Versuch, diesen genealogisch nachzuspüren und beschränke mich auf einen punktuellen Einblick in das spezifische Verständnis von Othering in postkolonialen Theorien. In diesen stellt Othering ein „key concept“ (Thomas-Olalde/Velho 2011: 27) dar. In der Darstellung dieses Konzept dominiert eine spezifische Erzählung, nach der die Entwicklung des Konzepts entlang von Edward Said und Gayatri Spivak dargestellt wird (Akbaş 2018; Jensen 2011; Scharathow 2014; Thomas-Olalde/Velho 2011).

In seinem sehr einflussreichen Buch Orientalismus (1978) hatte Edward Said herausgearbeitet, wie der ,Orient" als Wissensobjekt in den europäischen Wissenschaften und Künsten konstruiert wurde. Der ,Orient ${ }^{\star}$ als Wissensformation war Teil des imperialistisch-kolonialen Projekts und diente den politischen Interessen der kolonisierenden Länder sowohl als Legitimation kolonialer Herrschaft als auch als funktionales Wissen für Regierungstechniken. Außerdem funktionierte der diskursiv konstruierte ,Orient" auch als eine Art Spiegel, der die gleichzeitige Konstruktion des ,Okzident` ermöglichte. Der Orientalismus brachte nicht einfach den ,Orient" als das ,Andere" hervor, sondern konstruierte vielmehr das binäre Verhältnis von ,Orient" und ,Okzident', ,Anderem‘ und ,Eigenem‘. Die von Said analysierten Diskurse sind bis heute wirkmächtig, sind teilweise auch in den Vorstellungen der Lernenden zu finden und fließen insofern in meine Arbeit ein. Said verwendet dabei zwar nie den Terminus ,Othering', allerdings werden seine Studien in der postkolonialen Theorie als paradigmatisch für Prozesse des Othering interpretiert und rezipiert (Scharathow 2014: 44). Zum ersten Mal systematisch verwendet hat ihn, den Darstellungen zufolge, Gayatri Spivak in ihrem Text The Rani of Sirmur (1985). Hier entwickelt sie anhand der Reiseberichte und Briefe zwischen hochrangigen Angehörigen der Britischen Ostindien-Kompanie während der Kolonialisierung der Shimla Hills, im heutigen Himachal Pradesh in Indien, Othering als einen „dialektischen Prozess, bei dem gleichzeitig das kolonialisierende ,Other" als ,Master" und das kolonialisierte ,Other" als Subjekt" (Akbaş 2018: 43f) etabliert werden.

Problematisch ist die alleinige Fokussierung auf diese Traditionslinie insofern, als sie viele andere Autor_innen und Kontexte ausblendet, wie jede Konstruktion einer Genealogie dies tut, sie damit andererseits aber die gängige Traditionsbildung der postkolonialen Theorie stärkt, in der Saids Orientalismus sogar als „Gründungsdokument“ (Castro Varela/Dhawan 2005: 29) diskutiert wird. Andere 
bekannte Autoren, die Othering-Konzepte in postkolonialen Kontexten verwendet haben, sind beispielsweise Frantz Fanon $(1952 ; 1961)$ und W.E.B. Dubois (1903). Beide analysieren Othering-Prozesse in Verhältnissen zwischen Kolonisierten und Kolonisierenden sowie Schwarzen und Weißen. Es gibt aber durchaus auch andere Genealogien des Othering-Konzepts, in denen beispielsweise Frantz Fanon immer mehr Berücksichtigung findet (Staszak 2009).

Doch zurück zur Operationalisierung des Othering-Konzepts: Othering wird auf verschiedene Weisen konzeptionalisiert. Bedia Akbaş beschreibt Othering beispielsweise als „Subjektivierungspraxis“ (2018: 42), während Wiebke Scharathow Othering als „Prozesse der Repräsentation“ (2014: 44) ansieht. Die unterschiedlichen Ansätze scheinen mir aber nicht auf grundsätzliche Abweichungen, sondern vielmehr auf unterschiedliche Anwendungsbereiche zu verweisen, insofern sind die Variationen des Konzepts aus meiner Sicht zu vernachlässigen. Im Folgenden möchte ich noch auf drei Aspekte eingehen, die für mein Verständnis von Othering zentral sind.

\section{1) Das ,Eigene' als Spiegelbild des ,Anderen“}

Das ,Eigene" wird erst im Prozess der Konstruktion des ,Anderen' konstruiert (Scharathow 2014: 45 f). Es gibt also weder ,Eigenes' noch ,Anderes' vor diesem Konstruktionsprozess. Zwar gibt es ,vorher' schon Menschen, Praxen, Subjekte usw. Die imaginierten Gemeinschaften, die in den Konstruktionsprozessen von Selfing und Othering entstehen, sind den Konstruktionsprozessen aber nicht vorgängig. Deswegen spreche ich von Selfing und Othering und nicht von ,Self“ und ,Other'. Statt von dem Verhältnis Selfing und Othering wird häufig auch nur von Othering gesprochen. Durch die zusätzliche Nennung von Selfing möchte ich den Aspekt stark machen, dass es in der Betrachtung von ,Othering '-Prozessen nicht nur um Zuschreibungen für ,Andere ' geht, sondern zum Verständnis dieser Prozesse die Konstruktionen von normalisierten, privilegierten Subjektpositionen mindestens ebenso zentral sind.

Stuart Hall hat diesen Zusammenhang in einem vielzitierten Satz auf den Punkt gebracht: „Die [weißen] Engländer sind nicht deshalb rassistisch, weil sie die Schwarzen hassen, sondern weil sie ohne die Schwarzen nicht wissen, wer sie sind.“ (Hall 1999: 93) Das ,Selbst“ ist insofern selbst ein ,Anderes', da es nicht an sich, sondern nur im Spiegel des ,Anderen' existiert. Durch die Bezeichnung als ,Self“ will ich also nicht eine Position privilegieren, sondern vielmehr die gesellschaftlich virulenten Hierarchisierungen von Subjektpositionen in den Blick nehmen. In Spivaks Worten: „In a certain sense, I think there is nothing that is central. The centre is always constituted in terms of its own marginality. [...] certain people have always been asked to cathect the margins so others can be defined as central." (Spivak 1986: $40 \mathrm{f}$ ) 


\section{2) Die Ungleichheit einer Normalisierungspraxis}

Das Verhältnis von ,Self' und ,Other' ist keines auf Augenhöhe. Das Verhältnis ist ein hierarchisches. Diese Form der Hierarchie zeichnet sich aber nicht einfach durch ein Mehr an Macht oder Abwertung aus. Dies sind zwar zentrale Dimensionen des Verhältnisses, allerdings kann Macht nicht einfach durch die abgewertete Gruppe an sich genommen werden oder eine Abwertung ausgelassen werden, da das Verhältnis tief in die Wissensstrukturen eingeschrieben ist. Das Verhältnis ist also nicht einfach aufheb- oder umdrehbar. „Die Markierung von Marginalität erschafft die Position des Zentrums. Durch diese Markierung imaginiert und konstituiert sich das Zentrum als Produzent der Wahrheit und der Wirklichkeit.“ (Gutiérrez Rodríguez 2003: 31). Das Verhältnis manifestiert sich in der Regel als eine Normalisierungspraxis, in der der dominante Ort, das ,Self‘ als das ,Normale“ und das ,Other' als das ,Deviante', ,Abweichende“ oder ,Defizitäre“ erscheint. Das ,Normale“ ist dabei ein Ort, der nicht benannt zu werden braucht. „Der machtvolle Ort, von dem aus das ,Andere“ repräsentiert und das ,Eigene' normalisiert wird, bleibt in der Regel unbenannt und unsichtbar." (Scharathow 2014: 46)

Dies ist besonders anschaulich in den Critical Whiteness Studies bzw. der kritischen Weißseins-Forschung herausgearbeitet worden. Weiß-Sein ist ein Konstrukt, das auf der rassistischen Verteilung von Macht basiert und diese ermöglicht. Beispielsweise Alfred J. López zeigt, dass ,whiteness [understood as a passport to privilege] itself remains a largely unexamined category“ (López 2005: 23). Whiteness fungiert dabei als das Nicht-Partikulare und als Raum der Normalität, ohne explizit eine so genannte Überlegenheit der 'weißen Rasse' benennen zu müssen (ebd.). Der Ansatz der Critical Whiteness hat sich zum Ziel gesetzt, die dadurch entstehenden Privilegien sichtbar zu machen und infrage zu stellen:

„The task of a postcolonial critique of whiteness must finally be, [...] to ask new questions of old histories, thus allowing us to move in from solipsism and myths of centrality that have maintained whiteness in its position as the invisible, omnipotent arbiter of world culture for far too long." (ebd.: 24)

Der Ansatz der Critical Whiteness Studies ist inzwischen teilweise auch im deutschsprachigen Raum implementiert (Eggers et al 2005) und stellt einen Ansatzpunkt postkolonialer Pädagogik dar (Baquero Torres 2012: 319 f). Die problematischen Interpretationen und Anwendungsformen dieses Ansatzes in Deutschland gilt es dabei kritisch zu reflektieren (Karakayalı et al 2013). Diese Frage beschäftigt mich an zahlreichen Stellen dieser Arbeit (2.2.3.5; 4.2.3.1). 


\section{3) Sich wandelndes und umkämpftes Verhältnis}

Die Prozesse des Selfing und Othering laufen dabei keinesfalls gradlinig und widerspruchsfrei ab; ,Self' und ,Other' bleiben immer potenziell prekär. Eine wichtige Kritik am Werk von Edward Said besteht darin, dass er in seiner Analyse des binären Verhältnisses von ,Orient ' und ,Okzident ' Ambivalenzen, Brüche und Widersprüche weitgehend ausblendet, so der kolonialen Dichotomie verhaftet bleibt und diese gewissermaßen essenzialisiert (Castro Varela/Dhawan 2005: 37 ff). Der radikale, konstruktivistische Gedanke, dass der ,Orient" als Wissensobjekt durch die orientalistische Praxis erst hervorgebracht wird, führt bei ihm dazu, dass seine Bewohner_innen in seinen Analysen - im Gegensatz zu seinen politischen Abhandlungen - gewissermaßen nicht vorkommen. Ich gehe mit Bhabha davon aus, dass die durch Selfing und Othering geschaffenen Subjektpositionen nie erreicht und abgeschlossen sind (Bhabha 1994). Sie sind vielmehr brüchig, voller Ambivalenzen und ständiger Transformation unterworfen. In den Praxen der Subjekte gibt es zahlreiche Strategien, die das reibungsfreie Funktionieren stören, wie etwa Mimikry, Ablehnung oder Resignifikation. Die Analyse dieses Verhältnisses als gebrochenes und widersprüchliches erscheint gerade aus einer bildungswissenschaftlichen Perspektive besonders fruchtbar, da hier die Punkte offenbar werden, an denen Irritationen möglich oder Stärkungen der Subjekte wirkungsvoll sein können.

Meiner Kategorie Selfing/Othering liegen all jene Aussagen von Schüler_innen zugrunde, in denen Zuschreibungen und Zugehörigkeiten in Bezug auf migrationsgesellschaftliche Prozesse des Selfing und Othering verhandelt werden. Aus der sich daraus ergebenden Datensammlung haben sich im Zuge der Analyse fünf Unterkategorien herauskristallisiert.

Im Abschnitt zu Islam vs. Westen gehe ich der Frage nach, inwiefern die Schüler_innen eben diese Dichotomie verwenden bzw. ob sie diese problematisieren und wenn ja, auf welche Weise. Hier folge ich den Spuren in drei Schritten. Zunächst arbeite ich die dominanten Formen heraus, wie sich anhand der Topoi Säkularität/Religiosität, Geschlechterrollen und Freiheit diese Dichotomie in den Vorstellungen der Schüler_innen entfaltet. Im Anschluss gehe ich dem, in diesem Zusammenhang sehr verbreiteten, Duktus der Toleranz und seiner verschiedenen Formen nach. Abschließend stelle ich einige Ansätze zur Kritik des antimuslimischen Rassismus dar.

Im zweiten Abschnitt geht es darum, inwiefern Farbe als Zugehörigkeitsmarker in den Vorstellungen der Schüler_innen als Form des Othering auftaucht und wie sich von dieser Form abgegrenzt wird und sie grundlegend infrage gestellt wird.

Im dritten Abschnitt geht es um Vorstellungen, die sich mit sogenannter Integration im Kontext migrationsgesellschaftlicher Realitäten befasst. Ich werde hier 
darstellen, wie insbesondere anhand der Themen Sprache, Arbeit und Kultur Zugehörigkeitspatterns konstruiert werden. Diese machtvollen Formen fasse ich als Integrationsparadigma. Während dieses kaum explizit kritisiert wird, ist auffällig, dass viele die Verwendung der damit zusammenhängenden Logik quasi umschiffen.

Der vierte Abschnitt dreht sich um Hybridität. Hier habe ich vier Typen von Vorstellungen herausgearbeitet, wie Hybridität in der Migrationsgesellschaft von den Schüler_innen gedacht wird: (1) Irritation oder Angst vor Vermischung, (2) der konsumierbare Andere, (3) Erweiterung des Erfahrungsraumes, (4) Normalität gelebter Hybridität. In den ersten dreien spielen verschiedene Formen eines essenzialisierenden und homogenisierenden Kulturverständnisses eine große Rolle.

Im fünften und letzten Abschnitt dieser Kategorie Selfing / Othering geht es um ein Kulturverständnis, mit dem das Nicht-Okzidentale als Kultur erscheint, während durch die Konstruktion des Okzidentalen als Nicht-Kultur hier die koloniale Differenz auf ambivalente Art und Weise aufscheint und dabei allerdings nicht unwidersprochen bleibt.

\subsubsection{Islam vs. Westen}

In dieser Unterkategorie liegen alle Aussagen der Schüler_innen zugrunde, in denen es um ,Islam', Muslime, ,Araber' und den ,Westen“ geht. In der Analyse liegt der Fokus dabei auf der Frage, ob eine orientalistische Dichotomie konstruiert wird, wie diese ausgestaltet ist und wie dieses Paradigma umgangen oder infrage gestellt wird. Der ,Westen " wird in anderen Kontexten auch allgemeiner, beispielsweise als Gegenstück zum Globalen Süden, konstruiert. In diesem Kapitel geht es aber - wie oben genannt - um das imaginierte Verhältnis zwischen dem ,Islam ' und dem ,Westen'. Eine weitere Fokussierung in der Analyse dieser Unterkategorie besteht darin, dass ich nur die Aussagen untersuche, die relevant für migrationsgesellschaftliche Fragen sind. Andernfalls wäre eine Trennschärfe dieser Kategorie zu Unterkategorien des ersten Analyseabschnitts zu Eurozentrismus nur schwierig herzustellen. In der Analyse der Aussagen der Schüler_innen zum Westen und zum Islam habe ich drei Differenzmerkmale als zentral ausgemacht: Säkularität und Religiosität, Geschlechterrollen - wobei hier Fragen zum Kopftuch fast einen eigenen Unterpunkt darstellen - und Freiheit. Dies werde ich anhand von den zwei Beispielen Jannik (Gym01) und Finn (HS04) darstellen. Insgesamt tritt beim Sprechen über den Islam oder Muslime häufig ein Toleranzdiskurs hervor, den ich kurz anhand vom Beispiel Jennifer (HS12) zeige. Mehrere Schüler_innen äußern sich explizit kritisch zu antimuslimischem Rassismus und sehen das Problem nicht in einer kulturellen Differenz, sondern vielmehr in dem 
diese begründende Herrschaftsverhältnis. Hier werde ich exemplarisch die Fälle von Memnun (HS08) und Lara (Gym18) vorstellen.

\section{Säkularität/Religiosität, Geschlechterrollen und Freiheit}

Jannik (Gym01) antwortet auf die Frage, ob sich Kultur irgendwie durch Globalisierung verändert.

I: Mhm. Ja. Das stimmt. Ähm, ich habe noch eine Frage zu einem anderen Bereich: Glaubst du, Kultur verändert sich durch Globalisierung?

S: Ja. (...) In manchen Ländern mehr, in manchen Ländern weniger. Da wo die Kultur durch Religion bestimmt ist, denke ich mal, dass das eher langsamer geht, dass sich die Kultur verändert. Aber die, die eigentlich eher wie hier ... dass sich die Kultur hier schneller verändert. Auf jeden Fall. Ähm, da wo es halt sich entwickelt hat durch bestimmte Richtlinien wie, ich sag' ich jetzt mal, islamische Länder, da geht das bestimmt nicht so schnell, dass die Kultur komplett sich verändert. Komplett verändern wird sie sich wahrscheinlich sowieso nicht. Ein paar Sachen werden immer dableiben. Aber sie verändert sich schon im Großen und Ganzen. Die Kultur hier in Deutschland hat sich bestimmt auch geändert, jetzt in der letzten Zeit. Es gibt zwar immer noch dieselben Feiertage und so weiter und so fort. Aber, ähm, ich denke auch mal durch den kompletten Medieneinfluss wird sich das ein wenig auch ändern, weil man sich Kulturen aus anderen Ländern anguckt. Sich irgendwelche Dinge anguckt und auch abguckt, wo man dann denkt: „Ach ja. Das ist ja eigentlich doch ganz nett. Das kann man bestimmt hier auch irgendwie einführen." Und dass sich das dann alles miteinander vermischt. Außerdem hat man ja auch noch, dass durch die Globalisierung jetzt nicht mehr .../Früher war meine Mutter die einzige Türkin an einem Gymnasium. Und jetzt, wenn man sich hier heute unsere Schule anguckt, da ist ja die Hälfte oder drei Viertel hat ausländische Wurzeln. Ich bin ja selber halb Türke so. Und durch diese ganze Vermischung, ähm, denke ich mal, dass sich da die Kultur auch ein bisschen verändert. In manchen Ländern halt mehr und in manchen weniger. (Jannik, Gym01)

,Kultur ' - hier verstanden als eine Lebensweise, die einem spezifischen Land eigen ist - verändert sich, Jannik zufolge, verschieden schnell. Den Unterschied macht hier die Religiosität aus; wenn also eine „Kultur durch Religion bestimmt“ sei, verändere sie sich ,langsamer“. Sein Beispiel sind die ,,islamischen Länder“, wo es „,bestimmt nicht so schnell“ geht, dass ,die Kultur sich komplett verändert“. Er fügt hinzu: „Komplett verändern wird sie sich sowieso nicht.“ Es ist nicht eindeutig, ob diese Aussage nun als ein Spezifikum für ,,islamische Länder“ zu verstehen oder vielmehr allgemein gilt. Es liegt aber nahe, dass sie allgemein gilt, da er danach auf die Veränderung der Kultur in Deutschland zu sprechen kommt. Seine Ideen zur „Vermischung“ werde ich an dieser Stelle nicht ausführlich und explizit diskutieren, da sie dem Abschnitt zu Hybridität (3.2.4) angehören und hier in eine andere 
Richtung führen würden. An dieser Stelle ist davon von Interesse, dass er diese als positiv ansieht und sich selbst als ,halb Türke“ positioniert. Der zentrale Punkt für die Analyse dieses Zitats ist die Herstellung der Differenz durch das Kriterium der Religiosität, das er als ausschlaggebend für die Veränderbarkeit einer Kultur darstellt. Das implizite Gegenbild ist das einer säkularen Kultur. Dies stellt für Jannik das zentrale Differenzmerkmal zwischen den ,,islamischen Ländern“ und ,,Deutschland“ dar. Darauf folgt ein Gesprächsabschnitt zu der Veränderung von Film- und Esskultur, den ich hier nicht zitiere. In dem Abschnitt ist insbesondere der Gedanke der Erweiterung des kulinarischen Spektrums in Deutschland von ,deutschen Kartoffeln“ durch eingeführte Produkte auffällig, wie etwa „,spanische Tomaten“. Im Anschluss daran frage ich nach Sprachen.

I: Mhm. Du hast ja vorhin auch gesagt, dass überall jetzt Englisch gesprochen wird. Das ist ja vielleicht auch .../

S: Ja, stimmt! Das kann man auch nehmen, dass, ähm, jetzt mittlerweile nicht mehr nur Deutsch oder halt die eigene Sprache, Muttersprache gelernt wird, sondern, ähm, um mittlerweile hier in Deutschland an einem Gymnasium den Abschluss machen zu können muss man drei Sprachen können, zwei Fremdsprachen. Die eine mindestens fünf Jahre. Und, ähm, das ist auch Teil, auf jeden Fall, der Globalisierung und Kulturveränderung. Weil man dadurch den Leute schon praktisch das Angebot gibt: „Los. Geh’ ins Ausland. Mach' da irgendwas.“ Ja. (...) Und dadurch vermischt sich ja eigentlich auch alles miteinander wieder. (.....) Und ich weiß auch nicht, inwiefern sich die Kultur verändert .../ Also, wir haben jetzt, sag' ich jetzt mal, immer noch so die ziemlich deutsche Kultur. Ich weiß jetzt auch nicht wie das ist, wenn jetzt hier halt, ähm, Immigranten sind. Wie das bei denen dann ist mit der Kultur. Und wie die die deutsche Kultur sehen, wie ihre Kultur sehen und wie die die Veränderung oder Vermischung sehen. Jeweils halt. Aber man sieht es auch, dass es immer noch abgrenzt ist. Dass hier teilweise muslimische Schüler Feiertage haben an Tagen, wo wir Schule hätten zum Beispiel. Das gibt es ja auch. Ja, deswegen. In gewissen Weisen wird es vermischt, in anderen bleibt es halt gleich. (Jannik, Gym01)

Ohne hier das Kapitel zu Hybridität vorwegnehmen zu wollen, ist dieser Aspekt sehr zentral für Janniks Umgang mit der Diskussion um den Islam und Muslime in Deutschland. Für ihn, wie auch für viele anderen - kommt er immer wieder auf das Beispiel der Muslime als Andere zurück. Dabei diskutiert Jannik - und zahlreiche andere Schüler_innen - die Unterschiede sehr viel weniger absolut und auch unaufgeregter als es in Diskussionen in den Medien zu beobachten ist. Von seinen Überlegungen zu Sprachen kommt er wie automatisch zu ,Kultur ${ }^{6}$, die er scheinbar als eine Verknüpfung von einer vermeintlich gruppenspezifischen Lebensweise mit identitärer Verortung begreift. Er begreift sich als Teil der „deutsche[n] Kultur“, wenn er sagt, dass ,wir [...] immer noch die so ziemlich deutsche Kultur" hätten. 
Er thematisiert aber direkt im nächsten Argumentationsschritt die Perspektive von „Immigranten“ und fragt, wie diese wohl ,die deutsche Kultur“, ,,ihre Kultur“ und die „Veränderung oder Vermischung“ sehen. Er stellt fest, dass es ,immer noch abgegrenzt" sei. Als Beispiel führt er an, dass hier ,teilweise muslimische Schüler Feiertage haben an Tagen, wo wir Schule hätten“. So kommt er zu der unaufgeregten Schlussfolgerung: „In gewissen Weisen wird es vermischt, in anderen bleibt es halt gleich.“ Ich frage daraufhin nach seinem Verständnis von deutscher Kultur.

I: Mhm. Und was wäre für dich deutsche Kultur? Oder inwiefern wird die sozusagen ... verändert die sich durch die Globalisierung? (...) Auch wieder eine schwierige Frage.

S: Auch wieder eine schwierige Frage!

I: Ich bin gespannt.

S: Erstmal fragen was deutsche Kultur ist. So. Ähm (...). Mhm (...). Das ist wirklich, ähm, ja .../ Also was halt in Deutschland bei mir .../ Oder was da viel ist .../ Wo ich mir jetzt was vorstellen könnte war halt früher viel Theater und Vorstellungen und so was in der Art. Während die deutsche Kultur zum Teil aber auch christlich bedingte .../Ich meine man hat ja immer noch irgendwelche Feiertage wie Christ Himmelfahrt oder so was. Wo man dann frei hat. Deswegen, ein bisschen muss da ja auch gewesen sein. Ähm, kommt ja auch von den Ursprüngen hier ganz groß. Hier die Römer, die hier in Deutschland dann waren, haben das ja alles mitgebracht, denke ich mal. Ja, genau. Geschichte. Und, ähm, ja .../ Deutsche Kultur? Was gehört denn noch zur Kultur? Also die Deutschen waren ja generell eigentlich von der Kultur her immer etwas freier als die anderen. Wenn man jetzt FKK Strände zum Beispiel nimmt, das ist ja .../ Ist das deutsch? Kam das aus Deutschland?

I: Weiß ich gar nicht.

S: Aber auf jeden Fall ist das eine relativ freie Sache gewesen, wenn man das jetzt mit anderen Kulturen vergleicht wo die sich bedecken müssen oder ihre Reize verdecken müssen. Oder wollen. Sagen wir mal wollen, nicht müssen. Dass die Deutschen da eigentlich immer schon relativ frei waren. Und ich denke, dass jetzt auch dieser Trieb zum Freiheitsdenken auch immer weiter kommt. Das heißt die deutsche Kultur verändert sich vielleicht gar nicht so stark. Aber andere Kulturen eventuell schon, die jetzt auch denken: "Mhm. Ich kann jetzt mein Ding durchziehen und nicht irgendwie andere Sachen." Aber zu den Ländern habe ich jetzt kein Beispiel. Das weiß ich jetzt nicht. (Jannik, Gym01)

Eindeutig ist, dass er keine eindeutige Antwort auf die Frage hat, was deutsche Kultur ist. Im ersten Ansatz denkt er an ,Theater und Vorstellungen“, die es ,früher viel“ gegeben hätte. Dies erinnert mich an die nationalistische Metapher des ,Landes der Dichter und Denker‘. Doch diesen Gedanken verfolgt er nicht weiter und setzt neu an. So sei die „,deutsche Kultur zum Teil aber auch christlich“ geprägt. Er sieht aber 
das Christliche offenbar nicht als lebendige Praxis der Gegenwart der , deutschen Kultur' an, sondern vielmehr als Relikte der Vergangenheit, die noch in ,,irgendwelche[n] Feiertagen“, an denen ,man dann frei hat“, aufscheinen würden. Deswegen müsse da ,ein bisschen [...] ja auch gewesen sein“. Er sieht das Christliche also weniger als einen gegenwärtigen Teil , deutscher Kultur` an, sondern vielmehr als nur noch symbolisch aufscheinenden Teil des Entstehungskontexts der, deutschen Kultur“. So kommt er dann auch gedanklich zu den „Ursprüngen“, von denen das ja „ganz groß“" komme. Die „Römer“, die ,hier in Deutschland“ gewesen seien, hätten „,das ja alles mitgebracht“. Nun setzt er neu an. Dabei bleibt unklar, ob es eine Verbindung des neuen Arguments zu den christlichen oder römischen Ursprüngen gibt. Jannik stellt fest, dass , die Deutschen [...] ja generell eigentlich von der Kultur her immer etwas freier als die anderen" gewesen seien. Als Beispiel führt er die FKK-Strände an. Diese Praxis sei eine ,relativ freie Sache“ gewesen; insbesondere im Gegensatz zu ,,anderen Kulturen [...], wo die sich bedecken müssen oder ihre Reize verdecken müssen“. Im Anschluss korrigiert er sich selbst und tauscht ,müssen“ gegen ,wollen'. Damit spricht er implizit die Frage der Agency von Muslimen und vor allem Musliminnen an, zu der wir weiter noch kommen werden. Mit dem Herausstellen des, Wollens ' hebt er sich von einigen anderen Schüler_innen ab, bei denen Muslim_innen eher als willenlose Opfer einer religiösen Herrschaft erscheinen.

Aus dieser Gegenüberstellung der freiheitlichen Freikörperkultur in Deutschland und der Praxis der Verdeckung der „Reize“ leitet Jannik ein Wesensmerkmal der „Deutschen“ ab, die ,eigentlich immer schon relativ frei waren“. Er sieht hier einen „Trieb zum Freiheitsdenken“, den er als ,deutsch“ oder , westlich“ kategorisiert. Da dieser Trieb Teil des Deutschseins sei, gehe es immer weiter, ohne dass sich die „,deutsche Kultur [...] so stark“ verändern müsste. Im Gegensatz dazu würden sich ,,andere Kulturen“ eventuell schon stärker verändern müssen, wenn in diesen dieser „Trieb zum Freiheitsdenken“ auch Fuß fassen würde. Jannik beschreibt dieses Fußfassen des „Triebs zum Freiheitsdenken“ in ,,anderen Kulturen“ mit der Ausweitung individualistischer Freiheit, wenn ,,ich jetzt mein Ding durchziehen [kann] und nicht irgendwie andere Sachen“. In diesen ,,anderen Kulturen“ ist es also Jannik zufolge so, dass die Menschen bisher fremdbestimmt waren und keine individuelle Freiheit ausleben konnten und können. Im Gegensatz dazu zeichne sich ,deutsche Kultur" genau durch die Autonomie und Selbstbestimmung aus.

Er stellt fest, dass ihm kein Land als Beispiel einfalle. Allerdings lassen sich durch andere Stellen einige Verknüpfungen herstellen, die nahelegen, dass Janniks Vorstellungen über die Dichotomie der freien und unfreien ,Kulturen “ die ,,islamischen Länder" und die ,westliche Welt" meinen, wie etwa im folgenden Zitat. 
I: Und du hast vorhin schon die islamischen Länder angesprochen.

S: Ja.

I: Ähm, wieso verändern die sich anders als, ähm .../ Also, wieso sind die anders von der Globalisierung betroffen als jetzt zum Beispiel Deutschland?

S: Weil die einfach ganz andere Grundgedanken haben und eine ganz andere Mentalität. Also, ähm, die haben ja auch ganz .../ Also, die islamischen Länder, die sehnen sich ja alle ziemlich noch nach den nahöstlichen Ländern. Die halten sich ja so ziemlich daran. Und die westliche Welt .../ Das kann man jetzt auch wieder sagen: Westliche Welt/Östliche Welt/Globalisierung und so weiter. Mhm. Ähm, Türkei ist jetzt zum Beispiel ein Beispiel, die wollen sich ja immer weiter an die westliche Welt annähern. ABER, man merkt halt immer noch total, dass das ein islamisches Land ist. Also da bin halt auch öfter jetzt mal, ähm, gewesen. Man merkt halt an der Kultur, die sind schon freier als andere islamische Länder, aber halt trotzdem immer noch so ein bisschen ... nicht so frei. Also die .../ Mhm. Wie verändern die sich anders? (...) Wir haben halt Gesetze nach Grundgesetzen, würde ich jetzt man sagen, den Human Rights, ich weiß jetzt nicht den Menschenrechten oder halt nach Menschenverstand. Wir haben jetzt keine christlichen Gesetze, wie zum Beispiel .../ Na gut, okay „Du sollst nicht töten“ gibt es im Islam auch. Aber wir haben jetzt .../ Aber da wird das ja auch viel durch den Koran eigentlich, glaube ich schon, als Gesetz auch gegeben. Dementsprechend kann sich das da anders verändern als hier, wenn da andere Grundgedanken in der kompletten Lebensweise sind. (Jannik, Gym01)

War es an vielen Stellen im Gespräch mit Jannik unklar, inwiefern die Unterschiede zwischen den ,islamischen Ländern“ und der ,,westlichen Welt" eher graduell oder als Wesensunterschied denkt, erscheint die Differenz in diesem Abschnitt sehr absolut. Die ,,islamischen Länder“ hätten ,einfach ganz andere Grundgedanken“ und eine „ganz andere Mentalität“ als die „,westliche Welt“. Es scheint so, als stelle er zwischendurch diese Dichotomie als solche infrage, wenn er die ,westliche Welt“ als Kategorie einführt; ,das kann man jetzt auch wieder sagen: Westliche Welt/Östliche Welt/Globalisierung und so weiter". Hier erscheint ihm die dichotomische Kategorisierung leichtes Unwohlsein zu bereiten. Doch dieses wird von ihm durch die Beobachtung davon aufgelöst, dass es durchaus Anpassungsbestrebungen einiger ,,islamischen Länder“ an die ,westliche Welt“ gäbe. Als Beispiel führt er die Türkei an. Diese wolle sich zwar ,,annähern“, aber man merke ,,halt immer noch total, dass das ein islamisches Land“ sei. Man merke an der „Kultur“, dass „die“ da ,schon freier als andere islamische Länder“ seien, ,aber halt trotzdem immer noch so ein bisschen ... nicht so frei“". Der dichotomisierende Differenzmarker von Freiheit/Unfreiheit spielt bei vielen Schüler_innen eine zentrale Rolle. Die Grundannahme ist hier, dass die ,islamische Welt“ ihrem Wesen nach unfrei sei, während die ,westliche Welt“ im spiegelbildlichen Gegensatz frei sei, 
also Autonomie, Individualität, Meinungsfreiheit, Freiheit der Vernunft usw. beinhaltet. Auffällig ist außerdem das - nicht nur bei Jannik immer wiederkehrende - Rekurrieren auf die koloniale Temporalität, was sich in Ausdrücken wie „noch nicht“, ,immer weiter“, „schon“ usw. ausdrückt.

Jannik stellt eine einseitige Tendenz der - offensichtlich von Jannik befürworteten - Anpassung der ,östlichen Welt" an die ,westliche Welt" fest. Allerdings sieht er hier eine grundlegende Differenz, die diese Tendenz behindert. Die Fähigkeit zur Veränderung der „östlichen Welt“ sei eingeschränkt, da diese andere „Grundgedanken in der kompletten Lebensweise“ "hätten. Während ,wir“ - damit ist Deutschland oder die „westliche Welt“ gemeint - ,halt Gesetze nach Grundgesetzen“ bzw. den „Menschenrechten oder halt nach Menschenverstand" hätten, seien die Gesetze und die Gesellschaftsordnung in der "östlichen Welt" von der Religion bestimmt. „Hier“ gäbe es keine „,christlichen Gesetze“, während der „Koran“ in der „östlichen Welt“ das Gesetz bestimme. Diese Differenz wird auch nicht durch Ähnlichkeiten zwischen Christentum und Islam aufgehoben, wie etwa dem Gebot „Du sollst nicht töten“. Der Differenzmarker verläuft zwischen einer angenommenen Säkularität der „westlichen Welt“ und einer angenommen Religiosität der „östlichen Welt“ als wesensbestimmende Eigenschaften. Diese dem Westen zugeschriebene Säkularität funktioniere laut Jannik statt nach religiösen Prinzipien nach dem Prinzip der „Menschenrechte oder halt dem Menschenverstand“. Dies ist ein klassisches Theorem der Aufklärung. Andersherum steht also die „östliche Welt“ für Ungleichheit und Ungerechtigkeit statt für Menschenrechte und für Unvernunft statt für Vernunft. Gerechtigkeit und Vernunft wird so zu einer Eigenschaft der ,westlichen Welt“.

Finn (HS04) assoziiert mit dem Begriff, Globalisierung ' insbesondere ,Modernisierung". Dabei argumentiert er häufig auf einer technischen und infrastrukturellen Ebene. Das von ihm vermutete implizite Ziel der Globalisierung sieht er in der Herstellung von mehr Gleichberechtigung, die er befürwortet.

I: Mhm. Und fallen dir noch andere Aspekte zu Globalisierung ein? Also, du hast jetzt sehr stark Modernisierung gesagt. Und gibt es noch andere?

S: Globalisierung? Vielleicht, dass kein Krieg mehr ist zum Beispiel? Wie jetzt zum Beispiel gerade in ... wo ist das? Auch in Afrika da gerade? Ja, da jedenfalls.

I: Meinst du in Mali?

S: Genau in Mali. Da werden ja auch die Soldaten hingeschickt jetzt wieder. So wie es auch in Afghanistan war. Ich denke das ist, weil die wollen jetzt eigentlich auch damit erreichen, dass kein Krieg mehr auf der Welt existiert. Dass eben alle friedlich zusammenleben.

I: Mhm. Und du hast vorhin auch gesagt ,gleichberechtigt zusammenleben“? 


\section{S: Genau.}

I: Was heißt das? „Gleichberechtigt“?

S: Ja, dass zum Beispiel jetzt, wie in Saudi-Arabien .../Da sind die Frauen benachteiligt, da sind die Jungs wertvoller. Das finde ich wieder blöd, weil die ja auch nur Menschen sind. Und haben auch genau das gleiche Recht, wie ein Mann. Ja, und deswegen finde ich das eigentlich dann besser, wenn alle gleichberechtigt sind. (Finn, HS04)

Diese Wendung des Interviews war für mich vor allem deswegen überraschend, da Finn vorher über Armut und schwierige Lebens- und Arbeitsbedingungen im Globalen Süden berichtet hatte und insofern ein Bezug von „Gleichberechtigung“ auf diese Ungleichheiten nahegelegen hätte. Stattdessen assoziiert er damit aber die durch kulturelle Differenz begründete Gender-Ungleichheit.

I: Mhm. Und das passiert durch die .../ Wodurch passiert das, dass alle gleichberechtigt sind?

S: Ja, auch durch die Globalisierung. Dass eben dann friedliches Zusammenleben ist. Und dann wird sich das ja auch ändern irgendwann automatisch. Und wenn nicht der religiöse Hintergrund dabei so wäre. Weil, der bestimmt ja auch vieles der Menschen. Gerade in solchen Ländern dort.

I: In welchen Ländern?

S: Ja, auch so arabische Länder. Die haben ja so einen Glauben, dass Frauen nichts Wert, sag' ich mal, sind. Und die Männer alles können. Und damit hat das auch noch ein bisschen was zu tun, dass das nicht so schnell geändert wird. Denke ich mal. (Finn, HS04)

In der Globalisierung sieht er die treibende Kraft für Frieden und Gleichberechtigung, welche durch die Globalisierung ,,irgendwann automatisch“ einträten. Es ist aber die von Finn angenommene Religiosität in den ,arabische[n] Ländern“, die diesem Prozess im Weg steht bzw. die dafür sorgt, dass ,,das nicht so schnell geändert wird“. Er nimmt an, dass „,die“ in den „,arabische[n] Ländern“ einen „Glauben“ hätten, dass „Frauen nichts Wert [...] seien“. In diesen wenigen Sätzen konstruiert Finn eine homogene Gruppe der Menschen in den ,,arabische[n] Ländern“, die sich durch Religiosität und Gender-Ungleichheit charakterisieren. Religiosität und Gender-Ungleichheit werden auf diese Weise zum zentralen Differenzmarker zum ,Westen“ oder Deutschland.

Religiosität und Genderungleichheit werden hier auf eine spezifische Weise miteinander verknüpft. Während es - wie am Beispiel von Jannik gezeigt - bei der Verknüpfung von Religiosität und Freiheit eher allgemein die Religiosität sei, die 
insbesondere in den „,arabischen Ländern“ und bei ,Muslim_innen“ zu Unfreiheit führte, ist es in diesem Beispiel und in zahlreichen anderen Interviews bei der Verknüpfung von Religiosität und Genderungleichheit nicht die Religion als solche, sondern die muslimische Religion, die als ursächlich für die Genderungleichheit gesehen wird. In Finns Worten hätten ,die [...] ja so einen Glauben“, womit er auf den spezifischen Glauben verweist. In der Folge führt er seine Vorstellungen über Genderungleichheit weiter aus.

I: Mhm. Und jetzt in arabischen Ländern sagst du .../ Warum besonders in arabischen Ländern?

S: Ja, das kenne ich eben so, dass diese Scheichs und alle, die da sind, die Reichen, eben auch hunderte Frauen haben und die machen die ganze Arbeit, sag' ich mal. Und die Männer, die lassen sich ein schönes Leben machen. Also, die Frauen müssen arbeiten und die Männer haben ein schönes Leben.

I: Mhm. Und, ähm, das ist zufällig in arabischen Ländern so?

S: Es gibt auch noch vereinzelte andere Länder wo das so ist. Aber ich sag' jetzt mal so, insbesondere finde ich das immer bei den arabischen Ländern so. Weil ich das eigentlich bei fast jedem so ist, das ich kenne. Saudi-Arabien. Türkei, da ist das ja auch noch teilweise so, obwohl das verboten würde. Ja, eben solche Länder. Deswegen denke ich mal, dass es dort extrem ist. (Finn, HS04)

Finns Illustration der Genderungleichheit in den ,arabische[n]“ Ländern ist bestimmt von einem extremen Bild islamischer Polygamie, der an orientalistische Fantasien von ,morgenländischen' Haremsstrukturen erinnert. Dieses Bild verknüpft er mit der Frage von sozialer Ungleichheit und geschlechtlicher Arbeitsteilung. Zwar macht für ihn scheinbar diese patriarchale Struktur die Sozialbeziehungen in den ,arabischen Ländern“ aus, andererseits sei sie nur für die Reichen realisierbar. Die Rolle der Frauen innerhalb seiner Vorstellung der geschlechtlichen Arbeitsteilung wird dabei nicht durch als weiblich konnotierte Arbeit charakterisiert. Vielmehr stellt er sich die Frauen als ausgebeutete Arbeiterinnen vor, die die „ganze Arbeit“ machten, während die Männer „sich ein schönes Leben“ machten. Er schließt dabei nicht aus, dass es ,noch vereinzelte andere Länder“ gäbe, in denen es eine solche Genderungleichheit gäbe. Allerdings fände er das ,,insbesondere [...] immer“ in den „,arabischen Ländern“. Dort sei es „,bei fast jedem so“, das er kenne. Im Gegensatz zu Saudi-Arabien sei es in der Türkei nur noch „teilweise so“. Auch wenn Finn die Option offen lässt, dass es auch in ,nicht-arabischen ' Ländern Genderungleichheit gäbe und er graduelle Abstufungen sieht, charakterisiert er , arabische Länder' als durch Genderungleichheit geprägt, während, im Gegensatz dazu, eine solche im ,Westen ' von ihm nicht gesehen wird. 


\section{Toleranz}

Ebenfalls weit verbreitet in den Vorstellungen über das Verhältnis zwischen dem ,Westen “ und dem ,Islam“ ist ein Umgang, den ich als Toleranzdiskurs zusammenfasse. Auf die Frage, ob sich die Kultur irgendwie durch Globalisierung verändere, spricht Anna (HS16) das Thema Moscheen an.

I: Und glaubst du, dass sich die Kultur dadurch verändert? [...]

S: Ähm, und es werden jetzt Moscheen auch hier in Deutschland gebaut. Und, ähm, da gibt es schon Leute, die sagen, dass die das .../ So Menschen, die halt an Jesus glauben sagen, dass das nicht gut ist, weil dann mehrere von der Kirche zur Moschee gehen. Halt lieber zur Moschee gehen. Weil, diese Kultur gefällt denen halt besser. Oder halt auch andersherum. Und, ähm, deswegen gibt es auch immer so, denk' ich mal, Krieg so zwischen .../ Also, dass denen das in der Türkei das nicht so gefällt, weil sich das halt alles ändert. Dass immer mehr rübergehen nach Deutschland. Und da in die Kirchen auch dann gehen.

I: Und deswegen gibt es Krieg in der Türkei?

S: Also, nee. Also, ich weiß nicht wie ich das sagen soll. Aber ich denke schon, dass die das nicht ganz so toll finden. Die, die einen richtig starken Glauben haben. Oder halt auch was .../ Oder den Glauben unter etwas anderem verstehen. Also, dass sie .../ Es gibt ja hier so etwas wie, ähm, Allah oder so. Und der sagt ja auch: „Man soll nicht töten. “ Aber die Leute töten, ähm, Leute und drohen denen, damit sie halt in der Moschee bleiben, sozusagen. So kann ich mir das gut vorstellen halt. Ja [lacht].

I: Und was denkst du dazu? Warum machen die das?

S: Warum die das machen?

I: Oder machen das nur Leute in Moscheen?

S: Also, ich denke, dass das überall so ist in den Kulturen. Dass irgendwelche das nicht gut finden und deshalb, ähm, schlechte Sachen machen halt.

I: Mhm. Also auch im Christentum?

S: Ja, also ich denke schon. Es gibt ja halt sehr viele böse Menschen. (Anna, HS16)

Interessant erscheint mir zunächst, dass Anna bei der Frage nach einer Veränderung der Kultur durch die Globalisierung das Thema Moscheen assoziiert. Dabei hatte ich im Vorhinein schon mit dem Stichwort Coca Cola zum Thema Kulturveränderung eine andere Fährte gelegt, die möglicherweise zur globalen Arbeitsteilung, globalen Marken usw. hätte führen können. Stattdessen sieht Anna dieses Thema als wichtig an. Sie beschreibt das Verhältnis zwischen Anhänger_innen von christlichen Kirchen und dem Islam als zumindest potenziell konflikthaft. Dieser Konflikt entspringt 
in ihrer Vorstellung einem Konkurrenzverhältnis, in dem beide Glaubensinstitutionen um Anhänger_innen buhlen. Auf Nachfrage erläutert sie ihr Bild von einer potenziell gewaltvollen Kultur innerhalb von Moscheen. Trotz eines Widerspruchs zu den Lehren des Islam - wie beispielsweise ,du sollst nicht töten“ - würde getötet und bedroht, um den Weggang von Religionsanhänger_innen zu unterbinden. Auf weitere Nachfrage sieht sie diese Anwendung von Gewalt, die sie zunächst mit dem Islam assoziiert hatte, aber nicht als Charakteristikum des islamischen Glaubens, sondern vielmehr in allen „Kulturen“, auch im Christentum. Den Grund dafür sieht sie scheinbar nicht in der Religion, sondern darin, dass es ,halt sehr viele böse Menschen" gäbe.

Im weiteren Gespräch stellt sie die Frage der Religionszugehörigkeit noch expliziter als die Frage einer persönlichen Vorliebe heraus, die auch als solche akzeptiert werden sollte.

$\mathrm{S}$ : Also so .../ Mhm, das ist ja eigentlich wie als wenn .../ Das ist jetzt ein doofes Beispiel, aber wenn alle sagen .../ Das hatten wir letztens zum Beispiel. Ich mag kein Schokoladeneis. Und, ähm, wir wollten Eis kaufen. Und haben Leute gefragt: „Was magst du denn für Eis nicht?“ Damit man es halt nicht kauft. Da habe ich gesagt: „Ich mag kein Schokoladeneis.“ Und alle so: „Hä? Warum magst du kein Schokoladeneis? Das mag doch jeder!“ Und, ähm, ja .../

I: Dass so was halt doof ist, dass man einfach so eine Meinung oder Vorliebe von jemand dann so ... sich dann darüber lustig macht?

S: Ja, also die sagen dann halt: „Nee. Du sollst das aber mögen. Das mag jeder. Also sollst du das auch tun." Und das ist halt nicht schön. Das ist doof. (Anna, HS16)

Ihre Metapher ist dabei eine negative: Sie mag kein Schokoladeneis, wird deswegen als Abweichlerin angesehen und es wird ihr gesagt, dass sie es aber mögen sollte, da alle es mögen. Mit diesem Bild kritisiert sie Praxen innerhalb und zwischen Glaubensgemeinschaften, in denen eine religiöse Vorliebe nicht einfach als solche toleriert wird. Anna plädiert dafür, dass es eine persönliche Entscheidung ist, welche religiöse Vorliebe man hat. Sie findet es „nicht schön“ und „doof“, wenn in diese persönlichen Vorlieben reingeredet wird.

Jennifer (HS12) argumentiert ähnlich.

S: Ich finde .../ Die sagen ja, dass ihre Religion auch eine Religion ist. Und ich finde das ist auch so. Jeder kann ja nach seiner Religionsart leben. Und das ist ja auch in Ordnung, finde ich.

I: Mhm. Ja. Und glaubst du, dass manchmal Leute wegen ihrer Religion irgendwie diskriminiert werden oder so? 
S: Bestimmt. Ja, auf jeden Fall.

I: Auch hier in Deutschland?

S: Ja.

I: Wer zum Beispiel?

S: Zum Beispiel auch die Türken. Die meisten sagen dann: „Warum tragen die ein Kopftuch? Das ist doch voll hässlich.“ Das sagen ganz viele. Aber das ist ja deren Religion. Manche leben ja auch ... essen nur abends und so.

I: Mhm. Und wieso sagen manche Leute, dass ein Kopftuch hässlich ist?

S: Jeder hat ja einen anderen Geschmack. Aber, wenn das deren Religion ist, können die das ja machen. Das müssen die ja wissen so ein bisschen. (Jennifer, HS12)

Jennifer stellt zunächst fest, dass ,,jeder [...] nach seiner Religionsart leben“ könne. Auf die Nachfrage, ob Menschen wegen ihrer Religion möglicherweise diskriminiert werden, auch in Deutschland, bringt sie das Beispiel der ,Türken“. Die meisten würden hier sagen, ,warum tragen die ein Kopftuch? Das ist doch voll hässlich.“ Das würden ,ganz viele“ sagen. Diese Einstellung sieht sie also als sehr verbreitet an. Jennifer kritisiert dies aber. Diese Form der Abwertung sei nicht okay, da sie der Religionsfreiheit widerspreche.

Lisa (Gym07) reflektiert ausgehend vom Thema EU über die Haltung zum Islam und hier insbesondere zum Kopftuch.

I: [lacht] Alles gut. Mhm, dann hast du vorhin auch nochmal kurz die EU angesprochen.

Was hältst du von der EU?

S: Also, ich kenne mich eigentlich nicht so mit der EU aus. Aber ich weiß halt .../ Nee, also ich kenne mich da eigentlich nicht so richtig aus. Ich kenne halt nur ein paar Länder, die jetzt nicht mit dazugehören. Aber sonst? Ich weiß nicht. Ich glaube man muss halt bestimmte Vereinbarungen, also Bedingungen, einhalten, um in die EU zu kommen. Und ich finde das auch eigentlich ganz okay. Weil zum Beispiel .../Ich weiß jetzt nicht so genau die Bedingungen, aber war das nicht auch irgendwie so, dass die Frauen irgendwie kein Kopftuch tragen müssen in der Türkei? Ich bin mir nicht sicher. Also wenn das so war, dann finde ich das einerseits nicht so gut, weil eigentlich ist das ja deren Kultur und deswegen könnte man es so lassen. Aber anderseits finde ich es auch verständlich. Weil, wenn man sich schon so da rein integrieren will, dann muss man auch schon was dafür tun sozusagen.

I: Mhm. Und was denkst du zu dieser Kopftuch-Frage?

S: Oh Gott. Eigentlich .../ Ich bin mir da sehr unsicher. Jeder kann eigentlich entscheiden .../ Jeder Frau kann entscheiden, ob sie ein Kopftuch tragen will oder nicht. Und wenn es ihr jemand verbietet, dann finde ich das eigentlich unfair, weil es ist ja 
die, ähm, die Entfaltung der Persönlichkeit oder so. Das ist ja ein Grundgesetz auch irgendwie so. Und deswegen darf man das auch eigentlich nicht. Und, ähm, ich finde das auch zum Beispiel übertrieben, dass .../ Einmal hat irgendwie jemand eine Frau irgendwie umgebracht, so in zwanzig Sekunden oder ich weiß nicht, war sie tot. Mit achtzehn Messerstichen. Ich bin mir da jetzt nicht so sicher. Nur weil sie ein Kopftuch trug. Ähm, das war glaube ich auch irgendwie in der Politik war das mal. Ich weiß nicht irgendwo in einem Senat oder so. Ich weiß jetzt nicht genau, wo das passiert ist. Aber zum Beispiel so was finde ich nicht so gut, weil jeder darf ja seine Kultur frei entfalten und so. Deswegen würde ich einfach sagen, das finde ich so okay. (Lisa, Gym07)

Angesprochen auf die EU kommt sie zu der Frage der Eintrittsbedingungen. Sie vermutet, dass eine Bedingung für den Eintritt der Türkei in die EU sei, dass „die Frauen irgendwie kein Kopftuch tragen müssen in der Türkei“. Lisa stellt sich also vor, dass es in der Türkei eine Pflicht für alle Frauen gäbe, ein Kopftuch zu tragen. Die Frage des Kopftuchs sieht sie offenbar als eines der zentralen Felder im Verhältnis zwischen der EU und der Türkei an. Die Setzung der Bedingung der Abschaffung der vermeintlichen Kopftuchpflicht fände sie „einerseits nicht so gut“, weil es ,ja deren Kultur“" sei. Andererseits fände sie diesen Hinderungsgrund ,auch verständlich“. Wenn die Türkei sich in die EU ,integrieren“ wolle, dann müsse sie ,auch schon was dafür tun, sozusagen". Hier bleibt unklar, was sie genau meint. Geht es allgemein darum, dass eine solche Integration auch mit einer Leistung einhergehen muss? Oder sieht sie in dieser Frage eine grundlegende kulturelle Differenz, die in dieser gelebten Form zu tief geht, als dass eine Integration in die Europäische Gemeinschaft gelingen könne? Beides scheint denkbar, wobei ein Blick auf die anderen Interviews, die einer ähnlichen Argumentation folgen, die Gefährdung des Gelingens der ,Integration “ aufgrund der vermeintlich zu tief gehenden kulturellen Differenz nahelegen würde. Lisas argumentatives Abwägen - auch in dieser ambivalenten Form - zwischen dem Recht auf kulturelle Selbstbestimmung und dem Problem der kulturellen Differenz in Bezug auf den Islam, ist hier sehr verbreitet.

Auf die Nachfrage zu ihrer Meinung zur „Kopftuch-Frage“ plädiert sie gegen ein Verbot und für die Selbstbestimmung von Frauen, ein Kopftuch zu tragen. Dabei nimmt sie Bezug auf das Recht der „Entfaltung der Persönlichkeit“. Im Anschluss stellt sie einen Zusammenhang zwischen einem Kopftuchverbot und der gewaltvollen Dimension von antimuslimischem Rassismus her. Sie bringt das Beispiel eines Mordes an einer Frau „mit 18 Messerstichen“, „nur weil sie ein Kopftuch trug“. Damit nahm sie höchst wahrscheinlich auf den Bezug auf den Mord an 
Marwa el-Sherbini im Jahr 2009. ${ }^{3}$ Der Zusammenhang zwischen der Forderung nach einem Kopftuchverbot und der gewaltvollen Dimension des antimuslimischen Rassismus wird von ihr nicht weiter ausgeführt. Nichtsdestotrotz dient er ihr als Beleg für ihr Plädoyer dafür, dass sie es richtig findet, dass ,,jeder [...] seine Kultur frei entfalten“ können müsse. Damit wird deutlich, dass für Lisa das Problem nicht erst bei dem gewaltvollen Akt anfängt, sondern bereits bei ohne physische Gewalt auskommenden Diskriminierungsformen gegen Musliminnen. Möglicherweise liegt dieser Analogie auch ein Verständnis nicht-physischer Gewaltförmigkeit dieser Diskriminierungsformen zugrunde.

\section{Kritik am antimuslimischen Rassismus}

In den folgenden zwei Beispielen werde ich die Beobachtungen von Memnun und Lara zu antimuslimischen Rassismus darstellen. In einer längeren Interviewsequenz thematisiert Lara die Frage nach der ausgrenzenden Politik gegenüber Geflüchteten. Sie problematisiert, dass die juristische Dimension der Staatsbürgerschaft mehr wiegt, als die tatsächlichen Menschen mit ihren Fähigkeiten. Sie vermutet, dass gesetzliche und bürokratische Logiken mitursächlich für die durch die Asyl- und Flüchtlingspolitik hervorgebrachte Ungleichbehandlung sind. Daran anschließend stelle ich die Frage, ob das auch etwas mit Rassismus zu tun habe, womit ich ein Thema von Lara aus einem vorherigen Themenkomplex wieder aufgreife.

I: Glaubst du, es hat auch was mit Rassismus zu tun, dass das so passiert?

S: Mhm, ja. Also, jetzt nicht direkt die Regierung oder so, aber, ähm, es gibt Vorurteile, denke ich, auf der ganzen Welt schon. Also, vor allem in Deutschland würde ich aber eher sagen so bezogen auf Religion, wenn schon. Weil, muslimische Menschen vor allem sind ja auch die, die mehr kulturbezogen sind und sich weniger anpassen. In dem Sinne gibt es immer noch Menschen mit Kopftuch und so. Und das wird gar nicht

\footnotetext{
${ }^{3}$ Marwa el-Sherbini wurde am 1. Juli 2009 im Dresdner Landgericht mit 18 Messerstichen ermordet. Kurz vor dem Mord hatte sie in einem Beleidigungsprozess gegen ihren späteren Mörder ausgesagt. Dieser hatte el-Sherbini auf einem Spielplatz als „Islamistin“ und „Terroristin" beschimpft, als sie ihn bat, eine Schaukel für ihren kleinen Sohn freizugeben. Sein Motiv dafür war, dass sie ein Kopftuch trug. El-Sherbinis Ehemann Elwy Okaz erlitt beim Versuch, seiner Frau zur Hilfe zu kommen, ebenfalls 16 Messerstiche, überlebte aber seine lebensgefährlichen Verletzungen - die übrigen Anwesenden hatten sich in einem Nebenraum des Gerichtssaals in Sicherheit gebracht. Ein Polizist, der schließlich zur Hilfe gerufen wurde, hielt den Ehemann für den Täter, schoss auf ihn und traf ihn in den Oberschenkel. Der Grund dafür ist offiziell ungeklärt; eine Auseinandersetzung mit institutionalisiertem Rassismus hat dies nicht zur Folge gehabt. Augenzeuge der Tat wurde el-Sherbinis und Okaz damals dreijähriger Sohn. Das Kind und sein Vater leben inzwischen in Kanada. Zur weiteren Einordnung der Tat und die öffentlichen und vom antimuslimischen Rassismus geprägten Diskurse vergleiche die Forschung von Yasemin Shooman (2014: 165 ff).
} 
gerne gesehen. Und das ist halt Rassismus. Und das ist sehr .../ Manchmal kriegt man halt bestimmte Jobs nicht und so, obwohl man qualifizierter ist als andere. Ja. (Lara, Gym18)

Lara thematisiert an anderen Stellen im Interview mehrfach Rassismus gegen Schwarze Menschen. An dieser Stelle äußert sie aber, dass in Deutschland insbesondere bezogen auf Religion Diskriminierung - Rassismus - stattfände. Die Idee, Vorurteile gegenüber Muslim_innen in einen Zusammenhang mit Rassismus zu setzen, konnte ich nur bei vier Schüler_innen vorfinden. Damit meint sie aber offenbar nicht beliebige Religionen. Von Diskriminierung betroffen sind aus ihrer Sicht insbesondere muslimische Menschen. Den Grund dafür sieht sie darin, dass diese „,mehr kulturbezogen“ seien und sich „,weniger anpassen“ würden. So gäbe es „immer noch Menschen mit Kopftuch und so“. Das würde „gar nicht gerne gesehen“.

Es ist nicht ganz einfach herauszufinden, was Lara hier meint, wenn sie von einer höheren Kulturbezogenheit und einer geringeren Anpassungsfähigkeit muslimischer Menschen spricht. Eine Interpretation ist, dass sie ,Kultur ${ }^{\star}$ als etwas Ethnisches definiert, das nicht Teil der, westlichen', ,modernen' Nicht-Kultur, also der , westlichen“ Moderne sei. ${ }^{4}$ Doch was bedeutet dann Anpassung bzw. warum würden sich aus ihrer Sicht muslimische Menschen weniger anpassen als beispielsweise nicht-muslimische Migrant_innen? Eine mögliche Interpretation die ontologische - erscheint mir zu sein, dass sie muslimische Menschen stärker als andere durch ihre Religion geprägt sieht. Hinzu kommt möglicherweise, dass hier implizit zum hegemonialen Denkrahmen Bezug genommen wird, nachdem das muslimische Weltbild dem des, Westens ' in seinen Grundorientierungen stark widerspricht und eine tendenzielle Inkompatibilität unterstellt wird. In der Folge spricht sie jedoch über Menschen mit Kopftuch und, dass das ,gar nicht gerne gesehen" werde. Dies könnte für eine andere - eine nicht-ontologische - Interpretation sprechen. Sie nimmt hier implizit Bezug auf ein Blickregime, in dem sichtbare Kleidungsstücke oder Accessoires als Differenzmarker fungieren. Die ganz praktische hohe Sichtbarkeit und die hohe Symbolhaftigkeit des Kopftuches innerhalb des hegemonialen Blickregimes führten - dann dieser Interpretation zufolge - dazu, dass sich muslimische Menschen - in diesem Fall insbesondere muslimische Frauen, die ein Kopftuch tragen - weniger gut anpassen könnten. Beide Interpretationen scheinen mir in meiner Lesweise von Laras Argumentation - trotz ihrer Widersprüchlichkeit - gleichzeitig am Werk zu sein. Dass die Kulturbezogenheit, die Nicht-Anpassung und das Tragen des Kopftuchs „gar nicht gerne gesehen“ sind,

\footnotetext{
${ }^{4}$ Ausführlich dazu im Abschnitt 3.3.6.
} 
qualifiziert Lara als „Rassismus“. Dies habe Folgen für die Betroffenen. So kriege „man halt bestimmte Jobs nicht und so, obwohl man qualifizierter ist als andere“.

I: Mhm. Hast du da noch Beispiele? Oder kannst du noch erzählen, was du dazu denkst?

S: Ja, das ist auch unlogisch und so. Das passt natülich auch nicht in die Menschenrechte. Und die Religion entscheidet ja nicht, ob man klug ist oder so. Also ich meine, natürlich heißt das, man hat eine ein bisschen andere Sicht auf Dinge. Aber man kann trotzdem sich .../ Es gibt viele Menschen, die können irgendwie, ein bisschen entfernt von ihrem eigenen Glauben und so, für die ganze Welt denken und so. Und die kriegen dann aber nicht die Chance so, weil sie vielleicht äußerlich oder so ihren Glauben oder ihre Herkunft oder so zeigen und ausleben. Und .../ Ja. (Lara, Gym18)

Sie findet es ,unlogisch“. Vor dem Hintergrund der vorangehenden Textpassagen verstehe ich ihre Äußerung so, dass eine Nicht-Verwertung vorhandener Qualifikationen aufgrund von rassistischen Grenzziehungen ,unlogisch“ sei. Dies widerspreche auch den Menschenrechten. Die Religion entscheide ja nicht, ob ,man klug ist oder so“. Damit rekurriert sie einerseits auf die Idee, nach der das vorurteilsbehaftete Denken einen Menschen nicht mehr in seinen vielen Dimensionen - wie etwa Klugheit - in den Blick nimmt. Andererseits referiert sie hier wiederum auf die Frage der Nicht-Verwertung vorhandener Qualifikationen durch rassistische Vorurteile. Sie führt aus, dass eine bestimmte religiöse Überzeugung zu einer, ,bisschen andere[n] Sicht auf Dinge“ führen könne. Doch es gäbe ,,viele Menschen“, die könnten ,,ein bisschen entfernt von ihrem eigenen Glauben [...] für die ganze Welt denken“. In diesem Gedankengang liegt die Annahme zugrunde, dass die Religion die Weltsicht beschränke, während eine säkulare Sicht dazu führe, ,für die ganze Welt", also universal, denken zu können. Implizit referiert sie hier auf eine Denkfigur aus der Aufklärung, in der es den aufgeklärten Europäern vorbehalten war, eine universalistische Weltsicht innezuhaben, während alle anderen Nicht-Europäer_innen qua ihrer Positionierung auf eine partikulare Weltsicht limitiert waren. Diese Menschen, die ,trotz ihres „kulturbezogen[en]“ Hintergrunds, eine universalistische Weltsicht haben könnten, bekämen aber ,nicht die Chance“, weil sie ,vielleicht äußerlich oder so ihren Glauben oder ihre Herkunft oder so zeigen und ausleben“. Dies würde sie innerhalb des hegemonialen Blickregimes abwerten bzw. sie würden „gar nicht gerne gesehen“. Lara changiert hier also zwischen einer Reproduktion von Zuschreibungen über Muslim_innen und einer dezidiert vorgetragenen Kritik an antimuslimischen Rassismus. 
I: Ähm, und wie kommt das? Also, dass jetzt besonderes bei Muslimen da irgendwie gesagt wird: "Die gehören nicht dazu"? Oder da kriegt irgendein Muslime kein Job. Wie kommt das dazu?

S: Ja, also das kommt halt wegen der ganzen weltlichen Sache halt, dass es Terrorismus gibt und so. Und dann denkt man .../ Also man hört in den Nachrichten irgendwie von irgendwelchen Bombenanschlägen. Und vor allem die Politik oder der Staat hat dann sicherlich Angst, ähm, dass so was passiert halt auch in Deutschland. Und deswegen, wenn jemand so aussieht als würde er Moslem sein oder so, denkt man gleich, dass die Person möglicherweise was damit zu tun haben kann.

I: Mhm. Und was ist da dran?

S: Also, dass ist eigentlich dumm, das zu denken. Weil, man weiß ja, dass es im Koran oder so nicht drinsteht, dass man sowas machen soll oder so. Und es kommt ja immer auf die Interpretation an. Und es ist ja auch mit Christen so, die auch Dinge falsch machen. Aber in dem Sinne ist das einfach, dass man denkt, Terrorismus ist irgendwie das Schlimmste. Und vielleicht ist es auch .../ Also ich weiß auch nicht, warum man das macht. (Lara, Gym18)

Auf die Frage, wie es zur Diskriminierung von Muslim_innen käme, bringt sie eine neue Dimension ins Spiel. Dies sei nicht in der Religion oder religiösen Widersprüchen selbst begründet, sondern vielmehr in den ,ganzen weltlichen Sachen“, nämlich dem Terrorismus. Durch die mediale Berichterstattung über ,irgendwelche Bombenanschläge“ entstehe Angst, insbesondere in der „Politik“ oder dem „Staat“. Vor diesem Hintergrund entsteht nach Lara das Blickregime. Wenn also ,jemand so aussieht als würde er Moslem sein oder so, denkt man gleich, dass die Person möglicherweise was damit zu tun haben“ könnte. Durch die Verwendung des „man“ nimmt sie sich da selber nicht aus; anders als im vorherigen Komplex, wo sie sich selbst explizit von der Diskriminierungspraxis abgrenzt. In der Folge qualifiziert sie diese Vorurteilsstruktur allerdings als „,eigentlich dumm“. Schließlich stünde im Koran nicht drin, dass „man sowas machen“ solle. Es käme auf die Interpretation an und es gäbe ja auch „Christen so, die auch Dinge falsch machen“. Ich sehe hier zwei Argumente gegen den von ihr kritisierten antimuslimischen Rassismus. Zum einen stellt sie heraus, dass der islamistische Terrorismus nicht in der Religion verankert sei und dementsprechend die Tatsache Muslim_a zu sein, keinerlei Affinität zum Terrorismus beinhaltet. Zum anderen stellt sie fest, dass es ja auch Christen gäbe, die „Dinge falsch machen“. Damit ist die von ihr als vorherrschend wahrgenommene Verknüpfung von Terrorismus mit Muslim_innen nochmals ad absurdum geführt, da nicht unbedingt Terrorismus, aber zumindest ethisch falsches Verhalten ebenso durch Christen begangen werden könnte. Wenn also Terrorismus und ethisch falsches Verhalten weder in der Religion verankert, noch durch eine große Zahl von 
Muslim_innen befürwortet sowie ethisch schlechtes Verhalten auf die Zugehörigkeit einer bestimmten religiösen Gruppe beschränkt ist, dann erscheint ihr die durch den vorherrschenden Blick hergestellte Verkettung von Terrorismus und Islam als „,unlogisch“ und argumentativ widerlegt.

Memnun (HS08) schildert einen Vorfall in seiner Klasse. Wie bereits in den Reflexionen zum Forschungsprozess (2.1.2) dargestellt, wurde die Erhebung der Interviews an dieser Hauptschule von einigen Vorfällen im Lehrerzimmer begleitet. Nachdem ich den Lehrerinnen mitgeteilt hatte, mit welchen Schüler_innen ich Interviews führen will, sprachen sie mich im Lehrer_innenzimmer an. Sie sagten, dass ich mir dringend nochmal überlegen sollte, ob ich wirklich mit diesen Schüler_innen Interviews führen wolle, da diese ,keinen Satz auf Deutsch zu Ende bringen könnten“. Außerdem hätten sie von ,,so einem abstrakten Thema wie Globalisierung eh keine Ahnung“. Mit solchen, ihre Schüler_innen abwertenden Argumenten versuchten sie mich eindringlich zu einem Wechsel der Interviewpartner_innen zu bewegen. Ich lehnte dies höflich ab. Mit diesem Eindruck eines bestimmte Schüler_innengruppen und ihr Wissen abwertenden Schulklimas ging ich dann in die Interviews. Die Interviews mit diesen als Nicht-Deutsche angesehenen Schüler_innen waren entgegen der Erwartung der Lehrerinnen sehr ergiebig, vielschichtig und thematisch tief. Einer von ihnen war Memnun.

Nach bereits einer knappen Stunde Interviewdauer stelle ich Memnun noch wie in allen Interviews - die Abschlussfrage. Dieser Frage stelle ich voraus, dass ich nun mit allen Fragen durch sei. Ich erwähne nochmal, dass wir uns ja mit der Gestaltung von Bildungsprozessen, „Schulbücher und sowas“, beschäftigen. Dann Frage ich, ob er mir noch irgendwas mit auf den Weg geben wolle, was wir beachten sollten. Im vorherigen Interviewverlauf wurden bereits viele Themen besprochen. An eines davon knüpft Memnun hier an. Er hatte berichtet, dass er durch Lehrer_innen benachteiligt worden sei. Den Grund vermutete er darin, dass er als „Ausländer“" angesehen werde und schwarze Haare habe.

S: Wissen Sie auch, wann ich das gemerkt habe? Also, meine alte Lehrerin, dass die so ein bisschen rassistisch war? Weil es gab so ein Mädchen in meiner Klasse, die war Türkin und die trug kein Kopftuch. Und dann .../ Wir hatten Sommerferien und dann hatten wir wieder Schule und dann trug dieses Mädchen ein Kopftuch. Und die Lehrerin hat sie angemacht: ,Warum trägst du ein Kopftuch? Haben Deine Eltern dich gezwungen? Du brauchst das nicht zu machen?“

I: Krass.

S: Dann habe ich mir gedacht, was ist das für eine?

I: Und warum hat die Lehrerin das gemacht? 
S: Ja, keine Ahnung. Weiß ich nicht. Weil viele .../ Ich weiß nicht. Dass viele denken, dass die Ausländer immer gezwungen werden, ähm, von unseren Eltern, das zu machen. So, dass das Kopftuch Muss ist. So dass die .../ Keine Ahnung. Weiß ich nicht. (...) Dass die denken, also andere Menschen, also Deutsche und so, egal welche, ähm, dass die denken, wie gesagt, dass die Eltern die Kinder zwingen, so wie diese Lehrerin, dass die dieses Mädchen zwingen, ein Kopftuch zu tragen. Aber sie hat gesagt: "Nein. Ich habe es freiwillig gemacht. Wegen meiner Religion und so was. Habe ich alles alleine gemacht." Sagte sie so dies und das. Ja.

I: Mhm. Und das wollte die Lehrerin nicht glauben, weil die so denkt ein Kopftuch ist nur ... das ist nicht freiwillig.

S: Genau. Ja. (Memnun, HS08)

Er bewertet die Haltung der Lehrerin als „,rassistisch“, da sie der Mitschülerin vor der Klasse das Tragen ihres Kopftuchs zum Vorwurf macht bzw. ihr unterstellt, sie würde dazu gezwungen werden. Dieses Verhalten der Lehrerin stellt er in den gesellschaftlichen Kontext, in dem ,viele denken“, ,,also andere Menschen, also Deutsche und so“, würden, dass die „Ausländer immer [von unseren Eltern] gezwungen“ würden, ein Kopftuch zu tragen. Dieses Bild findet er offensichtlich nicht nur falsch, sondern auch problematisch. Dieser gesellschaftlich verbreiteten Äußerung der Lehrerin stellt er die Aussage seiner Mitschülerin entgegen. Diese erklärte, Memnun zufolge, dass sie es „freiwillig gemacht“ habe und es mit ihrer Religion begründete. Durch die Kontrastierung der Äußerungen der Lehrerin mit der sprechenden Mitschülerin, die auf ihrer Selbstbestimmung beharrt, stellt er implizit heraus, dass die Äußerung der Lehrerin eine Objektivierung der Mitschülerin zur Folge hat. In Memnuns Darstellung der Lehrerin projiziert diese nicht nur ihre stereotypen Bilder auf die Schülerin, sie enthebt sie auch dem Status eines für sich selbst sprechenden Subjektes. Dadurch erhebt sich die Lehrerin in die Rolle der okzidentalen Retterin des orientalen Mädchens, das vor dem orientalen Patriarchat beschützt werden muss. Eine solche differenzierte Analyse suchte man im Lehrerzimmer dieser Schule vermutlich vergeblich.

Interessant ist hier auch Memnuns Selbstverortung. Er spricht von „unseren“ Eltern. Dabei ist er in Deutschland geboren, hat die deutsche Staatsbürgerschaft und eine als deutsch geltende Mutter. Dennoch fühlt er sich als „Ausländer“ und fühlt sich solidarisch mit der von Rassismus betroffenen Mitschülerin. 


\subsubsection{Farbe als Zugehörigkeitsmarker}

In diesem Abschnitt liegen alle Aussagen zugrunde, in denen Farbe als Zugehörigkeitsmarker in der gegenwärtigen Migrationsgesellschaft angesprochen wird. Ich spreche hier von Farbe und nicht von Hautfarbe, da ich damit alle auf farblichen Unterschieden basierenden phänotypischen Merkmale mit einschließe, die zur Konstruktion von rassialisierter Differenz verwendet werden. Außer Hautfarbe ist hier insbesondere die Haar- und Augenfarbe als phänotypischer Differenzmarker zu nennen.

Bemerkenswert ist, dass das Thema fast ausnahmslos von Schüler_innen aufgebracht wurde, die von eigenen Diskriminierungserfahrungen berichten. Drei nicht-betroffene Schüler_innen sprechen das Thema an. Zwei von ihnen nehmen Bezug auf am Nationalsozialismus orientierte rechte Bewegungen der Gegenwart, die ein Bild des Deutschen als blond und blauäugig verträten. Eine weitere berichtet über die ungleichen Chancen auf dem Arbeitsmarkt aufgrund von Diskriminierung von Schwarzen Menschen, was sie neulich im Englischunterricht durchgenommen habe. Für die anderen scheint das Thema, soweit eine NichtNennung in den Interviews diesen Rückschluss zulässt, keine hohe Relevanz zu besitzen - zumindest nicht für die Gegenwart. Dort wird dies eher auf die Vergangenheit der Sklaverei oder des Nationalsozialismus bezogen, ohne einen Bezug zur Gegenwart herzustellen. Kaum ein_e Schüler_in - es gibt zwei Ausnahmen - bringt eine auf die Farbe Bezug nehmende Äußerung, die Farbe - genauer: farblich begründete phänotypische Merkmale - mit positiven oder negativen Attribuierungen in Verbindung setzt. Dies steht im Kontrast zu den weiter unten dargestellten Erfahrungen der von farblich begründetem Rassismus Betroffenen. Mehrere berichten dabei von dem Gefühl, beispielsweise durch Lehrkräfte aufgrund ihrer schwarzen Haare anders behandelt - insbesondere eher und öfter ermahnt sowie anders benotet - zu werden. Zwei berichten von ihrer Beobachtung von Benachteiligungen auf dem Arbeitsmarkt, so zum Beispiel Özgür (Gym15), der berichtet, dass er „Afrikaner“ besonders häufig in „minimalbezahlten Jobs" sehen würde, was er auf vorhandene Vorurteilsstrukturen zurückführt und ,voll unfair“ findet. Im Folgenden werde ich mich auf die Darstellung eines Beispiels beschränken, in dem mehrere Themenbereiche in Bezug auf Farbe als Zugehörigkeitsmarker angesprochen werden. Ich habe mich für dieses Beispiel entschieden, da sich Lara (Gym18) ausführlich mit Rassismus gegen Schwarze Menschen auseinandersetzt, ihre Erfahrungen analysiert und darüber hinaus diese in einen Kontext mit dem Umgang mit dem kolonialen Heritage und der Reflexion ihrer eigenen Verortung darin diskutiert. 
Nach einer Gesprächssequenz mit Lara (Gym18) zum Thema der Situation der Muslim_innen in Deutschland frage ich nach anderen Formen von Rassismus.

I: Mhm. Ja. Und gibt es noch andere Formen von Rassismus? Außer gegen Muslime in Deutschland?

S: Ja, also natürlich gibt es dann immer so Menschen, die, ähm, das mit den Nazis oder so, die diese Ansicht so teilen. Dass blond und blauäugig oder so, das einzig Richtige ist. Obwohl heutzutage ist blond jetzt nicht mehr das Einzige. Vielleicht auch braune Haare, solange man Arier ist, also hellhäutig. Und .../ Ja.

I: Und begegnet dir das im Alltag auch?

S: Ähm, also mir direkt ist es nicht oft, oder eigentlich gar nicht, passiert. Also, im Kindergarten oder so, wenn die anderen alle klein waren und so, fällt es einem natürlich nicht auf oder so. Aber mein Bruder zum Beispiel, der ist auch etwas älter und so, und der spielt Fußball. Und im Sport passiert das sehr oft, finde ich. Also ihm ist das jetzt nicht direkt sehr oft passiert, weil er mehr so der offene Mensch ist und man ihn dann schnell mag. Aber natürlich passiert das. Man streitet sich, also es ist irgendwie passiert, da war er in der Zehnten glaub' ich. Und da haben die Fußball gespielt und dann haben sie trotzdem gestritten und so. Also, er hat irgendwie ein Tor geschossen oder so und dann gab es natürlich Stress. Und, ähm, dann kam halt so ein Deutscher - also das waren eigentlich Freunde - aber dann rutscht einem mal ein rassistischer Kommentar raus. (Lara, Gym18)

Zunächst assoziiert sie mit Rassismus die „Nazis“, die fänden, dass „blond und blauäugig“ das „einzig Richtige“ sei. Dann schränkt sie wieder ein, dass dieses Ideal der „Nazis“ heutzutage nicht mehr ganz zuträfe, da auch „braune Haare“ akzeptiert würden, solange man „Arier“ sei, ,also hellhäutig“. Lara sieht die Frage der Farbe als rassistischer Differenzmarker in Bezug auf die Ideologie der Nazis als entscheidend an. Auf die Nachfrage, ob ihr das im Alltag begegne, erzählt sie von einer Erfahrung ihres Bruders. Dieser hätte beim Fußball spielen einen Streit unter Freunden, unter anderem mit einem „Deutsche[n]“ gehabt, der eigentlich ein Freund von ihm gewesen sei. „Aber dann rutscht einem mal ein rassistischer Kommentar raus“. Sie sagt hier nicht, dass dem Freund in dieser Situation ein rassistischer Kommentar rausgerutscht sei. Die Formulierung, dass es „einem mal ein rassistischer Kommentar" rausrutsche, deutet an, dass dies erwartbar sei. Sie verschiebt das Thema rassistischer Diskriminierung, das sie erst durch den Bezug zu den Nazis aus ihrer alltäglichen Lebenswelt externalisiert zu haben schien, von den Nazis zu den Freunden ihres Bruders. Folgende Interpretation ist zwar nicht mit einer Notwendigkeit daraus zu schlussfolgern, sehr wohl aber als Möglichkeit darin angelegt. Aus dieser Formulierung, das ,einem mal ein rassistischer 
Kommentar" rausrutsche, klingt eine gewisse Natürlichkeit bzw. Normalität heraus. Zwar sind die Artikulationen von rassistischen Kommentaren möglicherweise nicht alltäglich, rechnen müsse man damit jedoch $\mathrm{zu}$ jeder Zeit. Die farblich begründete rassistische Differenz schwingt somit im Subtext des Alltags ständig mit und kann jederzeit - wie bei einem Streit um ein Tor - „einem mal“ rausrutschen.

Nach über einer Stunde Interview stelle ich Lara dann meine Abschlussfrage danach, ob sie uns als Gestalter_innen politischer Bildung noch etwas mitgeben will. Hier greift sie das Thema erneut auf.

I: Mhm. Hast du noch irgendwas, was du mir mitgeben willst? Weil wir beschäftigen uns ja damit und auch damit, was in der Schule gelehrt werden soll zum Thema Globalisierung. Gibt es irgendwas, wo du sagst, daran MÜSST ihr denken so?

S: Mhm. Also zum Thema Globalisierung und so?

I: Ja, wobei alles. Also auch diese Kultursachen. Oder zu Rassismus. Oder dazu, dass irgendwas irgendwo produziert wird. Oder zu Armut und Reichtum. Also was du willst.

S: Ja, also ich finde so Kultursachen und so oder Rassismus oder so, da finde ich, ist es eigentlich heutzutage ziemlich wichtig, den Menschen was dazu beizubringen. Weil ich sehe halt, die meisten interessieren sich gar nicht mehr für die Geschichte. Im Bereich Geschichte zum Beispiel die Geschichte mit den Sklaven und so was in der Art halt. Die dunklen Seiten der Geschichte, sag' ich mal. Also natürlich möchte man nicht an das Schlechte aus der Vergangenheit irgendwie erinnert werden. Aber ich finde, man sollte vielleicht ein bisschen was lernen dazu, um vielleicht ein bisschen anders zu denken. Und dass man irgendwann Menschen nicht nach ihrem Stand oder gesellschaftlichen Ansehen irgendwie beurteilt. Oder Nationalität und so. (Lara, Gym18)

Aus den von mir vorgeschlagenen Themen, über die wir im Interviewverlauf gesprochen hatten, sucht sie sich das Thema Kultur und Rassismus heraus. Sie setzt es in Beziehung zum Verhältnis ihres Umfeldes zur Geschichte. Sie problematisiert, dass sich die meisten ,gar nicht mehr für die Geschichte“ interessieren würden. Dabei meint sie insbesondere die ,dunklen Seiten der Geschichte“, wie etwa die Sklaverei. Auch wenn ,man nicht an das Schlechte aus der Vergangenheit" erinnert werden möchte, findet Lara, dass man daraus lernen sollte, um „ein bisschen anders zu denken“. Aus einer Reflexion dieser ,dunklen Seiten der Geschichte“ könnte beispielsweise folgen, dass ,man irgendwann Menschen nicht nach ihrem Stand oder gesellschaftlichen Ansehen“ sowie ihrer „Nationalität“ beurteilt. Anders herum bedeutet ihre Aussage, dass sie feststellt, dass es gegenwärtig virulent sei, Menschen nach diesen Kriterien zu bewerten. Die Geschichte - oder vielmehr die Auseinandersetzung mit ihrer „dunklen Seite“ - erscheint 
hier als Ressource, um gegenwärtige Denkstrukturen zu irritieren und diese zu reflektieren.

I: Mhm. Und hast du den Eindruck, dass Sklaverei oder die Geschichte des Kolonialismus, dass das gar nicht in der Schule vorkommt?

S: Also das kommt vor. Aber es interessiert eigentlich keinen, weil keiner irgendwie das Ausmaß davon mitbekommt. Weil alle denken: „Heute ist alles wieder gut. Es gibt keine Sklaven. Es gibt keine Kolonien mehr. Es ist alles in Ordnung." Aber eigentlich stimmt das ja nicht. Also jeder weiß, dass es Rassismus gibt. Oder so was in der Art halt. Aber keiner sieht irgendwie, dass es doch schon ziemlich schlimm ist noch. Und dass es eigentlich sehr schwer war, dieser Schritt halt davon loszukommen und so. Und das ist irgendwie .../ Die meisten merken vielleicht nicht, dass Geschichte wirklich passiert ist. (Lara, Gym18)

Lara problematisiert die Haltung gegenüber der Geschichte bzw. die Abtrennung der Geschichte von der Gegenwart. So interessiere sich niemand dafür, weil „keiner irgendwie das Ausmaß“ mitbekomme. Alle würden denken: „Heute ist alles wieder gut. Es gibt keine Sklaven. Es gibt keine Kolonien mehr. Es ist alles in Ordnung." Dies stimme aber nicht. Diese Geschichte habe zu dem Rassismus geführt, den es in der Gegenwart gebe und der dazu führe, dass es ,doch schon ziemlich schlimm ist noch“. Hier verknüpft sie die Frage der subjektiven Verortung in der gegenwärtigen Welt mit dem Blick auf Geschichte. Beide Fragen hängen für Lara scheinbar konstitutiv zusammen. Die Geschichte als etwas wahrzunehmen, was „wirklich passiert ist“, bedeutet für sie, ihre Relevanz für und Verstrickung mit der Gegenwart zu verstehen. Das ist für sie aber nur möglich, wenn in der Gegenwart Perspektiven herrschaftskritischer Konzepte, wie etwa Rassismusanalyse, miteinbezogen würden. Hatte sie vorher noch Geschichte als Ressource für die Entwicklung der Fähigkeit der Infragestellung problematischer Konzepte in der Gegenwart dargestellt, bringt sie hier eine weitere Schleife in ihre Argumentation, indem sie kritische Perspektiven auf Geschichte letztlich als abhängig von der Kritik von problematischen Strukturen in der Gegenwart darstellt.

Außerdem ist für sie problematisch, dass nicht gesehen wird, wie schwer der Schritt war, Sklaverei und Kolonialismus zu überwinden. Damit kritisiert sie einen Blick auf die Geschichte, deren Fortschreiten sie als ein entweder teleologisch zu mehr Emanzipation führenden oder durch die Mächtigen vorangebrachten Prozess sieht, statt die Perspektive der Unterdrückten miteinzubeziehen, was ein Konzept von Geschichte als umkämpft und Leid produzierend sowie gesellschaftliche Umbrüche als Folge großer Anstrengungen und sich Gefahren aussetzender Betroffener implizieren würde. 
I: Und dass das Auswirkungen auch auf heute hat? Also du sagst ja einmal, es hat Auswirkungen darauf, dass es Rassismus heute gibt. Und gibt es noch mehr Aspekte, wo du sagen würdest, da hat die Geschichte von Sklaverei, von Kolonialismus und solchen Sachen hat noch Auswirkungen auf heute?

S: Ähm, also wie?

I: Na ja, dass das, was in der Geschichte passiert ist, diese ganzen Ungerechtigkeiten - zum Beispiel Sklavenhandel oder was weiß ich - würdest du sagen, das hat noch .../ Also, du hast ja gesagt manche Leute sagen: „Ja. Das ist doch alles vorbei heutzutage. Das hat doch nichts mit heute zu tun." Würdest du sagen, dass es noch Aspekte gibt, wo du sagst: „Das beeinflusst, wie es heute ist.“?

S: Ähm, ja. Es gibt ja immer noch heutzutage - in Amerika zum Beispiel - nicht direkt Rassismus. Aber vor allem von Seiten jetzt der Schwarzen zum Beispiel, den AfroAmerikanern, die immer noch denken, dass sie .../ Oder nicht denken, dass sie weniger wert sind, aber eher so sagen, sie gehören in Ghettos. Oder sich so fühlen, als sollten sie nicht in den Positionen sein, keine Ahnung, so Business-Männer oder so. Die denken, sie sollten im Bereich Sport, Musik sein. Und ich speziell zum Beispiel lese gerne in meiner Freizeit. Und ich war immer so, die die längsten Geschichten geschrieben habe und so. Und ich wollte immer Autorin werden. Aber als ich dann .../ Aber irgendwann habe ich halt gemerkt, dass in den Büchern die Autoren halt auch alle Europäer sind. Oder Weiße oder Engländer mehr so. Und ich meine halt, ich mag lesen. Und wenn ich schreiben will, kann ich das genauso machen, ohne dass man denkt, dass ich eher singen sollte oder so was. Und nicht das alle denken, dass das nicht zu mir gehört und dass ich dadurch nicht Schwarz bin oder so was. (Lara, Gym18)

Auf die etwas umständlich und missverständlich gestellte Frage antwortet Lara, indem sie sich der subjektiven Dimension des Umgangs Schwarzer Menschen mit rassistischen Strukturen zuwendet. Zunächst spricht sie über Subjektivierungsweisen von Schwarzen in den USA, in denen der Rassismus zu einer Selbstabwertung oder Selbstmarginalisierung führe. Schwarze Menschen in den USA dächten beispielsweise, dass sie ,,in Ghettos“ gehörten und nicht in Positionen wie „Business-Männer oder so“ sein sollten, sondern stattdessen im „Bereich Sport, Musik“. Es bleibt unklar, wie sie sich die Internalisierung dieser Subjektivierung rassistischer Strukturen erklärt. Statt zu erklären, scheint sie vielmehr zu beobachten. Sie leitet ihre Gedanken ein, mit dem Ausdruck ,nicht direkt Rassismus“, womit sie deutlich macht, dass sie hier einen Zusammenhang zum Rassismus sieht, ohne dies jedoch selbst als Rassismus zu werten. Diese Subjektivierungsweise Schwarzer Menschen scheint vielmehr eingebettet zu sein, in die Erfahrung mit rassistischen Strukturen in der Vergangenheit und der Gegenwart.

Anschließend wendet sich Lara ihrer eigenen subjektiven Erfahrung zu. Sie lese gerne in ihrer Freizeit, schrieb ,die längsten Geschichten“ und wollte immer Autorin werden. Ihr Plan wurde offenbar irritiert, als sie irgendwann gemerkt 
habe, dass ,in den Büchern die Autoren halt auch alle Europäer $[, \ldots]$ Weiße oder Engländer" seien. Es bleibt unklar, ob sie davon ausgeht, dass Bücher in der Regel von den durch Rassismus Privilegierten geschrieben worden sind oder ob sie auf die Sichtbarkeit und Anerkennung bzw. deren Fehlen für Schwarze Autor_innen rekurriert. Ersteres scheint angesichts des nicht aufgezeichneten Gesprächs im Anschluss an das Interview unwahrscheinlich, da sie hier durchaus einzelne Schwarze Autor_innen nannte. In beiden Fällen problematisiert sie jedenfalls das gesellschaftlich verfügbare, literarische Wissensarchiv als eurozentrisch, durch Weiße dominiert und hier insbesondere von starken Kolonialmächten, konkret England, bestimmt.

Diese Irritation ihres Plans, Autorin zu werden, die durch das Fehlen Schwarzer Autor_innen hervorgerufen wurde, scheint nicht dadurch begründet, dass ihr Vorbilder fehlen würden. Vielmehr knüpft sie an ihr Argument der Subjektivierungsweise an, wobei sie dieses verschiebt und erweitert. Scheinbar gegen ihre Irritation argumentierend stellt sie fest: „Und wenn ich schreiben will, kann ich das genauso machen, ohne dass man denkt, dass ich eher singen sollte oder so was. Und nicht das alle denken, dass das nicht zu mir gehört und dass ich dadurch nicht Schwarz bin oder so was." Hatte ihr Argument der Subjektivierung Schwarzer Menschen in den USA noch im Unklaren gelassen, wie und warum Schwarze Menschen sich bestimmte gesellschaftliche Positionen angehörig fühlten, bringt sie hier die Dimension der gesellschaftlichen Erwartungen ein. Mit ihrer Entscheidung, Autorin zu werden, hat Lara offenbar damit zu kämpfen, dass sie damit mit der Erwartung bricht, dass sie ,eher singen sollte oder so was“. Anders herum gewendet kann die Umsetzung ihres Plans aus ihrer Sicht auch dazu führen, dass alle denken, dass das Schreiben eigentlich nicht zu ihr gehöre und sie „dadurch nicht Schwarz" sei. Lara geht offenbar davon aus, dass sie mit ihrem Plan dermaßen mit den gesellschaftlichen Erwartungen an sie als Schwarze bricht, dass ihr Plan zum einen nicht ernst oder für unterstützenswert gehalten werde und zum anderen ihre Selbstverortung als Schwarze damit infrage gestellt wäre. Es ist davon auszugehen, dass sie nicht denkt, dass sie zu einer Weißen würde, wenn sie als nicht-Schwarz angesehen würde. Diese Aussicht des Verlusts der Anerkennung als Schwarze gesehen zu werden, ohne ein neues Selbstverortungsschema anvisieren zu können, kann möglicherweise verängstigend sein. Gegen beide mögliche Folgen dieses rassistischen Erwartungshorizontes argumentiert Lara hier an.

Auf die Nachfrage, ob manche Menschen in ihrem Umfeld so denken würden, erläutert sie insbesondere die Auseinandersetzung mit ihrer Mutter.

I: Und hast du das Gefühl, dass manche Leute in deinem Umfeld so denken: „Na ja. Lass' sie mal schreiben. Aber eigentlich sollte sie singen.“ 
S: Ja, also natürlich sagt man mir das nicht. Also ich kann Träume .../ Oder generell wenn man sagt: „Ich möchte schreiben.“, sagen sie: „Hol’ dir einen besseren, einen guten, Job.“ Oder so was halt. Meine Mutter sagt immer, ich soll gerade einen Job nehmen, der so richtig normal ist und so. Sowas wie, keine Ahnung, Anwältin oder sowas in der Art. Und sie sagt, gerade weil ich nicht weiß bin und so, soll ich das so verändern. Und gerade weil ich nicht komplett Deutsch bin, sollte ich zeigen, dass ich in so einer Position sein will. Aber, wenn ich es speziell nicht will, denke ich eigentlich, muss ich das nicht machen. Und halt in dem Sinne die Welt beeinflusse oder so. Was eigentlich auch gut ist.

I: Mhm. Aber ist das nicht auch irgendwie Ausdruck von Rassismus, dass deine Mutter dir sagen muss: „Du sollst nicht machen, was du willst. Sondern du sollst das machen, womit du hier klarkommst und akzeptiert wirst."?

S: Also, natürlich verbietet sie es mir nicht.

I: Nee, klar. Aber das ist ja eine Empfehlung so.

S: Aber ich finde .../ Ich erkläre ihr auch immer. Ich sollte das machen natürlich, was ich will. Und, ähm, die Tatsache, dass ich aus irgendeinem Land komme oder irgendeine Hautfarbe habe oder so, sollte ja nicht entscheiden, was ich mache. Und auch wenn ich jetzt Sängerin werden will, dann sollten nicht alle denken, ich werde Sängerin, weil ich Schwarz bin. Sondern ich werde Sängerin, weil ich es mag und weil ich es kann und so. Und das ist zum Beispiel natürlich auch blöd. Dass man einen gleich so halt so in eine Schublade schiebt und denkt, wenn ein Läufer Schwarz ist: „Er macht das nur weil er Schwarz ist. Oder er ist gut dafür, weil er Schwarz ist.“(Lara, Gym18)

Am Beispiel ihrer Mutter zeigt sie, wie es Widerstand gegen ihren Plan gibt, Autorin zu werden, der mit Rassismus zu tun hat. Ihre Mutter erwidere auf ihre Absicht, dass Lara - ,gerade weil [sie] nicht weiß“ und ,gerade weil [sie] nicht komplett Deutsch“ sei - einen Job annehmen sollte, ,der so richtig normal ist“" bzw. gut angesehen ist, wie beispielsweise „Anwältin oder sowas in der Art“. Hier verläuft ein Konflikt zwischen den beiden. Lara setzt dem entgegen, dass sie das nicht machen müsse, wenn sie ,es speziell nicht will“. Auf diese Art würde sie auch ,die Welt beeinflusse[n]“, was sie „gut“ fände. Sie verknüpft ihre eigene Berufswahl mit ihrem Ziel der Veränderung rassistischer Erwartungshorizonte. Dabei ist das eine Argument, dass sie machen können muss, was sie will. Das andere Argument ist das der Beeinflussung der Welt hin zu ihrer normativen Vorstellung, dass ,die Tatsache, dass ich aus irgendeinem Land komme oder irgendeine Hautfarbe habe oder so", nicht entscheiden sollte, ,was ich mache“. Sie strebt die Entrassialisierung von Erwartungshorizonten und damit letztlich die Abschaffung rassistischer Kategorisierungen von Menschen an. Dies führt sie weiter aus. Selbst wenn sie jetzt Sängerin werden wolle, sollte dies nicht damit verknüpft werden, dass sie Schwarz sei, sondern, ,weil ich es mag und weil ich es 
kann“. Gleiches gilt für den Sport: „Wenn ein Läufer Schwarz ist“, wird gedacht, dass der Grund, dass er möglicherweise auch ein guter Läufer ist, darin liegt, dass er Schwarz ist. Diese Reduktion Schwarzer Menschen auf ihr Schwarzsein und den damit im rassistischen Denken verbundenen Attributen und Erwartungshorizonten hält sie für problematisch. In ihren Worten: Sie hält es für problematisch, „dass man einen gleich so halt so in eine Schublade schiebt" und damit nur ein - rassistisches - Abziehbild statt den Menschen mit seinen Fähigkeiten und individuellen Eigenheiten sieht.

Einig sind sich Lara und ihrer Mutter aber scheinbar in der Einschätzung, dass Lara „nicht weiß“ und ,nicht komplett Deutsch“ sei und dass dies eine entscheidende Rolle für die eigene Zukunftsplanung spielt bzw. spielen muss. Der Dissens der beiden entsteht in der Frage des Umgangs damit. Während Lara sich dem stellen und die rassistischen Erwartungshorizonte verändern will, wünscht sich die Mutter offenbar einen Weg für ihre Tochter, der ihr - trotz eines gesellschaftlichen Kontextes, in dem rassistische Schubladen prägend sind - gesellschaftliches Ansehen verspricht und ihr möglicherweise ein Leben mit weniger Rassismuserfahrungen ermöglicht. Doch was bedeutet es aus dieser Perspektive eigentlich, „,nicht weiß“ und ,nicht komplett deutsch“ zu sein. Lara ist in Deutschland geboren und hat die deutsche Staatsbürgerschaft. Trotzdem sieht sie sich - in der Form der unwidersprochenen Aussage ihrer Mutter - als ,nicht weiß“ und ,nicht komplett deutsch“ an. Wie stehen diese beiden Attribute im Zusammenhang? Eine Lesart - die genealogische - ist, beide Attribute als unabhängig voneinander zu begreifen. Dann würde sich das ,nicht komplett deutsch“ auf die Migrationsgeschichte ihrer Mutter beziehen. Um ,komplett deutsch“ zu sein, müssten die Vorfahren dementsprechend spätestens zwei Generationen vorher eingewandert sein. Eine zweite Lesart - die differentielle - ist, beide Attribute als miteinander in Beziehung stehend zu begreifen. Hier würde ihr ,,nicht komplett deutsch“ -Sein daraus resultieren, dass sie als Schwarz gilt. Gerade vor dem Hintergrund ihrer kritischen Auseinandersetzung mit dem auf Hautfarbe basierenden Rassismus ist davon auszugehen, dass die zweite Lesart in jedem Fall zutrifft, wobei wahrscheinlich beide als verschränkt zu begreifen sind und in Laras Lebensumfeld als Zugehörigkeitsmarker gelten. Schwarz-sein führt hier also dazu, dass Schwarze Menschen nicht als ,komplett deutsch“ gelten. Interessant ist hier die Formulierung ,nicht komplett“. Wird das Schwarzsein in Laras Lebensumfeld als Makel begriffen, der aus ihr statt einer $100 \%$-Deutschen, eine $30 \%$-, 60 \%- oder $90 \%$ Deutsche macht? Wieviel kann durch andere Attribute ausgeglichen werden, die als Zugehörigkeitsmarker fungieren, wie beispielsweise Sprache, kulturelle Praktiken, Staatsbürgerschaft oder lokale Eingebundenheit? Was bzw. wer wäre ein $100 \%$-Deutscher? Denkbar wäre auch eine nationale Zugehörigkeitslogik, in der 
eine Schwarze als komplett deutsch und zusätzlich auch noch als Schwarz angesehen würde. Dies ist im Lebensumfeld von Lara offenbar nicht der Fall. Hier fungiert Schwarzsein- wenn nicht als Ausschluss - so doch als Differenzmerkmal, das aus Lara eine „nicht komplett[e]“ Deutsche macht.

Zum Ende der Analyse komme ich nochmal auf den Anfang ihrer Ausführungen zurück. Sie begann ihre Reflexionen zum Thema Rassismus gegen Schwarze Menschen mit ihrer Haltung zur Geschichte. Im Umgang mit der Geschichte sah sie einen Ausgangspunkt, von dem Gegenwartsstrukturen kritisch reflektiert werden können. Insbesondere die Reflexion der „dunklen Seiten der Geschichte“, wie etwa Sklaverei und Kolonialismus, sieht sie als Möglichkeit an, gegenwärtige Formen des Rassismus zu reflektieren. Dies wendet sie in der Folge auf ihre eigene Subjektposition an. Sie stellt eigene Erfahrungen in einen analytischen Zusammenhang mit rassistischen Unterscheidungs- und Zuschreibungspraxen und plädiert für ihre Abschaffung. Dieser aus der Gegenwart gerichtete Blick in die Vergangenheit wird hier als Ressource angeführt, um normalisierte Orientierungsrahmen und Zugehörigkeitsregime infrage zu stellen.

\subsubsection{Integrationsparadigma und nationale Zugehörigkeit}

In diesem Abschnitt liegen alle Vorstellungen der Schüler_innen zugrunde, in denen es um Integration geht. Der Begriff Integration muss nicht zwangsläufig genannt werden, allerdings muss es um die Frage nationaler Zugehörigkeit und die Frage der Bedingungen des Zugehörigwerdens gehen sowie ein impliziter Bezug zum Integrationsdiskurs vorhanden sein. In den allermeisten Fällen wird jedoch auch der Begriff selbst genannt. In den Vorstellungen der Schüler_innen konnte ich drei Felder ausmachen, in denen Bedingungen für die Integration formuliert wurden: Sprache, Arbeit und Kultur. Sprache als Kriterium für Integration wird von über der Hälfte der Schüler_innen mit Abstand am häufigsten angesprochen. Arbeit als Kriterium für Integration wird von weniger als einem Fünftel thematisiert. Kultur wird zwar häufiger als Feld der Differenz genannt, jedoch sehr selten als Bedingung des Zugehörigwerdens. Dies ist angesichts des dominanten Integrationsdiskurses in den Medien oder durch staatliche Organisationen bemerkenswert, da dort die Frage der kulturellen Differenz und der kulturellen Anpassung eine sehr viel größere Rolle einnimmt. Die damit verbundene Frage unterschiedlicher Wertesysteme, die ebenfalls im öffentlichen Diskurs eine große Rolle einnimmt, spielt in den Vorstellungen der Schüler_innen im direkten Bezug der Frage des Zugehörigwerden praktisch keine Rolle. Dies liegt - auch unter der Gefahr hier in den Bereich der Spekulation zu geraten 
- möglicherweise auch darin begründet, dass die Erhebung fast ausschließlich in Stadtteilen urbaner Zentren durchgeführt wurden, in denen die Klassenzusammensetzung den hohen Anteil von Menschen spiegelt, die als Menschen mit Migrationshintergrund gelabelt würden. Auffällig war außerdem, dass viele Schüler_innen, denen ein Migrationshintergrund diagnostiziert werden würde, den Begriff und die Logik des Integrationsparadigmas umschifften. In ihrer Weise über die Migrationsgesellschaft zu sprechen, kam der Begriff zunächst nicht vor.

Im Folgenden werde ich anhand von einigen Beispielen zeigen, wie Sprache, Arbeit und Kultur als Integrationsfaktoren und -indikatoren von den Schüler_innen gefasst werden. Neben dem Beispiel von Michael, der ein verhältnismäßig exkludierendes Verständnis von Integration verfolgt, stelle ich im Zuge der anderen Beispiele heraus, dass die Schüler_innen meist ein - gemessen am öffentlichen Diskurs - relativ gelassenen und weniger exkludierenden Umgang mit dem Thema haben. Das Spannungsfeld von exkludierendem und nicht-exkludierenden Vorstellungen von Integration bestimmt sich durch folgende, hier als Fragen formulierte, Faktoren. Inwiefern wird ,Integration' als eine einseitige Anpassungsleistung der Migrant_innen oder vielmehr als die Aufhebung exkludierender Gesellschaftsstrukturen vorgestellt? Inwiefern wird durch die Vorstellung von ,Integration“ die Differenz eines homogenen Eigenen und des dazukommenden ,Fremden “ produziert oder verstärkt? Inwiefern werden repressive und disziplinierende Facetten des Integrationsdiskurses affirmiert oder abgelehnt?

Michael (HS18) diskutiert den Zusammenhang von Sozialstaat und Migration.

I: Mhm. Und du hast vorhin noch gesagt, du findest es bei der Schweiz auch ganz gut, dass die halt nicht so einen Sozialstaat haben und ALLE einfach aufnehmen. Sondern die Leute müssen eine Arbeit haben. Und in Deutschland? Wie ist es in Deutschland?

S: In Deutschland ist es ja so, ähm, so habe ich das auch mal von N24 gehört, dass .../ Nach dem Zweiten Weltkrieg .../ Wir haben ja Juden und alles getötet und Deutschland wäre ja dran schuld - waren wir auch, geb' ich ja auch zu. Aber wenn wir jetzt sagen, ähm: „Nee. Du darfst nicht hier rein.“ Dann wird ja von anderen Ländern gleich wieder gesagt, wir wären feindlich. Judenfeindlich oder rassistisch, ne? Ähm, und wenn wir das nicht tun, also wenn wir sagen: „Ja. Komm' rein. Komm' rein. Komm’ rein. “Dann wird ja gesagt: „Ja. Sozialer Staat. Sozialer Staat.“ Aber trotzdem kostet uns das was, dass wir die hier behalten, ne?

I: Mhm.

S: Und manchmal denke ich auch, wenn ich jetzt um die Straßen gehe und ich höre von irgendwo anders jetzt Türkisch .../ Ich finde, wenn es der deutsche Staat ist, dann soll man auch ein bisschen Deutsch reden. Wenn es unter der Familie ist, ist es ja etwas anders. Aber auf der Straße, ist meine Meinung: Deutsch reden und es ist okay. Aber 
manchmal ist es auch so, mhm, ist nicht so mein Ding, wenn auf einmal da Türkisch geredet wird und da Russisch und hier wieder Deutsch. Man will ja auch sagen .../ Vielleicht beleidigt der dich ja, ne? Das weiß man ja nicht. Deswegen. (Michael, HS18)

Er findet es problematisch, dass Deutschland keine Migrant_innen ablehnen dürfe, da sie sonst aufgrund der auf dem Zweiten Weltkrieg und der Judenvernichtung basierenden Schuld als ,judenfeindlich oder rassistisch“ angesehen würden. Die Vorkommnisse, die zu der Schuld geführt haben, gebe er ,,ja auch zu“. Die Art, in der er dies äußert, scheint davon zu zeugen, dass ihm eine andere Geschichtsschreibung lieber wäre, da die schulderzeugende ihm unangenehm ist und in seinem Nationalstolz kränke.

Diese Schuld führe laut Michael dazu, dass alle reinkommen dürfen sowie, dass der Sozialstaat stark beansprucht würde. Das findet er offenbar aus zwei Gründen falsch. Der erste Grund sind die Kosten, die entstehen, wenn ,wir die hier behalten“. Michaels Pronomen verweisen nicht nur auf eine drastische Grenzziehung zwischen der Wir-Gruppe der Deutschen und der Die-Gruppe, in diesem Fall Migrant_innen oder Geflüchtete. Seine Formulierungen implizieren auch eine Verfügungsgewalt der einen über die andere Gruppe - beispielsweise in der Formulierung einer Gruppe, die die andere hier behalten oder eben auch weg schicken könne. Der zweite Grund ist die Sprache. Es stört ihn offenbar, wenn er auf der Straße ,Türkisch“ oder „Russisch“ höre. Michael findet, dass innerhalb des deutschen Staates ,,auch ein bisschen Deutsch“ geredet werden solle. In der Familie sei es ,etwas anders“, aber auf der Straße sollte Deutsch gesprochen werden.

I: Und wie sollte .../ Also, die Leute sollten dann Deutsch reden?

S: Ich weiß ja nicht. Wenn die schon vierzig Jahre hier leben, dann können die ja eigentlich auch Deutsch reden.

I: Mhm.

S: Und wenn die hier jetzt zehn Jahre leben oder fünf Jahre leben, kann ich das ja noch verstehen, dass die kein Deutsch können. Aber ich habe .../ Bei uns in [eine Mittelstadt in Niedersachsen] ist es so, dass sehr viele Türkisch reden. Und dann will man ja trotzdem mal wissen: „Beleidigt der dich jetzt? Oder was denkt der jetzt über dich? Und was labern die miteinander?“"

I: Warum sollte er dich denn beleidigen?

S: Weiß man ja nicht. Du weiß ja nicht .../ Man kennt sich, man hatte einen kurzen Streit oder so was. Und dann, ähm, wenn er dich sieht, sagt er irgendwas auf Türkisch: „Der scheiß Hurensohn“ oder so was. Und man weiß ja nicht, wie die das da nennen, ne? Aber dann kann ich ja auch so sagen .../ Aber wenn ich jetzt irgendwas mit meinem Kumpel rede auf Deutsch, das verstehen die ja. Ich kann ja jetzt nicht in Englisch sagen: 
„Mhm.“ Ich bin ja nicht so gut in Englisch. Das ist so mein Geschmack.“ (Michael, HS18)

Michael findet, dass „die ja eigentlich auch Deutsch reden“ könnten. Sein „Können" scheint eher ein Sollen zu meinen. Er formuliert mit dieser Vorstellung die Hoffnung auf einen Imperativ des Deutsch Redens im öffentlichen Raum. Er schränkt dies für diejenigen ein, die noch nicht so lange hier seien und deswegen noch nicht genug Zeit gehabt hätten, genügend Deutsch zu lernen. Diese Befürwortung eines Imperativs des Deutsch Redens im öffentlichen Raum untermauert er mit einem Beispiel. So redeten viele in seiner Stadt Türkisch. Wenn dann Türkisch gesprochen werde, könne man ja nie wissen, ob man gerade beleidigt werden würde.

Auf Nachfrage stellt er eine Situation vor, in der er möglicherweise auf Türkisch beleidigt worden sei, er und sein „Kumpel“ aber nur auf Deutsch hätten reden können, also keine Möglichkeit gehabt hätten, miteinander zu reden, ohne von den anderen verstanden zu werden. Implizit erkennt Michael hier die Kompetenz der Mehrsprachigkeit an. Damit ist er vielen Diskursen in und um Schulen weit voraus. Er nimmt dabei aber die Kompetenz der Mehrsprachigkeit als Bedrohung wahr. In den in seiner Vorstellung ethnisch strukturierten Konflikten wünscht er sich eine Art Waffengleichheit, die dadurch erreicht werden könnte, dass alle Deutsch sprechen müssten.

I: [lacht] Und, ähm, jetzt gerade wird das so gemacht, dass alle Leute hierherkommen können?

S: Ähm, wie ich weiß, gab es jetzt die Flüchtlinge, was weiß ich, die kommen ja manchmal hier rüber von irgendwo, wo es Krieg gibt. Oder jetzt wie in der Türkei, weiß ich nicht, da gab es wohl früher so was. Wo es Krieg gab oder mehr Streitereien mit der Politik und Menschen. Dann kommen die immer hier rüber, aber können ja wieder zurück. Aber manchmal sagen die: „Gefällt mir hier so.“Wenn die eine Arbeit haben, habe ich ja nichts dagegen, dass sie hier arbeiten. Aber manchmal sehe ich so, ähm, das ist ja jetzt vielleicht auch ein Vorurteil, weiß ich nicht, sehe ich da einen dicken, fetten BMW in der Garage stehen. Und so ein älterer Herr, oder jüngerer, schon ganz jung, so 18 Jahre, der vielleicht nur auf Partys geht. Und dann, der hat so einen fetten BMW da hängen. Weiß man ja nicht.

I: Mhm. Und was denkst du dann, wenn du so was sieht.

S: Manchmal denke ich, WIR müssen suchen für die Arbeit. Und die kriegen .../ Wenn die fünf Kinder haben, das sind ja schon mal fünfhundert Euro Kindergeld ja, ne?

I: Mhm. 
S: Ähm, kann man ja schon was leisten dafür, ne. Kann man ja schon mal, ähm, vielleicht nach billigen Kram erst, dann hat man immer noch vierhundert Euro pro Monat. Und dann kann man das ja in was reinstecken, was man haben will. Wie einen BMW, ne? (Michael, HS18)

Asylrechtliche Gründe für Migration scheint Michael zu akzeptieren. Dabei bleiben die Eingewanderten aber Gäste, schließlich könnten ,die [...] ja wieder zurück“. Das würden „die“ aber oft nicht machen, da ,ihnen“ das hier gefalle. Dies sei für Michael dann akzeptabel, wenn „die“ eine Arbeit hätten. Michael meint allerdings offenbar, dass viele blieben ohne zu arbeiten und problematisiert den Sozialstaat bzw. die Vergabe des Kindergeldes. Das von ihm gezeichnete Bild des Nicht-Deutschen, der durch das Kindergeld seinen „dicken, fetten BMW“ finanziert, löst in ihm selbst die Frage danach aus, ob es nur ein Vorurteil sei. Nichtsdestotrotz funktioniert hier seine Argumentation über dieses Bild.

Dieser Figur des BMW-fahrenden Nicht-Deutschen stellt er eine nationales, homogenes „WIR“ entgegen. Angehörige dieses „WIR“ müssten „suchen für die Arbeit“, während „,die“ einfach so das Kindergeld kriegten. Es bleibt nicht ganz klar, worauf er mit seinem Argument hinaus will. Geht es ihm darum, dass Arbeit das Bleiberecht selbst bedingen sollte oder geht es um eine Kritik an der Partizipation von Nicht-Deutschen am Sozialstaat. In einer drastischen Interpretation stellt sich die Frage, ob Michaels Ausführungen eigentlich in die Kategorie Integration gehören, da die Differenz der „Wir“ - und „Die“ -Gruppe als so drastisch erscheint, dass auch diejenigen mit Arbeit und Sprachkenntnissen als Dauergäste toleriert würden, jeder -noch so unwahrscheinliche - Weg hin zu einer Zugehörigkeit zur Wir-Gruppe dabei aber nicht in Aussicht gestellt wird. Doch in vielen Integrationsdiskursen geht es weniger um eine tatsächlich erreichbare Zugehörigkeit, da hier der Status des seine Integrationswilligkeit beweisen Müssenden perpetuiert wird. In jedem Fall sind seine Ausführungen für diesen Bereich relevant, denn hier wird die Differenz der Wir-Gruppe und der Nicht-Wir-Gruppe über Sprache und Arbeit exemplarisch vorgeführt. Diese Aspekte kommen öfter vor. Mit dieser drastischen Form, wie die Differenzlinien gezogen werden, gehört Michael allerdings zu einer Minderheit.

Niklas (HS17) bringt ebenfalls eine klare Unterscheidung der Wir- und NichtWir-Gruppe hervor. Allerdings gibt es bei ihm eine weitere interessante Facette, derentwillen ich sein Beispiel kurz vorstellen werde.

I: Und du hast gesagt, sozusagen, die sollten sich nicht so benehmen wie sie wollen. Also, so daneben verhalten, irgendwie so .../ 
S: Ja, sie sind ja immerhin sozusagen noch Gäste. Und jetzt nicht unbedingt .../ Natürlich, sie sollen jetzt auch nicht irgendwie ausgeschlossen werden. Sie sollen sich halt irgendwie integrieren zwar, aber .../

I: Mhm. Und was heißt Integration?

S: Ähm, das ist halt .../Wenn man jetzt zum Beispiel eine Klasse hat, eine deutsche Klasse, und dann ja jetzt zum Beispiel ein Ausländer reinkommt, dass man den halt mit in die Gruppe aufnimmt und nicht ausschließt.

I: Mhm.

S: Das der sich halt integriert. Ähm, ein anderes Wort? (...) Da weiß ich jetzt kein anderes Wort.

I: Mhm.

S: Auf jeden Fall .../

I: Und du hast ja auch gesagt: „Die Ausländer sollen sich integrieren.“ Also gerade hast du ja ein Beispiel gebracht, dass da zum Beispiel eine deutsche Gruppe sagen soll: „Hier komm’. Kannst teilnehmen.“ Und was würde das heißen, wenn .../ Was muss der Ausländer dafür tun?

S: Ja, also der sollte sich da halt nicht unbedingt gegen sträuben. Weil dann geht das halt nicht. (Niklas, HS17)

Niklas bringt zunächst ein sehr klares Statement dafür, dass ,Integration“ dazu dient, dass die Nicht-Deutschen lernen, sich zu benehmen. Schließlich seien sie „sozusagen noch Gäste“. Dieser Ausdruck ist sehr interessant. Einerseits greift er hier das dominanzgesellschaftliche Bild des Gastgebers und des Gastes auf. Dieses Bild hat mit den sogenannten ,Gastarbeitern“ der 1950er bis 1970er Jahre einer ganzen Ära migrationsgesellschaftlicher Geschichte ihren Namen gegeben. Das Bild und damit auch Niklas implizieren mit der Figur des Gastgebers einerseits die Gütigkeit, Einlass und Aufenthalt zu gewähren, und damit gleichzeitig andererseits die Macht, den Gaststatus an Bedingungen zu knüpfen, wie etwa, dass er sich an die Regeln im gastgebenden Haus zu halten habe. Doch im Anschluss nimmt sein Argument eine Wende. Auf die Nachfragen, was er unter ,Integration“ verstehe, verschiebt er das Problem. Am Beispiel einer ,deutsche[n] Klasse“, in die ein „Ausländer" komme, sagt er, dass es die Aufgabe der Klasse sei, den „Ausländer [...] mit in die Gruppe“ aufzunehmen und nicht auszuschließen. Irritiert durch diese argumentative Wendung frage ich danach, was der Ausländer dazu beitragen müsse. Der von mir dadurch eingeschlagene Richtung, ihn wieder auf seinen exkludierenden Argumenten festzunageln, lag vermutlich eine bereits unbewusst erfolgte Kategorisierung von Niklas Integrationsverständnis zugrunde. Doch Niklas lässt sich davon nicht beirren. Niklas antwortet, dass dieser sich 
„halt nicht unbedingt [da]gegen sträuben“ solle. Zunächst scheint in Niklas Argumentation das Verhältnis der Dominanzgesellschaft zu Migrationsanderen eines zu sein, in dem es von der dominanzgesellschaftlichen Perspektive her als legitim erscheint, das ,Benehmen“ von einzelnen als „Ausländer“ gesehenen Menschen als ein Benehmen von „Ausländer[n]“ allgemein zu sehen, dieses zu bewerten und ein ,besseres Benehmen " einzufordern. Danach verschiebt Niklas das Argument. Danach ist es die Aufgabe der Dominanzgesellschaft, ,Integration`zu ermöglichen, indem sie nicht ausschließend agiert.

Im Sprechen über Integration geht es auch immer wieder um die Frage der nationalen Identität, mit der die Frage der Zugehörigkeit diskutiert wird. Melina (Gym08) bringt die Fragen der Sprache zusammen mit der Frage von Kultur und Lebensführung.

\section{I: Was macht einen Deutschen zum Deutschen?}

S: Ähm, ich denke, die Sprache natürlich. Also, so ein akzentfreies Deutsch. Dann, ähm, also dieses ein bisschen Neutrale und Höfliche. Also dass nicht so laut irgendwie geschrien wird oder angebrüllt wird auf offener Straße. Sondern das ist halt so ein höflicher und freundlicher Umgang. Also klar, das ist nicht nur bei Deutschen so. Aber wird das halt vielleicht auch oft so damit definiert. Und dann natürlich auch solche Sachen, wie die wohlbehütete Familie. So eine Familie mit zwei oder drei Kindern. Ein guter Schulabschluss, eine Ausbildung oder ein Studium. Und dann halt so ein geregeltes Leben so vielleicht. [...]

I: Mhm. Und was wären dann so Gegenbeispiele, wo das nicht zutrifft?

S: Na ja, ich denke zum Beispiel Asien, Türkei oder Afrika. Da sind ja, jetzt auf die Familie bezogen, manchmal acht bis zehn Kinder. Und das Bildungssystem ist manchmal noch nicht so ausgereift. Und, ähm, es gibt ja auch in Afrika, dass ein Mann mehrere Frauen haben darf. Ähm, und das halt auch das Polizeisystem noch nicht so ausgereift ist. Also, dass man halt in manchen Bereichen noch nicht mal alleine als Frau auf die Straße gehen darf. Oder halt sich verhüllen muss. Und so was ist halt zum Beispiel so ein Gegenbeispiel. Also, dass Deutschland eher dann noch so geordnet ist. Also man spricht jetzt eigentlich so ein bisschen über Vorurteile. Das ist natürlich nicht immer so. Aber so ist dieses typische Bild. (Melina, Gym08)

Melina beantwortet die Frage nach ihren Kriterien für nationale Zugehörigkeit mit fünf Aspekten, die sowohl die Felder Sprache als auch Kultur beinhalten. (1) Zum einen sei ,,akzentfreies Deutsch“ ein Kriterium für nationale Zugehörigkeit. Melina spricht hier nicht von der Fähigkeit des Deutschsprechens, sondern vom akzentfreien Deutschsprechen. Dies stellt einen klaren Differenzmarker für die Frage nationaler Zugehörigkeit für sie dar. (2) Diesen Aspekt ergänzt sie mit der Frage nach Umgangsformen. Undeutsch sei es, wenn „laut irgendwie geschrien 
wird oder angebrüllt wird auf offener Straße“, während für Melina „ein höflicher und freundlicher Umgang“" als deutsch gilt. (3) Der dritte Aspekt besteht in der Familienstruktur. Eine deutsche Familie - als eine „wohlbehütete“ mit „zwei oder drei Kindern“ - stellt sie einer Familie in „Asien, Türkei oder Afrika“ gegenüber, in der es „manchmal acht bis zehn Kinder“ gäbe. Als weiterer Differenzmarker im Feld Familie fühlt sie die Polygamie in Afrika an. So gäbe es das ,,in Afrika“, dass „ein Mann mehrere Frauen“ haben könne. Dem gegenüber steht die als deutsch angesehene Monogamie. (4) Zum Deutschsein zählt sie hier außerdem das Bildungsniveau. Einen Deutschen zeichnet - Melina zufolge - auch tendenziell „ein guter Schulabschluss, eine Ausbildung, oder ein Studium“ aus. Dies begründet sie damit, dass das Bildungssystem in den anderen Weltregionen „manchmal noch nicht so ausgereift" sei. Eine angenommenes Entwicklungsdefizit im Globalen Süden wird hier mit den Menschen von dort identifiziert und als nationale Differenzmarker eingeführt. (5) Der fünfte Aspekt den Melina als Faktoren der nationalen Zugehörigkeit ausmacht, ist der des „geregelte[n] Lebens“. Auch hier überträgt sie vermeintliche Entwicklungsdefizite im Globalen Süden als Gegenentwurf, um Deutsch-Sein zu charakterisieren. Im Globalen Süden sei beispielsweise das „Polizeisystem noch nicht so ausgereift“, Frauen könnten „noch nicht mal alleine [...] auf die Straße“ gehen oder müssten „,sich verhüllen“ und „Deutschland sei im Gegensatz dazu „eher dann noch so geordnet“. Nach all diesen Differenzmarkern nimmt ihr Argument eine interessante Wendung, in dem sie das Gesagte mit Vorurteilen in Verbindung bringt. Ihr ist bewusst, dass die von ihr angeführten Bilder auf Vorurteilen basieren und problematische Pauschalisierungen beinhalten; „das ist natürlich nicht immer so“. Dies sei das „typische Bild“. Nichtsdestotrotz ist dieses Bild für sie und ihr Verständnis von Deutsch-Sein offensichtlich wirksam, auch wenn die Reflexion dessen in ihrer Argumentation bereits angelegt ist.

Clara (Gym11) hat eine Vorstellung von ,Integration', die ich zum Typ des entspannten Anpassungsdrucks zähle. Dieser ist sehr weit verbreitet.

I: Und, ähm .../ Ja, wieso wird das so kompliziert manchmal gemacht? Oder, warum musste zum Beispiel deine Mutter gleich deinen Vater heiraten um hierbleiben zu können? Wieso konnte sie nicht einfach hierher kommen?

S: Das weiß ich nicht. Vielleicht liegt es daran, dass die nicht wollen, dass hier so viele Menschen leben, die sich nicht so richtig integrieren oder so.

I: Mhm. Und was denkst du, wenn du so was hörst?

S: Also, wenn das jetzt der richtige Grund ist, dann, ähm, finde ich das schon normal. Also, okay, ich möchte auch nicht in meinem Land haben, wo Leute ... also, wenn die 
Hälfte die Sprache nicht können. Aber wenn es halt so Ausnahmen gibt, wie die Leute die dringend nach Deutschland ziehen müssen oder so, dann ist es schon unfair.

I: Mhm. Was heißt denn Integration eigentlich?

S: Integration heißt, wenn man .../ Also, wenn man sich anpassen kann. Also wenn man zum Beispiel jetzt einigermaßen die Sprache beherrschen kann. Wenn man .../Ich denke mal einfach nur, wenn man sich hier einleben kann, aber immer noch so man selbst bleibt. Also, man kann immer noch aus .../ Man kann sagen: „Ich komme aus Ägypten." Oder aus dem Iran oder was weiß ich. Aber du kannst immer noch normal reden. Und du kannst dich hier mit Leuten treffen. Ja, also solange du in Deutschland lebst und glücklich bist und andere dich akzeptieren, dann denke ich mal reicht das. (Clara, Gym11)

Ausgehend von migrationspolitischen Fragen, bringt sie Integration bzw. die Angst vor Nicht-Integration als ein migrationsgesellschaftliches Thema ein. Den Wunsch danach, dass sich alle Zuziehenden ,integrieren“, findet sie ,schon normal“. Sie selbst möchte auch nicht in einem Land leben, in dem mehr als ,die Hälfte die Sprache nicht" kann. Auf Nachfrage, was denn Integration eigentlich heiße, erwidert sie, ,wenn man sich anpassen kann“. Als Beispiel für Anpassung bringt sie, ,einigermaßen die Sprachen beherrschen“ zu können. In der Folge wird jedoch aus dem einfachen Anpassungsimperativ in ihrer Argumentation ein Verhältnis zwischen zwei Polen. Auf der einen Seite müsse ,man sich hier einleben“, dabei müsse „man“ auf der anderen Seite ,immer noch so man selbst" bleiben. Damit stellt sie heraus, dass ,Integration“ für sie nicht eine Aufgabe einer anderen nationalen Identität impliziert. Das zur Integration notwendige $\mathrm{Maß}$ der Anpassung erscheint bei Clara beschränkt. Es könne auch ein anderes Herkunftsland genannt werden, ohne dass der Status des Integriertseins dadurch eingeschränkt wäre, solange - und hier formuliert sie eine Bedingung für ,Integration“ - „du [...] immer noch normal reden“ kannst. Was genau sie hier mit ,normal“ meint, ist leider nicht herauszufinden. Vermutlich geht dies aber über Deutsch sprechen hinaus und umfasst auch bestimmte habituelle, distinktive Sprachdispositionen, die sowohl auf Klassenfraktionen basierenden als auch auf ethnisch strukturierten Zuschreibungen basieren können. Diese Vermutung ist an dieser Stelle allerdings etwas zu indizienarm und spekulativ. Solche Andeutungen tauchen jedoch in zahlreichen Interviews auf, was - so vorsichtig formuliert - eine solche These plausibel erscheinen lässt. Im Anschluss weicht Clara diese Bedingungen für die Integration wieder auf, indem sie sagt, dass es für die ,Integration“ reiche, sich mit ,Leuten“ zu treffen, in Deutschland zu leben, glücklich zu sein und von anderen akzeptiert zu werden. Dies ist eine gänzlich andere Vorstellung von ,Integration', insbesondere, weil die Faktoren nicht als zu erfüllende 
Bedingungen der Zugezogenen, um von der konstruierten Wir-Gruppe aufgenommen, akzeptiert oder zumindest toleriert zu werden, sondern vom Standpunkt des Glücks der Migrierenden gesehen werden.

Im Sprechen über ,Integration“ nehmen zahlreiche Schüler_innen die Perspektive der vermeintlich zu Integrierenden ein, wie beispielsweise Bilal (HS15).

I: Ja, super. Das ist doch cool. Mhm, und ganz viele sagen ja auch: „Ja. Die Ausländer kommen hierher. Aber die integrieren sich gar nicht richtig." Was denkst du dazu?

S: Das stimmt bei den älteren Leuten. Stellen Sie sich vor, Sie gehen jetzt in ein anderes Land. Und Sie kennen die Sprache Null. Das ist schwer für Sie.

I: Mhm. Ja. Und was denkst du zu dieser Integration? Dass immer alle sagen: Integration. Integration. Integration?

S: Man sollte sich schon integrieren. Auf jeden Fall. Wenn du eine Sprache mehr kannst, bist du ja wieder noch ein Mensch optisch. Du bist ja dann zwei Personen. Weil du kannst ja .../ Eine Sprache ist ein Mensch. Bei uns sagt man: „Wenn du eine Sprache mehr kannst, dann bist du ein Mensch mehr dazu." Und deswegen, wenn man eine Sprache mehr kann oder selber zum Einkaufen fahren kann.

[...]

S: Auf jeden Fall. Man sollte schon alleine einkaufen gehen oder zum Arzt gehen können. Briefe lesen halt, wenn Briefe kommen. Man muss ja nicht so komplett integriert sein, dass man jetzt Alkohol und so trinken kann. Jeder hat ja seine eigene Meinung vom Leben. Aber so ein bisschen integrieren sollte man sich auf jeden Fall. (Bilal, HS15)

Angesprochen auf ,Integration“ stellt Bilal zunächst die besondere Schwierigkeit für alte Migrant_innen heraus, die neue Sprache zu lernen. Bilal findet, „man sollte sich schon integrieren". Die Perspektive darauf unterscheidet sich jedoch von den vorhergehenden. Es geht hier nicht um die Formulierung von Bedingungen als Eintrittskarten zu Zugehörigkeit und Teilhabe. Bilal diskutiert vielmehr die durch seine Vorstellung von ,Integration' zu erzielenden Vorteile für die Zugezogenen. Hier sieht er vor allem die Mehrsprachigkeit und die Selbstständigkeit. Bei ihm sage man: „Wenn du eine Sprache mehr kannst, dann bist du ein Mensch mehr dazu." Durch die ,Integration“ - also das Erlernen einer weiteren Sprache - kannst du dich als Mensch entwickeln und neu erfinden. Selbstständigkeit spielt für ihn aber auch eine Rolle. So sei es wichtig, dass man ,alleine einkaufen gehen oder zum Arzt gehen“ sowie „Briefe lesen“ könne. Hier geht es nicht darum, funktional für die Dominanzgesellschaft sein zu müssen, wie es im Subtext des Integrationsimperativs mitschwingt. Seine Perspektive scheint vielmehr 
die der Migrant_innen zu sein, denen diese Fähigkeiten ein besseres, unabhängigeres Leben ermöglichten. Bilal stellt sich ,Integration“ eher als Möglichkeitsraum für Zuziehende vor. Dabei sieht Bilal weder die Notwendigkeit noch einen Vorteil darin, „,komplett integriert“ zu sein, sodass man zum Beispiel „Alkohol und so trinken“ könne. Diese Art der Anpassung hält er nicht für nötig, da ,,jeder [...] ja seine eigene Meinung vom Leben“ habe. Er thematisiert hier ,Integration“ im Feld der Kultur und sagt, dass diese nicht vollständig sein müsse. Durch die Wahl seines Beispiels bringt er aber subtil noch eine weitere Facette in seine Vorstellung ein. Es scheint so zu sein, dass er die implizite Setzung der Kultur der Dominanzgesellschaft als überlegen herausfordert, indem er diese mit Alkohol trinken charakterisiert. In seiner Vorstellung von ,Integration“ finden sich daneben aber keine Spuren auf eine durch das Sprechen über Integration sich vertiefende Differenz zwischen der Wir-Gruppe, in die es sich zu integrieren gilt, sowie der Nicht-Wir-Gruppe, also denen, die sich an diese Wir-Gruppe anzupassen haben.

Nach einer Gesprächssequenz mit Özgür (Gym15) zum Thema ,Parallelgesellschaften" greife ich das Stichwort der Integration auf und frage nach seiner Meinung dazu.

I: [lacht] Und was denkst du, es gibt ja auch manchmal Leute die sagen: „Ja. Manche integrieren sich nicht gut genug." Was denkst du wenn du das hörst? Dieses Integrations- .../

$\mathrm{S}$ : Na ja, man versucht halt, das Beste zu tun. Weil es ist halt nicht leicht sich sofort zu integrieren. Weil man braucht halt Zeit, um sich zu integrieren. Um zu lernen, wie man sich verhalten soll möglichst, um eben nicht so, ich sag' mal, aufzufallen. Man kann ja positiv und negativ auffallen. Am besten positiv.

I: [lacht] Was heißt denn Integration für dich?

S: Integration für mich heißt „,sich einleben“. Also ,sich anpassen“.

I: Mhm.

$\mathrm{S}$ : Ja, integrieren ist, die neue Kultur zu erlernen halt.

I: Und ,sich anpassen“? Findest du das eher gut oder schlecht? Oder beides?

S: Also man sollte möglichst nicht immer gleich sein, das ist ja das Schlechte daran. Aber man sollte sich möglichst anpassen und nicht halt komplett anders sein. (Özgür, Gym15)

Özgür nimmt im Gegensatz zu vielen anderen Schüler_innen die Perspektive von Migrant_innen und nicht der Dominanzgesellschaft ein. Auf die Frage nach seinem Verständnis von ,Integration“ nennt er zwei Dimensionen, die sich auch in den anderen Antworten widerspiegeln. Zum einen versteht er unter ,Integration“ 
„,sich einleben“ und zum anderen „,sich anpassen“. Das sind keine gegensätzlichen Aspekte; sie scheinen vielmehr miteinander zu tun zu haben. Das Sich-Einleben verweist auf die Herausforderung, die Özgür darin sieht, ,,die neue Kultur zu erlernen“. Dies brauche „Zeit“, auch wenn man versuche, ,das Beste zu tun“. Damit scheint er Menschen in Schutz nehmen zu wollen, die aus der Perspektive dominanzgesellschaftlicher Diskurse nicht dem Integrationsimperativ Genüge zu tun scheinen. Mit „sich anpassen“ verweist er auf eine andere Dimension des gleichen Prozesses. Ziel dieser Anstrengungen ist für ihn, nicht ,aufzufallen“. Unklar bleibt, als was oder womit man auffallen würde. Man könne ,positiv und negativ“ auffallen. Doch auffallen scheint man in dem Moment, wo man als Migrationsanderer gesehen und damit nur teilweise zugehörig sein kann. Deswegen müsse man sich nach Özgür anstrengen, sich zu integrieren, ,um zu lernen, wie man sich verhalten soll möglichst, um eben nicht so [...] aufzufallen“. Es geht hier also nicht um den Prozess des Zugehörigwerdens, sondern vielmehr darum, weniger - nicht in diesem Maße - als nicht-zugehörig gesehen zu werden. Özgür scheint damit implizit das offizielle Ziel von ,Integration“ - volle Teilhabe durch ,Integrationsbemühungen " - infrage zu stellen, verschiebt die Perspektive und ersetzt es durch ein anderes Ziel. Ziel von ,Integration', hier verstanden als eine Praxis von Migrant_innen, ist es für Özgür, Wege zu entwickeln, nicht so sehr als Migrationsanderer gesehen zu werden. Dies impliziert die Sichtweise, dass Özgür es für nachteilig hält, in dieser Gesellschaft als Migrationsanderer erkannt und gelabelt zu werden. Anpassung, um nicht so aufzufallen, erscheint hier als selbstverständlicher Weg, einen Umgang mit diesen machtvollen Othering-Prozessen zu finden. Aus der Perspektive Migrationsanderer argumentierend erscheinen für Özgür sowohl die möglichen negativen Konsequenzen des Auffallens als Migrationsanderer sowie auch der Versuch, als Migrationsanderer unsichtbar zu werden, als selbstverständlich.

Auch Şahin (HS21) argumentiert aus der Perspektive der als zu IntegrierendenAngesehenen.

I: Ja klar. Und, ähm, wenn jetzt Leute hierherkommen, glaubst es ist hier auch schwierig irgendwie klarzukommen?

S: Anfangs schon, später nicht. Mit der Sprache. Wenn die die Sprache beherrschen, können die alles. Und ein bisschen Verständnis haben.

I: Mhm. Aber glaubst du die Leute hier sagen: „Schön, dass ihr da seid.“ Oder gibt es auch Schwierigkeiten?

S: Ja, es gibt auch Ausländerfeindliche. Nazis oder allgemein auch normale Menschen.

Die meinen so: „Ihr klaut unser Geld.“ Dies und das. 
I: Was denkst du dazu?

S: Ich hab’ nichts dagegen. Das ist deren Sache, deren Meinung.

I: Also es ist okay, wenn jemand sagt: „Du bist kein richtiger Deutscher. Du gehst ja nur klauen."? Dann denkst du, das ist eine Meinung wie alle anderen?

S: Ja. Ich steh' dazu. (Şahin, HS21)

Er führt ebenfalls die Sprache als Schwierigkeit an. Aber nicht als Bedingung für Integration, sondern als zentrale Herausforderung für Migrant_innen, die nach Deutschland kommen. Auf Nachfrage spricht er über „Ausländerfeindliche“, die für ihn „Nazis oder allgemein normale Menschen“ sein könnten. Diese zeichneten sich dadurch aus, dass sie rassistische Stereotype - „Ihr klaut unser Geld.“ vertreten würden. Şahin sieht dies gelassen und meint, es sei „deren Sache, deren Meinung".

Nach einer Gesprächssequenz zu einem anderen Thema greift er das Thema anhand der Frage nach Gewinnern und Verlierern der Globalisierung wieder auf.

I: Ja. Mhm, was würdest du denn sagen, wer sind die Gewinner und wer sind die Verlierer davon, dass es .../ Du hast ja vorhin gesagt es gibt Leute die sind hier, es gibt Leute die wohnen woanders, wo es Armut gibt und so weiter .../

S: Ja. Ich glaube mehr die Ausländer, also die nicht ausländerfeindlich sind, sind Gewinner. Meiner Meinung nach.

I: Und wer sind die Verlierer?

S: Ja, die Ausländerfeindlichen. Die kommen eh nicht durch. Die gewinnen eh nicht. Das ist schon klar.

I: Wieso nicht?

S: Ja, wir sind halt zu viele. Ohne uns würden die vieles schaffen. (Şahin, HS21)

Für Şahin sind die „Ausländer“ bzw. diejenigen, „die nicht ausländerfeindlich sind“, die Gewinner der Globalisierung, während die „Ausländerfeindlichen“ die Verlierer seien. Diese kämen „eh nicht durch“. Es sei „schon klar“, dass „die [...] eh nicht" gewinnen würden. Hatte er sich schon vorher klar von einer Position der „Ausländerfeinde“ abgegrenzt, begründet er hier seine wenig konfrontative Haltung, die deren Meinung so hinnahm. Er argumentiert offenbar aus einer postmigrantischen Selbstsicherheit heraus, mit der er trotz des Anerkennens der Position der „Ausländerfeindlichen“ sich weder als angstvoll noch als Opfer positioniert. Den Grund für seine Sicherheit, dass „die [...] eh nicht gewinnen“, begründet er damit, dass ,wir [...] halt zu viele“ seien. Ohne die Anwesenheit 
von der von Şahin angeführten Wir-Gruppe wäre es denkbar, dass die „Ausländerfeindlichen“" gewinnen würden, nicht jedoch angesichts der Präsenz von Migrationsanderen in der Migrationsgesellschaft.

\subsubsection{Hybridität}

In dieser Kategorie werden alle Aussagen der Schüler_innen eingeordnet, die sich mit Hybridität in der Migrationsgesellschaft auseinandersetzen. Hybridität meint in diesem Zusammenhang das Themenfeld der Vorstellungen von der Vermischung - und damit auch vice versa möglicherweise der Vorstellung einer Reinheit - kultureller Identitäten. In dieser Kategorie konnte ich vier Typen von Vorstellungen ausmachen, wie Hybridität gedacht wird. (1) Bei einer kleinen Gruppe löst die Vorstellung der Auflösung klarer Grenzen, insbesondere in Bezug auf den erhöhten Anteil von Migrant_innen im öffentlichen Leben, Irritationen oder Ängste aus. (2) Eine Mehrheit der Schüler_innen kann dem hybriditätsbefürwortenden Typ des den Anderen konsumierend zugeordnet werden. In dieser Vorstellung wird die Präsenz anderer kultureller Praxen und Objekte begrüßt, da so das Spektrum des individuellen Konsums erweitert wird. Hier spielen Essensläden und -angebote eine zentrale Rolle. (3) Etwa ein Drittel der Schüler_innen sieht in der hybriden Migrationsgesellschaft die Möglichkeit der Erweiterung des Erfahrungsraums. Dieser Typ hat Überschneidungspunkte zum vorherigen Typ des konsumierbaren Anderen und ist nur mit Einschränkungen Trennscharf von ihm abzugrenzen. (4) Von etwa einem Viertel der Schüler_innen wird die Normalität einer gelebten Hybridität betont. Das bedeutet, dass die Überschreitung der Grenzen vermeintlich nebeneinander stehender kultureller Identitätskonstruktionen von als Normalität angesehen wird und eine gelebte Praxis dazu in ihrer Lebenswelt benannt wird. Hier verweisen die meisten Schüler_innen auf eigene oder familiäre Migrationserfahrungen und ihre Erfahrungen mit Mehrfachzugehörigkeiten in der Migrationsgesellschaft. Die folgenden Beispiele dienen der Illustration dieser Vorstellungstypen.

\section{Irritation oder Angst vor Vermischung}

Marcel (HS06) kann dem ersten Typ - Irritation oder Angst vor Vermischung zugeordnet werden, wobei er darin eher keine Bedrohung sieht, vielmehr wird aus seiner Sicht die vorherige Ordnung durcheinander gebracht.

I: Und, ähm, glaubst du, dass sich die Kultur verändert durch Globalisierung? 
S: Ja.

I: Inwiefern?

S: Dass zum Beispiel die Buddhisten und so, dass das sich alles ein bisschen verringert und sich auseinander lebt. Weil die meisten überall woanders hinziehen, und da ist dann wieder eine neue Kultur. Und heiraten wen anders. Und dann vermischt sich das alles so.

I: Mhm. Zum Beispiel bei den Buddhisten?

S: Ja.

I: Und, ähm, findest du das gut oder findest du das schlecht?

S: Tja. Ich habe damit kein Problem.

I: Und passiert das nur bei den Buddhisten? Oder auch hier zum Beispiel?

S: Bei allen. Ich kann jetzt auch nach Thailand ziehen und da dann Buddhist werden oder wie das heißt.

I: Mhm.

S: Ja und dann bin ich glaube ich ein Gott oder ein Buddha. Also das ist dann ... das mischt sich alles so.

I: Mhm. Hast du da schon mal drüber nachgedacht, das zu machen?

S: Nee, noch nicht [lacht].

I: [lacht] Und verändert sich die Kultur auch hier vor Ort?

S: Ja. Mit den Ausländern, zum Beispiel Türken und Kurden. Die glauben ja an ... wie heißt der?

I: Du meinst den Islam? An Allah?

S: Ja. Und dann heiraten die hier eine deutsche Frau und dann ist das ja auch alles durcheinander.

I: Und meinst du das passiert schon ganz viel?

S: Ich denke mal, es wird immer schlimmer. Also es wird immer mehr.

I: Warum?

S: Weil sich alle überall hinpflanzen, sag' ich jetzt mal. Also sich auf die ganzen Länder aufteilen. Weil jeder überall hinzieht und dann ... ja.

I: Und merkst du das auch selber im Alltag?

S: Nee. (...) Eigentlich nicht.

I: Und findest du das .../ Also glaubst du, das kann irgendwie auch blöd sein, dass sich das so verändert? Oder passt das schon?

S: Das passt mir eigentlich. (Marcel, HS06) 
Auf die Frage der Veränderung der Kultur durch Globalisierung kommt er sofort auf das Thema Vermischung, das er mehrfach wieder aufgreift. Er scheint das einfach zu beobachten und findet das weder negativ, noch positiv. In Bezug auf die „Buddhisten“ hat er die Vorstellung, dass sich ,alles ein bisschen verringert und sich auseinander lebt, weil die meisten überall woanders hinziehen und da ist dann wieder eine neue Kultur". Migrationsbewegungen sieht er also als ursächlich an - damit stimmt er mit allen Schüler_innen überein. Er sieht hier offensichtlich die Gefahr, dass die die Kultur des Buddhismus ,,sich verringert“, weil viele Menschen wegzögen. Was meint er aber mit einer „neue[n] Kultur“? Ich interpretiere das im Kontext so, dass die emigrierenden Buddhisten an den jeweils anderen Orten auf eine andere Kultur treffen würden. Eine andere Interpretation wäre, dass dort jeweils - im Zusammentreffen - neue Kulturen entstünden. Unabhängig davon scheint für ihn die Heirat von Menschen aus unterschiedlichen ,Kulturen ' das zentrale Moment der Vermischung zu sein. Vor dem Hintergrund der langen Tradition des Denkens von Hybridität in Deutschland, die auf der rassistischen Annahme der Vermischung von Blutslinien basiert sowie Sexualität und Heirat als zentrales Feld dieses Diskurses platzierte, muss gefragt werden, ob Marcels Fokus damit etwas zu tun hat. Kultur wäre hier eine Chiffre für ,Rasse'. Die Frage lässt sich jedoch nicht weiter beantworten und es ginge zu weit, Marcel diese Kontextualisierung unterzuschieben, die dennoch bei den Vorstellungen dieses Typs immer mitschwingen. In Bezug auf die „Ausländer, zum Beispiel Türken und Kurden“ in der deutschen Migrationsgesellschaft argumentiert er ähnlich. Als Differenzmerkmal führt er den vermeintlichen muslimischen Glauben dieser Gruppen an. Diese würden dann „hier eine deutsche Frau“ heiraten und dann sei ,ja auch alles durcheinander“. Marcel legt hier offenbar eine Vorstellung zugrunde, nach der es klar unterteilte kulturelle Gruppen gäbe, die prinzipiell untereinander und getrennt voneinander blieben, insbesondere in Bezug auf die Ehe. Diese Ordnung wird durch die aus seiner Sicht zunehmenden Migrationsbewegungen ,durcheinander“ gebracht. Dies irritiert ihn anscheinend. Allerdings sieht er diesem Prozess gelassen entgegen und äußert keinerlei negativen - oder positiven - Gefühle in Bezug darauf: „Das passt mir eigentlich.“

Lennart (HS02) führt ebenfalls seine Skepsis gegenüber der vermeintlichen Vermischung der Kulturen aus.

I: Und, ähm, dann habe ich noch eine Frage zu Kultur. Glaubst du, Kultur verändert sich durch Globalisierung?

S: Ja. Massiv. Ich würde sagen vor vierzig, fünfzig Jahren war hier in Deutschland noch mehr Kultur. Allgemein so in Europa. Das verschwimmt ja alles. Das ist ja nicht mehr so, dass man jetzt sagen kann, dass das alles so einheitlich ist. Das verschwimmt 
alles, dass jedes Land ein bisschen Kultur mit reinbringt. Das ist halt multikulturelles Leben mittlerweile. Kann man sagen. Bei uns jetzt kommt es langsam. Schleichend.

I: Mhm. Und findest du das gut oder schlecht?

S: Teilweise. Gemischt. Also es ist so, dass man schon seine eigene Kultur ein bisschen hochhalten sollte. Weil sonst geht die verloren. Und dann sollte man halt sagen, dass man im gewissen Maße schon multikulturell ist, aber auch eine bestimmte Abgrenzung hat. Dass man sagt: „Bis hier hin und nicht weiter halt.“ Das muss man dann gucken, wie man das macht?

I: Wo zum Beispiel? Fällt dir da was ein?

S: Also ich finde man sollte unsere Bräuche, Wintersonnenwende und so was, schon hochhalten. So alte Bräuche finde ich schon wichtig. Um es halt den Kindern weiterzugeben. Und halt unsere Werte Pünktlichkeit, Sauberkeit, Ordnung und so was halt auch weiter so führt. Finde ich schon wichtig. (Lennart, HS02)

Vor ,,vierzig, fünfzig Jahren“ sei ,hier in Deutschland“ bzw. ,,allgemein so in Europa“ noch „mehr Kultur“ gewesen. Den Grund für dieses Weniger an Kultur sieht er darin, dass heute alles verschwimme. Damit meint er, dass in einem Land nicht mehr ,alles so einheitlich“ sei. Kultur zeichnet sich in diesem Verständnis dadurch aus, dass sie von einem Volk einheitlich praktiziert werde. Das Einheitliche, Homogene wird so zum Gradmesser von Kulturalität. Kultur erscheint so ähnlich wie im Herderschen Verständnis als Kugel. ${ }^{5}$ Dieses Verschwimmen der Kulturen ist Lennarts Verständnis des ,multikulturelle[n] Lebens[s]“. Dies komme ,jetzt [...] bei uns an“. Den Prozess des Ankommens des Multikulturalismus attribuiert er mit den Ausdrücken „langsam“ und ,schleichend“. Damit unterstreicht er die von ihm ausgemachte Gefährlichkeit dieses Prozesses. Auf seine Meinung dazu angesprochen antwortet er zunächst ,gemischt“. Er plädiert dafür, dass ,,man schon seine eigene Kultur ein bisschen hochhalten sollte“, weil diese sonst ,verloren“ ginge. Er spricht sich dafür aus, zwar Multikulturalität anzuerkennen, gleichzeitig aber auch eine klare Grenze zu ziehen und die eigene Kultur als solche zu erhalten. In diesem Kulturverständnis geht er offenbar davon aus, dass es quasi ursprünglich eine kulturelle Essenz gibt, die jedem Land eigen ist. Diese verschwimme dann durch Migrationsprozesse. Die aus diesem Prozess des Verschwimmens resultierenden kulturellen Formen scheinen dabei keine Kultur mehr darstellen zu können, da sich diese durch den Grad an Einheitlichkeit und Homogenität dieser nationalen kulturellen Essenz zu bemessen scheint.

\footnotetext{
${ }^{5}$ Vergleiche hierzu den Exkurs zu Kultur in 4.2.3.
} 
Diese nationale Kulturessenz muss aus seiner Sicht vor dem Verschwimmen gerettet werden. Hier führt er mehrfach ein Motiv an, das als Bewahrung des kulturellen Erbes durch das Praktizieren nationaler Bräuche und Werte erscheint. So findet Lennart, dass ,,man [...] unsere Bräuche, Wintersonnenwende und so was, schon hochhalten“ sollte. Solche ,alten Bräuche“ fände er "schon wichtig“. Den Grund für die Relevanz dieser Bräuche sieht er in der Bewahrung selbst: So sei es wichtig, ,um es halt den Kindern weiterzugeben“. Die Praktizierung dieser Bräuche scheint in einem Verhältnis zu den imaginierten nationalen Werten zu stehen. „Unsere Werte“ - mit ,unsere“ meint er vermutlich die vorgestellte Gemeinschaft der Deutschen - seien „Pünktlichkeit, Sauberkeit, Ordnung und so was halt“. Und diese Werte weiterzuführen, fände Lennart ,schon wichtig“.

Diese als deutsch imaginierten Werte erscheinen auf den ersten Blick stereotyp und etwas - salopp gesagt - altbacken. Auf den zweiten Blick stellt sich aber die Frage danach, was er denn anderen Kulturen für Werte zuschreiben würde und wie radikal sein Verständnis des grundlegend-Andersseins der Kulturen ist. Dies versuche ich im Anschluss durch meine Fragestellung herauszubekommen.

I: Mhm. Und, ja .../ Also jetzt zum Beispiel, wenn andere Leute hier sind, aus einer anderen Kultur .../

S: Ja, die bringen halt ihre Kultur mit.

I: Mhm. Und die ist komplett anders?

S: Na ja, kommt jetzt drauf an, wo die herkommen. Wenn man jetzt sagt aus China oder Japan oder so, die sind schon anders von der Kultur her. Aber auch ziemlich ordentliche Menschen.

I: Und wer zum Beispiel nicht?

S: Also ich weiß nicht. Also jetzt fällt mir die (...) Roma gibt es nicht mehr. Nee, Zigeuner .../ Nee, eigentlich gibt es momentan gar nicht mehr so Menschen, die jetzt so komplett .../ Nee, gibt es gar nicht.

I: Gibt es gar nicht? Aber gab es?

S: Na ja, also früher hat man halt gesagt, dass der Jude es wäre. Aber war ja nicht so.

I: Mhm.

S: Ja.

I: Okay. Aber es gibt ja Leute, die .../

S: Ja, natürlich gibt es Leute, die sich in einem Land nicht so gut verhalten. Aber kann man nichts gegen machen. Gibt's ja bei uns auch. (Lennart, HS02) 
Lennart führt aus, dass beispielsweise Menschen aus „China oder Japan oder so“ schon ,anders von der Kultur her“" seien. Diese würden aber nicht das Gegenbild zu den genannten deutschen Werten darstellen. Schließlich sieht er diese ,auch“ als ,ziemlich ordentliche Menschen“. Auf die Frage, wer denn diesen Werten gar nicht entsprechen würde, fängt er zu überlegen an. Zunächst assoziiert er hier „Roma“ bzw. ihre Kultur - er benutzt hier auch die rassistische Bezeichnung - als das imaginäre Negativ der deutschen Werte. Stellt aber gleichzeitig fest, dass es diese gar nicht mehr gäbe, wobei er nicht den Grund dafür nennt. Er ist nach wie vor in der gedanklichen Suchbewegung nach den Menschen, deren Kultur ,jetzt so komplett“ den deutschen Werten entgegengestellt wäre. Dabei scheint ihm aufgegangen zu sein, dass seine scheinbar nur deskriptive Skizze einer Landkarte der nationalen Kulturen und ihrer Werte durch diese Umdrehung eine pejorative Wendung nimmt. Möglicherweise wird ihm hier auch bewusst, dass seine Skepsis gegenüber dem Verschwimmen der Kulturen irreduzibel mit der Unterteilung in überlegene und minderwertige Kulturen verwoben ist. Dies ist jedoch nur Spekulation.

Auf die Frage, ob es denn in der Vergangenheit solche, den deutschen Werten entgegenstehende Kulturen gegeben hätte, verlässt er die ontische Argumentationsebene und spricht auf der Metaebene über das, was gesagt wurde. So wäre früher gesagt worden, dass es ,,der Jude“ wäre, der das Negativ der deutschen Werte verkörpere. Unabhängig davon, ob er oder jemand anders in der Vergangenheit das behauptete, ist zunächst festzuhalten, dass die Assoziationsketten vom Verständnis der deutschen Kultur zu Vorstellungen vom antiziganistisch und antisemitisch imaginierten Anderen vorhanden sind. Trocken fügt er an: „Aber war ja nicht so.“ Die Interpretation dieser Trockenheit wäre zu spekulativ, offensichtlich scheint er sich aber auch hier mit den vergangenen und gegenwärtigen Repräsentant_innen der deutschen Kultur zu identifizieren und gleichzeitig ein Unwohlsein zu verspüren, wohin der Interviewverlauf ihn geführt hat. Schließlich sieht Lennart sich selbst nicht als ausschließenden Menschen, wie sich in anderen Interviewabschnitten gezeigt hat. Der bis zu diesem Punkt im Interviewverlauf sehr selbstbewusst, überzeugt und klar argumentierend auftretende Lennart scheint hier verunsichert und sieht sich möglicherweise ins falsche Licht gerückt. So verstehe ich seine Wendung zum Ende des zuletzt zitierten Abschnitts, mit dem er sich gegen die homogenisierende Zuschreibung wendet. So gäbe es immer Leute, ,die sich in einem Land nicht so gut verhalten“, die gäbe es ,,ja bei uns auch“.

\section{Der konsumierbare Andere und die Erweiterung des Erfahrungsraums}

Die Aussagen von Metin können dem zweiten Typ des konsumierbaren Anderen zugeordnet werden. 
I: Ja. Dann habe ich noch eine Frage. Du hast ja gesagt, dass viele Leute hierher kommen, um hier zu arbeiten. Aus anderen Ländern. Glaubst du das verändert hier irgendwie die Kultur?

S: Ja.

I: Und was zum Beispiel? Oder wie merkst du das?

S: Also die Leute bauen hier ja auch ihre eigenen Firmen auf.

I: Mhm. Und wo merkst du das so im Alltag, dass sich das verändert?

S: (......) Im Alltag? Es gibt hier viele China-Restaurants.

I: Mhm.

S: Bei denen da viele Chinesen arbeiten.

I: Mhm.

S: Oder indische Läden. Oder türkische. Dass halt die Menschen von dort hierhin gekommen sind. Machen eigene Läden auf.

I: Und wie findest du das?

S: Ja, es bringt Neues ins Land.

I: Mhm.

S: Wir sehen mal was Neues. Und .../ Ja, gut. (Metin, HS09)

Kulturelle Veränderung durch Migration sieht sie insbesondere in dem Entstehen von Restaurants mit ethnischem Label, also „China-Restaurants“, ,indische“ oder „türkische“ Läden. Das findet sie gut, weil es „Neues ins Land“ brächte und wir „mal was Neues“ sehen könnten. Metin steht hier exemplarisch für die große Gruppe von Schüler_innen, die das Thema Hybridität in der Migrationsgesellschaft als eine Frage der kulinarischen Angebotserweiterung diskutieren.

Die Vorstellungen von Alexander (Gym05) können ebenfalls dem zweiten Typ des konsumierbaren Anderen sowie insbesondere dem dritten Typ der Erweiterung des Erfahrungsraums zugeordnet werden.

I: Mhm. Oder glaubst du, dass sich .../ Eine Sache noch zur Kultur. Dann bin ich auch ruhig [lacht]. Glaubst du, dass sich die Kultur dadurch verändert, dass auch viele Leute aus anderen Ländern hier sind?

S: Ja, ich denke schon. Weil die einzelnen Leute immer andere Sachen mitbringen. Also dass sie andere Eigenschaften mitbringen nach Deutschland und so was.

I: Mhm. 
S: Und ich weiß nicht, früher waren hier fast nur Deutsche mit weißer Hautfarbe. Und jetzt kommen halt immer mehr Afrikaner und so, die eine andere Hautfarbe haben und so. Und ich denke, dass die auch nochmal andere Sachen mitbringen. (Alexander, Gym05)

Auf die Frage nach der Veränderung von Kultur durch die Anwesenheit von „Leute[n] aus anderen Ländern“ erklärt Alexander, dass sich die Kultur verändere, da diese ,immer andere Sachen“ bzw. „Eigenschaften“ mitbrächten. Im Anschluss versucht er, seine Aussage zu konkretisieren. Er führt aus, dass ,früher“ in Deutschland fast nur „Deutsche mit weißer Hautfarbe“ gewesen seien, während ,,jetzt [...] immer mehr Afrikaner und so [kämen], die eine andere Hautfarbe haben und so". Zu diesem Zeitpunkt bleibt unklar, warum er vom Thema kultureller Veränderung zum Thema der Hautfarbe umschwenkt. Angedeutet wird nur, dass „,die auch nochmal andere Sachen“ mitbrächten. Interessant erscheint mir der Ausdruck ,und so“. Er scheint hier mehrere Funktionen für Alexander zu erfüllen. Die erste Verwendung in „Afrikaner und so“ möchte er das Spektrum der einwandernden Gruppen offenbar nicht auf „Afrikaner" beschränken; gleichzeitig stellt sich damit aber die Frage, welche übergeordnete Gruppe er mit dem ,und so“ im Sinn hat. Nicht-Deutsche oder ,Ausländer" ergibt keinen Sinn, da die Frage der Hautfarbe daran anbindet. Es geht offenbar um eine kulturelle Differenz, die von Alexander als so wesentlich empfunden wird, dass die Angehörigen dieser „und so"-Gruppe ,andere Sachen“ mitbringen könnten. Das ,und so" in Bezug auf die Hautfarbe referiert offenbar auf eine phänotypisch feststellbare Differenz über die eine grundlegende kulturelle Differenz festzustellen ist. Um Missverständnisse zu vermeiden: Mir geht es hier nicht darum, Alexander als rassistisch zu brandmarken, sondern seinen Rekurs auf das gängige Kulturverständnis zu analysieren.

Im Anschluss frage ich ihn, was sie denn zum Beispiel mitbrächten.

\section{I: Mhm. Was denn zum Beispiel?}

S: Ja, Musik zum Beispiel. Also ich denke mal, dass Musik da bei denen wirklich eine riesen Rolle spielt in den Ländern. In Südafrika oder so. Das hat man bei der WM gesehen, dass das da wirklich alles eine riesige Rolle spielt. Auch wen Vuvuzela nicht zur Musik gehören [lacht].

I: [lacht]

S: Aber ich denke, dass ist auf jeden Fall, ähm .../ Ja, dass einfach die afrikanischen Länder und so sehr Musik .../ Dass die sozusagen die Musik, den Rhythmus im Blut haben. Sagt man auch immer wieder. Und ich denke, dass das sich schon in einigen Formen dann verändert. Doch. 
I: Und bringen die noch etwas anderes mit als so einen, ähm, „Rhythmus im Blut“?

S: Ähm, Essensgewohnheiten und so was bringen die vielleicht noch mit. Weiß ich aber auch nichts Genaues zu.

I: Mhm. Und wie findest du das, dass sich das dann .../

S: Ich finde es eigentlich ziemlich gut. Weil ich finde so ein bisschen Abwechslung, so ein bisschen Musik hier rein bringen ist schon nicht schlecht. Und mag ich auch eigentlich. Und ich finde schon, dass es schon sinnvoll ist, so was mal reinzubringen hier nach Deutschland. Weil Deutschland wirklich .../ Also was heißt öd? Also Deutschland ist kein öder Kontinent, äh, kein ödes Land. Ähm, aber ich denke Deutschland hat schon .../ Irgendwie Musik oder so haben sie jetzt nicht so. Aber ich denke Deutschland hat andere Sachen dafür toll. Keine Ahnung, was kann man da sagen? Ja, die haben wie gesagt Autos [lacht]. Das gehört jetzt nicht unbedingt zur Kultur. Aber zum Beispiel Essen haben sie auch einiges schon hier und so was. Und die Religionen und so was. Und ich denke doch, dass hier auch es kein ödes Land ist. Aber das es sinnvoll ist, dass sich hier ein bisschen was erneuert.

I: Mhm.

S: Das denke ich schon. (Alexander, Gym05)

Auf die Nachfrage danach, was sie denn mitbrächten, nennt er Musik. Dies spiele bei ,denen wirklich eine riesen Rolle“. Mit Südafrika, der WM und der Vuvuzela nennt Alexander Kontexte, in denen er diese Zuschreibungspraxen offenbar aufgegriffen hat. Weiterhin führt er aus, dass ,die“ in und aus den ,,afrikanischen Länder[n] [...] sozusagen die Musik, den Rhythmus im Blut" hätten. Dadurch, dass „die“ diese Eigenschaften mitbrächten, würde sich hier schon was verändern. Dies findet Alexander ,eigentlich ziemlich gut“. Hier stellt er „Deutschland“ und ,Afrika“ gegenüber. Er diskutiert, ob Deutschland im Vergleich als „öd“ einzuschätzen sei. Dabei kommt er zu dem Schluss, dass es in Deutschland anerkennenswerte kulturelle Praxen in Bezug auf Autos, Essen und Religionen gäbe, es aber trotzdem „,sinnvoll“ sei, ,so was mal reinzubringen hier nach Deutschland“. In der Gegenüberstellung erscheint Deutschland als das unmusikalischere. Er greift hier das in der kolonial-rassistischen Ideologie verbreitete Bild der afrikanischen Musikalität auf. Durch die Aussage, dass ,denen“ der ,Rhythmus im Blut“ läge, wird deutlich, dass Alexanders Zuschreibung auf der Verknüpfung von Blut und Hautfarbe mit kulturellen Eigenschaften basieren. Wie bei Marcel - und durch seine Bildersprache noch stärker - stellt sich hier die Frage, inwiefern ,Kultur' in diesem Kontext eine Chiffre für ,Rasse‘ sein könnte. Anders als bei Marcel beunruhigt ihn dabei 
keineswegs eine Vermischung. Vielmehr begrüßt er diese explizit. Er sieht hier Vorteile für Deutschland, das von den mitgebrachten Eigenschaften profitieren könne. Sie könnten dazu dienen, dass „sich hier ein bisschen was erneuert“.

Im zweiten Typ des konsumierbaren Anderen und dem dritten Typ der Erweiterung des Erfahrungsraums wird Hybridität als etwas gefasst, in dem potenziell essenzialisierte Differenzen als auf einem Markt zur Verfügung gestellt erscheinen. Von diesen Artefakten der als anders konstruierten Kultur könne dann entweder individuell oder als nationale Kultur profitiert werden. Ob diese kulturellen Zuschreibungen als essenzialisiert oder praxeologisch-kontextuell erscheinen und inwiefern die Einverleibung dieser die eigene Kultur verändert oder beide kulturelle Entitäten unverändert nebeneinander bestehen bleiben, variiert sehr stark und ist nur in einigen Interviews eindeutig nachvollziehbar.

\section{Normalität gelebter Hybridität}

Der vierte Typ - derjenige der Normalität der gelebten Hybridität - wird insbesondere von Schüler_innen vorgebracht, die auf ihre eigene oder familiäre Migrationserfahrung oder vereinzelt die auf ihren migrantisch geprägten engen Freundeskreis verweisen. Für Memnun (HS08) erscheint Hybridität als Uneindeutigkeit der Zugehörigkeit bzw. Mehrfachzugehörigkeit als Normalität und selbstverständlicher Teil seiner Lebenswelt und nicht als Besonderes oder eine Ausnahme. Im Kontext einer Gesprächssequenz über rassistische Diskriminierung durch eine Lehrerin definiert er seine eigene Positionierung wie folgt.

I: [...] Weiß ich nicht. Du hast vorhin gesagt, die eine Lehrerin hat zum Beispiel mal wegen deiner Kultur .../ Was ist denn deine Kultur? Was würdest du sagen, was ist denn deine Kultur?

S: Ja, nee. Weil sie wusste, dass ich ja halb Deutscher und halb Palästinenser bin. Wie mein Vater ja auch. Und das sage ich ja auch. Ich bin ja halb Deutscher und halb Palästinenser. Und, keine Ahnung.

I: Sprichst du Arabisch.

S: Ja. Fließend. Schreiben, lesen und das auch.

I: Geil. Ernsthaft sogar schreiben? Geiles Ding! (...) Und was würdest du dann sagen, was ist deine Kultur?

S: Ja, ich spreche Deutsch, ich spreche Arabisch. Also so ein Mischmasch. (Memnun, HS08)

Er definiert sich als „,halb Deutscher und halb Palästinenser“. Dies sage er ,ja auch“; dieser Ausdruck legt nahe, dass es auch anders sein könnte; dass es auch eine Option 
darstellt, diese Mehrfachzugehörigkeit nicht explizit werden zu lassen. Unklar bleibt dabei, in welche Richtung. Lässt die Formulierung , halb Deutscher und halb Palästinenser" noch Spielraum für eine additive Positionierung beider damit potenziell klar unterscheidbaren ,Identitäten“, deutet seine Beschreibung des „Mischmasch“ bereits ein nicht additives Verständnis von Hybridität an.

I: [...] Wenn du noch irgendwas sagen willst, kannst du gerne noch was sagen. Aber ich bin mit meinen Fragen durch.

S: Ich denke gerade nach so. (...) Also ich höre auch Rap Musik. Deutsche Rap Musik. Ähm, dass da so Ausländer, die hier so herkommen nach Deutschland - aus dem Iran, türkische Kurden oder irgendwie so was - und dann so rappen, wie die so aufgewachsen sind hier. Und wie da. Und wie die, keine Ahnung, also ich habe eigentlich keine Fragen so.

I: Aber das ist für dich auf jeden Fall ein Thema einfach? Dieses, dass man in zwei Kulturen Zuhause ist? Oder in mehreren Kulturen?

S: Ja. Ja.

I: Und das ist für dich sozusagen normal.

S: Genau.

I: Ja. (Memnun, HS08)

Für Memnun ist Mehrfachzugehörigkeit offensichtlich ein Thema. Anders als in den Aussagen der anderen Typen von Hybridität geht es in seiner Auseinandersetzung aber nicht um die Angst vor den Anderen oder den eigenen Vorteil durch den Konsum von oder die Erweiterung des Erfahrungsraums durch die ,Anderen'. Vielmehr setzt er sich aktiv mit den Erfahrungswelten von Menschen mit Mehrfachzugehörigkeitserfahrungen auseinander. Dies macht er anhand von Rap-Musik, in der ,so Ausländer, die hier so herkommen nach Deutschland - aus dem Iran, türkische Kurden oder irgendwie so was - und dann so rappen, wie die so aufgewachsen sind hier. Und wie da." Anders als bei Alexander verweist der Ausdruck ,,irgendwie so was“ als Ergänzung zu „Ausländern [...] aus dem Iran, türkische Kurden“ nicht auf tendenziell grundlegende kulturelle Differenzen, in deren Aufeinandertreffen die deutsche Kultur von der nicht-deutschen Kultur profitieren könne. Vielmehr verweist der Ausdruck des ,irgendwie so was“ bei Memnun auf die gemeinsame Erfahrungswelt von Mehrfachzugehörigkeit sowie der dadurch entstehenden Erfahrung von Differenz in der Migrationsgesellschaft. Für ihn ist diese Form gelebter Hybridität alltäglich und normal. 


\subsubsection{Die Anderen als, Kultur'}

In dieser Kategorie liegen alle Aussagen der Schüler_innen zugrunde, in denen es um ,Kultur' als ethnische Kategorie geht, die sich durch Differenz zu anderen abhebt und die einer nicht-kulturellen Modernität entgegengesetzt wird - und um diejenigen Fälle, wo dies explizit infrage gestellt wird. Es geht hier also nicht allgemein um den Kulturbegriff - das wäre zu umfassend und unspezifisch. Vielmehr interessiert hier insbesondere das Verhältnis von Kultur zu Nicht-Kultur. Dabei ist dieses spezifische Verhältnis von ,Kultur' und ,Nicht-Kultur ${ }^{\text {‘ }}$ nicht selbstverständlich. In der dekolonialen Theoriegeschichte sind durchaus auch gegenteilige Diagnosen von (neo-)kolonialen Diskursräumen angestellt worden. So kam beispielsweise Frantz Fanon zu der Einschätzung, dass im kolonialen Diskurs die europäischen ,Kulturen' als ,Kulturen' klassifiziert würde, während den nicht-europäischen das Prädikat ,Kultur“ nicht zugedacht wurde: „Und man kann nicht leugnen, daß die Hauptverantwortlichen für diese Rassisierung des Denkens oder zumindest der Denkweisen die Europäer sind und bleiben, die unablässig die weiße Kultur den anderen Unkulturen gegenübergestellt haben.“ (Fanon 1961: 180) Dies ist von der Struktur her ähnlich, wie die im bürgerlichen Diskurs bis vor wenigen Dekaden gängige Gleichsetzung von ,Kultur' mit bürgerlicher Hochkultur und der Abwertung der ,Kultur' der Arbeiter_innenklasse zur ,Nicht-Kultur'. Dieses koloniale Bild von Kultur lässt sich jedoch in den Aussagen der Schüler_innen nicht finden. Die argumentative Struktur, die sich hier findet, scheint eine quasi umgekehrte. Dies gilt zumindest für die von mir hier untersuchte Gruppe. Einige wenige Schüler_innen benutzen den Begriff ,Kultur ‘ auch in einem allgemeineren Sinne menschlicher Praxis. Zunächst möchte ich jedoch dem Kulturbegriff nachgehen, dem ein Begriff von Nicht-Kultur entgegengesetzt wird. Ein solcher ist bei etwa einem Viertel der Schüler_innen explizit oder implizit vorzufinden. Bei den anderen Schüler_innen ist aus dem Material kein derartiges Verständnis zu diesem Aspekt des Kulturbegriffs herauszulesen.

Die Analogie zum Argument bei Fanon besteht darin, dass auch diesem Kulturbegriff eine ,Nicht-Kultur' entgegengesetzt wird. Im kolonialen Diskurs repräsentierten nach Fanon die Kolonisierenden die Kultur, während - als Akt der kolonialen Abwertung und Distinktion - die Kolonisierten die ,Nicht-Kultur repräsentierten. Die Umkehrung besteht dann darin, dass in den Vorstellungen der Schüler_innen im migrationsgesellschaftlichen Kontext vielmehr die ,Anderen' als ,Kultur' erscheinen, während das ,Eigene` das ,Moderne‘ und damit eine ,Nicht-Kultur` darstellt. Das Machtverhältnis besteht fort, nur artikuliert es sich anders. 
Hierfür gibt es bereits Ansätze in der dekolonialen Theorietradition. So führte beispielsweise Edgardo Lander aus, wie in der kolonialen Denkweise ausschließlich der Okzident nicht als bloße Kultur erscheint. „In den Augen der Okzidentalen ist der Okzident und nur der Okzident keine Kultur, er ist nicht nur eine Kultur."6 (Lander 2000: 24) Lander zufolge erscheinen dabei im kolonialen Denken die kolonialen Anderen, also die Nicht-Okzidentalen, als bloße Kultur, da ihnen Logos und Modernität abgesprochen werden. Trotz der Umkehrung des Fanonschen Arguments liegt diesem Kulturverständnis also die gleiche koloniale Differenz zugrunde. Bloß Kultur zu sein und Nicht-Kultur zu sein, läuft also auf der Ebene der Macht in diesem Fall auf das Gleiche hinaus. Ich möchte hier keine geschichtliche Abfolge beider begrifflichen Verhältnisse von Kultur und Nicht-Kultur suggerieren, denn ich vermute, dass beide Argumentationsstrukturen sowohl in der Vergangenheit und der Gegenwart parallel zueinander existierten. Meine Gegenüberstellung mit Fanons Argument dient vielmehr der analytischen Schärfe gegenüber der Argumentationsstruktur.

Zur Illustration der Vorstellung von Kultur, die den ,Anderen“ vorbehalten ist, möchte ich das Beispiel von Lara vorstellen. Im Anschluss möchte ich anhand des Beispiels von Mahamadou zeigen, wie er - wie eine kleine Gruppe von Schüler_innen - diese machtvolle Konstruktion des Verhältnisses von ,Kultur ' und ,Nicht-Kultur' infrage stellt.

Lara (Gym18) führt ihr Verständnis von ,Kultur`aus.

I: Ja. Und, ähm, glaubst du, dass sich Kultur durch Globalisierung verändert?

S: Also es könnte schon passieren. Also wenn man genau guckt, heutzutage gibt es eigentlich so - vor allem in den westlichen Ländern - nicht wirklich viel Kultur. Oder es ist mehr so was Spezielles, was nur zu besonderen Anlässen ist oder so. Weil .../ Also jeder hat ein Handy. Jeder hat einen Fernseher. Jeder hat dieselben Klamotten. Alles ist gleich eher. Und die Kultur ist dann halt nicht so wichtig.

I: Mhm. Was wäre dann zum Beispiel Kultur?

S: Also sagen wir zum Beispiel das Essen. Ich weiß jetzt nicht, was Amerika für eine Kultur hat oder so. Aber wenn man da halt hingeht, gibt es Chinatown und keine Ahnung. So irgendwelche Städte und überall chinesisches Essen. Oder indisches Essen und so. Und, ja, das ist dann keine Kultur von denen direkt, aber .../ Ja.

I: Mhm. Ist das in Deutschland auch so?

S: Ja, zum Beispiel in Deutschland gibt es im Prinzip keine Kultur. Außer halt in Bayern das und so. Aber das macht hier zum Beispiel keiner. Also jeder stellt sich vielleicht

\footnotetext{
${ }^{6}$ Übersetzung MK, Original: „En los ojos de los occidentales, el Occidente, y solo el Occidente no es una cultura, no es solo una cultura.“ (Lander 2000: 24)
} 
vor: „Deutschland ist Lederhosen und Dirndl und so.“ Aber wenn man genau guckt, hier in Hannover sehen alle aus wahrscheinlich wie die in Amerika oder in Spanien oder sonst wo.

I: Mhm. Und es gibt nichts Eigenständiges sozusagen? Die „deutsche Kultur“ sozusagen?

S: Eigentlich nicht. (Lara, Gym18)

Lara findet, dass es ,heutzutage [...] eigentlich so - vor allem in den westlichen Ländern - nicht wirklich viel Kultur" gäbe. Die Ursachen für die Absenz von ,Kultur' haben hier also offenbar eine temporale und räumliche Dimension. ,Kultur' würde zu dieser Zeit und an diesem Ort nur zu ,,besonderen Anlässen“ praktiziert. Lara begründet das damit, dass ,,jeder“ ein Handy, einen Fernseher und dieselben Klamotten habe. Alles sei ,gleich“. Und die „Kultur sei dann halt nicht so wichtig“. Dadurch, dass alles gleich sei, also die Artefakte keine differenzierenden Effekte zwischen ,Kulturen“ mehr hervorbringt, wertet Lara diese als ,nicht-kulturell‘. Damit etwas für Lara als ,Kultur' gilt, muss es also an einer bestimmten differenziell verstandenen ,Kultur' oder vielleicht auch einer Gruppe von Ethnien, Nationen, Regionen oder Ländern zugeordnet werden können und für diese charakteristisch sein. Erst dieser Effekt der ,kulturellen" Distinktion macht offenbar für Lara ein Artefakt oder eine Praxis zur ,Kultur`. Dadurch, dass der globalisierte Konsum dazu führe, dass in verschiedenen Ländern gleiche Produkte gekauft würden, würde die ,Kultur' verloren gehen. Dieses Verständnis von ,Kultur' führt sie zu der Aussage, dass es ,,in Deutschland [...] im Prinzip keine Kultur“ gäbe. Hier sähen ,alle aus [...] wie die in Amerika oder in Spanien oder sonst wo“. Die einzige Ausnahme in Deutschland stellt für sie Bayern dar. Bayern habe noch ,Kultur“, die sie mit „Lederhosen und Dirndl“ assoziiert.

Lara macht dabei nicht explizit, wie sie das nennt, was an die Stelle der ,Kultur' getreten ist. In ihrer Ausführung klingt an - und damit unterscheidet sie sich von den meisten anderen Vertreter_innen dieses Kulturverständnisses -, dass der globalisierte Weltmarkt dazu führe, dass die Objekte des alltäglichen Lebens überall gleich werden. Während andere Schüler_innen expliziter den Status der ,Nicht-Kultur' des ,Westens“ als Modernität benennen, verbleibt es bei Lara im Unklaren, wie sie die an die Stelle der ,Kultur' getretenen ,Nicht-Kultur' sieht. Ihre eigene Lebenswelt erscheint ihr als ,Nicht-Kultur'. Ihre Aussagen lassen darauf schließen, dass es nicht die Marktförmigkeit selbst ist, die ein Ding oder eine Praxis zur ,Nicht-Kultur' werden lässt; im Sinne eines Simulacrums von Baudrillard (1978) oder ähnlichen postmodernen Medientheoretikern. Ihr Argument läuft vielmehr darauf hinaus, dass eine ,kulturelle ' Praxis zu einer ,nicht-kulturellen “ wird, wenn es nicht mehr als charakteristisch für eine ,Ethnie‘, eine Region 
oder ein Land angesehen wird. Demgegenüber steht der globalisierte Konsum als ,Nicht-Kulturelles‘. Dieses ,Nicht-Kulturelle' hat dabei, wie bereits festgestellt, eine temporale und eine räumliche Dimension. Meiner Lesart zufolge steht das ,Nicht-Kulturelle“ dabei für die Gegenwart, die sich insbesondere in den ,westlichen Ländern“ manifestiere. Das ,Kulturelle" hat hier - auch wenn Lara sich positiv darauf bezieht - den Beigeschmack des Anachronistischen, einer Spur aus der Vergangenheit. Das ,Nicht-Kulturelle‘ verweist dagegen nicht nur auf das Gegenwärtige, sondern - entsprechend der ,Gefahr' des Verdrängens von allem ,Kulturellen' - auch auf die Zukunft. Das ,Nicht-Kulturelle“ erscheint somit als das ,Moderne‘, was gleichzeitig mit dem ,Westlichen“ assoziiert wird.

Ähnlich, und doch ganz anders argumentiert Mahamadou (Gym04).

I: Ähm, ja vielleicht fangen wir einfach so an, dass du nochmal erzählst, was dir zu Globalisierung einfällt.

S: Also Globalisierung, da fällt mir am Anfang gleich die, man sagt ja immer die „westliche Globalisierung“, ein. Dass die Welt nach dem Westen sich orientiert. Also Westen sag' ich .../ Also jetzt Europa, USA. Dass die Leute, ähm, ja nach deren Kultur und nach deren Tradition gehen und nicht mehr ihre eigene Kultur und Traditionen haben.

I: Mhm.

S: Also das verbinde ich so damit. Ja.

I: Mhm. Und woran liegt das, dass das so ist?

S: Ähm, also ich denke mal so, dass die .../ Also USA und Europa ist ja eine sehr moderne und eine sehr, sagen wir, wirtschaftlich gute Region. Also Orte. Und vielleicht Asien und, ähm, Afrika vielleicht ein bisschen oder .../ Ja, vielleicht sind die ein bisschen ärmer. Und die wollen sich vielleicht an denen so ein bisschen anpassen.

I: Mhm.

S: ICH denke das so, aber .../

I: Und wie findest du das? Dass die jetzt quasi .../ Du sagst ja, das ist so, dass alle sich dem Westen oder der westlichen Art anpassen. Was hältst du davon?

S: Also ich finde es einerseits gut, anderseits nicht. Weil, ähm, ich denke mal, jedes Land sollte seine eigenen Traditionen haben. Oder seine eigenen Kulturen haben. Und nicht von anderen abhängig sein. (Mahamadou, Gym04)

Gleich zu Beginn des Interviews wirft er kultureller Machtverhältnisse auf. Er stellt fest, dass ,die Welt nach dem Westen sich orientiert“. Damit meint er, dass die Menschen in anderen Weltteilen als „Europa“ und den „USA“ nach der ,westlichen“ ,Tradition gehen und nicht mehr ihre eigene Kultur und Traditionen 
haben“. Als Grund dafür führt er an, dass die „USA und Europa [...] eine sehr moderne und eine sehr [...] wirtschaftlich gute Region"seien. Da andere Weltteile „ein bisschen ärmer“ wären, würden die sich deswegen ein ,,bisschen anpassen“. Damit spricht er ein ähnliches Thema an, wie Lara, nämlich das Verschwinden von ,Kulturen“, die von etwas verdrängt werden. Nur ist bei Mahamadou dieses Etwas nicht die ,Nicht-Kultur', sondern vielmehr die ,westliche“ Kultur. Dies korrespondiert mit seinem Begriff der Moderne, der zwar an eine räumliche, nicht aber an eine zeitliche Dimension gebunden zu sein scheint, sondern vielmehr an die Frage von Reichtum, der geopolitisch situiert wird. Dementsprechend kritisiert er das Verschwinden von ,nicht-westlichen“ ,Kulturen“, da er findet, dass ,,jedes Land [...] seine eigenen Traditionen [...] oder [...] Kulturen haben“ und ,nicht von anderen abhängig sein" sollte. Mit der Dimension der Abhängigkeit bringt Mahamadou explizit die Frage der Macht mit ein. Es erscheint also weniger als eine Frage von ,Kultur' bzw. ,Nicht-Kultur' oder Modernität oder Vergangenheit, sondern vielmehr eine Frage, welche ,Kultur' die Macht besitzt, andere zu verdrängen.

\subsection{Agency/Subalternität}

\subsubsection{Das Feld strukturieren: Was meint Agency?}

In der Kategorie Agency/Subalternität geht es um die Vorstellungen der Schüler_innen davon, wer als handlungsmächtig gesehen wird und wer nicht. Welche Gruppen kommen in den Denkweisen der Globalisierung als handlungsmächtige vor und welche erscheinen gar nicht oder nur in ohnmächtigen Positionen? Zur Operationalisierung von dem analytischen Spannungsfeld von Agency und Subalternität greife ich auf den Ansatz von Gayatri Spivak zurück. Im Feld dekolonialer Theorien gäbe es hierfür zahlreiche andere Möglichkeiten ${ }^{7}$, doch für mein Anliegen erscheint mir die Theorie von Spivak angemessener. Ich werde meine Leseweise ihrer Begriffe von Agency und Subalternität kurz skizzieren, um dann zu zeigen, was ich davon für meine Forschungsperspektive übernehme. Anschließend werde ich die Struktur dieses Analyseabschnitts darstellen.

Spivak wird insbesondere in Bezug auf ihren Begriff der Subalterne oft reduktionistisch rezipiert. Entweder ihr komplexes Argument wird auf eine Dimension

\footnotetext{
${ }^{7}$ Beispielsweise Maria del Guadalupe Davidson (2017) entwickelt in ihrem Buch Black Women, Agency, and the New Black Feminism eine dekoloniale Theorie von Agency und gibt einen Überblick über Agency-Ansätze im Feld des Black Feminism.
} 
verengt, die ich im Sinne des strategischen Essenzialismus (Spivak 1988b: 205) substanzialistisch nennen würde, oder ihre berühmte Aussage, dass die Subalterne nicht sprechen könne, steht isoliert im Zentrum der Betrachtung. Für meine Darstellung lege ich zwei Texte von ihr zugrunde: Can the Subaltern Speak? (1988), und Scattered Speculations on the Subaltern and the Popular (2012). Wie bereits angedeutet, enthält Spivaks Begriff der Subalternen mehrere Dimensionen, was eine eindeutige Definition verunmöglicht. Dies ist jedoch kein argumentatives Manko, sondern liegt vielmehr in der Komplexität des Problems begründet. Ich werde im Folgenden zwei Dimensionen ihres Arguments herausarbeiten, die jedoch nicht voneinander zu trennen sind, wie ich im Anschluss zeigen werde. Eine Dimension ihres Arguments referiert auf die sozioökonomische Positionierung. In dieser Dimension erscheinen diejenigen als subaltern, die von jeder Möglichkeit sozialer Mobilität ausgeschlossen sind: „The reasonable and rarefied definition of the word ,subaltern' that interests me is: to be removed from all lines of social mobility." (Spivak 2012a: 430) In ihren Beispielen trifft dies beispielsweise auf bestimmte Gruppen entrechteter, unter Umständen landloser Bauern und insbesondere Bäuerinnen im postkolonialen Indien zu. Dieser ,substanzialistischen“ Dimension liegt eine Analyse von Ausbeutungs- und Herrschaftsverhältnissen in (gegenderten) Klassenverhältnissen in postkolonialen Nationalstaaten und der internationalen Arbeitsteilung innerhalb der neokolonialen Globalisierung zugrunde. Aus dieser Analyse leitet sich in dieser Dimension die Subalternität ab.

Eine zweite Dimension ihres Arguments spielt sich auf der Ebene der Repräsentation ab. Ihre - oft missverstandene - Aussage, dass die Subalterne nicht sprechen könne (Spivak 1988a: 106), meint keineswegs, dass die Subalterne nicht in der Lage wäre, sich zu artikulieren. Anhand des Beispiels des Satī - des Rituals der Witwenverbrennung - zeigt sie, wie die Subalterne zum Schweigen gebracht wird. Die Praxis der Witwenverbrennung wurde im kolonialen Indien des 19. Jahrhunderts zum ideologischen Kampfplatz zwischen einer indigenen, nationalistischen Elite einerseits und dem britischen Kolonialismus andererseits. Während die einen die Praxis der Frauen als Opfer für das nationalistische Projekt ausgaben, instrumentalisierte die Kolonialmacht den Kampf dagegen für die Legitimation des imperialen Projekts. Letztere verwenden dabei die koloniale Logik des „weiße Männer retten braune Frauen vor braunen Männern“ (ebd.: 78), die bis heute eine virulente und machtvolle koloniale Diskurspraktik darstellt. In beiden Fällen wird die Handlungsmacht der Frauen aus dem Diskurs gestrichen; die Subalterne spricht nicht, denn egal was die Frauen sagen, sie werden nicht gehört, sondern vielmehr von einem der beiden um Hegemonie ringenden 
Diskurse geschluckt. Hier etabliert Spivak die Verschränkung ihres Begriffs der Subalternität mit dem der Handlungsmacht (agency).

Spivak definiert als eine Bedingung der Subalternität das Nicht-Sprechen verstanden als nicht-als-solches-gehört-werden. Zur Entwicklung ihres Gedankens geht sie von einer Textpassage von Marx aus dem Text Der achtzehnte Brumaire des Louis Bonaparte aus (Spivak 1988a: 30, Spivak 2012a: 434): „Sie sind daher unfähig, ihr Klasseninteresse im eigenen Namen [...] geltend zu machen. Sie können sich nicht vertreten, sie müssen vertreten werden." (Marx 1852: 198) Diese Passage liest sie als eine Auseinandersetzung von zwei Arten, die analytische Kategorie Klasse zu denken. Dies ist nicht neu, sondern verweist vielmehr auf die im Marxismus gängige Unterscheidung zwischen der Klasse an sich und der Klasse für sich. Spivak entwickelt von hier aus jedoch die aufeinander bezogenen Begriffe von Subalternität und Agency.

"Agency was the name I gave institutionally validated action, assuming collectivity, distinguished from the formation of the subject, which exceeds the outlines of individual intention. The idea of subalternity became imbricated with the idea of non-recognition of agency." (Spivak 2012a: 432)

Ein entscheidender Unterschied zu klassischen marxistischen Texten ist hier, dass es nicht um das Bewusstsein der Subalternen geht, sondern um die Anerkennung von Agency. Es ist also bei Spivak durchaus denkbar, dass Subalterne sich den herrschenden Verhältnissen widersetzen, ohne dabei jedoch als solche wahrgenommen zu werden. Spivaks Begriff der Subalterne impliziert dabei auch, dass es eine Position ohne Identität ist. Anders als die frühen Studien der indischen Subaltern Studies geht sie davon aus, dass niemand sich anerkannterweise als subaltern erklären kann: „No one can say ,I am a subaltern“ in whatever language.“ (ebd.: 434) Wird Subalternität zur Identität, nimmt sie einen anderen Namen und eine andere Form an, die häufig als , Volk ${ }^{8}$ verstanden wird. "Today, realizing that subalternity is a position without identity - that like the value-form it is contentless - I cannot think that the project is to fill it with a 'negative' essence. Subaltern content takes on identity, names itself 'people'." (ebd.: 432)

Subalternität ist nicht einfach der sozioökonomische und nicht-politische Zustand, der im Sinne orthodoxer marxistischer Theorie der Bewusstseinsbildung vorangeht, sondern beschreibt vielmehr gleichzeitig die damit verschränkte Dimension von anerkannter und nicht-anerkannter Agency. Im Sinne orthodoxer

\footnotetext{
${ }^{8}$,Volk' (people) trägt hier nicht den völkischen Beigeschmack, der im deutschen Kontext - häufig mit guten Gründen - oft dabei vermutet wird, sondern vielmehr um das Auftauchen des Politischen und des politischen Subjekts.
} 
marxistischer Theorie ist die Klasse an sich die noch nicht zu ihrem eigentlichen Bewusstsein gekommene Klasse, die zur Klasse für sich gebracht werden müsste. Es geht also immer um beides; in marxistischen Begriffen um die Subalterne als Klasse an sich und als Klasse für sich. Dieses Verhältnis ist dabei als komplex zu beschreiben, da nicht von einem quasi mechanistischen Verhältnis ausgegangen werden kann. Spivak vergleicht dieses Verhältnis mit anderen Formen sozialer Ungleichheit.

„Subalternity is a position without identity. It is somewhat like the strict understanding of class. Class is not a cultural origin, although there is working class culture. It is a sense of economic collectivity of social relations of formation as the basis of action. Gender is not lived sexual difference. It is a sense of the collective social negotiation of sexual differences as the basis of action. Race assumes racism. Subalternity is where social lines of mobility, being elsewhere, do not permit the formation of a recognizable basis of action." (ebd.: 431)

Es geht in ihrer Betrachtung dieser Kategorien - ob Klasse, Gender oder Rasse - also immer um die gesellschaftlichen Strukturen, die den Handlungen vorausgehen. Das Vertrackte dabei ist, dass es beispielsweise die Kategorie sex - das naturalisierte Geschlecht - zwar als natürlich gegeben erscheint, es aber keineswegs ist. Gender ist dementsprechend also nicht der Ausdruck einer natürlichen Kategorie, sondern vielmehr die auf sozialen Aushandlungen basierende sinngebende Struktur mit Bezug zur naturalisierten Kategorie sex. Um Subalternität zu denken, müssen diese analytischen Kategorien innerhalb kolonialer Globalität einbezogen werden und diese in Beziehung zu Agency gebracht werden. Dabei arbeitet Spivak mit einer Art double bind, also einer rhetorisch-argumentativen Figur, in der zwei sich widersprechende Denkweisen zusammengedacht werden. Einerseits hat das Verständnis von Subalternität keine unabhängig von den Subjekten und ihrer (Nicht-)Agency bestimmbare Basis; es gibt keine materielle Basis vor dem Text. Andererseits ist eine Analyse globaler Herrschafts- und Ausbeutungsverhältnisse zur Bestimmung von Subalternität notwendig; die ,materielle ‘ Basis vor der textuellen Sinngebung ist notwendigerweise zu beachten. Diese epistemologische Zwickmühle wird teilweise durch den Begriff des Textes aufgefangen, den Spivak sich ausgehend von den Texten von Jacques Derrida erarbeitet; der double bind aber bleibt unaufgelöst (Huddleston 2015).

Der double bind entspricht den beiden oben genannten Dimensionen ihrer Argumentation. Auf der einen Seite muss nach ihr die neokoloniale Globalität einbezogen werden, also die Subalternität in den Blick genommen werden, die die nicht sprechen können; deren Agency, ja deren Situation als solche eben nicht angemessen repräsentierbar ist. Wenn diese Dimension nicht einbezogen wird, 
resultieren daraus Spivak zufolge grundlegende Defizite. Beispielsweise anhand von einer Analyse von Texten von Gilles Deleuze und Michel Foucault zeigt sie, wie eine Nicht-Beachtung dieser globalen Zusammenhänge und der Subalternen nicht nur dazu führt, dass eine Kritik zu kurz greift, sondern auch die eigene Analyse Gefahr läuft, unwillentlich am imperialen Projekt mitzuwirken (Spivak 1988a).

Gleichzeitig problematisiert sie eine vereinfachende Perspektive auf Subalternität, die die Nicht-Repräsentierbarkeit der Subalterne ignoriert:

„Subalternity is the name I borrow for the space out of any serious touch with the logic of capitalism or socialism. Please do not confuse it with unorganised labour, women as such, the proletarian, the colonized, [...] migrant labour, political refugees etc. Nothing useful comes out of this confusion." (Spivak 1995: 115, zitiert nach Dhawan 2007)

Spivaks Ziel scheint mir nicht zu sein, den double bind in der Theorie aufzulösen, sondern vielmehr, ihn als solchen produktiv werden zu lassen. Normativ gewendet zielt ihr Ansatz darauf auf ab, sowohl die sozialen Verhältnisse zu verändern, die Menschen subaltern machen und Agency verunmöglichen.

Für meine Forschungsperspektive muss ich einige Aspekte in Spivaks Ansatz verändern. Ihr Projekt einer ,,aesthetic education in the era of globalization“ (2012) zielt auf die Analyse der Unmöglichkeit und Möglichkeiten einer Agency der Subalterne ab. "This is where aesthetic education kicks in, sees the way reasonable agency is nestled in the permission to be figurative - the right to the metonym/synecdoche political performance of collectivity." (Spivak 2012a: 437) Mit ihrem Ansatz von Subalternität und Agency will ich die Komplexität von materieller Positionierung, Repräsentation und der irreduziblen Verwobenheit mit globalen Ungleichheitsstrukturen einfangen. Dies muss ich in der Analyse der Vorstellungen der Schüler_innen berücksichtigen. Zunächst handhabe ich den Begriff von Subalternität nicht so strikt. Um Missverständnisse zu vermeiden: In dieser Analyse geht es mir aber nicht um die Handlungsfähigkeit der Schüler_innen selbst, sondern um ihre Vorstellungen von Subalternität und Agency. Wen sehen die Lernenden als Handelnde in der globalisierten Welt an, sowohl in der Vergangenheit, in der Gegenwart und der Zukunft? Welche Gruppen erscheinen in ihren Vorstellungen als Subjekte und wer als Objekte? Wem wird zugetraut, an gesellschaftlichen Transformationsprozessen teilzuhaben? Und wem nicht? Wer erscheint nicht in den Vorstellungen von Agency? Und was sind die diskursiven Voraussetzungen in den Vorstellungen der Schüler_innen, die einigen Gruppen Agency zu- und anderen absprechen? 
Es geht zwar in meiner Analyse auf den ersten Blick nicht um die Handlungsfähigkeit der Schüler_innen, aber letztlich haben diese Fragen, wer als handlungsfähig gesehen wird und wer nicht, grundlegenden Einfluss auf die Handlungsweisen der Schüler_innen. Das normative Ziel, das hier zugrunde liegt, zielt dabei sehr wohl auf eine Veränderung der Handlungsfähigkeit der Schüler_innen. Dieses normative Ziel könnte ich dekoloniale Agency nennen, die ich im folgenden Kapitel behandeln werde. In meiner Analyse fasse ich den Begriff von Subalternität nicht so rigide wie Spivak, denn kontextueller Gradmesser ist nicht ihre Analyse des neokolonialen Kapitalismus in der globalen Welt, sondern die Vorstellungswelten der Schüler_innen von globaler Ungleichheit. Während Spivak beispielsweise unter Umständen die Fabrikarbeiter_innen in indischen Städten angesichts ihrer verhältnismäßig hohen sozialen Mobilität innerhalb der indischen Klassen- und Kastengesellschaft als nicht subaltern einschätzen würde, besteht die Kontextualisierung meines Begriffs der Subalternität im Blick der Schüler_innen, also Jugendlichen im Globalen Norden. Spivak stellt mir für meine Analyse allerdings die Instrumente zur Verfügung, um die subtilen - aber deswegen keineswegs weniger virulenten oder wirkmächtigen - Prozesse in den Blick zu nehmen, die Subjekte als solche erscheinen lassen und ihnen Agency zuschreibt oder aberkennt, indem sie in andere, koloniale Texte eingeschrieben sind.

Dabei spielt bei Spivaks Perspektive auf Kolonialität immer die Klassendimension eine entscheidende Rolle. Es geht dabei dann nicht nur um die soziale Konstruiertheit von Repräsentationsmodellen, sondern vielmehr immer um die Aporien, die sich aus der dekonstruktiven Aufhebung des marxistischen BasisÜberbau-Modells ergeben, also aus dem nicht-linearen Zusammendenken vom Realen und dem Symbolischen, von sozialer Materialität und Repräsentation, von Darstellung und Vertretung - auch wenn diese Wortpaare das aporetische Problem jeweils nur unzureichend fassen können. Dabei setzen sich sowohl die Schüler_innen als auch ich als interpretierender Beobachter mit diesem aporetischen Feld auseinander. Für den Blick auf die Subjekte heruntergebrochen bedeutet das, dass es Makrostrukturen gibt, in denen die jeweils potenziell Handelnden nur als Spielbälle dieser erscheinen. Andersherum, ist aber jede Makrostruktur in ihrer lokalen Realisierung Subjekten ausgesetzt, die nicht nahtlos in ihr aufgehen, sondern Devianzen kreieren. Diese Perspektive wurde unter anderem vom Ansatz der Autonomie der Migration entwickelt, an dem ich mich in diesem Abschnitt insgesamt und insbesondere in der Auseinandersetzung mit der Subalternisierung von Geflüchteten orientiere. Yann Moullier Boutang fasst diese Haltung so, dass Menschen „keine beliebig formbare Materie“ seien und Migration nicht als „Wasser, das durch einen Hahn fließt" (Moullier Boutang 2007: 170) verstanden werden kann. Hiervon inspiriert ist meine zugrundeliegende normative Perspektive, nach 
der es Ziel einer dekolonialen Bildung nicht nur sein sollte, ausbeuterische und herrschaftliche Strukturen sichtbar zu machen, sondern auch darum, eine Perspektive der Solidarität zu entwickeln, die subalterne Gruppen dabei weder zu viktimisierten Objekten macht noch zu revolutionären Subjekten glorifiziert. Solidarität bedeutet in diesem postkolonialen Kontext für mich unter anderem, die Anderen als Subjekte zu begreifen, die nicht nur Spielball machtvoller Prozesse sind, sondern über Agency verfügen.

In der Analyse der Vorstellungen der Schüler_innen haben sich drei Unterkategorien ergeben, die sich mit den Vorstellungen der Schüler_innen von drei subalternen Gruppen beschäftigen. Mit subalternen Gruppen meine ich hier nicht tatsächliche Gruppen von Menschen und spreche auch nicht über ihre tatsächliche Agency. Es geht darum, wie die Schüler_innen Agency von diesen drei Gruppen denken und ich konzipiere diese drei Gruppen als subaltern, da die große Mehrheit der Schüler_innen diesen Gruppen Agency abspricht. Natürlich werde ich mich auch, und oft sogar, insbesondere mit den Ausnahmen von der Mehrheitsmeinung beschäftigen, also den Fällen, wo diesen Gruppen eben doch eine Agency zugeschrieben wird.

Im ersten Analyseabschnitt geht es um die subalterne Gruppe der Arbeiter_innen im Globalen Süden. Diesen wird nur in Ausnahmefällen eine Agency zugeschrieben. An die Stelle ihrer Agency treten drei Akteursgruppen: Unternehmer, Politiker_innen und Konsumierende, die ich zu Beginn des Abschnitts skizzieren werde. Anschließend geht es um die Konstruktion von Agency bzw. Subalternität dieser Gruppe in den Vorstellungen der Schüler_innen.

Im zweiten Analyseabschnitt geht es um die subalterne Gruppe der Kolonisierten. Wiederum wird ihnen nur in Ausnahmefällen Agency zugeschrieben. Stattdessen werden von den Schüler_innen insbesondere Kolonisierende und ,Entwicklungshelfer_innen' genannt. Unter Kolonisierten verstehe ich dabei nicht nur Kolonisierte während der Epoche des historischen Kolonialismus, sondern auch Bewohner_innen ehemals kolonisierter Länder, wenn diese nicht als Arbeiter_innen, sondern im Sinne des Entwicklungsparadigmas als Bewohner_innen von , unterentwickelten' Kulturen dargestellt werden. Einige Ausnahmen heben sich dabei von dieser mehrheitlichen Subalternisierung ab.

Im dritten Analyseabschnitt geht es um die subalterne Gruppe der Geflüchteten. Auch ihnen wird mehrheitlich keine Agency zugesprochen. Zwar gibt es hier viel Wissen um schwierige Lebenslagen von Geflüchteten und ein humanistisch begründetes Unwohlsein damit, doch kommen die Geflüchteten mehrheitlich darin nicht als tatsächlich oder potenziell Handelnde vor. Diese mehrheitliche Vorstellung der Subalternität wird in diesem Abschnitt ex negativo über sieben Aspekte dargestellt, mit denen Geflüchteten Agency zugeschrieben wird. 


\subsubsection{Subalterne Positionen I: Arbeiter_innen im Globalen Süden}

In diesem Abschnitt liegen alle Aussagen der Schüler_innen zugrunde, in denen es um Arbeiter_innen im Globalen Süden geht. Alle Schüler_innen äußerten sich zu diesem Themenfeld. Dabei geht es in der Analyse um die Frage, inwiefern diese als tatsächlich oder potenziell Handelnde gesehen werden. Welche Bilder von Arbeiter_innen im Globalen Süden sind in den Vorstellungen der Schüler_innen vorzufinden? Welche anderen Akteure überlagern eine mögliche Vorstellung von Arbeiter_innen als Akteure? Viele Schüler_innen berichten detailreich und bildhaft von ihren Vorstellungen von Arbeits- und Lebensbedingungen von Arbeiter_innen im Globalen Süden. Diese erscheinen dabei meist als hilfsbedürftig, nur in einigen, sehr wenigen Fällen als (potenziell) handelnde Subjekte, die an einer Veränderung der Verhältnisse mitwirken könnten. Dominant in den Vorstellungen der Schüler_innen ist ein humanistischer Duktus, der die Arbeitsund Lebenssituation der Arbeiter_innen im Globalen Süden als zutiefst ungerecht empfindet. Dieser führt jedoch im gleichen Zuge zu einer verobjektivierenden Viktimisierung. Diese drückt sich auch darin aus, dass viele Schüler_innen in dem Moment, wo es um die Arbeiter_innen geht, anfangen über Kinderarbeit und die dieser innewohnenden Ungerechtigkeit zu sprechen. Im Bild der arbeitenden Kinder kommen beide Aspekte zugespitzt zusammen: Die aufrichtige, humanistische Empörung der Schüler_innen über die vorgestellten Arbeits- und Lebensverhältnisse sowie die entsubjektivierende Viktimisierung der Arbeiter_innen und das damit verbundene Abschreiben von Agency. An die Stelle von den Arbeiter_innen als Akteur treten insbesondere Unternehmer, Politiker_innen und Konsumierende. Dies werde ich im Folgenden kurz ausführen. Anschließend stelle ich anhand einiger Beispiele dar, wie Agency von Arbeiter_innen von den Schüler_innen diskutiert wird. Dabei stellt sich heraus, dass in der Auseinandersetzung über den Grund für die vermeintlich fehlende Agency von Arbeiter_innen im Globalen Süden insbesondere die - analog zur kolonialen Differenz konstruierte - defizitäre Disposition der Arbeiter_innen angeführt wird.

\section{Der Markt und , die Politik ${ }^{6}$}

In der großen Mehrheit der zugrundeliegenden Interviewsequenzen geht es nicht um Arbeiter_innen als tatsächliche oder potenzielle Akteure, sondern vielmehr als Opfer. Statt Arbeiter_innen als Akteure zu sehen, dominiert in den Vorstellungen der 
Schüler_innen die Sicht auf Unternehmer ${ }^{9}$ und Politiker_innen. Die entsprechend von den Schüler_innen besprochenen Kontexte Markt und ,Politik' sind so die zentralen Felder, in denen Agency gedacht wird. Dabei unterliegen beide Kontexte in den Vorstellungen der Schüler_innen limitierenden Regeln bzw. Gesetzmäßigkeiten, die nur in Ausnahmefällen infrage gestellt werden. Da diese beiden Akteure als die zentralen Akteure angesehen werden, wird häufig die Hoffnung formuliert, dass diese zur Einsicht zu bewegen sein müssten, etwas an der Situation zu verändern. Während einige Schüler_innen hier aber eher skeptisch sind, da sie einen schlechten Charakter dieser Akteure vermuten, weist eine Mehrheit der Schüler_innen auf kontextbestimmende Gesetzmäßigkeiten beim (1) Markt und in der (2) Politik hin.

(1) Die Unternehmer werden häufig als die Probleme anderer ausnutzende und egoistische Akteure gezeichnet. Viele Schüler_innen stellen dabei aber fest, dass Unternehmer nicht einfach anders handeln könnten, da es auf dem Markt darum ginge, Gewinne zu erzielen und diese ja wesentlich darauf basierten, dass die Arbeiter_innen im Globalen Süden geringer bezahlt werden als im Globalen Norden. In den Vorstellungen der Schüler_innen gibt es ein Bewusstsein für internationale Arbeitsteilung und die damit verbundenen Ungleichheiten. Marktwirtschaftliche Gesetze bestimmen allerdings das Denken über diese Themenfelder; der Markt wird von den meisten Schüler_innen als unumstößlicher, naturalisierter Handlungsrahmen vorausgesetzt. Alle Beteiligten, insbesondere Staaten und Unternehmen, scheinen ,Sachzwängen ' zu unterliegen und nach diesen handeln zu müssen. ${ }^{10}$ Diese werden von den Schüler_innen sehr oft benannt, doch nur in Ausnahmefällen problematisiert oder deren Naturalisierung infrage gestellt. Einige wenige diskutieren auch andere, nicht-marktwirtschaftliche Ansätze, lehnen diese jedoch meist aufgrund fehlender funktionierender Alternativen ab. Auch problematisieren einige wenige die Priorisierung marktwirtschaftlicher Gesetze gegenüber humanitärer Logik.

(2) Eine andere Argumentation sieht , die Politik' prinzipiell in der Verantwortung, etwas an den Arbeits- und Lebensbedingungen der Arbeiter_innen im Globalen Süden zu verändern. Politiker_innen erscheinen oft als einziger Akteur, der prinzipiell mit entsprechender Handlungsfähigkeit ausgestattet sei. Allerdings sieht eine große Mehrheit diese Handlungsmacht als begrenzt an. Begrenzt wird sie insbesondere dadurch, dass die Politiker_innen des Globalen Nordens keinen großen Einfluss auf die Länder des Globalen Südens hätten. Im Nachdenken der Schüler_innen über mögliche Veränderungen von Strukturen globaler Ungleichheit

\footnotetext{
${ }^{9}$ Unternehmerinnen werden nie genannt. Diese Gruppe erscheint in den Vorstellungen eindeutig männlich gegendert.

${ }^{10}$ Für eine Illustration dieser Zusammenhänge verweise ich auf die Studie „Globalisierung und Politische Bildung“ (Fischer et al 2015), insbesondere die Abschnitt 5.2.1 und 5.2.2.
} 
spielt auch das bereits in den vorherigen Abschnitten analysierte Entwicklungsparadigma eine zentrale Rolle, dem ich an dieser Stelle aber nicht nachgehen werde. Nur so viel: Diejenigen Schüler_innen, die die Verhältnisse auf die ,unterentwickelten * politischen Strukturen der Länder des Globalen Südens zurückführen, plädieren für eine Entwicklungspolitik des Globalen Nordens für den Globalen Süden sowie eine Kontrolle der Arbeitsverhältnisse im Globalen Süden durch Regierungen des Globalen Nordens. Das Problem wird in der Haltung der Firmen und Staaten im Globalen Süden ausgemacht, auf die die Politiker aus Deutschland ja keinen oder kaum Einfluss hätten. Den Regierungen des Globalen Südens wird hier im Kontrast zu den Regierungen des Globalen Nordens unterstellt, dass diese keine Veränderung an den Verhältnissen wollten, während eine große Gruppe von Schüler_innen den Regierungen des Globalen Nordens das Gegenteil unterstellt. Knapp die Hälfte der Schüler_innen denkt über Kontrollen als Instrument der Verbesserung der Arbeitsund Lebensbedingungen nach. Hier stellen sie sich jedoch die Frage, wer eigentlich die Kontrollen durchführen sollte. Die Vorschläge reichen von Regierungen des Globalen Nordens, was jedoch meist wieder verworfen wird, bis zu - in sehr wenigen Fällen - der UNO als Kontrolleur der Bedingungen in Fabriken.

,Die Politik' erscheint in den Vorstellungen von den Schüler_innen meistens als ein enger Politikbegriff. Gemeint sind damit in der Regel staatliche Institutionen und insbesondere die Kaste der Politiker_innen. Dies ist eine entscheidende Voraussetzung dafür, dass im Denken über eine politische Transformation der Verhältnisse im Rahmen internationaler Arbeitsteilung die Arbeiter_innen oder andere mögliche nicht-staatliche Akteure fast völlig aus dem Blick geraten.

\section{Der Konsumierende als Akteur}

Im Sprechen über mögliche Veränderungen der Lebens- und Arbeitsbedingungen von Arbeiter_innen im Globalen Süden wird die/der Konsumierende von einer Mehrheit der Schüler_innen als möglicher Akteur gesehen. Dieser Handlungsraum wird insbesondere dann thematisiert, wenn die Schüler_innen über eigene Handlungsmöglichkeiten nachdenken. Auch hier wird der Markt als zentraler Ort der Vergesellschaftung gedacht. Die große Mehrheit der Schüler_innen sieht sich selbst über die Wertschöpfungskette mit den Arbeiter_innen im Globalen Süden in Verbindung stehend. Aus dieser Verbindung sehen die Schüler_innen eigene Handlungsmacht erwachsen. Meist wird hier als Handlungsoption der Kauf von Fair-Trade-Produkten diskutiert, von einigen wenigen auch ein Boykott bestimmter Firmen in Betracht gezogen. Die Abwägung verläuft dabei in der Regel zwischen der Notwendigkeit den eigenen Konsum einzuschränken auf der einen Seite und der eigenen moralischen Verantwortung auf der anderen Seite. Dabei gibt es beide Fälle: Einige Schüler_innen machen klar, dass sie nicht in der Lage oder nicht 
willens sind, den eigenen Konsum einzuschränken. Andere wollen unbedingt FairTrade-Produkte kaufen. Dies ist jedoch an dieser Stelle nicht der zentrale Punkt. Entscheidender ist, dass nur wenige in diesem Kontext versuchen, einen Blick auf die Arbeiter_innen des Globalen Südens als Subjekte zu werfen. Stattdessen geht es um sie selbst und in vielen Fällen noch um Unternehmer, die durch diese Aktionen umgestimmt werden könnten. Einige wenige stellen die Strategie des Boykotts oder der Veränderung der Markenwahl infrage, weil dies dazu führe, dass die dortigen Arbeiter_innen noch ihre sowieso schon unterbezahlte Arbeit verlören. Die Schüler_innen benennen ihre Verbindung zu den Arbeiter_innen im Globalen Süden über die internationale Wertschöpfungskette; Veränderung oder Solidarität wird in der Vorstellung von den Konsumierenden als Akteuren aber nur über den Markt gedacht. Die Arbeiter_innen kommen hier nicht als tatsächliche oder potenzielle Subjekte vor.

\section{Arbeiter_innen im Globalen Süden als Akteure?}

Eine Mehrheit spricht angesichts der ausgeführten Denkstrukturen von Agency in diesem Kontext keinerlei tatsächliche oder potenzielle Agency von Arbeiter_innen im Globalen Süden an. Auf Nachfrage bestätigen viele, das heißt alle dazu Befragten, dass sie noch nie etwas von Protesten oder Streiks im Globalen Süden gehört hätten. Ein knappes Viertel der Schüler_innen setzt sich explizit mit der in ihren Vorstellungen nicht vorhandenen Agency der Arbeiter_innen im Globalen Süden auseinander. Ein zentrales Problem wird hier in der Disposition der Arbeiter_innen gesehen. Diese Schüler_innen sehen die Arbeiter_innen aufgrund sozialer Bedingungen, fehlender Bildung oder kultureller Dispositionen als unfähig an, von sich aus als Akteur aufzutreten. Einige formulieren hier die Notwendigkeit, dass, westliche' Akteure die Arbeiter_innen dazu bringen müssten. Im Folgenden will ich vier Beispiele vorstellen, in denen sich einige der genannten Punkte wiederfinden. Die letzten zwei habe ich deswegen ausgewählt, da sie einige der bei den Schüler_innen dominanten Denkweisen problematisieren.

David (Gym14) berichtet ausführlich über die arbeitsteilige Globalisierung, in der Produktionsort und Konsumtionsort stark divergieren. Auf die Nachfrage, warum das so gemacht wird, antwortet er mit einer Beschreibung des Unterschieds zwischen der Einstellung der Europäer_innen und Asiat_innen.

I: Und du hast ja schon erzählt, bei den Lebensmitteln ist klar, Erdbeeren wachsen hier im Winter nicht, also lässt man das irgendwo anders wachsen. Aber mit technischen Geräten oder mit Kleidung, warum macht man das? 
S: Das liegt an dem Stolz quasi der Europäer ein bisschen. Die Europäer sind sich für diese Arbeit, für diese Fabrikarbeit in China zum Beispiel, viel zu schade. Das würden die nie machen zu dem Hungerlohn. Das ist halt .../ Man lässt es in Asien billig produzieren, verkauft es hier teuer, weil die Leute da das halt machen. Eigentlich auch nicht gerne. Aber da irgendwie haben die noch nicht so den Mut, für ihre Rechte zu kämpfen, anscheinend. Also die Drecksarbeit, die da gemacht wird, glaube ich, würden die meisten Europäer ablehnen aus Prinzip.

I: Mhm.

S: Aber trotzdem kaufen die es halt.

I: Mhm. Und weißt du irgendwas über die Arbeitsbedingungen da? Also du hast es gerade schon Drecksarbeit genannt. Aber .../

S: Also ich habe Dokumentationen über Apple zum Beispiel gesehen, wie die produzieren lassen. Weil ja viele sagen das ist so überteuert, stimmt ja auch. Aber man kann es, glaube ich, generalisieren. Die lassen alle so produzieren. Riesige Fabriken, die schlafen teils zu acht in diesem Wohnheim auf zwei, drei Quadratmetern. Und vierundzwanzig Stunden Arbeit. Schichtarbeit. Also die können gerade so davon leben, aber die haben kein eigentliches Leben außerhalb der Arbeit.

I: Mhm.

S: Die leben, um zu arbeiten. Und umgekehrt. (David, Gym14)

Davids Argumentation liegt die Annahme zugrunde, dass der Grund für die Verlagerung der Produktion in den Globalen Süden das unterschiedliche Lohnniveau sei. Den Grund für dieses unterschiedliche Lohnniveau vermutet er in der (1) Einstellung der Menschen sowie der (2) sich aus den Arbeitsbedingungen ergebenden Lebensrealitäten; beide Argumentationen sind dabei nicht losgelöst voneinander zu betrachten. (1) Die „Europäer“ seien zu „stolz“ und wären sich „für diese Arbeit [...] viel zu schade“. Sie würden nie für einen „Hungerlohn“ arbeiten. Die „Drecksarbeit, die da gemacht wird, [...] würden die meisten Europäer" ablehnen. Die Menschen in Asien bzw. China würden diese Arbeit zwar „eigentlich auch nicht gerne" machen. Sie hätten „da irgendwie [...] noch nicht so den Mut, für ihre Rechte zu kämpfen“. In dem „,noch“ deutet sich möglicherweise ein Bezug zur kolonialen Raum-Zeit-Matrix an. Anders herum gewendet sagt er damit, dass Europäer_innen mutiger seien und führt so die Unterscheidung der Einstellungen anhand der Parameter Stolz, Selbstwertgefühl und Mut weiter aus. (2) David zeichnet ein detailreiches Bild von den von ihm als ungerecht und inhuman wahrgenommenen Arbeitsbedingungen. Sein Bild von den Arbeitsbedingungen bestimmt auch sein Bild von den Arbeiter_innen. Angesichts der inhumanen Arbeitsbedingungen und der schlechten Bezahlung, könnten die Arbeiter_innen ,gerade so davon leben“, sie 
hätten dabei ,kein eigentliches Leben außerhalb der Arbeit“. Die Arbeiter_innen würden ,leben, um zu arbeiten [...] und umgekehrt“. In seiner Vorstellung reduziert er die Arbeitenden im Globalen Süden damit auf ihre Funktion als Arbeitende. Sie erscheinen als Teil einer Maschine; Agency ist damit ausgeschlossen. Unklar bleibt hier, worin er die Ursache für diesen prinzipiellen Unterschied der Einstellung von Europäer_innen und Asiat_innen sieht. Auf Nachfrage führt er dies aus.

I: Ja. Und du hast vorhin gesagt, dass die Leute da noch nicht so weit sind, dass sie für ihre Rechte kämpfen. Also dass sie diesen Stolz nicht haben. Woran liegt denn das?

S: Puh. An der Kultur glaube ich schon fast. Also es gibt ja viele, die dafür kämpfen. Auch viele aus Europa, die da jetzt die Leute dazu bringen wollen, dafür zu kämpfen. Das ist ja auch richtig so. Nur halt, China ist ja auch kommunistisches System noch. Alle sind gleich quasi. Und da war ja auch lange Kaiserdynastie. Und in Asien ist ja eh viel Unterdrückung und alles. Also „die Leute sind es gewohnt“ klingt falsch, aber die haben sich manchmal vielleicht damit abgefunden einfach. Weil die schon lange unter sowas leben und schon viel versucht haben und das hat alles nicht geklappt. Und deswegen, denke ich, brauchen die - vielleicht auch dadurch, dass sich die Kulturen jetzt verbinden von Europa und Asien - mal so ein bisschen diese Hilfe aus Europa. Dass die sich mal ein bisschen dagegen auflehnen und sagen: „Wir kämpfen für unsere Rechte."(David, Gym14)

Die Ursache für den Unterschied zwischen Europäer_innen und Asiat_innen sieht er in der „Kultur“. Sein Kulturbegriff bleibt dabei amorph; „Kultur“ ist für ihn weder nur essenzialisierte Wesenszuschreibung noch ausschließlich abgeleitet aus den gesellschaftlichen Verhältnissen. In jedem Fall ermöglicht ihm der Kulturbegriff, die Unterscheidung zwischen Europäer_innen und Asiat_innen als Grund für das unterschiedliche Lohnniveau greifbar zu machen. Da er eine Abschaffung der inhumanen Arbeitsbedingungen befürwortet, sucht er vor diesem Hintergrund nach einem möglichen Weg. Er sieht ihn in der Verbindung der „Kulturen [...] von Europa und Asien“. Es gäbe ,viele aus Europa, die da jetzt die Leute dazu bringen wollen, dafür zu kämpfen“. Um eine Veränderung zu ermöglichen, dass ,die sich mal ein bisschen dagegen auflehnen“ und für ihre Rechte kämpfen, bräuchte es David zufolge „Hilfe aus Europa“. In der Rhetorik erinnert diese Argumentationsstruktur an die zivilisatorische Mission des Kolonialismus. Dabei ist eine Agency der Asiat_innen in seiner Vorstellung keineswegs prinzipiell ausgeschlossen. So seien sie aber nicht in der Lage, selber etwas zu verändern, weil ,die schon lange unter sowas leben und schon viel versucht haben und das [...] alles nicht geklappt" habe. In der Vergangenheit gab es also Asiat_innen, die versucht hätten, etwas an den gesellschaftlichen Verhältnissen zu ändern, also möglicherweise auch stolz und mutig waren. Wiederum sind hier beide Ebenen am Werk; sowohl die Begründung 
über die unterschiedliche kulturelle Disposition als auch eine Erklärung aus den gesellschaftlichen Verhältnissen. In beiden Fällen ist das Resultat aber, dass „die“ über keine Agency verfügen und „ihnen“ Agency beigebracht werden müsste.

I: Mhm. Und wer könnte denen quasi helfen?

S: Jeder! Jeder der, sag' ich mal, das Geld und die Möglichkeit hat, dahin zu gehen und die Leute dazu zu bringen, für ihre Sache zu kämpfen, kann das machen.

I: Mhm.

S: Man sollte Asiatisch möglichst noch sprechen. Chinesisch .../ Also Asiatisch gibt es ja nicht, aber Chinesisch, Koreanisch, Japanisch. Irgendeine Sprache. Und, ja, ansonsten .../ Auf politischer Ebene das irgendwie regeln ist halt schwierig. Weil in der Politik muss man immer viel berücksichtigen ja. Auch die ganzen Wirtschaftsbeziehungen. Wir können uns ja jetzt nicht mit China anlegen. Dann stellen die ihre Lieferungen ein. Das wäre auch keine .../ Aber man muss halt irgendwie .../ Deswegen ja. Man kann nicht auf das Land zugehen und sagen: „Wir wollen euer System ändern.“ Sondern man muss die Leute dazu bringen, dass die das selber sagen, dass die ihr System ändern wollen.

I: Mhm.

S: Man kann das nicht erzwingen. Wenn die sich damit abfinden und man kann die durch nichts dazu bringen, das anders zu machen, dann muss man es auch akzeptieren. (David, Gym14)

In Davids Vorstellung kann der Helfende ,jeder“ sein. Das schränkt er kurz darauf wieder ein. Es müsse „das Geld und die Möglichkeit [...], dahin zu gehen“ vorhanden sein. Außerdem sollten möglichst noch entsprechende Sprachkompetenzen vorliegen. Mit ,jeder" meint er außerdem nicht-staatliche Akteure, da er eine Einmischung eines Staates in die inneren Verhältnisse eines anderen als problematisch einschätzt. Deshalb müssten „,die Leute“ dazu gebracht werden, „,dass die selber sagen, dass die ihr System ändern wollen". Wenn die sich aber damit abfänden und man sie nicht dazu bringen könnte, dann müsse „man es auch akzeptieren“. Anders als die meisten anderen nimmt David hier auf der einen Seite die Agency von Arbeitenden im Globalen Süden ernst. Auf der anderen Seite bräuchten diese die Hilfe aus dem Globalen Norden, um Agency entwickeln zu können. Mit ,jeder“ ist nämlich tatsächlich offenbar nicht jede_r gemeint, sondern vielmehr Individuen aus dem Globalen Norden. Diese müssten den Asiat_innen zeigen, wie man für seine Rechte kämpfen könne. Die kulturelle Differenz konkretisiert sich hier in der 
individuellen Disposition der einzelnen. Damit wird implizit eine koloniale Überlegenheitsstruktur reproduziert, die sich nicht nur auf das politische System, sondern auf die Individuen als Angehörige ihrer jeweiligen „Kultur“ bezieht.

I: Hast du mal was von Gewerkschaften gehört?

S: Ja. Gibt es in China soweit ich weiß nicht viele.

I: Mhm.

S: Hier in Deutschland sind sie ständig nur am Streiken. Haben wir auch gerade in Politik. Besprechen wir ja auch gerade. Aber in der Dritten .../ Nee, die Dritte Welt ist es ja nicht. Das ist ja Afrika. In Asien gibt es, glaube ich, nicht so viel von so was. Also ich weiß nicht, ob es zwischendurch .../ In den alten kommunistischen System, Sowjetunion, da war es ja glaube ich sogar verboten, eine Gewerkschaft. Aber ich weiß es gerade gar nicht. Also ich habe zumindest noch nie gehört, auch aus den Nachrichten oder so, dass in China irgendeine Gewerkschaft da sich mit wem angelegt hat.

I: Mhm.

S: Vielleicht sind die Leute auch einfach, wenn die so viel arbeiten, viel zu müde um über so was nachzudenken. Die essen, schlafen, arbeiten. Und das ist ihr Tagesablauf. Die haben gar keine Zeit. (David, Gym14)

Angesprochen auf Gewerkschaften stellt David fest, dass diese in Deutschland sehr aktiv seien, während es sie in der „Dritten Welt“, worunter er „Afrika“ versteht, Asien und Ländern mit der Vergangenheit von „kommunistischen Systemen“ kaum gäbe. Er habe „,noch nie gehört“, dass in „China irgendeine Gewerkschaft da sich mit wem angelegt hat“. In seiner Redewendung, dass er noch nie davon ,gehört“ habe, ist bereits die Möglichkeit der fehlenden Repräsentation, beispielsweise in den Medien, tatsächlich stattfindender Prozesse angelegt, womit es also nicht mehr um Nicht-Agency, sondern um die Frage der (Un-)Sichtbarkeiten von Agency ginge. Diesen argumentativen Schritt geht er jedoch nicht. Stattdessen kommt er auf eines seiner Ausgangsargumente zurück. Als Grund für die von ihm als tatsächlich angenommene Nicht-Agency von Arbeiter_innen im Globalen Süden führt er nochmals aus, dass ,die Leute auch einfach, wenn die so viel arbeiten, viel zu müde um über so was nachzudenken“. Sie würden „essen, schlafen, arbeiten“. Ihr „Tagesablauf“ ließe ihnen gar „keine Zeit“. Dieses Argument scheint auf den ersten Blick zwar die Nicht-Agency mit den Arbeits- und Lebensbedingungen, also den gesellschaftlichen Verhältnissen zu begründen, es transportiert auf den zweiten Blick jedoch auch problematische Annahmen. So wird hier das Bild der entsubjektivierten chinesischen Massenarbeiter_innen reproduziert, die auf ihre Funktion innerhalb der Produktionsmaschinerie reduziert werden. Im Kontext der prinzipiellen Unterscheidung der 
Einstellung von Europäer_innen und Asiat_innen erscheint auch die Entstehung dieser gesellschaftlichen Bedingungen an kulturellen Dispositionen geknüpft zu sein. Der Begründungszusammenhang, der die Nicht-Agency der Arbeitenden im Globalen Süden scheinbar über die gesellschaftlichen Verhältnissen erklärt, erscheint hier irreduzibel mit der kolonialen Vorstellung der kulturellen Differenz verschränkt. Diese Verschränkung findet sich bei einer Reihe von Schüler_innen.

Auch Luka (Gym02) beschäftigt sich mit der Nicht-Agency von Arbeiter_innen im Globalen Süden. Im Gegensatz zu David führt er seine Überlegungen nicht am Beispiel von China, sondern am Beispiel von Afrika durch. Zunächst bewertet er die ökonomische Globalisierung als sehr positiv.

I: Mhm. Und wie findest du das? Dass jetzt zum Beispiel überall produziert wird und das dass überall hingebracht wird?

S: Also ich finde das richtig gut. Das ist ja auch produktiv. Also wir haben überall alles. Das finde ich eigentlich perfekt. So sollte es sein. (Luka, Gym02)

An dieser Stelle lobt er die Produktivität der ökonomischen Globalisierung sowie den Zustand, in welchem „wir [...] überall alles“ hätten. An dieser Stelle ist noch unklar, wen er mit "wir“ und welches Wo mit ,überall“ er meint. Auf Nachfrage nach den Arbeits- und Lebensbedingungen im Globalen Süden, stellt er einige Überlegungen zu dem Thema an und äußert seine Unzufriedenheit.

I: Und, ähm, was denkst du, wenn du davon hörst, dass in anderen Ländern die Arbeitsoder Lebensbedingungen nicht so gut sind?

S: Ja, also ich denke mir halt: „Wieso eigentlich?“ Also: "Wieso ist es da ausgerechnet günstiger?" denke ich mir dann. Stelle ich mir dann halt die Frage. Ich meine, ähm, das sind ja auch genauso Menschen wie wir, und wieso ist es denn bei denen günstiger? Okay, vielleicht weil die .../ Also die Arbeitsbedingungen sind schlechter. Aber ist da keiner der das kontrolliert? Also da stelle ich mir dann so die Frage so. Ich meine, da muss ja das irgendwer kontrollieren. Das kann ja nicht sein, dass wir jetzt hier in Deutschland einen höheren Standard haben als da. Das sind ja auch nur Menschen, sag' ich jetzt mal.

I: Mhm. Mhm. Und woran liegt das dann, dass das so ist? Hast du eine Idee?

S: Ähm, ich könnte mir halt vorstellen, weil zum Beispiel halt in Afrika, sag' ich jetzt mal, da sind ja auch die Leute nicht so gebildet, sag' ich jetzt mal. Weil da ist es halt auch vom Klima her sehr dürre und da gibt es halt auch Probleme. Und deswegen, vielleicht denken die Leute sozusagen, dass sie die so ausnutzen, sag' ich jetzt mal, ausnutzen können. So benutzen können in einer Weise.

I: Mhm. Und wer denkt das? Wer will die da ausnutzen? 
S: Also die Konzerne, sag' ich jetzt mal, die die Leute da halt anstellen. Die Unternehmer, die dann denken: „Okay. Da ist es billig. Da gehen wir hin. Die sind auch nicht so intelligent. Die arbeiten für uns auch für kleines Geld. Können wir ja dahin gehen.“ Ja. (Luka, Gym02)

Luka bringt sofort das Thema der unterschiedlichen Lohnniveaus auf. Er findet diesen Zustand offenbar ungerecht und stellt fest, dass das ,genauso Menschen wie wir" seien. Da alles Menschen seien, empfindet er eine Ungleichbehandlung bzw. -bezahlung als ungerecht. Als Grund für diese Nichteinlösung des universalistischen Gleichheitsversprechens vermutet er zunächst, dass die Arbeitsbedingungen schlechter seien und kritisiert, dass es doch Kontrollen geben müsste und die gleichen Standards in Deutschland und dem Globalen Süden gelten müssten. Auf die Frage, warum es diese Unterschiede gäbe, antwortet er mit einem Modell von Ausbeutungsrationalität. „Konzerne“ und „Unternehmer“ würden „die Leute“ ausnutzen und dort günstiger produzieren lassen. Als Beispiel führt er „Afrika“ an, wo die „Leute nicht so gebildet“ seien. Weil „die [...] nicht so intelligent“ seien, würden die Konzerne sich überlegen, sie ,,ausnutzen“ zu können und sie ,auch für kleines Geld“ arbeiten zu lassen. Die Arbeiter_innen im Globalen Süden bzw. in „Afrika“ erscheinen hier als Opfer, deren fehlende Bildung bzw. Intelligenz von den Konzernen ausgenützt würde. Dieses Verhalten der Konzerne wird von Luka scharf verurteilt und die zugrunde liegende Rationalität moralisch verurteilt. Gleichzeitig kommen die Arbeiter_innen in Afrika in der Vorstellung von Luka nicht als Akteure vor. Die kulturelle Differenz, die das verschiedene Lohnniveau begründet, wird hier über den Grad der Intelligenz hergestellt. Damit ist Luka ein Teil einer Gruppe von acht Schüler_innen, die so argumentiert. Anders herum bedeutet das, dass Luka die Menschen des Globalen Nordens als intelligenter ansieht.

Da Luka das Klima als Grund für die geringere Intelligenz angeführt hat, frage ich zu diesem Punkt nach.

I: Mhm. Und, ähm, das heißt das Klima führt dazu, dass die Leute da nicht so viel Bildung gehabt haben?

S: Nein, nein! Nicht nur das Klima halt. Also auch generell die Bedingungen, die sind .../ Also hier zum Beispiel, hier haben wir ganz viele Schulen und ganz viel Bildung. Zum Beispiel in München, das ist ja „Municon-Valley“, da haben wir ja ganz viel Entwicklung halt. Und die haben da halt ganz viel vereinzelte Schulen. Die haben vielleicht auch fast gar keine Schulen. Und deswegen haben die auch weniger Bildung als wir. Und deswegen denken die: „Ha. Die sind dumm, die nutzen wir aus.“ So, grob gesagt.

I: Mhm. Aber woran liegt das, dass da keine Schulen sind? Also, ist ja komisch quasi? 
S: Ja, finde ich jetzt auch komisch. Also ich weiß nicht, vielleicht .../ Da habe ich noch gar nicht drüber nachgedacht so groß. Das ist echt eine gute Frage. Mhm, vielleicht denkt sich .../Vielleicht weil das so ein großes Land ist? Ich weiß ja nicht, Deutschland ist ja eigentlich gar nicht so groß. Vielleicht haben die da in den großen Städten ganz viele Schulen und so weiter. Aber jetzt so .../ Aber das ist ja ein riesen .../ Südafrika ist ja riesig. Und vielleicht können sie es sich gar nicht erlauben überall Schulen zu bauen. Vielleicht deswegen. (Luka, Gym02)

Luka sieht jedoch nicht nur das Klima als Grund für die geringere Bildung an, sondern auch die Bildungsstrukturen. „Die“ hätten ,weniger Bildung als wir“, da es „da [...] fast gar keine Schulen“ gäbe. Als Grund dafür vermutet er, dass „das so ein großes Land“ sei, während Deutschland ,ja eigentlich gar nicht so groß" sei. Bleibt zunächst unklar, welches Land er denn meint, bringt er dann das Beispiel Südafrika, das ja riesig sei, und die sich deswegen ,gar nicht erlauben überall“ könnten „Schulen zu bauen“. Luka macht hier erneut seine Unzufriedenheit mit der Situation deutlich, in der Menschen in „Afrika“ über weniger Bildung verfügen würden und deswegen auch noch ausgenutzt werden würden. Agency vermutet er jedoch in keinem Moment bei den Menschen dort. Vielmehr impliziert seine Argumentation fehlende Agency aufgrund von fehlender Bildung bzw. Intelligenz.

Universalistischer Gleichheitsanspruch und das damit verbundene Ungerechtigkeitsempfinden gegenüber globaler Ungleichheit scheint hier irreduzibel mit der kolonialen Differenz verwoben zu sein. Die sich daraus ergebenden Ambivalenzen schwingen im Subtext von David und Luka - und anderen Vertreter_innen dieser Gruppe - durchaus mit, lösen jedoch nicht diese Verstricktheit auf. Eine andere Form, wie die Agency der Arbeiter_innen des Globalen Südens unsichtbar gemacht wird, ist die des Fokussierens auf Kinderarbeit. 21 Schüler_innen (elf Gymnasium, zehn Hauptschule) fangen an über Kinderarbeit, wenn es im Gesprächsfluss eigentlich ganz allgemein um Arbeiter_innen im Globalen Süden geht. Melina stellt hier schon eine Ausnahme dar, weil sie das Thema Agency hier bespricht. Anschließend an einen längeren Dialog über die Bedingungen von Arbeiter_innen im Globalen Süden und die Schwierigkeiten etwas daran zu verändern, weil die Regierungen nicht die Möglichkeit und die Unternehmen kein Interesse hätten, spricht sie die Notwendigkeit der Hilfe aus dem Globalen Norden an.

I: Mhm. Und glaubst du das passiert, dass Hilfe von anderen Ländern kommt?

S: Ähm, also ich denke, vielleicht kommt das immer mehr schleichend. Also so weil jetzt gibt es ja ganz viele Hilfsorganisationen, die halt Schulen bauen oder so. Ähm, aber ich denke nicht, dass das jetzt irgendwie in ein paar Jahren schon total ausgereift ist, weil dazu halt oft einfach die Mittel fehlen. 
I: Mhm. Und sollten die Länder versuchen möglichst viel von der westlichen Kultur zu übernehmen?

S: Ähm, also ich denke .../ Also man muss das halt schon irgendwie .../ Also zum Teil. Also ich denke halt, wenn man das total übernehmen würde, dann würde ja auch diese eigene Kultur ja auch gar nicht mehr da sein. Also ich finde die Länder sollten schon ihre eigene Kultur behalten. Aber was halt gerade das Bildungssystem oder, ähm, Versorgungssystem oder so anbelangt .../ Oder vor allem, was ich auch bei der westlichen Kultur ziemlich schätze und auch sehr wichtig finde, ist auch Gleichberechtigung zwischen Männern und Frauen. Was auch sogar in den westlichen Kulturen ja noch nicht mal richtig ausgereift ist.

I: Mhm. Ja.

S: Aber dass es wenigstens Ansätze dafür gibt, das finde ich halt, ähm, auch sehr wichtig. Und, ja, so was zum Beispiel auch wie Kinderarbeit oder so, was ja auch noch ziemlich ausgereift ist in Afrika aber auch, ähm, in Asien so oder Indien und so. Das müsste auch abgeschafft werden.

I: Mhm. Und wieso wird das gemacht, mit Kinderarbeit zum Beispiel?

S: Na ja, weil es halt, ähm, billig ist.

I: Mhm.

S: Und, ähm, also klar weil die Kinder sind halt billig, weil die müssen keine ganze Familie versorgen. Ähm, die verlangen auch nicht so viel Geld. Und die arbeiten wahrscheinlich auch ziemlich sorgsam. Und, ähm, also da ist wahrscheinlich auch nicht so eine Gefahr, dass die sich auflehnen oder so. Die wissen ja nicht, dass es eigentlich richtig schlecht ist. Und die kann man auch gut kontrollieren so. Also kann man auch dazu zwingen. Ich denke, das ist halt einfach unkomplizierter, als wenn man halt Erwachsene einstellt. (Melina, Gym08)

Auch mit Hilfe aus dem Globalen Norden scheint sie nicht sehr optimistisch zu sein, dass sich bald etwas an der Situation der Arbeits- und Lebensbedingungen im Globalen Süden verändert, weil ,dazu halt oft einfach die Mittel“ fehlten. Als zentrale Aktivität der „Hilfsorganisationen“ sieht sie den Bau von Schulen an, da sie die mangelnde Bildung als zentrales Problem ansieht. Ihr zentrales Thema im vorherigen Interviewverlauf war die ,,westliche Kultur“. Melina hält es zwar für wichtig, dass alle Länder ihre Kultur teilweise behalten würden, jedoch sollten viele Dinge von der „,westlichen Kultur“ übernommen werden. Als solche benennt sie das „Bildungssystem“, das „Versorgungssystem“, die „Gleichberechtigung zwischen Männern und Frauen" sowie die Abschaffung von Kinderarbeit. Diese sozialen Fragen erscheinen aus einer dekolonialen Perspektive durch diese Kontextualisierung kulturalisiert. Es ist die Logik der kolonialen Differenz - die Hierarchie der ,kulturellen' Rationalitäten -, durch die mangelhaftere Bildungs- und Versorgungssysteme, fehlende 
Gleichberechtigung von Männern und Frauen sowie Kinderarbeit erklärbar werden. Anders als die meisten anderen Schüler_innen führt sie Kinderarbeit nicht an dem Punkt an, wo es um die Arbeiter_innen und potenziell um ihre Agency gehen würde. Stattdessen erscheint hier Kinderarbeit - zwar im Kontext von Bedingungen der Arbeiter_innen im Globalen Süden - primär als Ausdruck einer kulturellen Disposition.

Gleichzeitig - und wiederum im Gegensatz zur Mehrheit der anderen Kinderarbeit ansprechenden Schüler_innen - bespricht sie implizit eine potenzielle Agency der erwachsenen Arbeiter_innen. Auf die Frage, warum das mit Kinderarbeit überhaupt gemacht werde, bringt sie zunächst das prinzipielle, strukturelle Argument, dass sie „halt billig“" sei. Damit ist die Rationalität der produzierenden Unternehmen angesprochen. Kinder als Arbeiter_innen sind laut Melina deswegen so „billig“, weil sie „,keine ganzen Familien versorgen“ müssten und ,nicht so viel Geld verlangen“ würden. Außerdem gäbe es bei ihnen „nicht so eine Gefahr, dass die sich auflehnen“ würden. Sie würden ,ziemlich sorgsam“ arbeiten. Die Kinder wüssten nicht, dass ,es eigentlich richtig schlecht ist“. Außerdem könne man Kinderarbeiter_innen ,auch gut kontrollieren“ und „Zwingen“, was es ,unkomplizierter“ mache, ,,als wenn man halt Erwachsene" einstellen würde. In dieser Argumentation spricht sie im Wesentlichen aus der Sicht von Unternehmern, problematisiert ihre Rationalität und zeigt auf, wie ungerecht die Ausnutzung der Verletzlichkeit der Kinder ist. Im Gegensatz zu den arbeitenden Kindern stehen in ihrer Argumentation aber die arbeitenden Erwachsenen, auf die vice versa die den Kindern zugeschriebenen Eigenschaften ja genau nicht zutreffen würden. Indirekt sagt Melina also, dass arbeitende Erwachsene im Globalen Süden mehr Geld verlangen würden, unter Umständen nicht sorgsam arbeiten oder sich auflehnen würden, sich nicht so gut kontrollieren und zwingen lassen würden und über ein Wissen von der Ungerechtigkeit verfügen würden. Im Gegensatz zu den meisten anderen dieser Gruppe schreibt sie also hier implizit den arbeitenden Erwachsenen eine Agency zu. Gleichzeitig verbleibt sie bei dem Thema Kinderarbeit, macht ihre impliziten Annahmen nicht explizit und spricht an keiner Stelle des Interviews nochmals von der Agency von Menschen im Globalen Süden.

Es gibt viele Punkte, an denen Agency von Arbeiter_innen im Globalen Süden punktuell aufscheinen. Auffällig ist hier, dass in keiner Vorstellung auf eine den Schüler_innen bekannte Handlung von Arbeiter_innen im Globalen Süden verwiesen wird, weder eine kollektive, noch eine individuelle. In vielen Vorstellungen der Schüler_innen erscheint potenzielle Agency der Arbeiter_innen dabei jedoch keineswegs prinzipiell ausgeschlossen. Allerdings erscheinen hier zahlreiche Hinderungsgründe, warum diese Potenzialität sich nicht entfaltet. Insgesamt dominiert eine Perspektive, die den Unternehmern, Politiker_innen und, westlichen 'Akteuren 
- nicht zuletzt in Form von Konsumierenden - Agency zuspricht, während Arbeiter_innen im Globalen Süden nicht als Handelnde, sondern als , billig ' und ,willig ‘ erscheinen.

\subsubsection{Subalterne Positionen II: Die Kolonisierten}

In dieser Kategorie liegen alle Vorstellungen zugrunde, in denen es um kolonisierte Menschen sowie diejenigen Ideen geht, die sich um Möglichkeiten zur Verbesserung der Lebensbedingungen in als explizit als ehemals kolonialisiert verstandenen Gesellschaften drehen. Der Wissensstand in Bezug auf die Kolonialgeschichte geht sehr weit auseinander. Während viele eine grobe Idee haben, gibt es sehr wenige (3), die ich in Relation als Expert_innen einschätzen würde, da sie sowohl über eine Überblicksperspektive über Teile der Kolonialgeschichte verfügen als auch punktuell über Detailwissen. Oft sind die Bilder, mit denen sich der historische Kolonialismus vorgestellt wird, von stereotypen Darstellungen geprägt, die häufig jede potenzielle Agency ausschließen. Manchmal wird auch die Kolonialgeschichte als Ursache für die vermeintliche ,Unterentwicklung * gesehen, wobei hier unklar bleibt, ob nicht der Kolonialismus trotzdem als bestmöglicher Aufstieg innerhalb der kolonialen Raum-Zeit-Matrix - oft ,Geschichte genannt - angesehen wird. Es finden sich Ähnlichkeiten zwischen den Denkweisen über Agency der Kolonisierten in den historischen Kolonien und Aussagen zu Entwicklungshilfe und Veränderungsmöglichkeiten für ehemals kolonisierte Länder in der Gegenwart. Auch hier ist das Bild von den Akteuren aus dem Globalen Norden dominant, die den Menschen im Globalen Süden helfen könnten, zu Akteuren zu werden. Nach der Darstellung von drei verschiedenen Sichtweisen auf die Kolonisierten werde ich auch diese Dimension der kolonialen Entwicklungsmentalität diskutieren. Insgesamt steht im Zentrum dieses Abschnitts die Frage, inwiefern Subjekte des Globalen Südens als Subjekte angesehen werden; dabei spielt auch das didaktisch-normative Ziel eine Rolle, mit dem ich danach frage, inwiefern vor diesem Hintergrund das Denken von Solidarität zwischen Globalem Norden und Globalem Süden als denkbar oder verunmöglicht erscheint. Solidarität verstehe ich hier in Abgrenzung zur Hilfsmentalität als eine selbstund machtreflexive und sich prinzipiell auf Augenhöhe mit den Anderen sehende Haltung, die immer die Akzeptanz der Agency der Anderen voraussetzt.

Finn (HS04) findet die „Benachteiligung“ Afrikas falsch und plädiert für eine Gleichberechtigung und Modernisierung der ganzen Welt. Auf die Frage nach der Ursache dieser Benachteiligung führt er die Geschichte der Sklaverei und der kolonialen Ausbeutung an. 
I: Mhm. Und woran liegt das, dass Afrika jetzt so, ähm ... wie hast du das genannt ... benachteiligt ist?

S: Ich denke mal, das liegt daran .../ Die wurden ja früher versklavt. Und, ich sag' jetzt mal, veräppelt. Also die haben wertlose Gegenstände bekommen und haben dafür ihr ganzes Gold und so was dahin gegeben. Und die Entwicklung ist noch nicht so weit da vorangekommen. Beim Menschen jetzt selbst. Dass ihr Gehirn vielleicht das eben nicht so weiß und nicht so viel Ahnung davon hat. Weil sie es eben nicht beigebracht bekommen haben. (Finn, HS04) ${ }^{11}$

Die Thematisierung von Sklaverei und insbesondere kolonialer Ausbeutung erscheint hier in einer stereotypen Form. „Die“ seien „veräppelt“ worden, indem sie „,wertlose Gegenstände bekommen“ hätten und dafür ,,ihr ganzes Gold und so was dahin gegeben" hätten. Bemerkenswert ist hier zum einen die Absenz der Täter_innen. Durch die grammatikalische Passivform kann Finn diese Prozesse beschreiben, ohne die Frage der Täterschaft zu stellen. Solche Formulierungen sind bei einer Reihe von Schüler_innen zu finden. Die versklavten oder vermeintlich „veräppelt[en]“ Afrikaner_innen werden von Finn hier als dumm und zurückgeblieben dargestellt. Neben der Ausblendung der Dimension der Gewalt in kolonialen Verhältnissen macht Finns stereotype Darstellung das Denken von Agency unmöglich, da die Afrikaner_innen hier nur als Ausdruck der vermeintlichen Unterentwicklung erscheinen. So sei die „Entwicklung [...] noch nicht so weit da vorangekommen“. „Sie“ hätten es „eben nicht beigebracht bekommen“. Dass sie sich also haben „veräppeln“ lassen, liege einerseits an ihrer ,Unterentwicklung', was von Finn wiederum als ihre Ursache erklärt wird. ,Unterentwicklung ' und ,Zurückgebliebenheit" sind hier also Ursache und Effekt zugleich und bilden somit - quasi tautologisch - einen zentralen und gefestigten Denkrahmen. $\mathrm{Zu}$ dem von ihm gezeichneten Tauschvorgang assoziiere ich das koloniale Bild von ,Eingeborenen' mit Baströckchen, deren vermeintliche Naturnähe im kolonialen Blick ihr Menschsein selbst infrage stellt. Im kolonialen Blick als jeglicher, Vernunft ‘ vorgängig erscheinende Existenzweisen können natürlich auch nicht als Akteure angesehen werden. Die koloniale Stereotypisierung verhindert hier also jegliche Möglichkeit des Denkens von Agency von Kolonisierten.

Im Gegensatz hierzu hat Mark (Gym09) einen facettenreicheren Begriff von der Kolonialgeschichte und der Rolle der Kolonisierten darin.

\footnotetext{
${ }^{11}$ In der Interpretation dieses Abschnitts werde ich mich auf die für die Frage von Agency besonders relevanten Aspekte konzentrieren. Andere Aspekte wurden schon im Kapitel zu Eurozentrismus (3.2.3) behandelt.
} 
I: Okay, vielleicht fangen wir einfach so an, dass du noch mal erzählst, was dir zur Globalisierung einfällt.

S: Ja, also damals als ich diesen Zettel ausgefüllt habe, wusste ich gar nicht mehr so genau, was das war. Ich dachte erst mal an Kolonisierung und so was.

I: Mhm.

S: Und, äh, ja dass sich die Menschen auf der ganzen Welt verteilen.

I: Mhm.

S: Also dass jede Rasse auch in jedem Land leben kann und so was. Und jede Religion.

I: Mhm.

S: Ja.

I: Und, ähm, was heißt das? Also, dass sie sich ausgebreitet hat?

S: Also, ähm, früher war es ja so, so im Mittelalter, dass sich zum Beispiel die Christen nur auf Europa beschränkt haben. Oder die Buddhisten in Asien. Dass die sich dann durch die Globalisierung auf der ganzen Welt verteilen und das überall bekannt ist dann. (Mark, Gym09)

Als einziger assoziiert Mark direkt zur Einstiegsfrage des Interviews „Kolonisierung“. Zunächst versteht er darunter die Verteilung der „Menschen auf der ganzen Welt". In den folgenden Aussagen wird klarer, was diese Aussage zu bedeuten hat. Er geht nicht davon aus, dass vorher unbesiedelte Erdteile nun zum ersten Mal von Menschen bewohnt würden. Vielmehr geht er davon aus, dass es einen Weltzustand vor der Kolonisierung gegeben habe, in dem ,,jede Rasse“ und ,,jede Religion“ in dem ihr entsprechenden Land gewesen sei. Dieser Vorstellung einer vorkolonialen Ordnung haftet die Idee eines geordneten Ursprungs an, in dem alles an seinem Platz gewesen zu sein schien. Die Globalisierung bzw. „Kolonisierung" habe dann, Mark zufolge, diese Ordnung durchbrochen, da sich dann die Angehörigen verschiedener „Rassen“ und „Religionen“ auf der ,ganzen Welt“ verteilt hätten.

I: Mhm. Und wie kam das dazu, dass die das gemacht haben?

S: Ja, sie wollten halt ihre Macht, also ihre Religion, weiter verbreiten. Zum Beispiel Kolumbus war das ja, der ja Amerika entdeckt hat, denkt sich: „Ein neuer Kontinent. Da leben auch viele Menschen. Die haben noch keine Ahnung von der Religion. Oder überhaupt, dass sie einer Religion angehören." Da wollte er die zum Christentum halt bekehren. Und ja.

I: Und was denkst du darüber? 
S: Ja, also ich finde es ist eigentlich eine ganz gute Idee. Jedoch werden die meisten beeinflusst, weil sie eigentlich keine Ahnung haben, um was es da wirklich geht. Was man da macht. Und, ja, wie man sich dann halt zu verhalten hat und so was.

I: Mhm. Also wenn man jetzt nicht so dolle beeinflussen würde, dann wäre das keine schlechte Sache?

S: Ja, also wenn es wirklich nur positiv wäre und nicht irgendwie abwertend gegenüber anderen Religionen oder anderen Völkern, dann wäre es eigentlich eine gute Sache. (Mark, Gym09)

Die europäische Kolonialisierung der Amerikas wird hier als Beispiel für die Ausbreitung der „Rassen“ und „Religionen“ über die Welt angeführt. An dieser Stelle führt er aber auch „Macht“ als eine Dimension und als Motiv dieser Ausbreitung an, was er wieder aufgreifen wird. Den Topos vom „Amerika“, entdeckenden“ Kolumbus macht Mark hier zum Aufhänger seines Narrativs der Geschichte des Kolonialismus. Dieser Topos allein verrät allerdings bereits sehr viel über die Denkstruktur von Agency und Subalternität. Das Sprechen von der ,Entdeckung Amerikas' nimmt klar eine Perspektive ein, um damit andere zu ignorieren. Die Perspektive der vielen Millionen Menschen, die vor der europäischen Kolonialisierung in den heute Amerikas genannten Kontinent lebten, wird mit diesem Topos ausgelöscht. Mark denkt sich in den gerade „Amerika“ ,entdeckenden“ Kolumbus hinein, der die „,vielen Menschen“ sieht, die „,noch keine Ahnung von der Religion“ hätten oder „dass sie einer Religion angehören“ könnten. Vor diesem Hintergrund habe er sich überlegt, sie „zum Christentum“ bekehren zu wollen. Interessant ist dabei, dass seine letztgenannte Aussage wohl bedeuten soll, dass sie durch die Kolonisierung nicht nur zur speziellen Religion des Christentums gekommen seien, sondern zur Religiosität überhaupt. Hier schwingen zwei konkurrierende Bilder der Kolonisierten mit. Das eine sich andeutende Bild zeichnet die Kolonisierten als noch nicht religiös, unwissend und naturnah; vor diesem Hintergrund erscheint für Mark die Christianisierung durch Kolumbus als eine Chance, einen Fortschritt zu erreichen. Das zweite sich andeutende Bild zeichnet die Kolonisierten als „Völker“ mit Traditionen und Religionen, denen gegenüber sich die Kolonisierenden ,abwertend“ verhalten könnten.

Insgesamt breitet Mark ein Bild der Geschichte des Kolonialismus aus, das zeigt, dass er über viel Wissen zu dem Thema verfügt.

I: Mhm. Und weißt du, welche Länder das vor allem gemacht haben mit der Kolonisierung? 
S: Ja, also früher waren es ja so Spanien und so was. Die europäischen Länder wie England, Frankreich. Die haben erst mal .../ Also Spanien vor allem hat dann die südamerikanischen Länder besiedelt. Deswegen spricht man da auch noch Spanisch im größten Teil der Länder. Und dann noch so im 19. oder 20. Jahrhundert waren ja auch noch die Deutschen und die Engländer und so beteiligt. Die haben dann Afrika kolonisiert und hatten auch ihre Kolonien dort. Dort sprechen sie auch noch ein bisschen ihre Sprache. Wenn sie dort Französisch sprechen, weil es dort eine französische Kolonie war oder so.

I: Mhm. Und was ist mit Asien?

S: Ja, in Asien war zum Beispiel Indien in englischer Hand. Da hat man diese EastIndia-Company oder so was gehabt. Da haben die auch meistens Englisch gesprochen und so. Ja, und halt andere Länder, die dort sind, wurden auch von anderen Ländern kolonisiert. (Mark, Gym09)

Er benennt hier sowohl eine chronologische als auch geographische Abfolge der europäischen Kolonisierungen. In seinem Schema steht zunächst Spanien, das Südamerika kolonisiert und später England, Deutschland und Frankreich, die im „19. oder 20. Jahrhundert“ Afrika kolonisiert hätten. An anderen Stellen nennt er auch noch Portugal als kolonisierendes Land und die Entstehung der USA als kolonisiertes Land. In dem zitierten Auszug benennt er postkoloniale Sprachverhältnisse sowie mit der East-India-Company auch einen nicht-staatlichen Akteur.

I: Mhm. Und, ähm, kannst du das noch mal beschreiben, was das heißt? Also wenn jetzt zum Beispiel Frankreich ein afrikanisches Land, oder Spanien Amerika, oder jetzt wenn die East-India-Company aus England Indien kolonisiert hat. Was heißt das? Oder wie kann man sich das vorstellen?

S: Ja, England hat sich früher ja immer nur auf Europa beschränkt. Ihre Macht dort weiter ausgebreitet. Und ihr Mutterland hat versucht, dann die anderen Länder zu erobern. Zum Beispiel Frankreich, die hatten ja diesen Jahrhundertkrieg da gehabt.

I: Mhm.

S: Aber dann haben sie eingesehen, dass die anderen Länder auch ebenfalls zu viel Macht haben, um sie zu erobern. Und haben sich dann auf die anderen Kontinente ausgebreitet, um ihre Macht dann weiter zu vergrößern.

I: Mhm. Und glaubst du, das war eher gut oder eher schlecht für die Länder?

S: Also für die Mutterländer an sich war es eher gut, weil durch die Verbreitung ihrer Kolonien haben sie mehr Handel und mehr Einfluss auf die Länder. Sie können mehr Handel betreiben und können auch mehr Menschen in ihr Land locken. Aber anderseits ist es auch ein bisschen doof für die Einwohner dort. Sie haben immer ein traditionelles Leben gehabt. Und haben immer so gelebt, wie sie es taten. Und wenn 
dann auf einmal solche Kolonisten kommen und ihr Leben verändern, dann werden ihre Religion, ihr Glauben, ihre Traditionen dadurch zerstört. Und ihnen vielleicht auch ihren Lebensraum genommen. Und, ja, das ist dann doof für die. (Mark, Gym09)

Obwohl die Frage in eine andere Richtung zielt, breitet Mark hier seine Idee für die Ursachen der Kolonisierung aus. Dabei knüpft er an das, von ihm schon vorher erwähnte, Konzept der Macht an. England sei ,früher ja immer nur auf Europa beschränkt gewesen“ und hätte versucht, seine „Macht dort weiter“ auszubreiten. Doch die anderen Länder in Europa hätten ,zu viel Macht gehabt, um sie zu erobern“. Vor diesem Hintergrund hätte sich England dann ,auf die anderen Kontinente ausgebreitet, um ihre Macht dann weiter zu vergrößern“. Dies habe England bzw. den „Mutterländer[n]“ - damit meint er wohl die kolonisierenden Länder Europas - „mehr Handel und mehr Einfluss“ gebracht und sie konnten „mehr Menschen in ihr Land locken“.

Für die Kolonisierten sei dies aber „,ein bisschen doof“ gewesen dort. Diese hätten immer ein ,traditionelles Leben“ gehabt und ,immer so gelebt, wie sie es taten“. Die „Kolonisten“ hätten ihr Leben verändert und dadurch seien dann ,ihre Religion, ihr Glauben, ihre Traditionen“ zerstört und ihr „Lebensraum“ genommen worden. Auch wenn er die Motive der kolonisierenden Länder offenbar nachvollziehbar oder einleuchtend findet, sieht er diese Kehrseite der Kolonisierung als „doof“ an. Hier deutet sich aber bereits ein Perspektivwechsel von der kolonisierenden zur kolonisierten Perspektive an, woraufhin ich die Frage danach stelle.

I: Mhm. Ja. Und, ähm, haben die das einfach so hingenommen, die Leute?

S: Also einige haben versucht zu fliehen vor den Arbeiten. Also die Kolonisten sind meistens umgekommen. Weil sie schlecht versorgt wurden. Zum Beispiel mussten sie immer arbeiten als Sklaven. Haben wenig zu Essen oder zu Trinken bekommen. Und hatten auch schlechte Umstände dort gehabt. Und deswegen war es auch schwer zu entkommen, weil sie dann keine Kraft mehr hatten. Und dann gibt es auch noch gewalttätige Aufstände, so wie in der East India Company. Die konnten sich dann durchsetzen gegen die Engländer. Auch wenn es etwas gedauert hat. Aber, ähm, sie haben sich dann alle zusammengeschlossen die Einwohner Indiens und, ähm, haben sich dann gegen die Engländer aufgelehnt und haben dann am Ende die Unabhängigkeit bekommen.

I: Mhm. Und was denkst du dazu? Findest du das gut oder schlecht?

S: Ja, ich finde es eigentlich gut. Weil die Menschen dort haben ja immer so gelebt, wie sie es wollten. Und wollen nicht, dass andere sie beeinflussen von außerhalb ihres Landes. Und, ähm, wollen ihr eigenes Land wieder zurück erobern. (Mark, Gym09) 
Auf die direkte Frage nach der Agency der Kolonisierten nennt Mark zwei Widerstandsstrategien. Zum einen sind einige Kolonisierte laut Mark geflohen bzw. sie hätten es versucht. Sie hätten versucht vor den „Arbeiten“ zu fliehen, da viele von ihnen dabei umgekommen seien, da die „Umstände“" schlecht gewesen seien. Sie mussten als „Sklaven“ arbeiten und hätten ,wenig zu Essen oder zu Trinken bekommen“. Diese Verhältnisse hätten sie allerdings so entkräftet, dass sie keine Kraft mehr für die Flucht gehabt hätten. Diese Form des Widerstands wird von Mark somit nur zu einem hoffnungslosen Versuch erklärt. Zum anderen hätte es noch ,gewalttätige Aufstände“ gegeben. Hier führt er das Beispiel des Aufstands innerhalb der East India Company an, wobei er diese mit der englischen Kolonialverwaltung gleichzusetzen scheint. „Die“ hätten sich letztlich „gegen die Engländer“ durchsetzen können. Die „Einwohner Indiens“ hätten sich „alle zusammengeschlossen [...], gegen die Engländer aufgelehnt und haben dann am Ende die Unabhängigkeit bekommen“. Dies findet Markt „eigentlich gut“, da die „Menschen dort [...] immer so gelebt [hätten], wie sie es wollten“. Sie wollten nicht, dass ,andere sie beeinflussen von außerhalb ihres Landes“ und wollten deswegen ,ihr eigenes Land wieder zurück erobern“.

Hatte Mark zu Beginn des Interviews noch die vermeintlichen Vorzüge der Kolonisierung stark gemacht, kritisiert er im weiteren Verlauf nicht nur die Behandlung der Kolonisierten aus humanistischer Perspektive, sondern bespricht ihre Agency. Er führt als einziger Schüler Agency der Kolonisierten anhand eines konkreten historischen Beispiels an. Er weiß also um konkrete Konstellationen antikolonialen Widerstands. In seiner Erzählung erscheint auch die Dekolonisierung Indiens als Resultat dieses Widerstands der „Einwohner Indiens“ und nicht einfach als eine Entscheidung des Globalen Nordens oder als ein Fortschritt der Geschichte. Mit dieser Form des Sprechens über Agency der Kolonisierten steht Mark fast alleine da. Der Frame, indem er die Dekolonisierung bespricht, ist dabei der der nationalen Unabhängigkeitsbewegungen, da er sagt, dass die nach nationaler Unabhängigkeit strebenden Inder_innen nicht mehr wollten, dass ,andere sie beeinflussen von außerhalb ihres Landes".

Dieser Frame der nationalen Unabhängigkeit steht dabei mit seinem Denken von Kulturen in Verbindung, in dem Kulturen als bereits bestehende, feste Entitäten erscheinen. Der folgende Exkurs zu Marks Begriff von Kultur geht zwar punktuell über die Fragestellung der Agency der Kolonisierten hinaus, erscheint aber insofern trotzdem als relevant, da mit ihr die Frage des Status des Subjekts der Kolonisierten geklärt werden kann, was wiederum entscheidenden Einfluss auf das Denken von Solidarität hat. Im Anschluss an den vorherigen Abschnitt zeigen sich weitere Facetten seines Kulturbegriffs. 
I: Mhm. Und du hast ja auch gesagt, dass dadurch mehr Import und Export möglich war. Und mehr Handel. Ähm, findest du das gut oder schlecht?

S: Also innerhalb des Landes ist das schon gut, weil wenn man jetzt zum Beispiel Kartoffeln oder so was haben möchte - man lebt aber in Europa, die Kartoffeln sind meistens aus Amerika oder so - kann man dann Kartoffeln bestellen und die werden dann geliefert. Und dann werden auch andere Sachen, die man aus dem Mutterland alltäglich kennt, auch in die Kolonien verfrachtet. Da kennt man zum Beispiel Tee. Tee hat man in England ja eigentlich nicht so getrunken früher. Dann hat man die East-India-Company bekommen und andere asiatische Länder und die haben dann Tee regelmäßig nach England verfrachtet.

I: Mhm. Glaubst du, dass sich die Kultur insgesamt stark dadurch verändert hat?

S: Ja, also mittlerweile gibt es ja keine Kolonien mehr. Bis auf einige Ausnahmen. Diese kleinen Inseln die England noch hat. Oder Frankreich, ich weiß es grad' nicht. $\mathrm{Ja}$, aber ansonsten haben die meisten ihre Unabhängigkeit wieder bekommen. Und konnten auch ihre Kultur wieder weiterleben. Ihre alten Sitten und Traditionen sind vielleicht ein bisschen ausgestorben. Aber grundsätzlich können sie wieder so leben, wie sie es früher gemacht haben. (Mark, Gym09)

Zunächst ist hier interessant, dass er auf die koloniale Geschichte von symbolisch aufgeladenen Gütern verweist. So würden Kartoffeln aus Amerika importiert und Tee sei von der East India Company nach England gebracht worden. Auf die Frage, ob sich die Kultur verändert habe, antwortet er mit einer Bestandsaufnahme kolonialer Verhältnisse. So gäbe es mittlerweile, abgesehen von ein paar „kleinen Inseln“, „keine Kolonien mehr“. Abgesehen von diesen „Ausnahmen“ hätten inzwischen ,die meisten ihre Unabhängigkeit wieder bekommen“. Dies hätte dazu geführt, dass sie ihre „Kultur weiterleben“ könnten. Mark merkt an, dass zwar ,ihre alten Sitten und Traditionen [...] vielleicht ein bisschen ausgestorben“ seien, sie aber ,grundsätzlich [...] wieder so leben“ könnten, ,wie sie es früher gemacht" hätten. In Marks Vorstellungen sind die kolonisierten Länder Entitäten, zu denen eine spezifische Kultur, Tradition und Identität gehört, die zwar gestört oder gar zerstört werden kann, in ihrem Wesen aber gleichbleibt. Bevor ich dies weitergehend diskutiere und in Bezug zu Agency setze, möchte ich noch ein weiteres Zitat von Mark anfügen, in welchem ich einen ähnlich essenzialisierten Kulturbegriff entdecke, allerdings in Bezug auf die kolonisierenden Länder.

I: Mhm. Mhm. Glaubst du durch diese ganze Globalisierung hat sich die deutsche Kultur irgendwie verändert? Oder auch dadurch, dass zum Beispiel jetzt mehr Leute hier sind, die woanders hergekommen sind oder so? 
S: Also speziell in Deutschland hat sich eigentlich nicht viel geändert, weil die Kolonien aus Deutschland waren nicht so gerade profitabel für Deutschland. Also für das Deutsche Reich. Und deren Kultur, ähm, hat sich eigentlich schon viel früher entwickelt, also noch in der Römerzeit. Die Germanen, die Barbaren haben sich dann nach und nach erst entwickelt. Aber auch intern und nicht irgendwie von äußeren Einflüssen. Wenn überhaupt nur durch Kriege oder durch irgendwelche, ähm, Pläne von Kaisern oder Königen, die die Grenzen und Bewohner dann ordnen. Und dadurch, ähm, hat man eine .../ Okay, man kann sagen, dass es von außen etwas Einfluss gab, aber so Traditionen und so, die behält man in seinem eigenen Land. (Mark, Gym09)

Die deutsche Kultur habe sich laut Mark durch den Kolonialismus nicht nennenswert verändert. Dafür führt er zwei Gründe an. Zum einen seien die „Kolonien aus Deutschland [...] nicht so gerade profitabel für Deutschland“ gewesen. Aber vor allem hätte sich zum anderen die deutsche ,Kultur [...] eigentlich schon viel früher entwickelt“. Ausgehend von der „Römerzeit“" hätten sich ,die Germanen, die Barbaren [...] dann nach und nach" entwickelt. Dies sei ein interner Prozess gewesen, der ,nicht irgendwie von äußeren Einflüssen“ bestimmt worden sei. Mögliche Lenkung sei möglicherweise durch „Kriege oder durch irgendwelche [...] Pläne von Kaisern oder Königen“ erfolgt, ,die die Grenzen der Bewohner dann ordnen“. Unabhängig von möglichen Einflussnahmen stellt Mark am Ende klar, dass man ,so Traditionen und so [...] in seinem eigenen Land“ behalte.

In Marks Vorstellungswelt stellen die Länder der Welt also ein globales Ordnungsschema dar, dessen grundsätzliche Historizität zwar festgestellt, welches aber gleichzeitig trotzdem als essenzialisierendes Ordnungsschema Anwendung findet. Dieses Ordnungsschema der Nationen, Völker und Kulturen wurde sowohl in den kolonisierenden als auch in den kolonisierten Ländern vom Kolonialismus nicht grundlegend verschoben, sondern vielmehr erscheint die Wiederherstellung dieser Ordnung als zentrale Antriebsfeder für das antikoloniale Streben nach nationaler Unabhängigkeit. Viele Äußerungen von Mark bieten das Potenzial, die Fragen von transnationaler Verwobenheit von Geschichte, nicht zuletzt durch den Kolonialismus, und die historische und arbiträre Konstruktion von Grenzen und Differenzen zu diskutieren. Beispielsweise sind seine Beispiele der kolonialen Einfuhr von Kartoffeln und Tee, die symbolisch und materiell zu zentralen Elementen der deutschen und britischen ,Kultur' wurden, Aspekte, anhand derer es naheliegen würde, die Verwobenheit der britischen und deutschen Geschichte und Identität mit transnationalen Prozessen und dem Kolonialismus zu diskutieren. Auch die postkoloniale Realität in ehemals kolonisierten Ländern wird von ihm als ein reines Wiederaufgreifen der als ursprünglich erscheinenden Lebensart gedacht. Staat also hier transnationale Verwobenheit und geschichtliche Kontingenz zu diskutieren, dominiert das essenzialisierende, starre Ordnungsschema der 
Nationen. Insgesamt diskutiert Mark also Agency von Kolonisierten und bringt sogar ein konkretes historisches Beispiel, doch auch in diesem erscheint das Subjekt des antikolonialen Widerstands als ein ,Volk', das in erster Linie danach strebt, wieder so zu leben, wie es immer gelebt habe. Damit ist Marks Gesamtargumentation in Bezug auf Agency als widersprüchlich anzusehen: Auf der einen Seite bricht er grundlegend mit der kolonialen Nicht-Beachtung von Agency der Kolonisierten, auf der anderen Seite erscheinen diese als reduziert auf ihre Kultur, was ihren Status des über Agency verfügenden Subjekts wieder in einen entsubjektivierten Status überführt. Dieser Widerspruch bleibt unaufgelöst.

Auch David (Gym14) verfügt über verhältnismäßig viel Wissen in Bezug auf den historischen Kolonialismus. In seiner Argumentationsstruktur in Bezug auf Agency erscheint mir ein anderer Widerspruch als bei Mark zentral zu sein. Ausgehend von seinen Überlegungen zur als ungerecht empfundenen globalen Ungleichheit und der daraus resultierenden Notwendigkeit, den Lebensstandard im Globalen Norden zurückzuschrauben, sprachen wir über die Gründe dafür, dass es nach David in Afrika alles ganz anders sei.

I: Ja. Und wie kam es dazu, dass es jetzt in Afrika .../ Oder nochmal dazu: Warum ist es in Afrika anders? Wieso ist es da so, dass die Politiker zum Beispiel einfach ihren Reichtum behalten wollen?

S: Da kann man weit ausholen. Also ich habe das mal so erklärt bekommen/gehört - ich weiß nicht ob es stimmt, ich habe das Buch dazu noch nicht gelesen, es liegt noch bei mir - dass im Kongo zum Beispiel, wo ja Krieg geführt wird, dass die Kolonialherren da mal die Stämme gegeneinander aufwiegelt haben, um die besser besiegen zu können. Und seitdem ist da Blutrache. Und die sind sich halt untereinander gar nicht einig, wer was bekommt. Und natürlich, wer gerade an der Macht ist, behält das Geld schön für sich und sorgt dafür, dass er gut durchkommt. Und der Rest ist ihm halt egal. Also man müsste da die politische Verständigung vielleicht erstmal voranbringen. (David, Gym14)

Als Grund für die Differenz der politischen Kultur in Afrika nimmt er Bezug auf den Kolonialismus, womit er einer von vier Schüler_innen insgesamt ist. Er führt die Praxis der „Kolonialherren“ als ursächlich für Verhältnisse in postkolonialen Situationen des ehemals kolonisierten Kongo an. Die „Kolonialherren“ hätten dort „,mal die Stämme gegeneinander aufgewiegelt [...], um die besser besiegen zu können“. Seitdem sei dort „Blutrache“. Diese bis in die Gegenwart anhaltende „Blutrache“ führe dazu, dass „die“ sich „,untereinander gar nicht einig“ seien, „wer was bekommt“. Dies wiederum führe dazu, dass derjenige, der ,gerade an der Macht“ sei, das „Geld schon für sich“ behalte, nur auf sich gucke und „der 
Rest“ ihm „egal“ sei. Aus einer dekolonialen Perspektive erscheint die Benennung von Praxen der Kolonialherren als prägend für postkoloniale Konflikte als sehr wichtig und fruchtbar. Auch in dekolonialen Analysen werden die in ,Ethnien“" und „Stämmen“ einteilenden kolonialadministrativen Praxen als notwendig zu beachtende Elemente für das Verständnis von postkolonialen Identitäten angesehen. Solche Analysen laufen aber Gefahr, im Zuge einer solchen Analyse die Agency der Kolonisierten zu dethematisieren. Bei David erscheinen die „Stämme“ dabei nicht als Teil des kolonialen Konstruktionsprozesses, sondern vielmehr als gegeben. Diese seien dann gegeneinander ,,aufgewiegelt“" worden, was zu „Blutrache“ geführt habe. Diese Sprache basiert auf kolonialen Bilder, die den Topos von ,unterentwickelten“ Afrikaner_innen reproduziert. David würde wohl kaum diese Begriffe verwenden, um kriegerische Konflikte im Globalen Norden zu beschreiben.

In Bezug auf die Frage von Agency ist hier bemerkenswert, dass das Vorgehen der „Kolonialherren“ hier zwar verurteilt wird, die Kolonisierten dabei aber als Spielball des Handelns der Kolonisierenden erscheinen. In Davids Bild hätten sich die Kolonialherren überlegt, sie gegeneinander aufzuwiegeln, hätten ihren Plan umgesetzt und die Kolonisierten agierten seitdem genauso, wie es sich die Kolonialherren vor 140 Jahren mal überlegt hätten. Die Rollen sind klar verteilt: Es gibt ein Subjekt, die ,Kolonialherren“, und ein Objekt, das als Subjekt nur insofern und auf die Art und Weise in Erscheinung tritt, wie es das dahinter stehende Subjekt ermöglicht hat. In dieser Darstellung scheinen klassische Binaritäten der kolonialen Differenz auf: Rationalität vs. Naturhaftigkeit, Strategie vs. Impulsivität, Aktion vs. Reaktion, bewusst Handelnde vs. unbewusst Reproduzierende, Rahmen Setzende vs. nur dem Rahmen Folgende. Dies gilt für David für die Zeit des historischen Kolonialismus ebenso wie für die postkoloniale Gegenwart. Diese Ähnlichkeit der Konstruktion von Agency bzw. Subalternität von Kolonisierten der Vergangenheit sowie Menschen des Globalen Südens lässt sich explizit oder implizit in Aussagen von fast allen Schüler_innen feststellen, die sich zu beiden Gruppen äußern.

Trotz der in Davids Argumentation vorhandenen Kritik und der Benennung der aus der Geschichte des europäischen Kolonialismus erwachsenden Verantwortung des Globalen Nordens für Problemlagen in Regionen des Globalen Südens erscheint seine Argumentation aus dekolonialer Perspektive als problematisch. Diese Problematik wird bei David insbesondere auch an seiner Vorstellung einer möglichen Lösung des Problems deutlich. Aus Davids Perspektive besteht das Hauptproblem ja im Egoismus der Afrikaner_innen, den er auf die Strategie der „Kolonialherren“ zurückführt, die für die „Blutrache“ unter den „Stämmen“ 
gesorgt hätten. Die Lösung dafür sieht er darin, dass ,die politische Verständigung" vorangebracht werden müsste. Ohne dass er es ausspricht, erscheint klar zu sein, wer diesen Prozess anstoßen müsste. Der nicht ausgesprochene Akteur scheint im Globalen Norden verortet. Dies wird auch in den von mir in der Folge angeführten Ausschnitten deutlich werden. Der Folgende knüpft direkt an den letzten an.

\section{I: Mhm.}

S: Man hat jetzt ja auch gesehen, in Libyen und Syrien ist ja immer noch der arabische Frühling. So hieß das glaube ich? Ich bin mir nicht ganz sicher.

I: Mhm [bejahend].

S: Also es ist schon in der Umsetzung, aber die politische Lage ist einfach noch zu risikoreich da. Oder die Demokratie ist da noch nicht weit genug.

I: Und wie könnte das dazu kommen?

S: Also dass die Demokratie weit genug ist?

I: Ja.

S: Also militärisches Eingreifen halte ich nicht für sinnvoll von der EU oder NATO. Also die Leute müssen sich im Grunde selber irgendwann dazu aufraffen. Man kann die dabei unterstützen. Also kann man, wie es ja zum Beispiel gemacht wird in Syrien, die Aufständischen mit Lebensmitteln und so versorgen, damit die das schaffen. Und man muss halt möglichst das fördern. Immer die politische Verständigung fördern. Und, ja, eben auch mehr humanitäre Hilfe hinsenden. Nicht nur jetzt vielleicht Leute, die da kochen und da, weiß ich nicht, Wasser verteilen. Sondern auch Leute .../ Schulbildung muss ganz dolle gefördert werden. Und die das psychologisch auch alles managen da mit den Diplomaten. (David, Gym14)

David kommt selbst vom Punkt der politischen Verständigung und der Veränderung in ehemals kolonisierten Ländern zum Beispiel des arabischen Frühlings. Obwohl David hier dieses Beispiel der unter dem Sammelbegriff des arabischen Frühlings fungierenden Protestbewegungen anführt, erscheint kein Akteur aus diesen Ländern in seiner Darstellung. Ihr Scheitern erklärt er mit einem Verweis auf das Entwicklungsparadigma. So sei „die Demokratie [...] da noch nicht weit genug“. Auf die Frage, wie sich das verändern könnte, wird durch seinen Ausschluss militärischen Eingreifens deutlich, wer zunächst für ihn als Akteur infrage käme, eine Veränderung herbeizuführen. Naheliegend scheint für ihn zu sein, dass der Impuls für eine Veränderung aus „,der EU oder NATO“ käme, wobei er ein militärisches Vorgehen nicht für „sinnvoll“ hält. Gleichzeitig stellt er fest, dass „die Leute“ - also die Bewohner_innen dieser Länder außerhalb des Globalen 
Nordens, in diesem Fall den Ländern des arabischen Frühlings bzw. „Libyen und Syrien“ - ,sich im Grunde selber irgendwann dazu aufraffen“ müssten. Sie sind also als potenzieller Akteur angesprochen. Dabei schreibt er der Unterstützung durch den Globalen Norden eine zentrale Rolle zu - so zentral, dass letztlich der Akteursstatus der Menschen dort schon wieder in den Hintergrund gerät. Er plädiert dafür, humanitäre Hilfe in diese Länder zu senden. David macht aber deutlich, dass sich die Unterstützung aus dem Globalen Norden unbedingt auch auf Politik und Bildung erstrecken müsse.

Bildung aus dem Globalen Norden für Menschen im Globalen Süden wird von einer Mehrheit der Schüler_innen als Schlüssel für eine Veränderung angeführt. Es bleibt dabei meist - zunächst auch bei David - unausgesprochen, was die Menschen aus dem Globalen Norden befähigt, den Menschen im Globalen Süden den Lösungsweg für die dortigen gesellschaftlichen Probleme zu liefern. Durch den Topos von Bildung durch den Globalen Norden für den Globalen Süden wird das Verhältnis zwischen den Menschen des Globalen Nordens und des Globalen Südens hierarchisiert. Die Menschen im Globalen Norden erscheinen als Wissende, die befähigt sind, ihr Wissen an die implizit als unwissender erscheinenden Menschen des Globalen Südens, weiterzugeben.

Im Folgenden Interviewauszug bringt David ein Beispiel, an dem Prämissen dieser Argumentationsstruktur deutlich wird. Auf die Frage, wer die Gewinner und wer die Verlierer der Globalisierung sind, antwortet David zunächst auf der ökonomischen Ebene, indem er sagt, dass die großen Konzerne die Gewinner und kleine Firmen die Verlierer seien. Dann schwenkt er von selber auf die kulturelle Ebene um.

I: Mhm. Und was würdest du sagen, wer sind die Gewinner und wer sind die Verlierer der Globalisierung?

S: [...] Und generell gewinnen .../ An der Kultur gewinnen eigentlich alle. Also es gibt kaum jemand, der darunter eigentlich leidet. Weil die meisten kleineren, rassistischen, fremdenfeindlichen Kulturen oder so werden ja dadurch geschluckt quasi und zerstört. Dadurch dass die großen, besseren Kulturen halt, ähm, in die Länder kommen.

I: Mhm. Was wäre ein Beispiel für so eine Kultur, die geschluckt wird?

S: Puh. Ich hoffe ja, dass die Kultur „Taliban“ zum Beispiel irgendwann geschluckt wird. Diese Ansicht von Rechtsextremisten, Extremisten allgemein. Dass sich irgendwann Extremismus - egal welche Richtung, Taliban ist immer so das Musterbeispiel - dass sich das irgendwann auflöst. Einfach dadurch, dass die Mehrheit der Leute da einfach nicht mehr hinter steht. Und die Leute, die das noch glauben .../ Jeder stirbt irgendwann mal an Altersschwäche. Und dass halt das irgendwann ausstirbt einfach. Durch die Aufklärung, die durch die Kulturenvermischung dann kommt. 
I: Mhm. Und, ähm, also durch welche Kultur wird das dann geschluckt oder ersetzt?

S: Demokratie, Akzeptanz, Multi-Religionismus. Das gibt es bestimmt nicht das Wort, aber halt, dass jeder die anderen akzeptiert in ihrer Ansicht und die anderen in ihrer Ansicht leben lässt.

I: Mhm.

S: Ja, halt dass jeder grundsätzlich jeder die Menschenrechte akzeptiert als Gesetz. Und das Grundgesetz seines Landes akzeptiert.

I: Mhm.

S: Und, ja, man kann ja immer noch .../ Selbst wenn jemand Rechtextremist ist. Wenn der seine rechten Ansichten hat, dann ist das okay, solange er das nicht auslebt. Man kann niemanden vorschreiben was er denkt, aber er darf nicht mit Gewalt das äußern. Und das sollte irgendwann halt aussterben. Und je mehr eine Kultur aufgeklärt wird und je mehr so was vermittelt wird, von Anfang an schon den Kindern, desto größer ist die Chance, dass das irgendwann mal ausgestorben ist. (David, Gym14)

Dass David das „Musterbeispiel“ der Taliban als Kultur wählt, ist kein Zufall. Globalisierung bedeutet für ihn, dass ,die Aufklärung, die durch die Kulturenvermischung dann kommt“, dazu führt, dass die ,kleineren, rassistischen, fremdenfeindlichen Kulturen“ von den ,großen, besseren Kulturen“, die ,,in die Länder" kommen, ,geschluckt quasi oder zerstört“ werden. Die „Kultur ,Taliban“" wird hier von ihm als Beispiel für „Rechtsextremisten, Extremisten allgemein“"gedeutet. In meiner Interpretation geht es mir hier nicht darum, eine Kritik der Taliban normativ falsch zu finden. Die Taliban fungieren hier aber als das Gegenstück zur ,westlichen“ Kultur. Diese wird hier symbolisiert durch die Werte „Demokratie, Akzeptanz, Multi-Religionismus“, Gewaltlosigkeit, Meinungsvielfalt sowie die Akzeptanz der „Menschenrechte“ und des Prinzips der Rechtsstaatlichkeit. Damit wird eine koloniale Differenz ins Verhältnis zwischen dem Globalen Norden und dem Globalen Süden eingeschrieben. Der Globale Norden bzw. die ,westliche“ Kultur stellt für ihn das normative Ziel globalgesellschaftlicher Veränderung dar. Dies erscheint mir als Davids implizite Denkvoraussetzung für seine Konstruktion von notwendigen Bildungsprozessen, die dem Globalen Norden die Verantwortung zuschreibt, Bildung und Aufklärung in den Globalen Süden zu bringen. Das Aussterben dieser Kulturen kann für ihn aber nur gewaltlos erreicht werden - über Bildungsprozesse. So sei zumindest die Chance dementsprechend größer, dass ,,das irgendwann mal ausgestorben“ sei, ,,je mehr eine Kultur aufgeklärt wird und je mehr so was vermittelt wird, von Anfang an schon den Kindern“. Direkt im Anschluss frage ich nach dem Akteur dieser Aufklärung. 
I: Und wer könnte diese Aufklärung voranbringen?

S: Puh. Die Regierung der Länder am besten, indem die mehr in die Bildung investieren, anstatt in den Waffenhandel.

I: Mhm.

S: Gut, in manchen Ländern Afghanistans ist es ja noch echt schwierig. Da sieht man auch, da müssen Bundeswehr und alle halt dabei helfen. Aber die müssen letztendlich neben der militärischen Hilfe halt sekundär die Bildung total voranbringen. Und allgemein die Infrastruktur aufbauen. Und so ein Land dazu bringen, dass es sich selber quasi wieder damit findet.

I: Mhm. Und gibt es noch andere Länder, wo das sinnvoll wäre, dass da Hilfe von außen bei der Aufklärung kommt?

S: Afrika, Asien. Viele Länder. Wobei Asien ein zweischneidiges Schwert ist, weil da viele der Regierungen doch sehr einflussreich ja auch sind inzwischen auch in der Welt. Ähm, Südamerika teils noch die Länder sind ja auch noch sehr ,gated community“ und so. Ja, Europa geht eigentlich. Na ja, Balkanstaaten, da so die Ecke ist ja auch nicht so besonders gut. Wobei da auch Russland mehr tun müsste eigentlich. Aber Russland ist ja selber so ein Problemfall.

I: Mhm. Aber wie könnte denn sowas aussehen? So eine Hilfe von außen? Vor allen Dingen, wenn auch die Bevölkerung .../ Oder wenn zum Beispiel die Regierung das gar nicht unbedingt will? Was könnte man da machen?

S: Ja, zum Beispiel halt hingehen. Wenn es eine Diktatur ist, den Leuten sagen: „Das verstößt gegen das Völkerrecht. Wehrt euch dagegen." Und das, soweit es geht, halt friedlich. Und dann wenn die es geschafft haben, eine Demokratie .../ Wenn die Regierung da nicht mit klarkommt, die unterstützen und denen halt Tipps geben, wie jetzt in der Dritten Welt .../ Nee, Dritte Welt nicht. Ich verwechsle das immer. „In Europa und Amerika haben wir eine funktionierende Demokratie. Guckt euch doch mal ab, so und so läuft das ganz gut bei uns. Probiert das doch auch mal." Und dann, wenn die halt Hilfsgüter brauchen, weil sie einfach die Rohstoffe nicht haben, die hinschicken. Auch ruhig Personal, Fachpersonal. Ärzte sind immer wichtig. Gut ausgebildete Lehrer. Dass die da vor Ort neue Leute ausbilden, damit die das langfristig selber machen können. Also quasi Anleitungen geben. Nicht lenken, nicht denen vorschreiben, was sie zu tun haben, sondern immer Hilfestellung geben. Bis sie es irgendwann alleine drauf haben und dann selber anderen Ländern helfen können. (David, Gym14)

Zunächst verweist David als Akteure einer „Aufklärung“ auf die Regierungen der jeweiligen Länder, die ,mehr in die Bildung investieren“ sollten, statt ,,in den Waffenhandel“. Wiederum am Beispiel Afghanistans schränkt er aber seine Aussage ein. Dort müssten „Bundeswehr und alle halt dabei helfen“. Die Bundeswehr müsste dabei ,neben der militärischen Hilfe“ insbesondere die „,Bildung total voranbringen“. Mit ,und alle" sind scheinbar entwicklungspolitische Akteure des Globalen Nordens gemeint. Einerseits scheint David hier die Bundeswehr 
als einen wichtigen Akteur innerhalb der Entwicklungspolitik zu sehen, andererseits betont er immer die höhere Effektivität der gewaltlosen Mittel. In seiner Argumentation taucht hier erneut ein ähnlicher Widerspruch auf: David sagt, die Bundeswehr müsse ,so ein Land dazu bringen, dass es sich selber quasi wieder damit findet“. Mit „sich selber“ wiederfinden rekurriert er in meiner Interpretation auf die Linearität innerhalb der kolonialen Entwicklungsskala, von deren Weg diese Länder abgekommen sind bzw. auf dessen Weg sie hinterherhinken würden.

Das Land oder dessen Regierung sieht er also einerseits als zentralen Akteur an, auf der anderen Seite soll dieser Prozess eine klar vorgesehene Richtung mit klar normativen kulturellen Vorgaben - nehmen, die im Zweifelsfall auch mit militärischen und entwicklungspolitischen Mitteln durch den Globalen Norden erreicht werden soll. Dabei stellen „Europa und Amerika“ - gemeint sind mit letzterem die USA - das Modell, Maßstab und Vorbild dar. Die implizite Botschaft der entwicklungspolitischen Praxis macht David explizit: „In Europa und Amerika haben wir eine funktioniere Demokratie. Guckt euch doch mal ab, so und so läuft das ganz gut bei uns. Probiert das doch auch mal." Neben anderen infrastrukturellen Dingen sollten auch besonders ,gut ausgebildete Lehrer“ hingeschickt werden, damit ,die da vor Ort neue Leute ausbilden, damit die das langfristig selber machen können“. Dabei sollten die entwicklungspolitischen Akteure des Globalen Nordens die Menschen des Globalen Südens ,,nicht lenken“ oder ,denen vorschreiben, was sie zu tun haben“. Stattdessen plädiert er dafür, so lange „Hilfestellungen“, zu geben, bis ,,sie es irgendwann alleine drauf haben und dann selber anderen Ländern helfen können“. David reproduziert hier das Mantra entwicklungspolitischer Diskurse der letzten Jahre, in denen die „Hilfe zur Selbsthilfe" zum zentralen Topos geworden ist. Damit stellt er einerseits Agency für die Menschen in den Ländern des Globalen Südens dar, die letztlich die Veränderungen bzw. die ,Entwicklung' selber vollziehen müssen. Dabei stammen aber sowohl die zentralen Akteure dieser Veränderungen als auch das normative Gerüst aus dem Globalen Norden. Damit erklärt er die Menschen des Globalen Südens so lange zu Akteuren, wie sie im Sinne und auf den Spuren vom Globalen Norden wandeln. Dies führt die zunächst erklärte Agency der Akteure des Globalen Südens ad absurdum. Die Akteure des Globalen Nordens sind und bleiben damit die Urheber des Skripts jeder wirklichen Agency in Davids Sinne und sind gleichzeitig auch in die Umsetzung dieser Entwicklung eingeschrieben, auch wenn David dies eher durch „Tipps“, „Aufklärung“ und Unterstützung statt durch Gewalt realisiert sehen möchte.

Wo er geographisch Agency verortet, zeigt er in der dritten Antwort des letzten Auszugs. Er fände es sinnvoll, dass „Hilfe von außen bei der Aufklärung“ in folgende Regionen käme. Zunächst nennt er „Afrika, Asien. Viele Länder.“ In 
Südamerika seien ,die Länder“ teilweise ,noch sehr , gated community“". Dies erscheint in diesem Kontext als Kontrast zum von ihm weltoffen konstruierten ,Europa'. Ob seine Assoziation von Südamerika und gated communities möglicherweise auf Reiseberichten basiert, ist zwar naheliegend, jedoch spekulativ und nicht von entscheidender Bedeutung, da hier der Effekt für seine Konstruktion von Agency betrachtet wird. Von dieser Einschätzung ,Europas' schließt er aber die „Balkanstaaten“ aus; in dieser „Ecke“ sei es ,,ja auch nicht so besonders gut". Russland sei zwar potenziell auch ein Kandidat dafür, Entwicklungshilfe zu leisten, sei aber „,selber so ein Problemfall“. Mit „Europa“ ist also nicht das geographische Europa gemeint, sondern der Teil, der in der Regel in verbreiteten Diskursen symbolisch mit ,Europa' assoziiert wird, nämlich West- und Mitteleuropa. Insgesamt malt David hier mit überraschender Klarheit ein dichotomes Bild der globalen Geographie der Agency bzw. Subalternität, in der die USA und ,Europa ' den Platz der Agency einnehmen, den die anderen teilweise auch, aber immer nur mit Einschränkungen und Hilfestellungen, einnehmen können.

\subsubsection{Subalterne Positionen III: Geflüchtete}

Dieser Kategorie liegen alle Aussagen der Schüler_innen zugrunde, in denen es um Geflüchtete geht. In der Analyse dieser Aussagen gehe ich der Frage nach, wie Agency bzw. Subalternität von Geflüchteten in den Vorstellungen der Schüler_innen konstruiert wird. Ich werde kurz die Vorstellungswelt zu dem Themenbereich Migration schildern, um die folgende Fragestellung zu Agency zu kontextualisieren.

Insgesamt äußern sich alle Schüler_innen zum Thema Migration und Flucht. Das dominierende Thema sind die Umstände der Flucht über das Mittelmeer. Viele Schüler_innen malen in ihren Darstellungen detailreiche Bilder von vollen Booten und durstigen und leidenden Passagieren. Fast ausnahmslos wird diese Situation von den Schüler_innen aus einer humanistischen Perspektive als moralisch falsch beurteilt. Bereits in der Primärstudie zu Globalisierung hatten wir herausgearbeitet, dass trotz der fast ausnahmslos vorhandenen empathischen Haltung zehn Gymnasiast_innen und vier Hauptschüler_innen in ihrer Argumentation darauf hinweisen, dass es ,faktisch oder potenziell zu viele Migranten und Geflüchtete in Deutschland oder der EU gäbe“ (Fischer et al 2016: 133). Dabei hatten wir eine von Hauptschüler_innen dominierte Gruppe ausgemacht, die in dieser Logik des, zu viele“ argumentiert und davon ausgeht, dass die Grenzen bereits zu offen seien. Aus dieser Perspektive wird die herrschende 
Migrationspolitik kritisiert und konkret die vermeintlichen Gefahren einer möglichen Ausnutzung deutscher Sozialsysteme, eines von Migration bzw. durch Migrant_innen verursachten Arbeitsplatzmangels, einer Steigerung von Kriminalität und des Verlusts der nationalen Identität angeführt. Im Gegensatz zu dieser Gruppe nimmt die von Gymnasiast_innen dominierte Gruppe positiv Bezug auf die ihnen bekannte migrationspolitische Regulierung. Sie legitimieren diese und denken sich dabei in die Position der Repräsentant_innen des deutschen Staates oder EU hinein, mit der sie sich weitgehend identifizieren.

Zwar haben alle Schüler_innen Vorstellungen von den Umständen von Flucht, gleichzeitig sprechen viele Schüler_innen aber keinerlei Aspekte des Grenzregimes an (ebd.: 134). Beispielsweise denken einige Schüler_innen, dass ein Pass oder Geld für ein Ticket ausreiche, um in die EU einzureisen. Sie stellen die vermeintlich offenen Grenzen der EU in den Vordergrund. Nicht benannt wird dabei, dass die Außengrenzen der EU nur für Menschen mit bestimmten Pässen oder großen finanziellen Ressourcen offen sind. Auf diese Weise werden eigene Privilegien durch den Besitz eines deutschen Passes und die damit verbundene globale Bewegungsfreiheit unhinterfragt verallgemeinert, indem davon ausgegangen wird, dass diese Privilegien für alle Menschen Realität wären. Auf diese Weise werden die mit Machtstrukturen und der herrschenden Migrationspolitik verbundenen gesellschaftlichen Kontexte ausgeblendet. Statt dieser gesellschaftspolitischen Ursachen erscheint die Situation von Geflüchteten als durch Naturgewalt verursacht. Diese dominanten Perspektiven werden von einigen kritischen Stimmen durchbrochen, die auf verschiedene Weisen das europäische Migrationsregime kritisieren.

In diesem Kontext von Vorstellungen über Migration gehe ich im Folgenden der Frage nach, wie Agency konstruiert wird. Ausgehend von den Darstellungen der Schüler_innen ko-konstruiere ich implizite Konzepte von Agency und Subalternität von Geflüchteten. In den Vorstellungen zu Flucht ist zunächst festzustellen, dass zwar eine humanistische und mitfühlende Haltung dominant ist, Geflüchtete aber kaum als - tatsächlich oder potenziell - Handelnde vorkommen. Ihnen wird also keine Agency zugeschrieben. In den bildhaften Darstellungen der Geflüchteten in Booten auf dem Mittelmeer erscheinen die Migrant_innen vor allem als Opfer. Eine mögliche Form, in der es um Agency der Geflüchteten geht, ist die Frage nach den Motiven für die Flucht. Viele Schüler_innen führen hier die Flucht vor Unterdrückung oder Armut bzw. ausbeuterischen Arbeitsverhältnissen an. Diese Flucht kann als ein Handeln angesehen werden - als Kampf darum, die eigenen Lebensbedingungen zu verbessern, indem Flüchtende Grenzen überwinden und in wirtschaftlich mit mehr Wohlstand ausgestattete und möglicherweise politisch weniger unterdrückerische Länder des Globalen Nordens migrieren. Dies 
kann auch als eine Abstimmung mit den Füßen gegen globale Ungleichheitsverhältnisse gedeutet werden. Diese Motive können aber andererseits auch in der Logik von Push- und Pull-Faktoren gedacht werden; in diesem Verständnis erschienen Geflüchtete nicht als Handelnde, sondern als Masse, deren Bewegung durch sozio-ökonomische Faktoren auf der makrostrukturellen Ebene bestimmt wird. In den Vorstellungen der Schüler_innen sind beide Facetten präsent, wobei diejenige der Push- und Pull-Faktoren die deutlich dominantere ist. Dabei sind oft beide Facetten innerhalb der Argumentation einer_s Schüler_in präsent. Es ist also eher als ein Spannungsverhältnis denn als klar trennbarer Widerspruch zu verstehen. Mit der Vorstellung der nur passiv auf makrostrukturelle Faktoren reagierenden Geflüchteten korrespondiert auch die Vorstellung von Geflüchteten als zu verwaltende Objekte, die durch migrationspolitische Maßnahmen gesteuert werden. Diese Art der als legitim erscheinenden Verfügungsgewalt durch den Staat ist in den Vorstellungen der Schüler_innen sehr verbreitet.

Im Folgenden möchte ich anhand von sieben Aspekten, die ich exemplarisch in Auszügen von vier Schüler_innen herausarbeite, ausführen, wie Agency von Geflüchteten von einigen Schüler_innen konstruiert wird. Diese heben sich dabei jeweils von der Mehrheitsvorstellung ab - vice versa stelle ich also auch die Subalternisierungsprozesse der mehrheitlichen Vorstellung dar. Mahamadou (Gym04) setzt sich damit auseinander, (1) wie Geflüchtete durch ihre Flucht für ein besseres Leben kämpfen. (2) Des Weiteren stellt er dar, wie die sogenannten Gastarbeiter der ersten Dekaden der BRD diese mitaufgebaut haben. Mark (Gym09) setzt sich mit der (3) Konstruktion von Illegalität durch Grenzregime auseinander. Max (Gym13) berichtet von (4) Strategien von Geflüchteten zur Umgehung des Grenzregimes. Er verschiebt die Perspektive, indem er von Geflüchteten als Handelnden und nicht in erster Linie als Leidenden berichtet. (5) Außerdem stellt er grundsätzlich die Legitimität der Beschränkung der Bewegungsfreiheit von Menschen infrage. Lara (Gym18) spricht als eine von wenigen von (6) Geflüchteten als Träger_innen von Rechten, die auch für diese kämpfen. (7) Des Weiteren stellt sie ein Modell der Subalternisierung von Geflüchteten dar.

\section{1) Kampf für ein besseres Leben}

Mahamadou (Gym04) spricht zunächst über globale Ungleichheit und kommt von diesem Themenkomplex zu Migration.

I: Und wie kommt das dazu, dass das arm ist und die Leute schlecht bezahlt werden?

S: Ähm, also arm denke ich mal, dass die allgemein keine Arbeit haben. Also die haben doch schon Arbeit, aber das sind eher so Arbeiten, die nicht viel einen weiterbringen Geld zu kriegen. Oder das sind so Arbeiten, wie jetzt zum Beispiel, an der Nähmaschine 
zu arbeiten. Das ist auch nicht gerade von jedermann der Traumberuf oder so. Und das gibt es hier auch, aber hier werden die Leute ja viel mehr bezahlt als die, die dort sind. Also ich habe auch wirklich keine Ahnung, wie es dazu kommt, aber auf jeden Fall werden die da schlecht bezahlt.

I: Und - auch wenn das jetzt nicht dein Hauptinteressensgebiet ist - aber hast du eine Idee, wie man das verändern könnte? Wie man das gerechter machen könnte?

S: Ähm (...) was fällt mir dazu ein? Also dazu fällt mir nichts ein. Also ich weiß nicht, vielleicht .../ Natürlich, irgendetwas gibt es da schon bestimmt, was man dagegen machen könnte. Weiß nicht. Also viele Leute, die auch in solchen Regionen leben, gehen ja auch ins Ausland und versuchen es dort. Manchmal ja mit Erfolg und manchmal nicht. Aber, ähm, ich habe auch keine Ahnung .../Vielleicht muss man schon am Anfang was dagegen getan werden oder so.

I: Was ist denn der Anfang?

S: Keine Ahnung [lacht].

I: [lacht] Das war auch eine gemeine Frage [lacht]. Aber, ähm, du sagst manche Leute gehen dann auch von da weg.

S: Ja. (Mahamadou, Gym04)

Mahamadou problematisiert die internationale Lohnungleichheit. So würden „die Leute [hier] ja viel mehr bezahlt als die, die dort sind“. „Hier“ und „,dort“ handelt er vorher an Beispielen ab, in denen ,hier" Deutschland ist und „,dort“" Türkei, Portugal, China und insbesondere Bangladesch. Er sagt, dass er „,keine Ahnung“ habe, wie es zur globalen Lohnungleichheit käme. Angesprochen auf die Frage, wie ,man das verändern könnte“, führt er Migration an. Er nimmt die Perspektive der Leute ein, die ,in solchen Regionen leben“. Diese würden ,ins Ausland“ gehen und „es“ dort versuchen. Er scheint es auch wichtig zu finden, schon etwas gegen die Situation der Lohnungleichheit und Armut zu unternehmen, also von „Anfang“ an, verweist aber auf seine vermeintliche Unwissenheit, worin dieser Anfang besteht. Der Punkt hier ist aber ein anderer. Mahamadou stellt die Migration aus dem Globalen Süden in den Globalen Norden in den Kontext einer Veränderung gesellschaftlicher Verhältnisse. Indem er dabei die Perspektive Geflüchteter einnimmt, hebt er sich von der verbreiteten Position ab, in der die Geflüchteten quasi schicksalhaft in Not geraten und sieht sie stattdessen als Handelnde und die Migration als Handlung an, die zwar innerhalb der globalen Ungleichheitsverhältnisse verortet wird, die Migration jedoch nicht als bloß reagierende Nicht-Handlung angesehen wird, sondern als der Versuch, die individuellen Lebensverhältnisse zu verbessern. 


\section{2) ,Gastarbeiter' als Subjekte}

Nachdem Mahamadou anhand des Beispiels der Migration von Mittelamerikaner_innen in die USA über die Schwierigkeiten der Grenzüberwindung, der Illegalisierung und der Möglichkeit des Aufstrebens vom „Tellerwäscher zum Millionär" gesprochen hatte, stelle ich die Frage des Kontextes Europa.

I: Passiert so was auch hier in Europa? Weißt du da was zu?

S: Ähm, also .../ Europa? Vielleicht so .../ Mittel- und Westeuropa denke ich eher so nicht. Aber vielleicht der Osten oder der Süden so. Denke ich mal. Also, ich weiß das sind eher auch die Regionen .../Zum Beispiel man sagt ja .../ Deutschland ist ja, weiß ja jeder, wirtschaftlich zehnmal besser als Bulgarien. Dass die Leute, ähm, vielleicht vom Osten nach Mitteleuropa wandern. Zum Beispiel es gibt ja auch .../ Vor vierzig Jahren oder so sind ja auch diese ganzen türkischen Einwanderer hierhin gekommen, um Arbeit zu finden. Und manche sind dann, weiß nicht, vielleicht Bandarbeiter geworden bei der Fabrik. Und manche sind dann vielleicht Polizist oder Lehrer geworden. Also, ich denke, dass es das hier so auch gibt.

I: Und, ähm, glaubst du, das hat auch die deutsche Gesellschaft verändert, dass hier viele aus der Türkei hergekommen sind oder aus anderen Ländern?

S: Ahm. Ja, denke ich schon. Weil wenn man sich schon denkt, dass als noch der zweite Weltkrieg war, dass hier alles zerstört wurde. Und dann diese Gastarbeiter, sagt man ja, dass die dann hier so ein neues Land gemacht haben. Dass die geholfen haben, weil die meisten deutschen Männer waren ja gefallen im Krieg. Viele. Und auch viele Frauen, aber eher viele Männer. Und dass dann diese Männer, die aus dem Ausland kommen, dass die Deutschland ... nicht neu gestaltet haben, aber so neu gebaut haben. Und, ja, ich denke schon, dass auch so eine gesellschaftliche Änderung schon da. (Mahamadou, Gym04)

Zunächst fällt mir hier auf, dass er einer der wenigen ist, der Migrationsprozesse aus Ost- oder Südosteuropa nach Mitteleuropa anspricht und diese in eine Tradition mit der Migration der sogenannten Gastarbeiter setzt. Er benennt die Ungleichheit zwischen Deutschland und Bulgarien als Beispiel für gegenwärtige Arbeitsmigrationsprozesse. Dies vergleicht er im Folgenden mit der Migration der sogenannten Gastarbeiter. Anders als in dominanten Vorstellungen - ob in den Medien oder bei den anderen Schüler_innen - spricht er nicht davon, dass die Gastarbeiter geholt wurden. Vielmehr seien die ,türkischen Einwanderer hierhin gekommen, um Arbeit zu finden." Innerhalb der sogenannten Gastarbeitermigration erkennt er also die Agency der Gastarbeiter an, was im Umkehrschluss nicht bedeuten muss, dass dadurch Anwerbeprogramme ignoriert werden würden. Es sind also wiederum beide Dimensionen präsent: Die der strukturellen Ungleichheit als Kontext für Migration und die Migrierenden als darin Handelnde. Auf die Frage, ob die Migration der 
sogenannten Gastarbeiter die Gesellschaft verändert habe, beschreibt Mahamadou seine Sicht auf ihre Rolle in der Nachkriegsgesellschaft der BRD. Diese hätten „,hier so ein neues Land gemacht“, da ja ,,alles zerstört“ war und „,die meisten deutschen Männer" und ,,auch viele Frauen [...] gefallen“ waren. Die sogenannten Gastarbeiter hätten dann „,Deutschland [...] neu gebaut“. Er schreibt so den sogenannten Gastarbeitern einen fundamentalen Anteil an der wirtschaftlichen und gesellschaftlichen Entwicklung in der Nachkriegs-BRD zu. Implizit betrifft dies dann auch gegenwärtige Arbeitsmigration, wie zum Beispiel aus Bulgarien. Diese Anerkennung des Beitrags der migrantischen Arbeiter_innen an der wirtschaftlichen Entwicklung in Deutschland kann auch als eine Form der Anerkennung von Agency gesehen werden. Hier werden die migrantischen Arbeiter_innen nicht in erster Linie als Bittsteller_innen, Empfänger_innen von Wohltätigkeit oder Problem gesehen, sondern vielmehr als Beitragende zur gesellschaftlichen Produktivität.

\section{3) Konstruktion von Illegalität durchs Grenzregime}

Mark (Gym09) denkt bei Globalisierung an Migration. Dabei thematisiert er Illegalisierungsprozesse durch das Grenzregime.

I: Mhm. Und wenn du jetzt Globalisierung hörst, fällt dir da noch was anderes zu ein als Kolonisierung?

S: Also so direkt eigentlich nicht. Weil Globalisierung ist ja der Globus, die ganze Welt. Und Globalisierung ist dann, wenn die Menschen dann um die ganze Welt reisen, besiedeln und dort leben. Also mehr fällt mir eigentlich dazu nicht ein.

I: Mhm. Und, ähm, gibt es heute auch noch so was wie Globalisierung?

S: Ähm, ich glaube indirekt. Zum Beispiel in Afrika, da leben ja die meisten Menschen in armen Umständen. Da wollen die gerne nach Europa, weil sie es so toll finden und es dort auch Arbeit gibt. Deswegen versuchen sie auch, meist illegal auch über das Mittelmeer zu kommen. Oder mit dem Flugzeug oder wie auch immer. Oder aus Mexiko zum Beispiel wollten auch viele nach Amerika kommen und dort Arbeit finden. Und sind dann meist über die Grenze dann gegangen. (Mark, Gym09)

Mark diskutiert das Thema Migration an den Beispielen der Migration aus Afrika nach „Europa“ und aus Mexiko nach „Amerika“. Da in Afrika „,die meisten Menschen in armen Umständen“ leben würden, würden ,die gerne nach Europa, weil sie es so toll finden und es dort auch Arbeit gibt". Um ihre Lebenssituation zu verbessern, würden sie dann übers Mittelmeer kommen, mit dem Flugzeug fliegen oder über die Grenze gehen. Dies würden sie ,auch meist illegal“ tun. Hier erscheint die Illegalität der Grenzübertretung als besondere Schwierigkeit, die implizit auf die Entschlossenheit der Migrant_innen zu verweisen scheint. 


\section{I: Und was denkst du dazu?}

S: Ja, also die meisten waren ja illegal. Aber manche hätten vielleicht auch das Recht darauf, Arbeit zu finden, Arbeit zu haben. Es ist ja vielleicht im Grundgesetz so festgeschrieben, dass man das Recht auf Arbeit und Bildung hat. Und, ja, es wäre schon besser, wenn mehr Menschen in die reicheren Länder kommen dürfen, anstatt illegal meist vielleicht auch gar keine Arbeit zu finden. Oder sogar zu sterben. Das wäre dann nicht so toll für die Menschheit.

I: Und wieso sind die illegal?

S: Ja, weil sie einfach über die Grenze rüber wollen. Und nicht irgendwie einen Pass oder so was vorzeigen, um dadurch zu kommen. Wobei das auch ganz schwer ist, da eine Erlaubnis dafür zu kriegen, weil da schon so viele Immigranten in den USA, oder wo auch immer, schon sind. Und deswegen wollen sie auch illegal rüber, um nicht irgendwie den Pass zu zeigen oder vielleicht auch noch viel Geld zu bezahlen, obwohl sie gar kein Geld haben.

I: Mhm.

S: Und vielleicht ist auch deren Familie auf der anderen Seite. Dass die gut leben und man selber vielleicht schlecht. Und man möchte die Familie vielleicht wieder besuchen und dort eine Arbeit finden, um mit ihnen wieder zu leben.

I: Und was passiert dann mit den Leuten, wenn die illegal sind?

S: Also, ähm, während des Grenzübergangs werden schon einige getötet. Zum Beispiel vielleicht durch Verdursten oder sie werden erschossen. Die, die es schaffen illegal zu leben, müssen dann gefährlich leben, weil sie vielleicht entdeckt werden können und wieder zurück in ihre Heimat geschickt werden. Wenn sie eine Arbeit gefunden haben und vielleicht auch ihre Familie wiedergefunden haben und dort wieder leben wollen und dann kommt die Regierung und sagt: „Sie dürfen nicht mehr in diesem Land sein und müssen wieder zurück in ihre Heimat.“ (Mark, Gym09)

Mark unterstreicht hier nochmal das Attribut der Entschlossenheit der Migrant_innen, die trotz fehlender Erlaubnis und der Gefahren die Grenze überqueren, weil ,sie einfach über die Grenze rüber wollen“. Dafür nähmen sie auch Gefahren in Kauf, beim Grenzübertritt „,getötet“ bzw. ,erschossen“ zu werden oder zu ,,verdursten“. Nach dem Grenzübertritt müssten sie dann ,,illegal“ leben, da sie der ständigen Gefahr ausgesetzt sind, ,,vielleicht entdeckt“ zu werden und ,,wieder zurück in ihre Heimat geschickt zu werden“. Diese Gefahren nähmen die Flüchtenden aufgrund ihrer Entschlossenheit der Verbesserung ihrer Lebensumstände in Kauf.

Die Flüchtenden überqueren die Grenze ,,illegal“, weil sie keinen „Pass oder sowas vorzeigen“" wollen, nicht bereit sind, ,,viel Geld zu bezahlen, obwohl sie gar kein Geld haben“ und keine Erlaubnis erfragen wollen, weil es ,ganz schwer ist, 
da eine Erlaubnis für zu kriegen“. Dieser ,illegal[e]“ Grenzübertritt erscheint dabei bei Mark als Handlung, als bewusstes Widersetzen gegen die herrschenden Regeln des Grenzregimes. Anders als bei vielen anderen Schüler_innen, die zwar ebenso nachvollziehbare Motive von Geflüchteten nennen, die Gefahren des Grenzübertritts aber auf quasi natürliche Ursachen zurückführen, führt Mark die staatlichen Regelungen als ursächlich an, die er mit dem Prozess der Illegalisierung von Migration umschreibt. Anders als viele andere Schüler_innen stellt Mark den Vorgang des Grenzübertritts als Handlung der Geflüchteten dar, die den Prozess der Illegalisierung und die damit verbundenen Gefahren auf sich nähmen und mit den staatlichen Regelungen aktiv brechen würden.

Die Illegalisierung erscheint so nicht als Normalität, sondern als Problem. Dem setzt er vorsichtig entgegen, dass ,,manche [...] vielleicht auch das Recht darauf [hätten] Arbeit zu finden, Arbeit zu haben“. Dies sei ,ja vielleicht im Grundgesetz so festgeschrieben, dass man das Recht auf Arbeit und Bildung" habe. Er fände es ,schon besser, wenn mehr Menschen in die reicheren Länder kommen dürfen“, anstatt „,keine Arbeit zu finden [...] oder sogar zu sterben“. Das wäre aus seiner Sicht ,nicht so toll für die Menschheit“. Mark formuliert hier eine humanistische begründete Kritik an der Illegalisierung von Migration bzw. den Migrant_innen selbst. Es findet sich zwar im Grundgesetz weder ein Recht auf Arbeit noch eines auf Bildung, letzteres aber zumindest in den Menschenrechten (Artikel 26). Es geht an dieser Stelle aber nicht um die Überprüfung des juristischen Wissens der Schüler_innen. Was er damit zum Ausdruck bringt, ist ein fundamentales Problem bezüglich der Grund- und Menschenrechte, das in seinem ,,man“ kulminiert. Sowohl Menschenrechte als auch das Grundgesetz erscheinen als universelle Rechtsnormen, die für alle Menschen gleich gelten. Mark verweist aber hier darauf, dass sie tatsächlich nur für einige gelten, da sie an Staatsbürgerschaften geknüpft sind. Indem Mark hier die Idee formuliert, Flüchtenden das Grundrecht auf Arbeit und Bildung zuzusprechen, kommt die Kolonialität im Widerspruch des vorgeblich universellen und tatsächlich partikularen und exkludierenden liberalen Menschenrechtverständnis zum Vorschein. Mit seinem Vorschlag unterläuft er fundamentale Prämissen des dominanten Diskurses über Flucht und Migration.

I: Und weißt du was über die Menschen, die über das Mittelmeer kommen? Das hast du ja auch erzählt.

S: Mhm. Ja, die kommen halt eigentlich auch illegal, weil sie dann auf Schiffen zusammen über das Mittelmeer fahren wollen. Das ist dann ein bisschen umständlich, weil sie auf kleinen Booten, aber mit vielen Menschen, dann zusammengeengt auf das Schiff kommen. Und meistens überleben nur die Hälfte oder ein Drittel von denen. Also nicht alle kommen dann rüber. Und selbst wenn man dann rüber gekommen ist, wird 
man dann von der Behörde dort abgefangen. Meist Italien oder Spanien, weil sie ja an der Mittelmeerküste sind. Und die könnten sie auch vielleicht wieder zurückschicken. Und, ja.

I: Mhm. Und was bedeutet das für die Menschen? Hast du eine Idee?

S: Also die, die über das Mittelmeer kommen, haben schon Schwierigkeiten überhaupt über das Mittelmeer zu gelangen. Und dann noch irgendwie von den Behörden den Aufenthalt zu bekommen ist schon schwer. Und, ähm, ich glaube nicht, dass sie wieder zurück wollen. Weil sie sind überhaupt erst aus dem Grund gekommen, dass dort Kriege zum Beispiel sind. Oder weil sie nicht genug zu essen oder zu trinken haben. Oder, wie ich schon gesagt habe, wenn ihre Familie schon in Italien oder Spanien oder in Europa sich gut eingelebt hat und man nachfolgen will. Dann ist es schwer, wieder zurück zu gehen. Und man möchte auch wieder an einem richtigen Leben teilhaben. (Mark, Gym09)

Hier wiederholt er hauptsächlich Argumente, die er vorher schon vorgebracht hatte. Er verweist auf die nachvollziehbaren Motive der Flucht: „Krieg“, zu wenig „,zu essen und zu trinken“ oder die Zusammenführung mit der „Familie“, die sich „in Europa [...] gut eingelebt hat“. Er benennt noch die Schwierigkeiten, die nach der Flucht dadurch entstehen, dass die „Behörde“ Geflüchtete abfangen und diese „,wieder zurückschicken“ könnten, obwohl man ,an einem richtigen Leben teilhaben“ möchte. In seiner Art darüber zu sprechen machen beispielsweise Verben wie ,wollen“ und „möchten“ deutlich, dass er sich Geflüchtete als Menschen vorstellt, die ständig Entscheidungen treffen und Gefahren überwinden, um ihre Ziele zu erreichen. In seiner Erzählung über die Menschen, die ,zusammen über das Mittelmeer fahren wollen“, schildert Mark die Gefahren. Die Fahrt ,mit vielen Menschen [...] zusammengeengt“ würden nicht alle überleben. „Meistens überleben nur die Hälfte oder ein Drittel von denen“. Diese Aussage zum massenhaften Sterben im Mittelmeer trägt in meiner Perspektive eine Ambivalenz in sich. Die Aussage thematisiert auf zwei sich widersprechende Weisen die Kolonialität der Wertigkeit des Lebens. (1) Die Art und Weise, wie er auf das massenhafte Sterben hinweist erscheint wie nebenbei. Tausende sterben und Mark erwähnt mit keiner Silbe ein Gefühl des Entsetzens oder der Trauer darüber. Ein solcher Umgang wäre kaum vorstellbar, wenn es sich um Europäer_innen oder US-Amerikaner_innen handeln würde, die beispielsweise einem Attentat zum Opfer fallen oder durch eine Naturkatastrophe umkämen. Dieses beiläufige Erwähnen des massenhaften Todes von Geflüchteten tritt häufig in den Darstellungen der Schüler_innen auf. Während in einem Fall eine Masse, Körper sterben, sind es im anderen Fall Menschen. (2) Womit sich Mark aber stark von vielen anderen Aussagen von Schüler_innen zum Sterben von Geflüchteten abhebt, ist der Kontext, in den er sie stellt. So problematisiert er - wie oben gezeigt - den 
Prozess der Illegalisierung der Migration bzw. der Migrant_innen. Vor diesem Hintergrund kann seine Benennung des Sterbens auch als Anklage des Grenzregimes gelesen werden: Aus Sterben wird Mord, Totschlag oder zumindest unterlassene Hilfeleistung. Das EUropäische Grenzregime und die damit verbundene Illegalisierung erscheinen hier als ursächlich für den Tod der vielen Flüchtenden im Mittelmeer. Mit dieser Interpretation von Marks Sprechen über das Sterben von Geflüchteten erscheint das EUropäische Grenzregime ebenfalls als ursächlich für die Kolonialität der Wertigkeit des Lebens.

Sehr viel später im Verlauf des Interviews erzählt Mark etwas über seine eigenen familienbiographischen Hintergründe, in denen Flucht eine Rolle spielt.

I: Was auch immer? Zum Beispiel mit Import/Export-Geschichten, die du mitkriegst. Oder mit Freunden die du kennst, die zum Beispiel Schwierigkeiten hatten nach Europa zu kommen? Oder irgendwie so was.

S: Ach so. Ja, ähm, eigentlich nicht so. Ich weiß grad' nur so von meiner Mutter, weil sie durch die Kriege .../ Also sie lebte in Vietnam. Und durch die Kriege dort musste sie dann aus ihrem Land raus, weil es da zu gefährlich wurde. Ihre Familie musste sie leider da zurücklassen, weil sie entweder zu alt waren oder keine Kraft mehr hatten. Oder überhaupt nicht das Geld hatten oder die Chance hatten, die Flucht zu ergreifen. Dann musste meine Mutter über den halben Kontinent, also über ganz Asien, rüber. Dann nach Russland, Ukraine. Dort musste sie kurz arbeiten, um überhaupt ihre Reise weiterzuführen und einen richtigen Ort zu finden. Also um ein wenig Geld zu bekommen, um zu überleben. Und dann irgendwann hat sie es nach Deutschland geschafft und dort einen guten Job gefunden. Ja, was heißt hier gut? Also zumindest konnte man davon leben. Und dann, ähm, hat sie sich einen festen Platz hier in Deutschland gesichert. Vielleicht haben die Eltern dort mehr Probleme gehabt und konnten sie halt nicht versorgen. Aber sie selbst konnte sich dann retten. (Mark, Gym09)

Marks Sensibilität für die Agency von Geflüchteten, die nicht nur als Opfer ihrer oft schwierigen Umstände gesehen werden, steht mit großer Wahrscheinlichkeit in einem Zusammenhang zu seinem familienbiographisch begründeten Wissen, das aus der Fluchterfahrung seiner Mutter resultiert. Einen solchen Zusammenhang konnte ich öfter feststellen. Dieser Zusammenhang ist jedoch nicht als Automatismus zu begreifen. Es gibt auch Gegenbeispiele, in denen Schüler_innen mit familienbiographischen Flucht- oder Migrationserfahrungen keine höhere Sensibilität für die damit verbundenen Formen von Machtverhältnissen aufweisen. Die Subjektposition bedingt also weder Haltung noch Wissen, kann aber sehr wohl einen Einfluss darauf haben. Anders herum ist aber zu vermuten, dass die mit der familienbiographischen Flucht- und Migrationserfahrung verbundenen Wissensformen in schulischen Lernumgebungen möglicherweise selten Wertschätzung erfahren. 


\section{4) Strategien von Geflüchteten zur Umgehung des Grenzregimes}

Auch Max (Gym13) ist durch familienbiographische Fluchterfahrungen beeinflusst. Er spricht zunächst ausführlich über mögliche Gründe für Flucht und Migration. Hier benennt er insbesondere fehlendes staatliches Fürsorgesystem und politische Verfolgung. Dabei bringt er die Fluchtgeschichte seines Vaters ins Spiel. Als ich eine damit verbundene Fragen stelle, bietet er an, von dieser Geschichte einige Dinge zu erzählen.

S: Okay. Ähm, dann soll ich jetzt die Geschichte erzählen? Oder was ist besser?

I: Mich würde das interessieren.

S: Okay, ähm, der ist als erstes nach Griechenland gefahren - mit so einem Boot halt, wie man das halt kennt - und wurde direkt zurück deportiert.

I: Mhm.

S: Ich habe nicht verstanden wieso, die haben auch keinen Grund genannt. Dann ist er in die Niederlande geflogen. Ich weiß nicht wie, das hat er nicht gesagt. Aber dann hat er halt, ähm, viel Geld bekommen von seinem Onkel. Und, ähm, er hat sich halt einen Pass gekauft, blaue Kontaktlinsen und sich halt blonde Haare gemacht. Und wollte halt von den Niederlanden nach Deutschland. Die haben ihn gefragt, wo er herkommt und er hat gesagt Niederlande. Und, ähm, die haben ihn halt sofort danach gefragt, ob er ein Buch vorlesen kann. Das war halt Niederländisch und das konnte er nicht. Dann wurde er halt wieder deportiert.

I: Zum zweiten Mal?

S: Ja.

I: Krass.

S: Dann hat er es noch mal versucht und ist über die Türkei zu Fuß oder mit dem Fahrrad - ich weiß es nicht, ich fand das aber echt krass - komplett nach Deutschland gefahren/gegangen.

I: Krass.

S: Ja. (Max, Gym13)

Zunächst macht Max hier die Schwierigkeiten deutlich, mit denen Flüchtende angesichts des EUropäischen Grenzregimes konfrontiert sind. Gleichzeitig stellt Max aber auch heraus, mit wieviel Entschlossenheit und Kreativität Flüchtende ihre Ziele verfolgen. Sein Vater probierte drei Mal, aus dem Iran nach Deutschland zu flüchten und es gelang ihm nach zwei gescheiterten Versuchen. Doch auch in Max Darstellung der gescheiterten Versuche macht er die Variabilität der Strategien Geflüchteter deutlich. Sein erster Versuch sei eine Fahrt - ,wie man das halt kennt“ - mit einem 
Boot nach Griechenland gewesen. Bei seinem zweiten Versuch habe er versucht, den Grenzübertritt zwischen den Niederlanden und Deutschland durch einen gefälschten Pass und eine Verkleidung bestehend aus blauen Kontaktlinsen und blonden Haaren zu realisieren. Bei seinem dritten, erfolgreichen Versuch habe er den Landweg genommen. Das fand er, ,echt krass“. Daraus spricht eine Form der Bewunderung für die Fluchtgeschichte seines Vaters. Durch diese Darstellung der Flucht und der Herausstellung der besonderen Strategien der Umgehung des Grenzregimes erscheint sein Vater als beispielhafte Figur der_s Geflüchteten weder als Teil einer gesichtslosen Masse, noch als bloß auf Push- und Pull-Faktoren reagierender Leidender, sondern als Subjekt, das sein eigenes Leben durch die Umgehung des Grenzregimes in die Hand nimmt. Trotz der Benennung des Leids durch die Verfolgung, die zermürbenden Fluchtwege, das Scheitern und die folgenden Abschiebungen erscheint sein Vater als über Agency verfügend; er erscheint als Subjekt.

\section{5) Recht auf Bewegungsfreiheit}

Aus der Geschichte seines Vaters leitet sich für Max ein politisch-ethisches Urteil über das Grenzregime ab.

I: Und was denkst du dann, wenn du so die Geschichte von deinem Vater hörst? Dass jemand aus politischer Verfolgung flieht, weil er politisch verfolgt wurde, und dann so was erlebt? Also dass er zurückgeschickt wird aus den Niederlanden. Wie findest du das?

S: Echt kacke, ne. Weil man kann ihn ja einfach ins Land lassen, das ist ja nicht so schwer.

I: Ja.

S: Ich meine die Welt, die Erde ist ja auch kein Eigentum oder so was. Weil wenn .../ Ich meine, wo soll er denn hin? Er muss doch irgendwas machen, weil im Iran würde er sonst sterben. Und, ähm, in Deutschland wollen die ihm nicht helfen anscheinend. Also wollten die ihm nicht helfen. (Max, Gym13)

Das Grenzregime, das für die Schwierigkeiten seines Vaters verantwortlich war, findet er ,echt kacke“. Max findet, dass , die Erde [...] ja auch kein Eigentum oder so was" sei. Damit stellt er grundlegend die Begrenzung der Bewegungsfreiheit von Menschen und Grenzregime im Allgemeinen infrage. Er untergräbt das als natürlich erscheinende Recht der Souveränität des Nationalstaats über die Bewegung der Menschen und plädiert implizit für globale Bewegungsfreiheit für alle, da die „Erde“ für Max ,kein Eigentum“ sei. Der durch die Beschränkung der Bewegungsfreiheit entstehenden Ungerechtigkeit stellt er die ausweglose Situation seines Vaters 
gegenüber, der „,sonst sterben“ würde. Er vermutet, dass „die“ ihm ,in Deutschland“ nicht helfen wollten. Mit ,die“ meint er vermutlich die verantwortlichen staatlichen Institutionen und möglicherweise auch das politische Klima.

\section{6) Geflüchtete als Träger_innen von Rechten}

Als eine von wenigen - mit ihr sind es drei - spricht Lara (Gym18) von Geflüchteten als Träger_innen von Rechten. Diese kämpften Lara zufolge selber für deren Umsetzung. Außer diesem Punkt möchte ich anschließend Laras Modell der Subalternisierung von Geflüchteten darstellen.

I: Reisen. Auswandern. Migrieren. Was auch immer.

S: Also ich glaube migrieren in andere Länder, also in Europa, ist sehr schwer. Also ich hab' halt auch letztens .../ Ähm, in Hamburg oder so gab es irgendwelche Proteste von, ähm, Menschen im Asyl waren, ne? Also die .../

I: Asylbewerber?

S: Ja. Ähm, die meinten halt, dass es sehr unmenschlich sogar ist in den Asylheimen in Deutschland. Also ich weiß jetzt nicht genau, wie es da ist. Aber ich hab' halt .../ Das waren welche aus Afrika, Nordafrika und .../ Ja, so Nordafrika, weil man da ja sehr schnell über Spanien oder so nach Europa kommt, ne?

I: Mhm.

S: Und die meinten halt, es wird immer versucht sie wegzuschicken. Sie werden in sehr enge Heimen oder so gebracht und so. Und, ähm, in Spanien vor allem ist es .../ Wer nicht rüberkommt .../ Man versucht sie aufzuhalten, ähm, ans Ufer zu kommen oder über so eine Mauer oder so.

I: Mhm.

S: Und wenn sie es aber schaffen, werden sie meistens direkt wieder zurückgeschickt. Und es gab irgendeinen Fall, das hatten wir im Spanischunterricht, da hat man die Menschen, die da waren, erstmal eine Weile dort gelassen. Und dann hat man sie in ein Flugzeug gesteckt und, ähm, irgendwo mitten in Afrika in der Wüste oder so ausgesetzt, wo sie verhungert oder verdurstet sind.

I: Mhm.

S: Ja. (Lara, Gym18)

Auf das Thema Migration angesprochen assoziiert Lara „Proteste“ von Menschen, die ,,im Asyl“ waren. Damit ist sie die einzige, die Proteste von Geflüchteten nennt. Vermutlich referiert sie hier auf die Proteste, die unter dem Schlagwort, Lampedusa in Hamburg' bekannt wurden. Ohne hier auf die spezifischen Probleme der von den 
sogenannten Dublin-Gesetzen Betroffenen einzugehen, thematisiert sie rund um die Proteste zahlreiche mit dem Themenkomplex von Flucht und Asyl verbundene Aspekte. Zunächst führt sie das Thema der Unterbringung von Asylsuchenden in Heimen in Deutschland als Grund für die Proteste an. Die Unterbringung in den „Asylheimen in Deutschland“ sei ,unmenschlich“ und die Menschen würden in „sehr enge Heime oder so gebracht“. Ebenfalls, ab ihrer ersten Antwort zu diesem Themenkomplex, benennt sie aber auch die Flucht selbst als problematisch und nimmt dabei explizit die Perspektive der Flüchtenden und nicht die staatlicher Institutionen ein. So glaubt sie, dass ,migrieren in andere Länder, also in Europa, [...] sehr schwer" sei. „Man“ versuche die Flüchtenden ,,aufzuhalten“, also bei der Überquerung des Mittelmeers ,, ans Ufer zu kommen“. Sie spricht auch ,eine Mauer“ als Hindernis an; vermutlich sind damit die Zäune in Ceuta und Melilla gemeint, die mit zahlreichen Toten in den letzten Jahren immer wieder mediale Präsenz erfahren haben. Zum Dritten thematisiert sie die Abschiebepolitik, die Flüchtende wieder zurückschickt. Sie schildert die teils drastischen Konsequenzen für die Flüchtenden, die in einigen Fällen zurückgeschickt wurden und dann, ,irgendwo mitten in Afrika in der Wüste oder so ausgesetzt“" worden seien, ,wo sie verhungert und verdurstet" seien. Dadurch, dass sie alles in einen Kontext mit den Protesten in Hamburg stellt, erscheinen diese Darstellungen des Leids in einem anderen Kontext, da die Flüchtenden so nicht nur als Opfer erscheinen.

I: Und was denkst du, wenn du so was hörst?

S: Also ich denke, dass das sehr gemein ist. Also ich meine, es ist unmenschlich vor allem. Natürlich ist das blöd, wenn zu viele Menschen kommen und man halt keinen Platz hat oder so. Aber ich denke mal, ein bisschen Platz hat man hier. Und man sollte denen vielleicht .../

[Unterbrechung/Person betritt den Raum]

I: Also ein bisschen Platz ist da? Und dann sollte man damit auch .../

S: Ja. Oder man sollte irgendwie versuchen denen zu helfen, mal wieder auf die Beine zu kommen. Und denen irgendwo Kontakt zu deren Heimat zu suchen und so, vielleicht dort gucken. Oder halt, es gibt noch andere Länder, ich glaub' Australien oder so, wo es total leer ist. Da kann man versuchen vielleicht irgendwas zu machen und so. Weil ich find', so zu tun als würden sie nicht zu einem gehören, weil sie aus einem anderen Land sind, ist ja ziemlich unfair. Weil es sind ja genauso gut Menschen. Und man könnte vielleicht versuchen, denen irgendwie zu helfen und so. Finde ich.

I: Mhm. Und, ähm, wieso wird das dann so gemacht? Dass einfach jetzt die Leute dann irgendwie abgeschoben werden. Also aus Spanien zum Beispiel mit dem Flugzeug in die Wüste, aber insgesamt ja auch. Wieso passiert das so? 
S: Also jetzt speziell in Europa passiert das glaube ich einfach wegen dem Ansehen auch ein bisschen. Man möchte nicht zu viele arme Menschen haben. Und, na ja, man hat genug eigene Probleme. Und möchte halt nicht noch so andere Menschen, die einen stören. [...] (Lara, Gym18)

Sie verurteilt das Vorgehen gegen Asylsuchende. Dies sei „sehr gemein“ und „unmenschlich“. Sie diskutiert im Folgenden gegen Argumente von Befürworter_innen der Migrationsabwehr, indem sie sagt, dass das Argument des fehlenden Platzes nicht überzeugend sei. Dafür denkt sie sich in die Position der migrationsregulierenden Institutionen hinein und führt aus, dass erstens ,ein bisschen Platz“ vorhanden sei, zweitens den Flüchtenden zumindest geholfen werden müsste, zum Beispiel, indem ihnen in ihrer „Heimat“ Perspektiven eröffnet werden müssten oder drittens doch auch ,andere Länder“ da seien, in denen es genügend Platz gäbe. Hier führt sie Australien an, „wo es total leer“ sei. Diese Vorstellung ehemals kolonisierter Länder als „total leer“ steht dabei in einer gewissen kolonialen Tradition. Gleichzeitig erscheinen Asylsuchende in diesen Argumenten wieder als zu administrierende Masse, die durch migrationsregulierende Behörden einfach an einen anderen Ort gebracht werden könnten, wenn es denn der migrationsregulierenden Ordnung diene. Letztlich scheint sie aber damit nur Gegenargumente entkräften zu wollen, um für den Rechtsanspruch von Asylsuchenden und den universellen Gleichheitsanspruch aller Menschen zu plädieren. Sie findet es nämlich ,ziemlich unfair“, so „zu tun als würden sie nicht zu einem gehören, weil sie aus einem anderen Land sind“. Asylsuchende seien „genauso gut Menschen“. Dies führt für Lara zu der Verpflichtung, ,denen irgendwie zu helfen“. Andersherum sagt sie damit offensichtlich, dass die herrschende Migrationspolitik die Menschenrechte von Asylsuchenden missachte.

Den Grund für die Migrationsabwehr vermutet sie neben der Annahme eines Platzmangels in der sinkenden Reputation, die durch die Anwesenheit von ,zu viele[n] arme[n] Menschen“ verursacht würde. Dieses Motiv, der Verteidigung des eigenen ökonomischen Wohlstands gegen Menschen, die nicht daran teilhaben, sowie die Privilegierung ökonomischer Kriterien über ethische findet sich an vielen Stellen im Interview mit Lara.

I: Aber jetzt zum Beispiel diese Leute, wo du gesagt hast, die in Hamburg sind. Die dagegen demonstrieren, dass sie immer Angst haben müssen abgeschoben zu werden. Dass sie unter ganz schlechten Bedingungen in so Heimen wohnen. Wer entscheidet denn dann, dass die nicht das Recht haben hier zu sein?

S: Also eigentlich steht ja in den Grundrechten, dass, ähm, man das Recht - also ein politisch verfolgter Mensch das Recht hat - Asyl zu beantragen und in Deutschland 
zu bleiben. Aber dadurch, dass man sie nicht unbedingt da haben will, einfach weil man nicht viele arme Menschen einfach in Deutschland haben möchte. Oder ich weiß nicht, aus irgendeinem Grund sagt man dann: „Okay. Wir glauben dir jetzt nicht, dass du politisch verfolgt wirst, weil wir keine Beweise haben." Sie fliehen ja, lassen alles dort. Und meistens haben sie jetzt nicht direkt irgendwas, was beweist, dass sie verfolgt werden. Und manche werden vielleicht nicht direkt politisch verfolgt, sind aber geflohen, weil sie zu sehr in Armut leben oder so. Und die können halt auch nicht sagen, also können nicht beweisen, dass sie irgendwie verfolgt werden.

I: Mhm.

S: Also .../ Ja. (Lara, Gym18)

Sie macht hier auf eine Diskrepanz zwischen - de jure - gesetzlichen Grundrechten und - de facto - ihrer (Nicht-)Umsetzung bzw. Umgehung aufmerksam, die so nur von ihr benannt wird. So habe „man das Recht“, also ,ein politisch verfolgter Mensch“ habe „das Recht" Asyl zu beantragen und in Deutschland zu bleiben. Da aber der politische Wille ein anderer sei, da „man nicht viele arme Menschen einfach in Deutschland haben möchte“, würde die Anerkennung der asylrelevanten Fluchtgründe dermaßen erschwert, dass de facto das Recht auf Asyl nicht existiere. Dabei denkt sie sich wiederum in die Perspektive von Geflüchteten hinein: „Sie fliehen ja, lassen alles dort.“ Deswegen hätten sie oft „keine Beweise“ für ihre politische Verfolgung. Des Weiteren kritisiert sie die Aufteilung in politische und ökonomische Fluchtgründe. So seien manche Asylsuchende ,vielleicht nicht direkt politisch verfolgt“, seien aber geflohen, weil „sie zu sehr in Armut leben oder so“.

Indem Lara die Asylsuchenden als Träger_innen von allgemeinen Menschenrechten sowie von bundesdeutschen Gesetzen benennt, hebt sich ihr Bild von Geflüchteten von der großen Mehrheit der anderen Schüler_innen ab. Für Lara sind nicht migrationsregulierende Überlegungen und auch nicht allgemeine humanistische Überzeugungsbekundungen ausschlaggebend, die den Geflüchteten mehr Mildtätigkeit wünschen würden. Es geht Lara um die Missachtung von Rechtsansprüchen qua Menschsein der Geflüchteten, die durch das EUropäische Grenzregime begangen würden. Vice Versa erscheinen die Geflüchteten nicht als potenzielle Empfänger_innen von Mildtätigkeit, sondern vielmehr als Menschen, die um ihren ihnen zustehenden Rechtsanspruch auf Menschenwürde und Asyl kämpfen. Dies sehe ich als eine spezifische Form von Agency an.

\section{7) Subalterne Stimmen}

Diese Form von Agency von Geflüchteten, in denen Asylsuchende als Träger_innen von Rechten und Subjekte ihrer Durchsetzung erscheinen, ergänzt Lara mit Überlegungen, in denen ich ein Modell von Subalternität sehe. 
I: Und nochmal ganz kurz zurück zu dem Protest, was du da in Hamburg erzählt hast. Wie könnten die sich denn .../ Wie könnten die denn dafür sorgen, dass der deutsche Staat denen zuhört? Oder, ja, warum wird das nicht ernstgenommen?

S: Ja, also die werden ja teilweise auch gar nicht mal als deutsche Bürger angesehen. Obwohl beim Protest waren auch deutsche Staatsbürger da. Aber die waren halt auch nicht gerade die Reichen der Gesellschaft und die Hohen. Und dadurch interessiert das dann den Staat sicherlich gar nicht, was die denken. Wenn man es irgendwie schaffen würde, gerade die deutschen Bürger, die dafür sind - für diese Asylsache da - sich eine Meinung zu bilden und klug oder intelligent ... also irgendwas in der Schule zu erreichen und dann in eine hohe Position zu kommen, dann könnte man das vielleicht versuchen. Und .../ Ja.

I: Mhm. Und das heißt der Staat hört nicht auf Leute, die nicht reich sind? Würdest du das sagen?

S: Ich denke, ja. Jetzt nicht direkt „nicht reich“. Einfach Menschen, die nicht grad die obere Schicht des Landes ausmachen. Weil die nicht wichtig sind im Prinzip. Die werden wahrscheinlich eher so als Last angesehen.

I: Mhm. Und, ähm, siehst du noch einen anderen Grund, warum vielleicht diese Asylbewerber und Asylbewerberinnen, warum die nicht ernst genommen werden? Du hast gesagt eben, die sind keine deutschen Staatsbürger?

S: Ja, man denkt wahrscheinlich eher von denen, dass die wenig Bildung haben. Was teilweise sicherlich auch zutrifft, weil die ja keine Möglichkeit hatten. Und wenn die vielleicht .../ Das ist natürlich sehr schwer, von einem Moment auf den nächsten irgendwie viel zu lernen oder so. Aber die können irgendwie versuchen - keine Ahnung, durch Lesen, Zeitung Lesen und irgendwelche Bücher in Deutschland und so - zu gucken, auch gesetzlich und so, wie Deutschland ist. Und, ähm, dann halt mit den Rechten und so entscheiden. Sie haben so gesehen ja das Recht, durch diese Menschenrechte oder so .../ Also sicherlich haben sie das Recht hierzubleiben. Und dann, wenn sie sich da ein bisschen schlauer machen würden, könnten sie es vielleicht schaffen, dass man denen zuhört wenigstens.

I: Mhm. Und vielleicht gibt es ja aber auch schon Leute unter denen, die total gebildet sind, aber trotzdem wird gesagt: „,Die sind ja keine deutschen Staatsbürger.“ Was hältst du davon, wenn so was vorkommt?

S: Ja, das ist einfach nur dumm, wenn man das sagt. Ich meine, wenn sie wirklich die Bildung haben, oder besondere Bildung haben, und wirklich die Möglichkeit haben entfernt von der eigenen Regierung sich so eine Meinung zu bilden, dann sind sie für mich eigentlich kluge Menschen. Weil sie denken eigenständig. Und das ist eigentlich, was wichtig ist. Also das ist Intelligenz, denke ich. Und deswegen sollte man denen zuhören, weil sie dann genauso intelligent sind, vielleicht intelligenter, als viele Bürger hier. (Lara, Gym18) 
Lara setzt sich hier mit der Frage auseinander, warum geflüchtete und nichtgeflüchtete Kritiker_innen der Migrationspolitik nicht gehört werden. Geflüchtete würden ,ja teilweise auch gar nicht mal als deutsche Bürger angesehen“. Sie führt also die Staatsbürgerschaft als ersten Faktor für dafür an, ob eine Stimme als relevant angesehen wird oder nicht. Während die Stimmen von Bürger_innen - verstanden als Inhaber_innen der nationalen Staatsbürgerschaft - gehört würden, werden die Stimmen von Nicht-Bürger_innen überhört oder als irrelevant betrachtet. Dieser Hierarchisierung entlang der Dichotomie Bürger_in/Nicht-Bürger_in differenziert Lara in der Folge weiter aus, denn es seien ,beim Protest“ auch „,deutsche Staatsbürger" dabei gewesen. Diese seien aber ,nicht gerade die Reichen der Gesellschaft und die Hohen“. Weil sie nicht zu den „Reichen [...] und Hohen“ gehörten, interessierte sich der „Staat" nicht dafür, ,,was die denken“. Die Frage der Hörbarkeit der Stimmen ist fundamentaler Teil von Agency, wie ich im Einleitungsteil dieses Kapitels mithilfe von Spivak zu zeigen versucht habe. Diese Hörbarkeit hängt also laut Lara wesentlich vom Stand in der Gesellschaft ab. Damit meint sie Menschen, die der „obere[n] Schicht des Landes“ angehören. Menschen, die nicht zu dieser gehören, würden laut Lara als „,nicht wichtig“ und ,eher so als Last“ angesehen. In Laras Vorstellung der demokratischen Realität in Deutschland hängt die Frage der Berücksichtigung der Interessen und Meinungen von Menschen also zum einen von der Zugehörigkeit qua Staatsbürgerschaft sowie zum anderen vom gesellschaftlichen Stand ab.

Diese Hierarchisierung empfindet Lara offensichtlich als falsch. Ihr Lösungsvorschlag impliziert jedoch keine Veränderung dieser hierarchischen Struktur der Hörbarkeit von Stimmen, sondern zielt auf eine Strategie der Durchsetzung der Interessen der Betroffenen innerhalb dieser hierarchischen Struktur. Sie sieht zwei Strategien: (1) Sie schlägt vor, dass ,gerade die deutschen Bürger, die dafür sind - für diese Asylsache da - sich eine Meinung zu bilden und klug oder intelligent ... also irgendwas in der Schule zu erreichen und dann in eine hohe Position zu kommen“. Es müssten also Menschen, die sich für die Rechte von Geflüchteten einsetzen, ,,in eine hohe Position“ kommen. Indem sich diese Menschen dann als Teil der „obere[n] Schicht des Landes" für die Anerkennung der Rechte von Asylsuchenden einsetzen würden, könnte sich an der entrechteten Situation von Asylsuchenden etwas verbessern. (2) Ihre zweite Strategie zur Veränderung der Situation von Asylsuchenden zielt auf das Empowerment von Asylsuchenden selbst. Die Nicht-Anerkennung der Perspektiven von Geflüchteten wird, nach Lara, auch dadurch unterstützt, dass von diesen gedacht würde, ,dass die wenig Bildung“ hätten. Dies sieht sie einerseits als ein Vorurteil an, andererseits treffe dies „teilweise sicherlich auch“ zu, weil „die ja keine Möglichkeit“ gehabt hätten. Durch Bildungsprozesse, wie zum Beispiel „durch Lesen, Zeitung Lesen und irgendwelche Bücher in Deutschland“ sowie 
auch ,gesetzlich“ und „,mit den Rechten und so“, könnten sie es ,,vielleicht schaffen, dass man denen zuhört wenigstens“. Laut Lara hätten sie ,das Recht, durch diese Menschenrechte“, hierzubleiben. Indem sie ihre Bildung verbessern würden, könnten sie ihre Mittel verbessern, um diese Rechte auch durchzusetzen oder zumindest mit ihrem Rechtsanspruch Gehör zu finden.

Laras Argumentation wird dabei von Ambivalenzen durchzogen. Die eine Ambivalenz besteht in der Frage, ob die geringere Bildung der Geflüchteten tatsächlich geringer ist oder vielmehr ein Vorurteil gegenüber Geflüchteten darstellt. Bei Lara scheint beides auf; ich bringe sie scheinbar mit meiner Nachfrage zur Favorisierung der Annahme, dass die geringere Bildung von Geflüchteten eine Unterstellung ist. Dies korrespondiert mit der Ambivalenz, ob es um einen Bildungsprozess geht, an deren Ende die geflüchteten Kritiker_innen der Migrationspolitik tatsächlich klüger sind oder die Werkzeuge haben, ihre Überzeugungen so zu verkaufen, dass sie nicht mehr überhörbar sind. In jedem Fall ist Intelligenz für sie das normative Kriterium dafür, ob eine Meinung gehört werden sollte bzw. nicht überhört werden darf. Für sie sollte also die Intelligenz der Menschen und nicht der Stand oder die Staatsbürgerschaft darüber entscheiden, wieviel eine Meinung wert ist. Dabei ist ihr Begriff der Intelligenz bzw. Bildung erwähnenswert. Für sie besteht Intelligenz nicht in verwertbaren Fähigkeiten, sondern in der Fähigkeit, sich ,,entfernt von der eigenen Regierung [...] eine Meinung zu bilden“. Dies würde „kluge Menschen“ ausmachen, da sie ,eigenständig denken würden“. Intelligenz und Bildung erscheinen bei ihr viele Überschneidungen zu dem zu haben, was oft unter dem Begriff Kritik firmiert. Diejenigen, die diese Form der Intelligenz praktizieren würden, ,sollte man [...] zuhören, weil sie dann genauso intelligent sind, vielleicht intelligenter, als viele Bürger hier".

Ich sehe in ihrer Auseinandersetzung mit der Frage der Hörbarkeit von Stimmen ein Konzept der Subalternität. Sie problematisiert die Hierarchisierung von Stimmen aufgrund von Staatsbürgerschaft und gesellschaftlichem Stand und plädiert dafür, (1) sich durch gesellschaftlichen Aufstieg mit kritischen Perspektiven am Ort der Macht und Hörbarkeit festzusetzen, (2) durch Bildung die Prozesse des Überhörens subalterner Stimmen zu erschweren und (3) die hierarchische Struktur des Gehört- und Überhört-Werdens grundlegend infrage zu stellen und diejenigen Stimmen wahrzunehmen und zu bevorzugen, die eine Kritik an gesellschaftlichen Ungleichheitsverhältnissen formulieren. 
Open Access Dieses Kapitel wird unter der Creative Commons Namensnennung 4.0 International Lizenz (http://creativecommons.org/licenses/by/4.0/deed.de) veröffentlicht, welche die Nutzung, Vervielfältigung, Bearbeitung, Verbreitung und Wiedergabe in jeglichem Medium und Format erlaubt, sofern Sie den/die ursprünglichen Autor(en) und die Quelle ordnungsgemäß nennen, einen Link zur Creative Commons Lizenz beifügen und angeben, ob Änderungen vorgenommen wurden.

Die in diesem Kapitel enthaltenen Bilder und sonstiges Drittmaterial unterliegen ebenfalls der genannten Creative Commons Lizenz, sofern sich aus der Abbildungslegende nichts anderes ergibt. Sofern das betreffende Material nicht unter der genannten Creative Commons Lizenz steht und die betreffende Handlung nicht nach gesetzlichen Vorschriften erlaubt ist, ist für die oben aufgeführten Weiterverwendungen des Materials die Einwilligung des jeweiligen Rechteinhabers einzuholen.

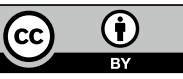

